\title{
Untersuchung der Heterogenität submitochondrialer Proteinverteilungen mit hochauflösender Mikroskopie
}

\author{
Dissertation \\ zur Erlangung des mathematisch-naturwissenschaftlichen Doktorgrades \\ "Doctor rerum naturalium" \\ der Georg-August-Universität Göttingen \\ im Promotionsprogramm Biologie \\ der Georg-August University School of Science (GAUSS)
}

vorgelegt von

Franziska Stagge

aus Wernigerode

Göttingen, 2014 



\section{Betreuungsausschuss}

Prof. Dr. Stefan Jakobs, Forschungsgruppe Struktur und Dynamik von Mitochondrien, Abteilung NanoBiophotonik, Max-Planck-Institut für biophysikalische Chemie Prof. Dr. Andreas Wodarz, Stammzellbiologie, Abt. Anatomie und Zellbiologie, GZMB

\section{Mitglieder der Prüfungskommission}

Referent: $\quad$ Prof. Dr. Andreas Wodarz, Stammzellbiologie, Abt. Anatomie und Zellbiologie, GZMB

Korreferent: Prof. Dr. Stefan Jakobs, Forschungsgruppe Struktur und Dynamik von Mitochondrien, Abt. NanoBiophotonik, Max-Planck-Institut für biophysikalische Chemie

\section{Weitere Mitglieder der Prüfungskommission}

PD Dr. Thomas Teichmann, Abt. Zellbiologie der Pflanze, Schwann-Schleiden Zentrum, Georg-August-Universität Göttingen

Prof. Dr. Peter Rehling, Institut für Zellbiochemie, Universitätsmedizin Göttingen

Prof. Dr. Dr. Stefan Hell, Abt. NanoBiophotonik, Max-Planck-Institut für

biophysikalische

Chemie

Prof. Dr. Michael Müller, Abt. Neuro- und Sinnesphysiologie, Universitätsmedizin Göttingen

Tag der mündlichen Prüfung: 

Für meine Familie 



\section{Inhaltsverzeichnis}

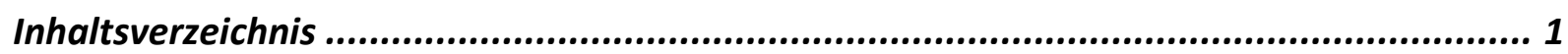

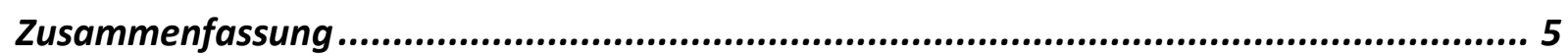

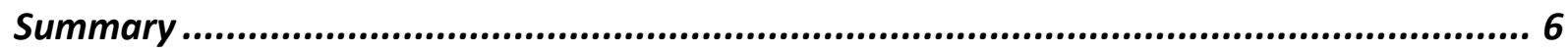

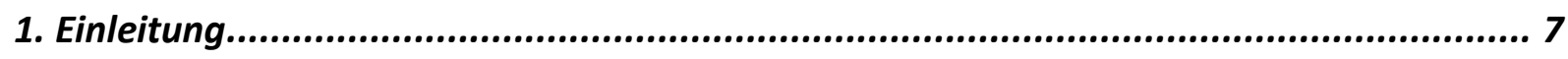

1.1 Mitochondrien: Funktion, Struktur, Dynamik .......................................................... 7

1.1.1 Evolution und Funktion von Mitochondrien ................................................................................

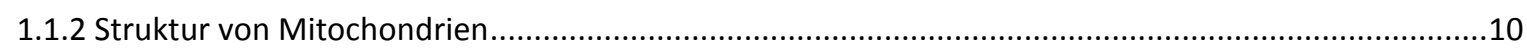

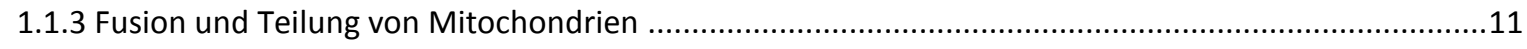

1.1.4 Transport von Mitochondrien/Interaktion mit dem Zytoskelett ................................................14

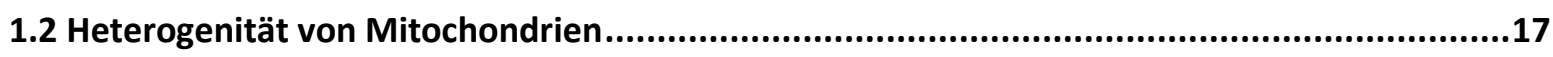

1.2.1 Mitochondriale Heterogenität zwischen verschiedenen Spezies ..................................................17

1.2.2 Mitochondriale Heterogenität zwischen unterschiedlichen Zelltypen ........................................18

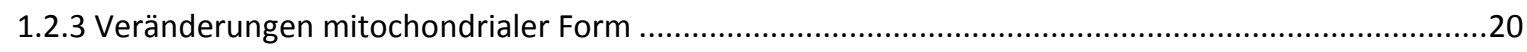

1.2.4 Mitochondriale Heterogenität innerhalb einzelner Zellen .......................................................21

1.2.5 Mechanismen und Ursachen der mitochondrialen Heterogenität ..............................................25

1.3 Bildgebende Verfahren zur Untersuchung der mitochondrialen Proteinlokalisation .............27

1.4 Zielsetzung dieser Arbeit................................................................................29

2. Material und Methoden ......................................................................... 31

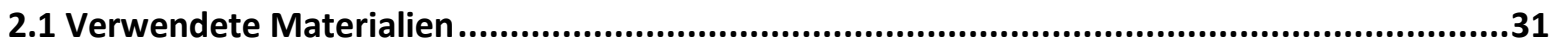

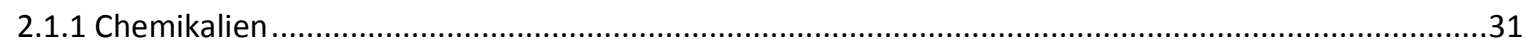

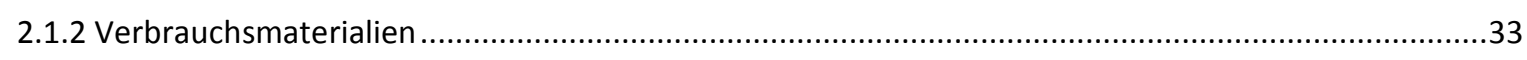

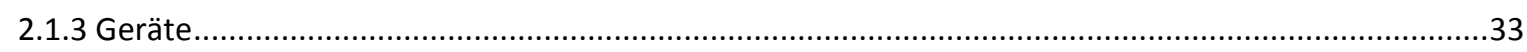

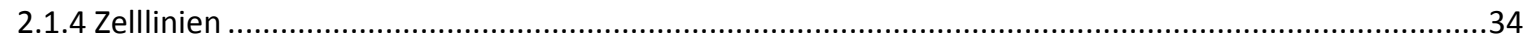

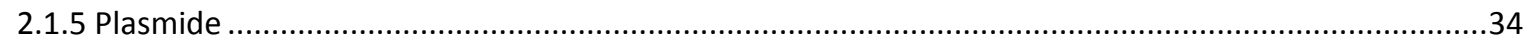

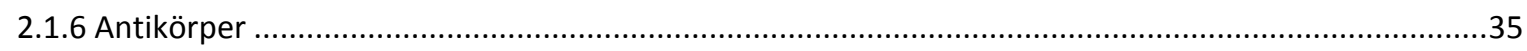

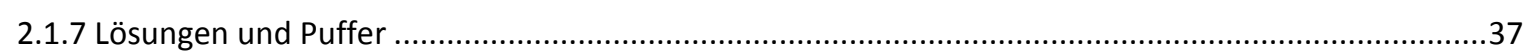

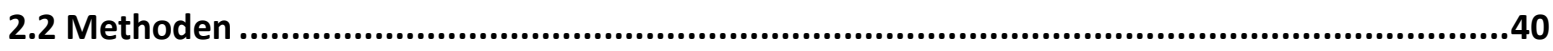

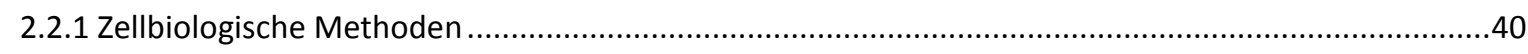

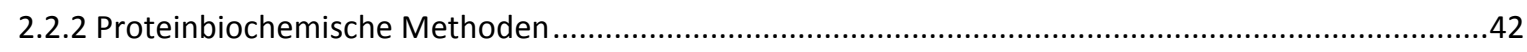




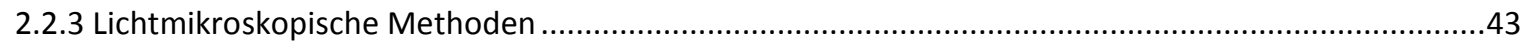

2.2.4 Nachbearbeitung, Auswertung und Simulation mikroskopischer Daten ......................................50

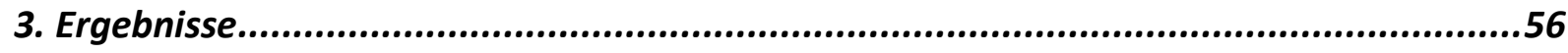

3.1 Untersuchung mitochondrialer Proteinverteilungen in unbehandelten Zellen ....................56

3.1.1 Konfokalmikroskopie als Instrument zur Analyse mitochondrialer Heterogenität ...........................57

3.1.2 Einfluss der Mitochondriendichte auf die Ergebnisse der Intensitätsanalyse .................................61

3.1.3 Einfluss der Antikörper-Färbungen auf die analysierten Proteinverteilungen...................................64

3.1.4 Gradientenverteilungen können für weitere mitochondriale Proteine beobachtet werden ...............66

\subsection{Untersuchung mitochondrialer Dynamik im Kontext der Heterogenität von}

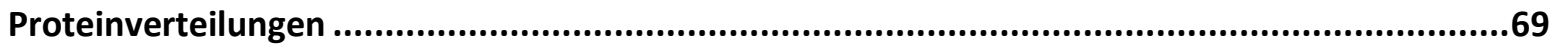

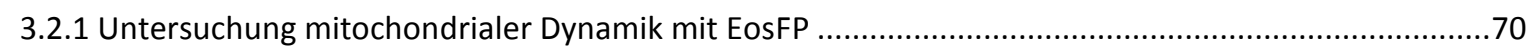

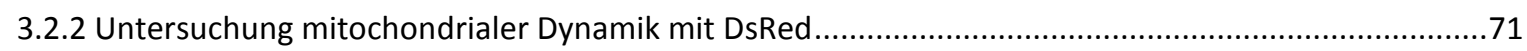

\subsection{Untersuchung des Einflusses mitochondrialer Morphologie auf die Heterogenität}

mitochondrialer Proteinverteilung.

3.3.1 Der Verlust mitochondrialer Fusions- und Teilungsfähigkeit hat deutliche Auswirkungen auf die mitochondriale Morphologie

3.3.2 Die Elongation von Mitochondrien hat Auswirkungen auf die Gradientenverteilung eines mitochondrialen Proteins. .75

3.3.3 Innerhalb einzelner elongierter Mitochondrien existiert keine Gradientenverteilung von Tom20 .....77

\subsection{Untersuchung der Heterogenität mitochondrialer Proteinverteilung im Laufe des Zellzyklus} mammaler Zellen.

3.4.1 Immunfluoreszenzmarkierungen spezifischer Zellzyklusmarker erlauben die Zuordnung der Zellzyklusphasen

3.4.2 Mitochondriale Proteine besitzen während der gesamten Interphase eine heterogene Verteilung ...81

3.5 Untersuchung des Einflusses der Interaktion von Mitochondrien mit Mikrotubuli auf die Verteilung mitochondrialer Proteine

3.5.1 Die Zerstörung des Mikrotubuli-Zytoskeletts vermindert die Heterogenität mitochondrialer Proteinverteilungen ....

3.5.2 Die Herunterregulierung von Proteinen des Komplexes für Kinesin-vermittelten mitochondrialen Transport vermindert die Gradientenverteilung von Tom 20.

3.6 Untersuchung mitochondrialer Proteinverteilung unter pathophysiologischen Bedingungen 90

3.7 Untersuchungen zur Identifikation von Signalen, welche zur Entstehung der

Gradientenverteilung mitochondrialer Proteine beitragen .95 
3.7.1 Untersuchung des Einflusses der Veränderung des mitochondrialen Membranpotentials auf die Gradientenverteilung von Tom20.....

3.7.2 Untersuchung des Einflusses verschiedenster Bedingungen auf die Gradientenverteilung von Tom20

4.1 Ursachen für die Heterogenität mitochondrialer Proteinverteilungen

4.1.1 Mitochondriale Heterogenität beruht auf einem aktiven Mechanismus

4.1.2 Energiebedarf als mögliche Ursache für mitochondriale Heterogenität

4.2 Faktoren, die zur Entstehung und Aufrechterhaltung der mitochondrialen Heterogenität beitragen

4.2.1 Das mitochondriale Netzwerk von Vero-Zellen ist nicht kontinuierlich

4.2.2 Die Elongation von Mitochondrien vermindert die intrazelluläre Gradientenverteilung mitochondrialer Proteine.

4.2.3 Mitochondriale Proteine besitzen während der gesamten Interphase des Zellzyklus eine heterogene Verteilung

4.2.4 Die Zerstörung des Mikrotubuli-basierten mitochondrialen Transports vermindert die Heterogenität mitochondrialer Proteinverteilungen

5. Abkürzungsverzeichnis

6. Literaturverzeichnis.

7. Anhang

7.1 Verwendete Farbtabellen

7.2 Verwendete Plasmide für die Expression in Säugerzellen

7.3 Immunfluoreszenzmarkierungen diverser mitochondrialer Proteine

7.4 Auflistung getesteter Substanzen auf ihren Einfluss auf mitochondriale Proteinverteilungen

7.5 Auflistung untersuchter Proteine auf ihren Einfluss auf mitochondriale Proteinverteilungen

7.6 Verwendeter Proteingrößenstandard. 
Inhaltsverzeichnis

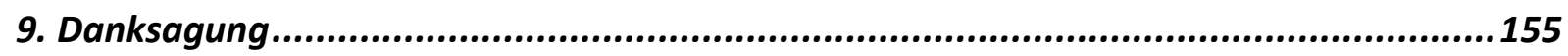

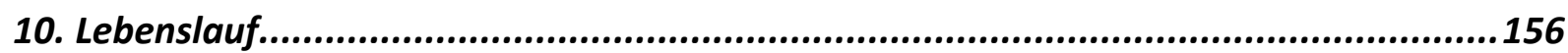




\section{Zusammenfassung}

Mitochondrien sind essentielle Organellen eukaryotischer Zellen. Sie erfüllen eine Vielzahl wichtiger Funktionen in den Zellen: neben ihrer herausragenden Bedeutung für die Energieproduktion haben sie eine zentrale Rolle im Stoffwechsel, der lonenhomöostase, sowie beim Zelltod.

Weiterhin sind Mitochondrien hochdynamische Organellen. Die Erscheinung des mitochondrialen Netzwerks wird durch die Vorgänge der Fusion und Teilung kontinuierlich verändert.

Eine morphologische oder funktionale Heterogenität dieser Organellen wurde bereits in verschiedenen Zelltypen und innerhalb einzelner Zellen beobachtet. Über die Bedeutung dieser Beobachtungen gibt es jedoch nur Vermutungen. Es wird angenommen, dass sie die Folgen eines mitochondrialen Anpassungsmechanismus an unterschiedliche metabolische Anforderungen darstellen. Bislang ist wenig darüber bekannt, ob mitochondriale Proteine auch eine heterogene intrazelluläre Verteilung aufweisen.

Um Informationen über die Lokalisation mitochondrialer Proteine zu erhalten, wird unter anderem die Fluoreszenzmikroskopie eingesetzt. Im Rahmen dieser Arbeit wurden sowohl Konfokal- als auch beugungsunbegrenzte STED-Mikroskopie in Kombination mit mathematischen Auswertealgorithmen verwendet, um mitochondriale Proteinverteilungen quantitativ innerhalb einzelner Säugerzellen zu analysieren.

In dieser Arbeit wurde gezeigt, dass eine Vielzahl mitochondrialer Proteine, welche in verschiedenen mitochondrialen Subkompartimenten lokalisieren und unterschiedliche Funktionen erfüllen, eine heterogene Dichteverteilung in Form eines Gradienten, mit einer höheren Proteindichte in Zellkernnähe, innerhalb einzelner Zellen aufweist. Diese Gradientenverteilung ist zudem bereits direkt nach der Zellteilung in beiden Tochterzellen zu beobachten. Des Weiteren wurde gezeigt, dass die Hyperelongation von Mitochondrien eine Verringerung des Ausmaßes der Gradientenverteilung von Tom20 bewirkt. Außerdem wurde im Rahmen dieser Arbeit gezeigt, dass in Zellen, in denen die Mikrotubuli depolymerisiert vorliegen, das Ausmaß der intrazellulären Tom20-Gradientenverteilung deutlich verringert ist. Diese Beobachtung legt die Vermutung nahe, dass der Vorgang des mitochondrialen Transports einen entscheidenden Einfluss auf die heterogene Verteilung mitochondrialer Proteine hat.

Somit wurde durch diese Arbeit das Verständnis der intrazellulären Heterogenität mitochondrialer Proteinverteilungen entscheidend verbessert. Durch die erhaltenen Ergebnisse kann festgestellt werden, dass viele mitochondriale Proteine eine heterogene Verteilung in Form eines intrazellulären Dichtegradienten aufweisen, die durch Vorgänge der mitochondrialen Dynamik (Teilung, Bewegung) kontrolliert wird. 


\section{Summary}

Mitochondria are essential organelles of eukaryotic cells. They fulfill a multitude of fundamental tasks: besides their outstanding significance for energy production they possess a central role in metabolism, ion homeostasis as well as cell death.

Furthermore, mitochondria are highly dynamic organelles. The processes of fusion and fission continuously change the overall appearance of the mitochondrial network.

A morphological and functional heterogeneity of these organelles has previously been observed between different cell types and even within single cells, although the meaning of this observation is still under debate. It has been suggested that mitochondrial heterogeneity is the result of an adaptation mechanism to meet different metabolic demands. So far little is known about the heterogeneous intracellular distribution of mitochondrial proteins.

Fluorescence microscopy is a common technique used to gain information on the localization of mitochondrial proteins. In this dissertation both confocal and superresolution microscopy combined with image-analysis algorithms have been applied to quantitatively analyze mitochondrial protein distributions within single mammalian cells.

In this thesis it was shown that the abundance of numerous mitochondrial proteins, which vary in both their submitochondrial localization and function, is heterogeneous across single cells and shows a gradient distribution with a higher protein abundance in mitochondria close to the nucleus. This heterogeneous distribution can be observed in both daughter cells directly after cell division. In addition, it could be demonstrated that excessive mitochondrial elongation significantly reduces the extent of the intracellular gradient distribution of the mitochondrial protein Tom20. Moreover, it was shown in this thesis that in cells with a disrupted microtubule network the extent of the intracellular gradient distribution of the mitochondrial protein Tom20 was significantly diminished. This observation indicates that mitochondrial transport plays a crucial role in the heterogeneous distribution of mitochondrial proteins.

In conclusion, this thesis substantially improves the understanding of the intracellular heterogeneity of mitochondrial protein distributions. Based on the obtained results one can conclude that the abundance of many mitochondrial proteins forms an intracellular gradient, which is controlled by events of mitochondrial dynamics (fission and movement). 


\section{Einleitung}

\subsection{Mitochondrien: Funktion, Struktur, Dynamik}

Der Begriff „Mitochondrium“ hat seinen Ursprung in den griechischen Wörtern Mitos, welches für „Faden“ steht und chondros, was mit „Korn“ übersetzt werden kann (Benda 1898). Dieser Begriff beschreibt gut die Morphologie dieser Organellen. Mitochondrien sind die „Kraftwerke“ der Zellen und produzieren einen Großteil des zellulären Energieäquivalents Adenosintriphosphat (ATP) durch die Oxidation energiereicher Kohlenhydratmoleküle. Ferner spielen sie auch eine entscheidende Rolle bei einer Vielzahl weiterer zellulärer Prozesse, wie zum Beispiel der Apoptose (Kroemer 1998), der lonenhomöostase, den Reaktionen des Fettsäurestoffwechsels (Kennedy et al. 1950), den Reaktionen des Harnstoffzyklus (Maier et al. 1974), der Biosynthese zellulärer Metabolite (Artom et al. 1951, Birt et al. 1960, Craddock et al. 1961, Scheffler 2001) sowie der Zellalterung (Navarro et al. 2007). Mitochondrien liegen in Zellen aller eukaryotischer Lebewesen (außer Metamonada) vor, darunter Tiere, Pflanzen, Algen, Pilze und Protozoen, jedoch nicht in Prokaryoten.

\subsubsection{Evolution und Funktion von Mitochondrien}

Die Entstehung von Mitochondrien wird über die Endosymbiontenhypothese erklärt. Diese besagt, dass Mitochondrien vor ca. 2 Milliarden Jahren aus der Inkorporation eines alpha-Proteobakteriums durch einen Vorläufer einer modernen eukaryotischen Zelle hervor gegangen sind (Margulis 1970, Gray 1999) (Whatley et al. 1979). Während der Evolution hat sich ihre Zusammensetzung und Funktion verändert. Den Doppelmembran-Charakter ihrer Vorgänger haben sie jedoch beibehalten. Weiterhin haben sie seitdem eine Vielzahl neuer Aufgaben in der Zelle übernommen (Friedman et al. 2014). Den Großteil ihres genetischen Materials haben Mitochondrien im Laufe der Zeit verloren oder auf den Zellkern übertragen (Gabaldon et al. 2004). Dennoch ist ihnen ein zirkuläres Genom, welches im Menschen eine Größe von ca. 16 kB hat, sowie ein eigener Replikations-, Translationsund Transkriptionsapparat erhalten geblieben. Das humane mitochondriale Genom enthält genetische Informationen für 13 mitochondriale Proteine (Meisinger et al. 2008), welche Hauptbestandteile der Innenmembran-lokalisierten mitochondrialen Atmungskettenkomplexe I - IV und besonders große hydrophobe, und damit schwer zu transportierende Proteine, sind. Zusätzlich zu diesen Proteinen kodiert das mitochondriale Genom für t-RNAs und r-RNAs (Anderson et al. 1981), welche essentielle Bestandteile seines eigenen Translationsapparates sind. Das humane 
mitochondriale Proteom umfasst ca. 1500 Proteine (Meisinger et al. 2008). Der Großteil dieser Proteine ist somit nukleär kodiert. Sie werden über Translokasen aktiv in die Mitochondrien importiert (Harbauer et al. 2014). Hierzu besitzen mitochondriale Proteine eine spezifische Erkennungssequenz (Omura 1998). Der Import verläuft zum Teil kotranslational, das heißt, dass die naszierenden Polypeptidketten zunächst von den zytoplasmatischen Ribosomen auf Translokasen der äußeren mitochondrialen Membran (TOM-Translocase of the Outer mitochondrial Membrane) übertragen werden (Sollner et al. 1992). Anschließend gelangen sie unter anderem über Translokasen der inneren mitochondrialen Membran (TIM-Translocase of the mitochondrial Inner Membrane) zu ihrem Bestimmungsort in den mitochondrialen Subkompartimenten, werden gefaltet und abschließend eingebaut (Abbildung 1.1).

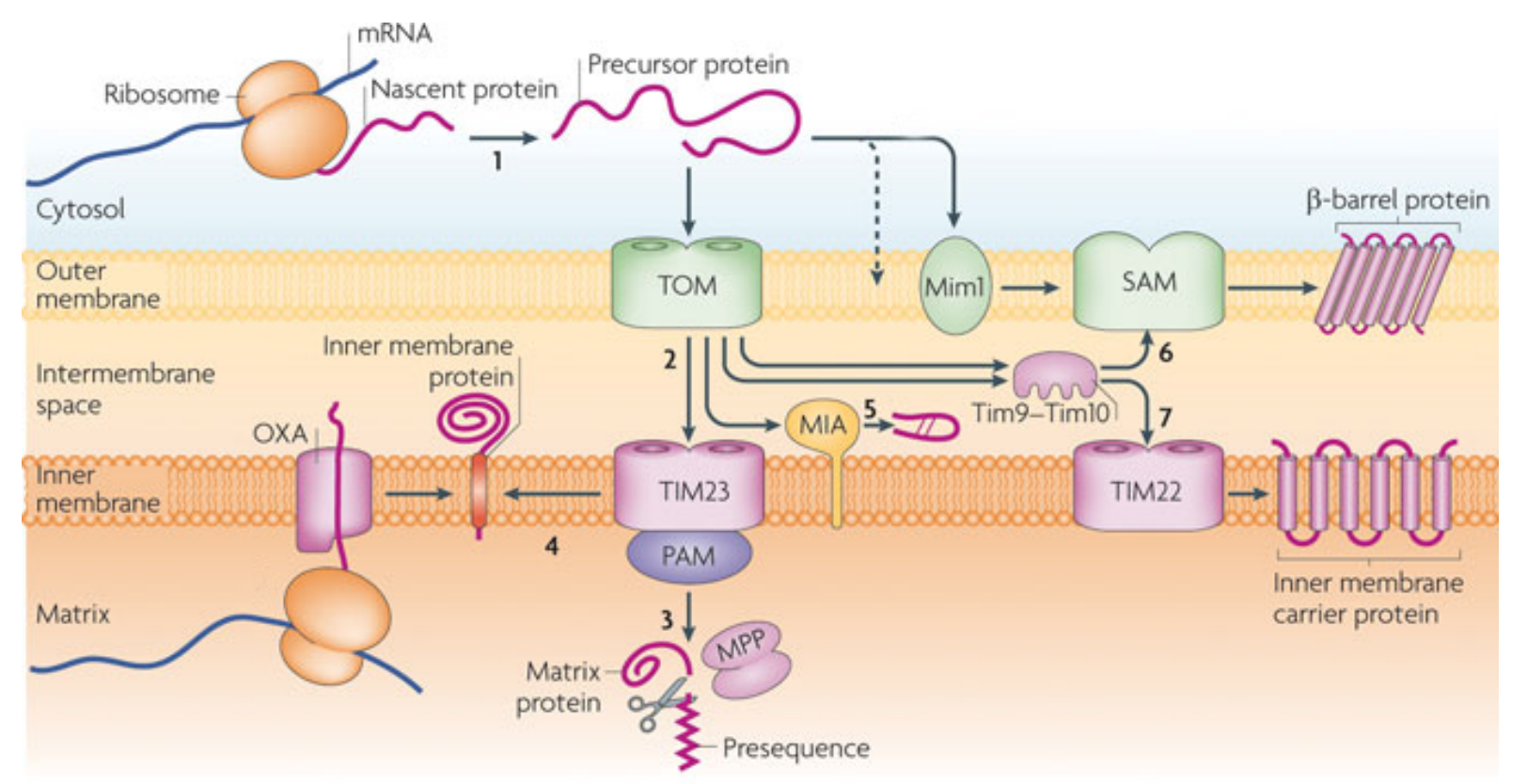

\section{Abbildung 1.1: Schematische Übersicht verschiedener Proteinimportwege in Mitochondrien.}

1.) Der Hauptteil kern-kodierter mitochondrialer Proteine wird als Vorläufermolekül über den TOM-Komplex in die Mitochondrien importiert. 2.) Anschließend erfolgt mittels verschiedener Sortierungs-Mechanismen die spezifische Lokalisierung mitochondrialer Vorläuferproteine. 3.) Matrixproteine, die mit einer Präsequenz versehen sind werden zunächst über TIM23 und weiterhin über den PAM-Komplex in die Matrix transportiert, wo ihre Präsequenz entfernt wird. 4.) Innenmembranproteine können lateral aus dem TIM23-Komplex austreten. 5.) Der MIA-Komplex ist verantwortlich für die korrekte Lokalisierung und Faltung von Proteinen des Intermembranraums. Sehr hydrophobe Proteine werden vom TIM9-TOM10-Chaperon-Komplex durch den Intermembranraum auf 6.) den SAM-Komplex, wenn es sich um Proteine der äußeren mitochondrialen Membran handelt, oder im Fall der Innenmembranproteine auf 7.) den TIM22-Komplex, transferiert. Abbildung verändert aus (Schmidt et al. 2010).

Neben einer Vielzahl bedeutender Funktionen, die Mitochondrien in anabolen und katabolen Stoffwechselwegen eukaryotischer Zellen ausüben, ist die Bereitstellung von ATP durch oxidative Phosphorylierung die Bedeutendste. Mitochondrien sind hierbei Reaktionsraum für den Krebs-Zyklus (Krebs 1940) und die Atmungskette (Ochoa 1940). 
Intermembranraum

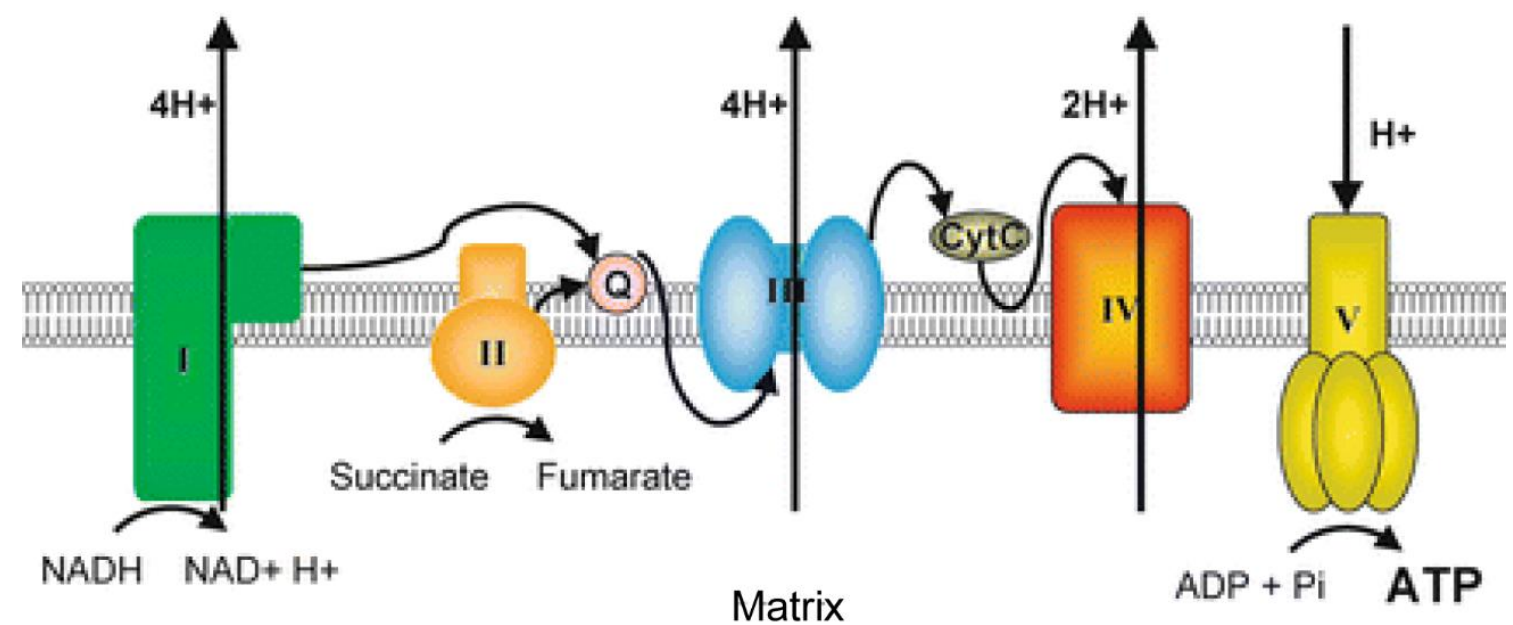

Abbildung 1.2: Schematische Darstellung des Ablaufs der Atmungskette.

Zusammen mit dem Krebs-Zyklus der Matrix erzeugt die Atmungskette einen elektrochemischen Gradienten, durch den gekoppelten Transfer von Elektronen auf Sauerstoff und den Transport von Protonen aus der Matrix über die innere Membran in den Intermembranraum. Dieser elektrochemische Gradient treibt Komplex V der Atmungskette, die ATPSynthase, an, welcher die Produktion des größten Anteils von ATP in der Zelle katalysiert. I: NADH-DehydrogenaseKomplex, II: Succinat-Dehydrogenase-Komplex, III: Cytochrom-c-Reduktase-Komplex, IV: Cytochrom-c-Oxidase-Komplex, $\mathrm{V}: \mathrm{F}_{1} \mathrm{~F}_{\mathrm{O}}$-ATP-Synthase. Abbildung verändert aus (Cuperus et al. 2010)

Die innere Membran der Mitochondrien, mit ihren eingebetteten Atmungskettenkomplexen und kleinen assoziierten Molekülen, ist der Reaktionsraum einer Reihe von Elektronen-TransportProzessen, die den Hauptteil zellulärem ATPs produzieren (Abbildung 1.2). Die Energieproduktion beruht auf dem Prinzip der chemiosmotischen Kopplung, das bedeutet, die Verknüpfung der Reaktion zur Bildung der energiereichen Bindung im ATP, an Membran-Transport-Prozesse. Der Kopplungsprozess läuft dabei in zwei verbundenen Schritten ab, welche durch die Atmungskettenkomplexe der inneren Membran bewerkstelligt werden: hochenergetische Elektronen (aus der Oxidation von Nahrungsmolekülen), werden entlang einer Reihe von Elektronenüberträgern (carrier-Proteine), welche in der Membran eingelagert sind, transferiert. Diese Elektronentransfers setzen Energie frei, welche verwendet wird, um Protonen $\left(\mathrm{H}^{+}\right.$, aus Wasser) über die innere Membran in den Intermembranraum zu pumpen und erzeugen dadurch einen elektrochemischen Protonengradienten. Der Rückfluss der Protonen entlang des elektrochemischen Gradienten ist die treibende Kraft der energiebhängigen Synthese von ATP aus ADP und anorganischem Phosphat durch den $\mathrm{F}_{1} \mathrm{~F}_{\mathrm{O}}$-ATP-Synthase-Proteinkomplex (Alberts et al. 2008). 


\subsubsection{Struktur von Mitochondrien}

Die Ultrastruktur von Mitochondrien ist sehr komplex. Sie werden von zwei hoch spezialisierten Membranen, der äußeren und der inneren mitochondrialen Membran, umschlossen, die sehr unterschiedliche Funktionen erfüllen. Zusammen formen sie zwei separate mitochondriale Kompartimente, die innenliegende Matrix und einen schmalen Bereich zwischen den beiden Membranen, den Intermembranraum (Palade 1952, Sjostrand 1953). Die innere Membran ist stark gefaltet und bildet dadurch in den Matrixraum reichende Einstülpungen, die Cristae genannt werden (Frey et al. 2000) (Abbildung 1.3).

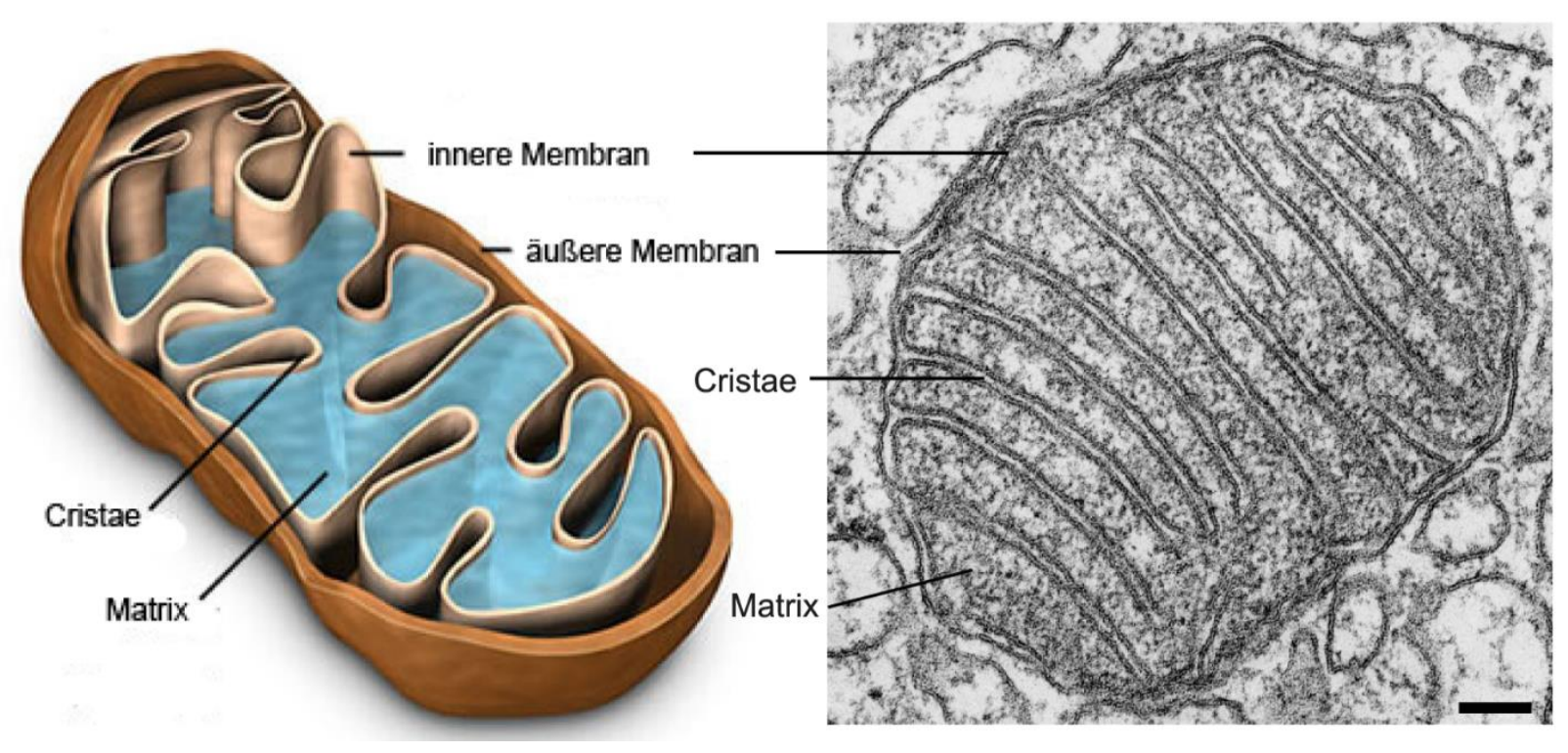

Abbildung 1.3: Die innere Struktur von Mitochondrien.

Links: Schematische Zeichnung eines einzelnen Mitochondriums. Deutlich zu sehen ist die klar abgegrenzte äußere Membran, welche die stark eingestülpte innere Membran umhüllt. Innerhalb der inneren Membran befindet sich die mitochondriale Matrix. Abbildung verändert aus:

(http://www.cartage.org.Ib/en/themes/sciences/zoology/animalphysiology/anatomy/animalcellstructure/Mitochondria/ Mitochondria.htm)

Rechts: Elektronenmikroskopische Aufnahme eines Mitochondriums von Leberzellen. Deutlich zu erkennen sind die zahlreichen Einstülpungen der inneren Membran, die Cristae. Des Weiteren lässt sich die klar abgegrenzte mitochondriale Außenmembran erkennen. Größenbalken: 100 nm. Abbildung verändert aus (Alberts et al. 2008).

Die mitochondriale Matrix im Inneren der Mitochondrien ist der größte Reaktionsraum und enthält zudem den Großteil aller mitochondrialen Proteine. In der Matrix finden die für die Energieproduktion wichtigen Stoffwechselreaktionen des Krebs-Zyklus und der $\beta$-Oxidation statt. Außerdem enthält sie die in multiplen Kopien vorliegende mitochondriale DNA und beherbergt ihren Replikationsapparat. 
Die innere und die äußere Membran unterscheiden sich sowohl in ihrer Protein-, als auch in ihrer Lipidzusammensetzung. Die äußere Membran hat aufgrund ihrer Lipid- und Proteinzusammensetzung große Ähnlichkeit mit der Plasmamembran, wohingegen sich die innere Membran durch einen sehr hohen Proteingehalt auszeichnet. Die innere Membran ist im Gegensatz zur äußeren Membran für die meisten lonen und Makromoleküle undurchlässig. Sie gelangen nur mit Hilfe spezieller Transportproteine in den Matrixraum der Mitochondrien.

Die innere Membran kann in die innere Grenzflächenmembran (der äußeren Membran benachbart) und die Cristae-Membran (in den Matrixraum reichend) unterteilt werden. Weiterhin kann für die innere Membran eine Struktur-Funktions-Beziehung beobachtet werden: Bestandteile der Atmungskette lokalisieren vorrangig in der Cristaemembran, wohingegen Komponenten der ProteinImport-Komplexe vorwiegend in der inneren Grenzflächenmembran zu finden sind (Vogel et al. 2006, Wurm et al. 2006). Die Verbindungen dieser Cristae zur inneren Grenzflächenmembran werden als Cristae Junctions bezeichnet (Perkins et al. 1997, Mannella 2006). Kürzlich wurde ein großer Proteinkomplex beschrieben, der an den Cristae Junctions lokalisiert. Dieser Komplex wird als MICOSKomplex (mitochondrial contact site and cristae organizing system) bezeichnet und ist von entscheidender Bedeutung für die Cristae-Morphologie (Harner et al. 2011, Hoppins et al. 2011, von der Malsburg et al. 2011, Alkhaja et al. 2012). Komponenten dieses Komplexes in humanen Zellen sind Mic60 (Mitofilin), Mic10, Mic19 und Mic27 (Pfanner et al. 2014).

\subsubsection{Fusion und Teilung von Mitochondrien}

Die mitochondriale Morphologie variiert zwischen verschiedenen Zelltypen und Organismen, sogar innerhalb einzelner Zellen. Sie reicht von kleinen Kugeln, über lange Tubuli, bis hin zu einer hochgeordneten Struktur (Kuznetsov et al. 2009). In den meisten Säugerzellen besitzen Mitochondrien einen typischen Durchmesser von 200 - 400 nm und bilden ein verzweigtes tubuläres Netzwerk aus, dessen Form sich durch fortwährende Fusions-, Teilungs- und Transport-Vorgänge kontinuierlich verändert (Bereiter-Hahn et al. 1994, Griparic et al. 2001, Frazier et al. 2006)(Abbildung 1.4). Fusion und Teilung von Mitochondrien sind nicht nur essentielle Prozesse für die Vermehrung von Mitochondrien und somit das Wachstum von Zellen (Qian et al. 2012). Es gibt Hinweise, dass sie außerdem entscheidende Faktoren der Erhaltung ihrer Funktionalität darstellen (Tatsuta et al. 2008, Twig et al. 2008). Fusion trägt hierzu bei, indem es zu einer Durchmischung geschädigter und gesunder Mitochondrien führt und somit zu einem Austausch von Metaboliten und einer Komplementierung ihrer Funktionen (Youle et al. 2012, Rolland et al. 2013). Es wurde vorgeschlagen, dass zur Beseitigung eines Mitochondriums, dessen Schaden irreparabel ist, dieses zunächst durch 
Teilung vom Netzwerk abgeschnürt und anschließend über Mitophagie abgebaut wird (Komatsu et al. 2005, Egan et al. 2011, Youle et al. 2012). Weiterhin besitzt mitochondriale Teilung eine wichtige Rolle bei dem Prozess der Apoptose (Suen et al. 2008). Die Bedeutung mitochondrialer Dynamik für eine intakte Zellfunktion wird dadurch deutlich, dass die Störung dieser Vorgänge eine normale Entwicklung beeinträchtigt und ursächlich für die Entstehung verschiedenster Krankheiten, unter anderem neurodegenerativer Erkrankungen, ist (Nunnari et al. 2012).

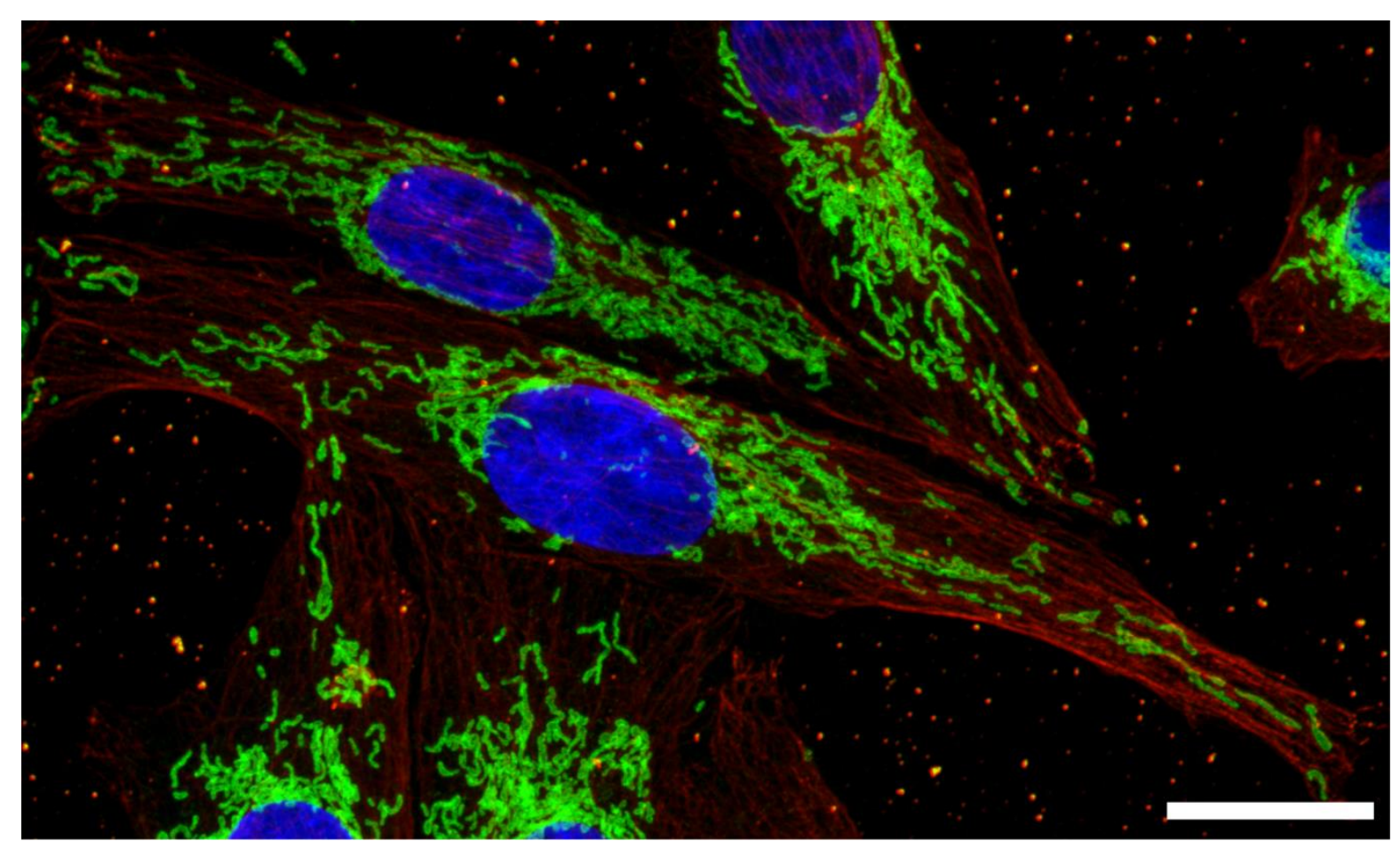

Abbildung 1.4: Mitochondrien bilden ein verzweigtes Netzwerk in Vero-Zellen.

Subzelluläre Strukturen wurden mittels Immunfluoreszenz markiert: Mikrotubuli in rot ( $\alpha$-Tubulin) und Mitochondrien in grün (Tom20). Der Zellkern wurde mittels DAPI angefärbt (blau). Größenbalken: $20 \mu \mathrm{m}$.

Die Häufigkeit mitochondrialer Fusion, Teilung und auch Bewegung wird reguliert und an die unterschiedlichen physiologischen Gegebenheiten verschiedenster Zelltypen dynamisch angepasst (Hoppins et al. 2007). Teilungs- und Fusionsvorgänge von Mitochondrien sind normalerweise im Gleichgewicht. Wird dieses Gleichgewicht jedoch, z.B. durch Schädigungen einer Zelle, gestört, hat dies dramatische Auswirkungen auf die Form der Mitochondrien. Einerseits führt der Verlust mitochondrialer Fusion zu einer Fragmentierung des Netzwerkes in viele kleine einzelne Mitochondrien, ausgelöst durch die nicht antagonisierte fortwährende Teilung (Chen et al. 2005). Andererseits entsteht bei der Störung mitochondrialer Teilung ein hyperfusioniertes mitochondriales Netzwerk mit stark elongierten Mitochondrien (Lee et al. 2004).

Die Aktivität hochkonservierter dynamin-related-proteins (mit Dynamin verwandte Proteine) bewirkt die Teilung und Fusion von Mitochondrien (Hoppins et al. 2007). Diese Proteine besitzen die 
Fähigkeit, zu oligomerisieren. Durch GTP-Hydrolyse vermitteln sie eine Membran-Umgestaltung, in Form von Fusionierung oder Teilung von Lipiddoppelschichten (Faelber et al. 2013).

\section{Mitochondriale Teilung:}

In Säugerzellen wurde dynamin-related-protein 1 (Drp1) als Hauptkomponente des Vorgangs der Teilung von Mitochondrien identifiziert (Smirnova et al. 2001, James et al. 2003, Yoon et al. 2003).

Drp1 ist ein zytoplasmatisch lokalisiertes Protein, welches jedoch auch vereinzelt punktförmig auf Mitochondrien beobachtet werden kann. Seine Bedeutung für mitochondriale Teilung wird ersichtlich wenn man Zellen betrachtet, in denen künstlich eine Herunterregulierung dieses Proteins, z.B. durch RNA-Interferenz, erzeugt wurde. Diese Zellen zeigen eine dramatisch veränderte mitochondriale Morphologie (Smirnova et al. 2001, Lee et al. 2004). Die Mitochondrien sind stark elongiert und das Netzwerk hyperfusioniert, was auf einen Verlust mitochondrialer Teilung hindeutet.

Die Beteiligung von Drp1 an der mitochondrialen Teilung wurde klar bewiesen, dennoch ist bislang wenig darüber bekannt, welche Signale die Translokation von Drp1 vom Zytosol an die Mitochondrien bewirken. Kürzlich veröffentlichte Studien belegen, dass diese Drp1-Translokation immer an Stellen von Mitochondrien erfolgt, die spätere Teilungspunkte repräsentieren und einen Kontakt zu dem endoplasmatischen Retikulum (ER) besitzen (Friedman et al. 2011). Die molekulare Basis für diese Verbindung wurde vor kurzem entdeckt und wird durch einen Multiproteinkomplex vermittelt, der als ERMES (ER-mitochondrial-encounter-structure) bezeichnet wird (Kornmann et al. 2009).

Eine weitere interessante Beobachtung ist die Tatsache, dass mitochondriale Teilung generell Tochtermitochondrien ergibt, die über mindestens ein Molekül mitochondrialer DNA verfügen (Margineantu et al. 2002, Legros et al. 2004). Dies gibt einen Hinweis darauf, dass die Bestimmung mitochondrialer Teilungsstellen in irgendeiner Weise gerichtet und nicht zufällig verläuft (Chan 2006).

Mitochondriale Teilung ist mit anderen zellulären Prozessen verknüpft. So spielt die Teilung von Mitochondrien eine entscheidende, jedoch in ihrer Funktion noch nicht gänzlich verstandene, Rolle während des Zellzyklus (Mitra et al. 2009). Säugerzellen besitzen stark fragmentierte Mitochondrien während der späten G2-Phase und der Mitose (Arakaki et al. 2006). Die Herunterregulierung von Drp1 in Säugerzellen führt zu einem Stopp des Fortschreitens des Zellzyklus und der Zellteilung (Qian et al. 2012). Möglicherweise dient die Teilung von Mitochondrien vor der Zellteilung der Erleichterung ihrer Aufteilung auf die beiden Tochterzellen (Jakobs et al. 2011). 


\section{Mitochondriale Fusion:}

Die Fusion von Mitochondrien erfordert die Aktivität zweier unterschiedlicher dynamin-relatedproteins. Die Fusion zweier Mitochondrien verläuft in zwei verschiedenen Prozessen. Hierbei sind die eng verwandten Proteine Mfn1 und Mfn2 (Mitofusin 1 und 2) verantwortlich für die Fusion der äußeren mitochondrialen Membranen, wohingegen Opa1 (optic atrophy 1) die Fusion der inneren mitochondrialen Membran vollzieht (Meeusen et al. 2004). Bei ihnen handelt es sich um integrale Membranproteine, die auch über eine GTPase-Funktion verfügen (Chen et al. 2003).

Die Beteiligung von Mfn1 und Mfn2 bei mitochondrialer Fusion zeigten Experimente mit Mäusen, die Mutationen dieser Gene trugen (Chen et al. 2003, Chen et al. 2005). Zellen mit gestörter Mfn1- oder Mfn2-Funktion wiesen eine verminderte mitochondriale Fusion auf. Dementsprechend waren die Mitochondrien fragmentiert.

Die Bedeutung von Mfn1/2 und Opa1, und damit mitochondrialer Fusion, für Säuger wird anhand der pathologischen Auswirkungen, die Mutationen dieser Gene zur Folge haben, deutlich. So sterben Mfn1 oder Mfn2 knockout-Mäuse bereits frühzeitig in der Embryonalentwicklung ab (Chen et al. 2003). Embryonale Maus-Fibroblasten, die einen Defekt beider Mitofusine tragen, können zwar kultiviert werden, zeigen aber physiologische Defizite, wie z.B. eine verminderte Anzahl an mtDNA oder ein verringertes Membranpotential und deshalb eine verminderte Atmungs-(ATP-SyntheseIrate, sowie ein verlangsamtes Wachstum (Chen et al. 2005). Außerdem sind Mutationen in Mfn2 kausal für die Ausbildung von Erkrankungen des peripheren Nervensystems, z.B. Charcot-MarieTooth disease type $2 A 2$ (Zuchner et al. 2004). Mutationen in Opa1 sind ursächlich für die autosomal dominant vererbte optische Atrophie (Alexander et al. 2000, Delettre et al. 2000).

\subsubsection{Transport von Mitochondrien/Interaktion mit dem Zytoskelett}

Bei der Betrachtung der Dynamik von Mitochondrien lebender Zellen wird ersichtlich, welch enorme Mobilität diese Organellen aufweisen (Jakobs 2006). Neben Fusion und Teilung, trägt mitochondriale Bewegung einen beträchtlichen Teil hierzu bei. Bewegungen von Mitochondrien werden hauptsächlich von den Mikrotubuli-basierten Motoren Kinesin und Dynein ausgeführt (Ligon et al. 2000, Hollenbeck et al. 2005). Mitochondrien sind über spezifische Adapterproteine an den Motoren, und somit den Mikrotubuli, verankert, welche eine Regulierung des Transports zulassen. Vereinzelt werden Mitochondrien auch über Aktin-Filamente mit Hilfe von Myosin-Motoren transportiert (Morris et al. 1995). 


\section{Anterograder mitochondrialer Transport:}

Anterograder mitochondrialer Transport entlang Mikrotubuli wird von Kinesin-Motoren vermittelt (Tanaka et al. 1998). Unter der Vielzahl in Säugern vorkommender Kinesine wurde Kinesin-1, auch als KHC (conventional Kinesin heavy chain) bzw. KIF5 bezeichnet, als verantwortlich für den Transport von Mitochondrien identifiziert (Aizawa et al. 1992, Kanai et al. 2000, Hirokawa et al. 2008). In Säugern gibt es drei KIF5-Isoformen; KIF5A, KIF5B und KIF5C, wobei KIF5B ubiquitär exprimiert wird. Zellen die ein Defizit der Funktion dieser Proteine besitzen weisen einen verminderten axonalen Transport von Mitochondrien, einhergehend mit perinukleärer Aggregation, auf (Tanaka et al. 1998), (Pilling et al. 2006). Zudem wurde beschrieben, dass zwei weitere Motoren der Kinesin-3-Familie für den mitochondrialen Transport von Bedeutung sind: KIF1B $\alpha$ und Kinesin-Like protein 6 (KLP6). Auch ihre Fehlfunktion beeinträchtigt den korrekten mitochondrialen Transport und Verteilung (Nangaku et al. 1994, Tanaka et al. 2011).

$\mathrm{Zu}$ den mitochondrialen Adaptoren des Kinesin-vermittelten anterograden Transports von Mitochondrien zählt zum Einen das mitochondriale neuronen-spezifische Protein Syntabulin (Cai et al. 2005), fasciculation and elongation protein-zeta 1 (FEZ1) (Fujita et al. 2007), RAN-binding protein 2 (RANBP2) (Cho et al. 2007), und ein Komplex aus dem mitochondrialen Protein Miro und dessen Bindungspartner Milton (Stowers et al. 2002, Fransson et al. 2003, Brickley et al. 2005, Guo et al. 2005, Fransson et al. 2006, Glater et al. 2006, Brickley et al. 2011). Am besten in seiner Funktion und Wirkweise verstanden und von ubiquitärer Bedeutung ist der letztgenannte Miro/Milton Komplex (Abbildung 1.5). Miro ist ein Transmembranprotein der mitochondrialen Außenmembran (Fransson et al. 2003, Fransson et al. 2006). Es bindet Milton, welches wiederum KHC bindet und somit eine direkte Verbindung zwischen Mitochondrien und Mikrotubuli entstehen lässt (Glater et al. 2006). Milton hat zwei Säugerhomologe: TRAK1 und TRAK2. Die Untersuchung von Drosophila melanogaster Mutanten führte zur Identifikation der Bedeutung von Milton für den mitochondrialen Transport (Stowers et al. 2002). In Photorezeptoren, welche Milton-Mutationen aufwiesen, verblieben Mitochondrien im Soma und wurden nicht in Axonen und ihren Enden beobachtet, was den Schluss zulässt, dass mitochondrialer Transport unterbunden war (Stowers et al. 2002, Gorska-Andrzejak et al. 2003).

Wie Milton besitzt auch Miro zwei Homologe in Säugern, Rhot1 und Rhot2 (Aspenstrom et al. 2007). Die Bedeutung von Miro für den mitochondrialen Transport konnte auch über einen Drosophilamelanogaster Mutanten Screen identifiziert werden (Guo et al. 2005). Es wurde gezeigt, dass MiroMutanten einen ähnlichen Phänotyp wie die Milton-Mutanten aufwiesen, nämlich die Abwesenheit axonaler und synaptischer Mitochondrien, wobei die Mitochondrien Aggregate im neuronalen Soma bildeten. Darüber hinaus führte die Identifikation Miros als einen direkten Interaktionspartner Miltons zu einer Aufklärung des Kinesin-Adapter-Komplexes (Fransson et al. 2006, Glater et al. 2006). 
A
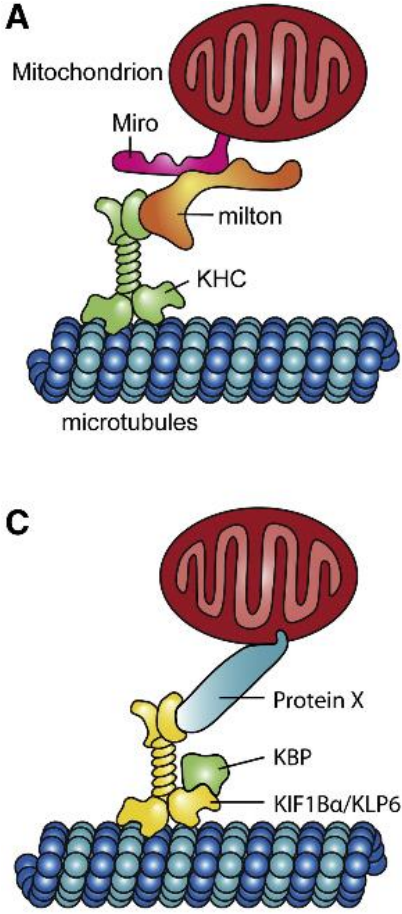

E

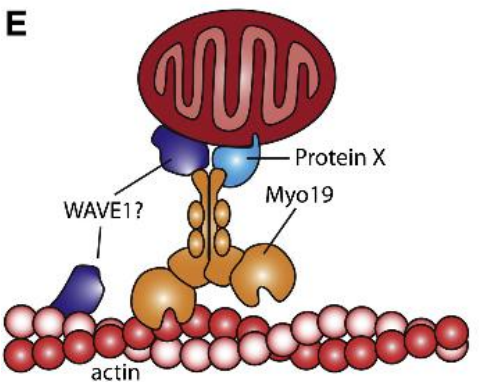

B

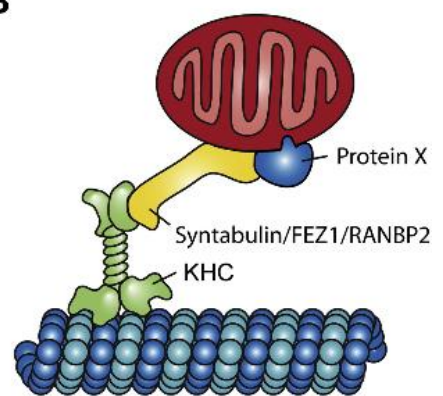

D

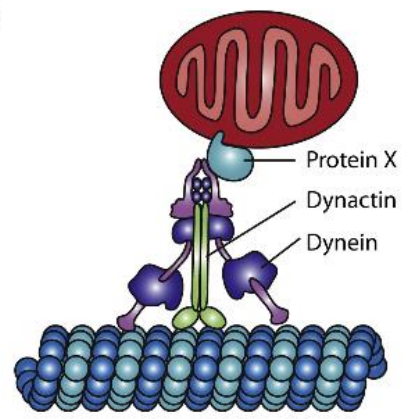

$\mathbf{F}$

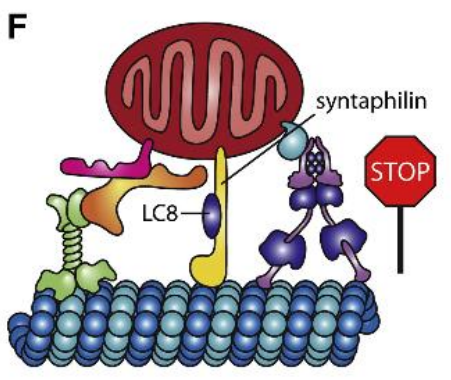

Abbildung 1.5: Schematische Darstellung unterschiedlicher mitochondrialer Transportwege.

A.) Mitochondrien können über das Motorprotein KHC entlang der Mikrotubuli transportiert werden. Weitere Komponenten dieses Komplexes sind Milton und das mitochondriale Außenmembranprotein Miro. B.) Anstelle von Miro und Milton, können auch Proteine wie Syntabulin, FEZ1 oder RANBP2 am KHCvermittelten Transport beteiligt sein. C.) Mitochondrialer Transport kann außerdem durch die Motoren KIF1B $\alpha$ oder KLP6 in Zusammenarbeit mit KBP vermittelt werden. D.) Ein Komplex aus Dynein und Dynactin ist verantwortlich für den retrograden mitochondrialen Transport. E.) Aktinbasierter mitochondrialer Transport erfolgt mithilfe des Motorproteins Myo19. F.) Das Protein Syntaphilin ist in der Lage Mitochondrien an einer bestimmten Position zu verankern und somit den Transport zu unterbinden. Abbildung aus (Lovas 2013).

\section{Retrograder mitochondrialer Transport:}

Über den retrograden Mikrotubuli-Transport mit Hilfe des Motors Dynein ist weniger bekannt, als über den Kinesin-vermittelten anterograden Transport. Es wurde berichtet, dass Dynactin an Dynein bindet (King et al. 2000). Beide Proteine können mit Mitochondrien assoziieren. Mutationen beider Proteine führen zu einem verminderten retrograden axonalen Transport (Pilling et al. 2006). Weitere Interaktionspartner dieses Komplexes sind unbekannt. Kürzlich wurde jedoch ein direkter Beweis für eine biochemische Interaktion des retrograden Motors Dynein mit dem Miro/Milton-Komplex erbracht (van Spronsen et al. 2013).

\section{Aktin-basierter mitochondrialer Transport:}

Es gibt verschiedene Hinweise, dass Mitochondrien nicht nur über Mikrotubuli-basierten Transport in Säugerzellen verteilt werden, sondern auch durch Interaktionen mit Aktin (Morris et al. 1993). Beispielsweise ist die Bewegung von Mitochondrien unterbunden, wenn das Aktin-Zytoskelett 
zerstört wird (Sturmer et al. 1995). Als mögliche Motoren wurden Myosin 19, II, III, V und VI vorgeschlagen (Berg et al. 2001, Quintero et al. 2009, Pathak et al. 2010), (Bridgman 2004).

\subsection{Heterogenität von Mitochondrien}

Mitochondrien bilden in vielen Säugerzelltypen ein verzweigtes Netzwerk. Außerdem wirken sie durch die Prozesse der Fusion, Teilung und des Transports sehr mobil. Umso erstaunlicher sind die Beobachtungen von (Collins et al. 2002) einzuschätzen. Sie untersuchten die Kontinuität des mitochondrialen Netzwerks mittels der FRAP-Methode und DsRed, welches in der mitochondrialen Matrix exprimiert wurde. Ihre Beobachtungen wichen deutlich von den allgemeinen Erwartungen eines dynamischen mitochondrialen Netzwerks ab. Die Fluoreszenz der gebleichten Regionen erreichte selbst eine Stunde nach Bestrahlung nur $10 \%$ des ursprünglichen Wertes. Daraus lässt sich schließen, dass die Mitochondrien der untersuchten Zellen unzusammenhängend waren und ermöglicht eine Heterogenität der Mitochondrien.

Die morphologische und funktionale Heterogenität von Mitochondrien ist eine Beobachtung, deren Bedeutung erst durch technische Entwicklungen der letzten Jahre erkannt wurde. Morphologische Unterschiede dieses Organells sind relativ einfach zu identifizieren und seit längerer Zeit bekannt (Kölliker 1857). Sie konnten gut durch die verschiedensten Anwendungen der Fluoreszenzmikroskopie, in Kombination mit spezifischen Markern, untersucht werden (Jakobs 2006). Weniger verstanden ist jedoch, wie sich die einzelnen Mitochondrien einer Zelle funktional voneinander unterscheiden, sowie die mechanistischen Ursachen dieser Unterschiede.

\subsubsection{Mitochondriale Heterogenität zwischen verschiedenen Spezies}

Die mitochondriale Morphologie, sowie ihre Dynamik, wurden in vielen eukaryotischen Organismen untersucht (Bereiter-Hahn 1990, Jakobs et al. 2003, Okamoto et al. 2005, Logan 2006, Kuznetsov et al. 2009). Dabei wurde deutlich, dass Mitochondrien eine große Variabilität bezüglich ihrer Morphologie in unterschiedlichen Organismen aufweisen. Vergleicht man die tubulären Mitochondrien der Bäckerhefe Saccharomyces cerevisiae (Abbildung 1.6 A) mit den kugelförmigen Mitochondrien der Schließzellen der Tabakpflanze Nicotiana tabacum (Abbildung 1.6 B) und dem komplexen mitochondrialen Netzwerk humaner Osteosarkom-Zellen (Abbildung 1.6 C) wird deutlich, welche morphologische Heterogenität der Mitochondrien zwischen verschiedenen Organismen existiert (Jakobs et al. 2011). 

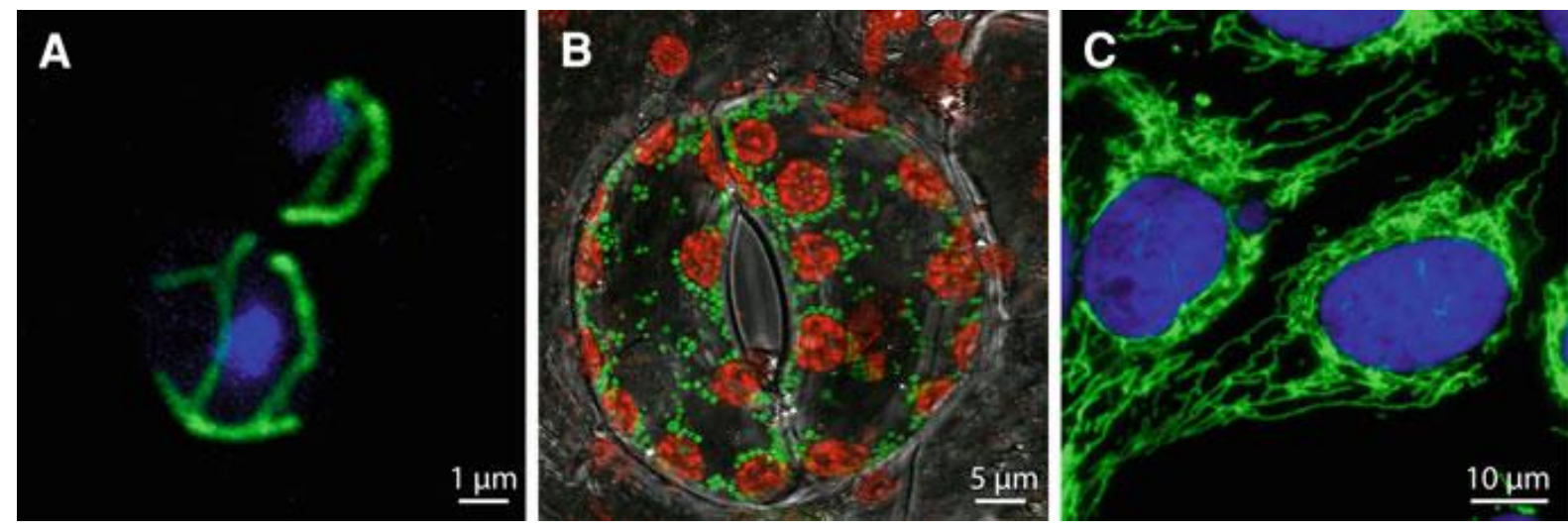

Abbildung 1.6: Verschiedene mitochondriale Morphologien in Hefe-, Pflanzen- und Säugerzellen.

Fluoreszenzmikroskopische Aufnahmen (A) der Bäckerhefe Saccharomyces cerevisiae, (B) einer Schließzelle der Tabakpflanze Nicotiana tabacum und (C) von kultivierten humanen Osteosarkom-Zellen (U2OS) verdeutlichen die Variabilität der mitochondrialen Morphologie. In A und B wurden die Mitochondrien (grün) durch die Expression des grünfluoreszierenden-Proteins (GFP) in der mitochondrialen Matrix markiert. Bei C wurden die Mitochondrien (grün) über eine Immunfluoreszenzmarkierung gegen das mitochondriale Außenmembranprotein Tom20 angefärbt. Die Chloroplasten (B) (rot) wurden durch ihre starke Autofluoreszenz visualisiert. Die Kerne (A, C) (blau) wurden durch den DAPI-Farbstoff sichtbar gemacht. Abbildung aus (Jakobs et al. 2011).

\subsubsection{Mitochondriale Heterogenität zwischen unterschiedlichen Zelltypen}

Mitochondrien können in Säugerzellen, je nach Gewebe und Zelltyp, sehr verschiedene Morphologien aufweisen, obwohl diese Zellen über einen ähnlichen Proteingehalt verfügen und ähnliche metabolische Funktionen erfüllen (Jakobs et al. 2011). Die Diversität mitochondrialer Formen reicht von kleinen Kugeln, über zylindrische Stäbe bis zu elongierten Filamenten (Kuznetsov et al. 2009). Darüber hinaus kann sich das Aussehen des gesamten mitochondrialen Netzwerks deutlich zwischen verschiedenen Zelltypen unterscheiden (Abbildung 1.7) (Collins et al. 2002).

Während kortikale Astrozyten, HUVEC-Zellen und COS-7-Zellen ein dichtes, oft verzweigtes Netzwerk langer mitochondrialer Tubuli besitzen, weisen die Mitochondrien in HeLa-Zellen eine eher verkürzte Stäbchen-ähnliche Morphologie, mit einer geringeren Konnektivität auf. Kortikale Neuronen verfügen eher über einzelne Mitochondrien im Gegensatz zum dichten Netzwerk der anderen abgebildeten Zellen (Abbildung 1.7). Die Form der Gesamtheit der Mitochondrien weicht in Hepatozyten deutlich von der Form, die in den meisten Zelllinien üblich ist, ab. Ihre Mitochondrien sehen kugelförmig aus. Außerdem lokalisieren die Mitochondrien hauptsächlich sphärisch um den Zellkern (Abbildung 1.7). 


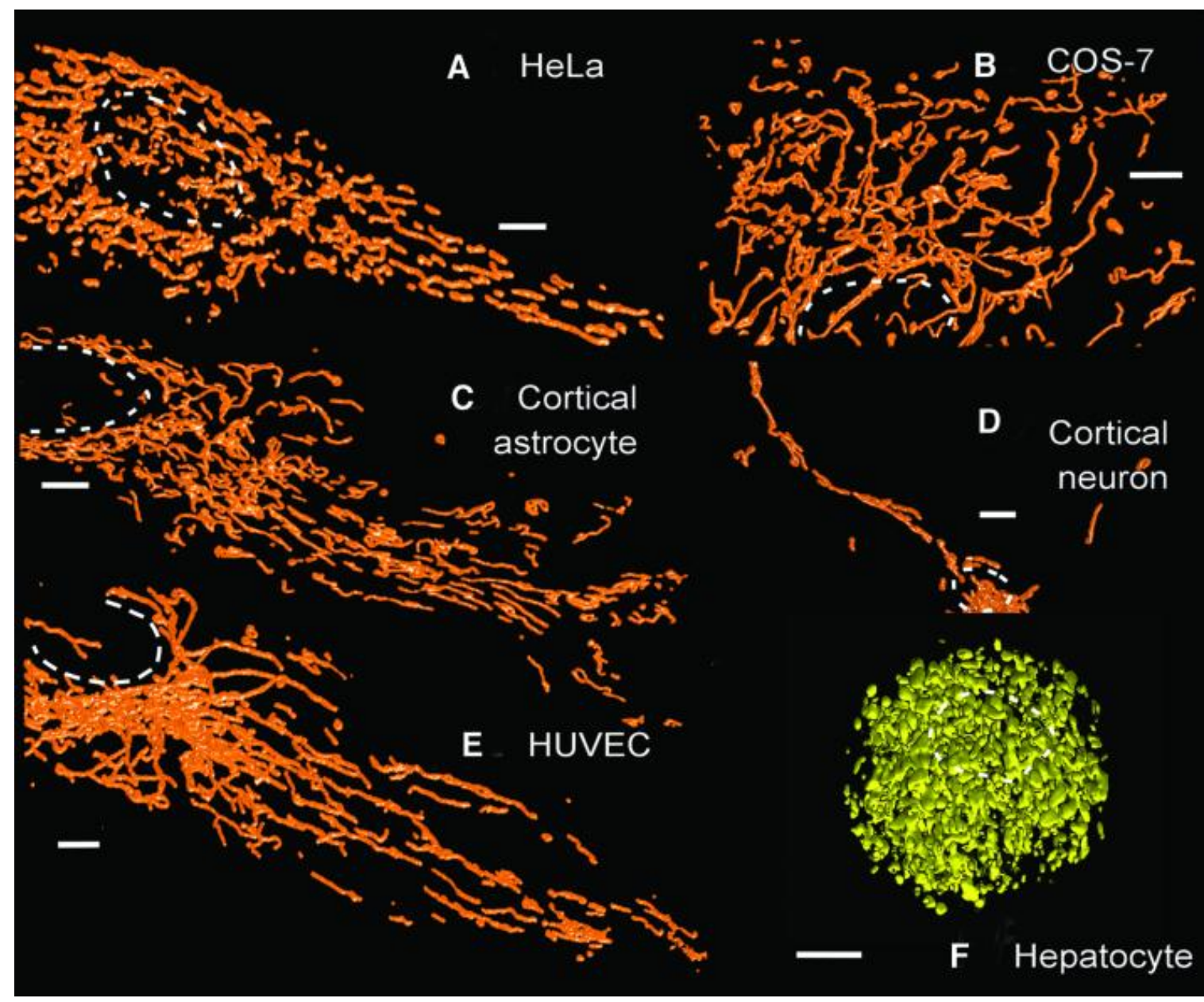

Abbildung 1.7: Verschiedene Formen des mitochondrialen Netzwerks in humanen kultivierten Zellen.

Drei-dimensionale Rekonstruktionen von Zellen, welche mito-DsRed1 exprimieren: (A) HeLa, (B) COS-7, (C) kortikale Astrozyten, (D) kortikale Neuronen, (E) HUVEC. (F) Eine dreidimensionale Rekonstruktion der mitochondrialen CalceinFluoreszenz eines Hepatozyten. Die gestrichelten Kreise zeigen die Position der Zellkerne an. Größenbalken: $5 \mu m$. Abbildung aus (Collins et al. 2002).

Eine gänzlich unterschiedliche Morphologie weisen Mitochondrien in Kardiomyozyten adulter Ratten auf. In diesen Zellen kann eine hochgeordnete Verteilung der Mitochondrien über die gesamte Zelle beobachtet werden (Lee et al. 2012).

Es wurden nicht nur Formunterschiede der Mitochondrien verschiedener Zelllinien belegt, sondern auch funktionale Unterschiede. Eine Studie beweist zum Beispiel, dass die untersuchten Zelllinien, welche verschiedene mitochondriale Morphologien aufwiesen, sich in der Stärke ihres mitochondrialen Membranpotentials unterschieden (Huang et al. 2004). Das mitochondriale Membranpotential ist ein etablierter Indikator für die Funktionalität von Mitochondrien, weil es die Leistung des Protonentransports über die innere Membran durch die Atmungskettenkomplexproteine wiederspiegelt und somit ein Maß für Energieproduktion darstellt (Jakobs et al. 2011) und weil es viele bioenergetische Parameter, wie z.B. ATP-Synthese, $\mathrm{Ca}^{2+}-$ 
Homöostase, Protein-Import, mitochondriale Fusion, Mitophagie und die Bildung von reaktiven Sauerstoffspezies (ROS) beeinflusst (Nicholls et al. 2000). Eine weitere Studie demonstrierte, dass das mitochondriale Membranpotential, die Atmungsrate, Cytochrom C-Oxidase-Aktivität, Atmung sowie die zelluläre Wachstumsrate in HeLa-, Vero- und Ptk2-Zellen unterschiedlich ist (Wurm et al. 2011). Diese Ergebnisse stellen somit eine mögliche Verbindung zwischen den Variationen mitochondrialer Morphologie und den individuellen Aufgaben der entsprechenden Zellen dar.

\subsubsection{Veränderungen mitochondrialer Form}

Die Existenz einer Beziehung zwischen mitochondrialer Form und bioenergetischen Anforderungen bestimmter Zellen wurde häufig postuliert (Rossignol et al. 2004, Benard et al. 2007). Beobachtungen, welche diese Annahme unterstützen, wurden in der Bäckerhefe Saccharomyces cerevisiae gemacht. Es wurde berichtet, dass das mitochondriale Gesamtvolumen dieser Zellen um bis das Dreifache erhöht ist, wenn das Zellmedium ausschließlich nicht-fermentierbare (Glycerol) anstatt fermentierbarer (Glukose) Kohlenstoffquellen enthält (Stevens 1977, Egner et al. 2002). Die Bäckerhefe gewinnt, wenn große Mengen Glukose im Zellmedium vorliegen, ATP ausschließlich über die Glykolyse. Dementsprechend benötigen sie Mitochondrien zur Energiegewinnung nur unter nichtfermentierbaren Wachstumsbedingungen (Jakobs et al. 2011).

In Säugerzellen laufen mitochondriale Teilungs- und Fusionsvorgänge kontinuierlich ab, sodass es zu einer fortwährenden Formveränderung des mitochondrialen Netzwerks kommt. Ein besonderer Aspekt dieses Prozesses stellt das Verhalten der mitochondrialen Dynamik während des Zellzyklus dar. Es wurde berichtet, dass sich die mitochondriale Morphologie im Laufe des Zellzyklus deutlich verändert (Mitra et al. 2009). Die mitochondriale Morphologie variiert nicht nur innerhalb einer Zelle und während des Zellzyklus. Auch als Antwort auf bestimmte Stimuli reagieren Zellen mit einer Formanpassung des mitochondrialen Netzwerk, entweder zu Gunsten eines hyperfusionierten oder eines fragmentierten Aussehens (Rambold et al. 2011, Rambold et al. 2011, Youle et al. 2012) (Abbildung 1.8). Während des Vorgangs der Apoptose kommt es zu einer induzierten Fragmentierung des Organells aufgrund verstärkter mitochondrialer Teilung (Youle et al. 2005). 


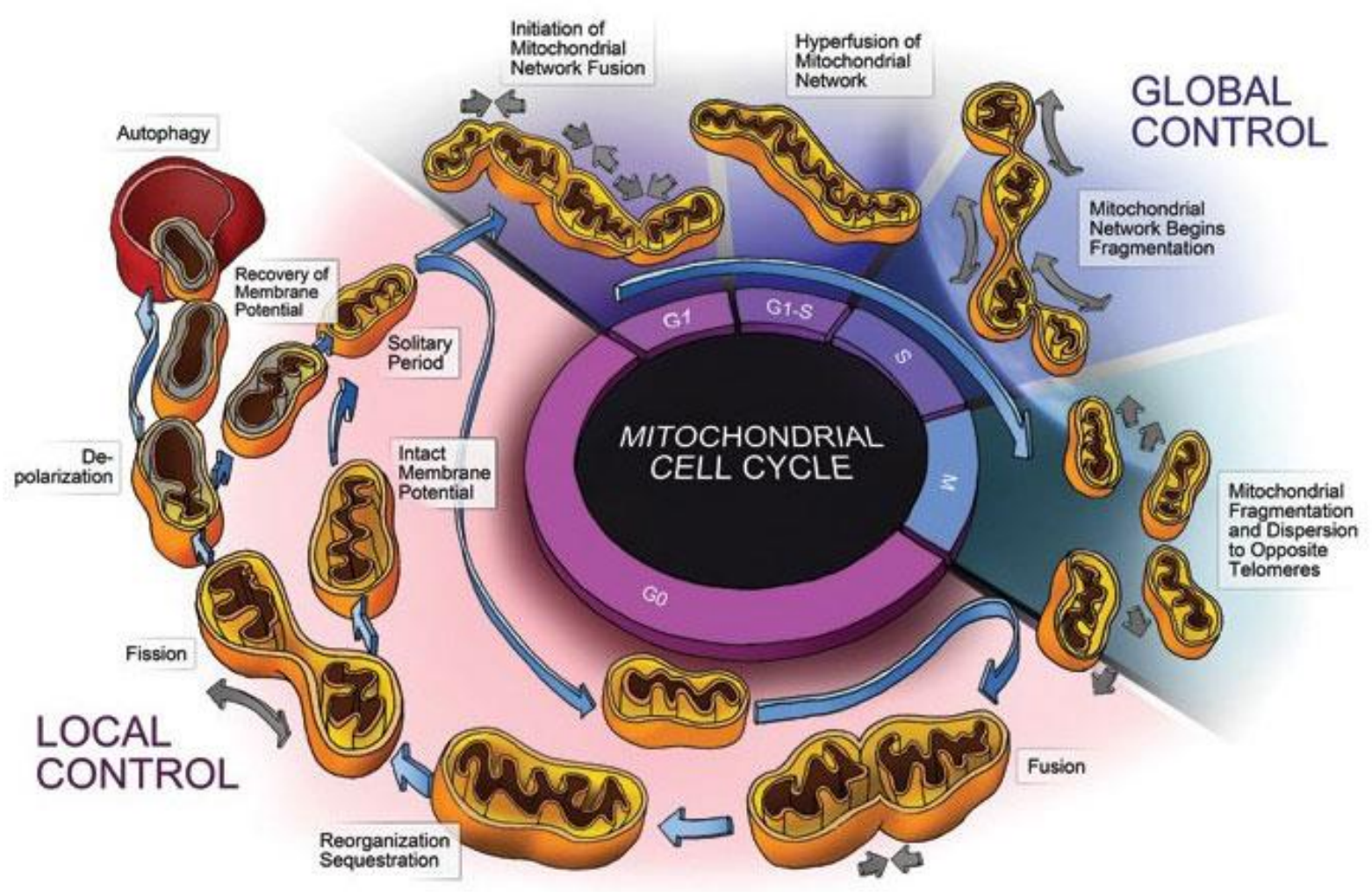

Abbildung 1.8: Schematische Darstellung des Lebenszyklus eines Mitochondriums.

Das Mitochondrium vollzieht Teilungs- und Fusions-Vorgänge, wird depolarisiert und durch Autophagie abgebaut. Hierbei handelt es sich um lokal stattfindende Kontrollprozesse, wobei die mitochondrialen Vorgänge hauptsächlich durch den lokalen Energiebedarf reguliert werden. Während des Zellzyklus führen allgemeine Signale zu gemeinsamen Veränderungen der mitochondrialen Population, wie zum Beispiel der Hyperfusion während dem G1-S-Übergang und der Fragmentierung während der M-Phase. Abbildung aus (Hyde et al. 2010).

\subsubsection{Mitochondriale Heterogenität innerhalb einzelner Zellen}

Die Form des mitochondrialen Netzwerks unterscheidet sich nicht nur zwischen benachbarten Zellen, sondern auch innerhalb einer einzelnen Zelle ist deutlich eine morphologische Heterogenität dieser Organellen zu beobachten. Des Weiteren ist auch die Verteilung der Mitochondrien innerhalb einer Zelle sehr heterogen. So kann man deutlich beobachten, dass die Mitochondrien häufig aggregiert in Kernnähe auftreten, obwohl sie sich im gesamten Zytoplasma verteilen könnten (Bereiter-Hahn 1990, Collins et al. 2002, Frazier et al. 2006).

\section{Heterogene mitochondriale Subpopulationen}

In einigen Zelltypen konnten morphologisch und funktional verschiedene mitochondriale Subpopulationen beschrieben werden, die unterschiedliche Aufgaben ausführen können. 
Die Existenz von drei verschiedenen Mitochondrienpopulationen wurde für pankreatische AzinusZellen berichtet (Park et al. 2001). Zu diesen Gruppen zählen perigranuläre Mitochondrien, perinukleäre Mitochondrien und periphere Mitochondrien nahe der basalen Plasmamembran. Außerdem konnte gezeigt werden, dass die Mitochondrien dieser drei Populationen kein kontinuierliches Lumen aufwiesen und unterschiedlich auf zytosolische $\mathrm{Ca}^{2+}$-Signale reagierten. Es wurde die Hypothese aufgestellt, dass sie an der lokalen $\mathrm{Ca}^{2+}$-Homöostase beteiligt sind.

Ein ähnliches Phänomen der elektrischen Diskontinuität von Mitochondrien wurde in adulten Kardiomyozyten gefunden (Zorov et al. 2000, Beraud et al. 2009). Sie können aufgrund funktionaler und struktureller Unterschiede in zwei Populationen, die subsarkolemmalen und die intermyofibrillären Mitochondrien, unterteilt werden (Kuznetsov et al. 2006). Es wurde eine größere Atmungsaktivität der intermyofibrillären Mitochondrien gegenüber den subsarkolemmalen Mitochondrien beobachtet (Palmer et al. 1977, Palmer et al. 1985).

Selbst morphologisch ähnliche Mitochondrien innerhalb einer Zelle können sich funktional unterscheiden.

\section{Heterogenität des mitochondrialen Membranpotentials}

Es gibt verschiedenste positiv geladene lipophile Fluorophore, die eine qualitative und quantitative Bestimmung des Membranpotentials von Mitochondrien erlauben (Scaduto et al. 1999, Nicholls et al. 2000, Jakobs 2006, Lemasters et al. 2007). Beispielsweise werden nachfolgend die Ergebnisse einiger Studien vorgestellt, welche unter Verwendung der Farbstoffe JC-1 und TMRM/TMRE entstanden sind.

Mittels JC-1 konnte eine Heterogenität des mitochondrialen Membranpotentials innerhalb einzelner Zellen verschiedener Zelllinien demonstriert werden. Hierzu gehören: humane Fibroblasten (Smiley et al. 1991); Hela-Zellen und Hepatozyten (Collins et al. 2002); Maus Oozyten und Blastozysten (Van Blerkom et al. 2003, Van Blerkom et al. 2006, Van Blerkom et al. 2006); Maus- und frühe humane Embryonen (Acton et al. 2004); pankreatische beta-Zellen (Wikstrom et al. 2007); humane Astrozyten, Hep-2-, MDCK- und Vero-Zellen (Diaz et al. 1999); Ratten Kardiomyozyten (Bowser et al. 1998), sowie isolierte Leber-Mitochondrien (Cossarizza et al. 1996).

Eine Vielzahl von Studien hat die TMRE/TMRM Farbstoffe zur Analyse des mitochondrialen Membranpotentials verwendet und seine Heterogenität innerhalb einzelner Zellen bewiesen (Abbildung 1.9) (Diaz et al. 2000, Buckman et al. 2001, Wikstrom et al. 2007, Distelmaier et al. 2008). 


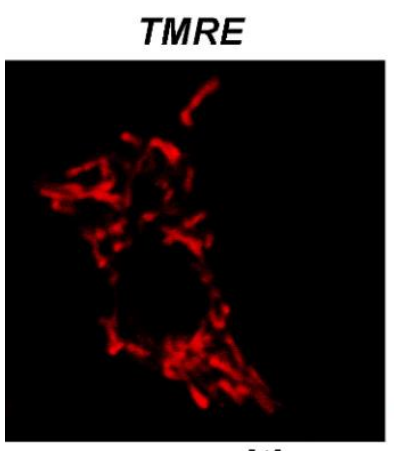

$\Delta \psi$ sensitiv

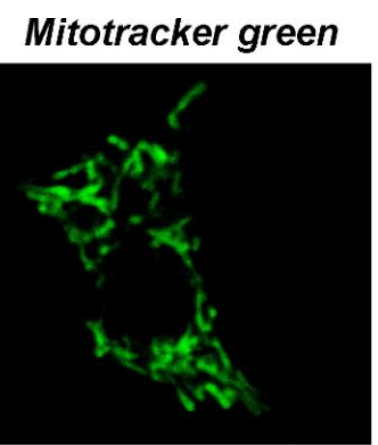

$\Delta \psi$ insensitiv
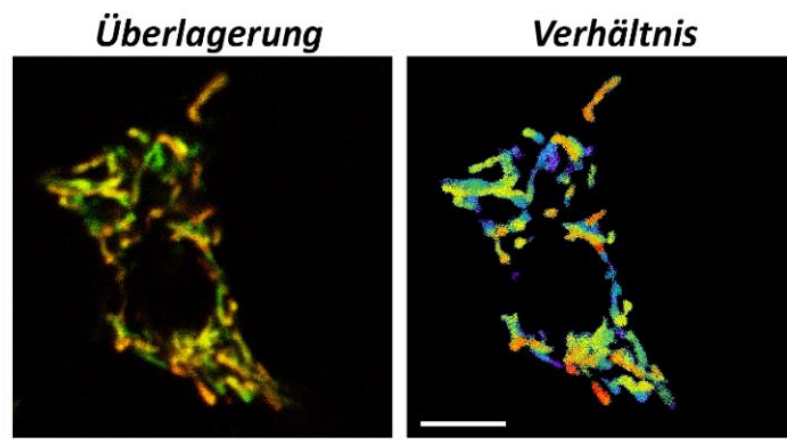

Abbildung 1.9: Heterogenität des mitochondrialen Membranpotentials.

In klonalen INS1 Beta-Zellen wurden Mitochondrien mit dem Membranpotential-unabhängigen Fluoreszenz-Farbstoff Mitotracker Green angefärbt. In diesen Zellen wurde das Membranpotential mit dem fluoreszierenden Farbstoff TMRE sichtbar gemacht. In der Überlagerung sieht man deutlich keine homogen gelbe Markierung der Mitochondrien, sondern auch einzelne rote und grüne Mitochondrien. Dies lässt den Schluss zu, dass sich Mitochondrien in ihrem Membranpotential individuell unterscheiden. Größenbalken: $5 \mu \mathrm{m}$. Abbildung verändert nach (Wikstrom et al. 2009).

Interessanterweise gibt es sogar Berichte von heterogenem Membranpotential innerhalb einzelner mitochondrialer Filamente (Benard et al. 2008). Es wurde ein erhöhtes Membranpotential, gemessen mittels JC-1-Fluoreszenz, in Bereichen mitochondrialer Tubuli von humanen Skelettmyoblasten beobachtet, welche sich näher an der Plasmamembran befanden.

\section{Heterogenität mitochondrialer $\mathrm{Ca}^{2+}-$ Konzentrationen}

Mitochondrien besitzen eine entscheidende Funktion bei der $\mathrm{Ca}^{2+}$-Homöostase. Dementsprechend wurde in einigen Studien die Verteilung von $\mathrm{Ca}^{2+}$ bezüglich einer möglichen Heterogenität untersucht. In HeLa-Zellen wurde eine heterogene $\mathrm{Ca}^{2+}$-Freisetzung aus den Mitochondrien, nach Induktion von oxidativem Stress, gezeigt (Collins et al. 2002). Sie führen ihre Beobachtung auf eine heterogene PTP-Öffnung zurück. Die Heterogenität von mitochondrialem Calcium wurde außerdem in Herzzellen beobachtet (Bowser et al. 1998).

\section{Heterogenität des ROS-Gehaltes}

Reaktive Sauerstoff-Spezies (ROS) entstehen als schädliches Nebenprodukt der oxidativen Phosphorylierung während der Atmungskette. Sie können zu immensen Schäden von Zellen führen (Li et al. 2002, Balaban et al. 2005). Die heterogene Verteilung von ROS innerhalb von Mitochondrien wurde für verschiedene Zelllinien gezeigt (Kuznetsov et al. 2009).

Insbesondere durch metabolischen oder photo-induzierten oxidativen Stress kann eine lokal erhöhte ROS-Produktion induziert werden (Romashko et al. 1998). Mehrere Forschungsgruppen beobachteten in erwachsenen Ratten-Kardiomyozyten (Beraud et al. 2009) (Zorov et al. 2000), sowie 
in HL-1-Zellen und verschiedenen Krebszelllinie (MCF-7, HAT-29) (Kuznetsov et al. 2004, Kuznetsov et al. 2006) eine heterogene mitochondriale ROS-Produktion und große Variationen im mitochondrialen Membranpotential durch photooxidativen Stress.

\section{mitochondriale Heterogenität und Apoptose}

Mitochondrien haben eine zentrale Funktion während des Vorgangs der Apoptose. Die Freisetzung von Cytochrom C aus den Mitochondrien ist dabei ein entscheidender Prozess (Liu et al. 1996).

In mehreren Studien wurde eine Heterogenität der Cytochrom C-Freisetzung nach Induktion von Apoptose berichtet (Leist et al. 1997, Kuznetsov et al. 2004). So lagen in diesen Zellen parallel Mitochondrien vor, die noch über Cytochrom $C$ verfügten und solche, die ihr Cytochrom $C$ bereits freigesetzt hatten (Leist et al. 1997).

\section{mitochondriale Heterogenität und Pathologie}

Einige Studien berichten von einer erhöhten mitochondrialen Heterogenität wenn Zellen pathophysiologischen Bedingungen ausgesetzt waren:

In pankreatischen Beta-Zellen wurde eine heterogenere Verteilung des mitochondrialen Membranpotentials beobachtet, wenn sie großen Mengen Glukose oder freien Fettsäuren ausgesetzt wurden (Wikstrom et al. 2007).

In Kardiomyozyten aus Ratten wurde nach kalter ischämischer Reperfusion eine Erhöhung der Heterogenität der Verteilung von mitochondrialem Membranpotential, $\mathrm{Ca}^{2+}$, reaktiver SauerstoffSpezies (ROS) und Flavoprotein demonstriert (Kuznetsov et al. 2004, Kuznetsov et al. 2006). Sie stellten die Hypothese auf, dass ihre Beobachtungen mit einer Heterogenität von PTP-Öffnungen oder Cytochrom C-Freisetzung in Verbindung stehen (Kuznetsov et al. 2004).

Bislang ist wenig darüber bekannt, ob diese funktionalen Unterschiede auf verschiedene Proteinverteilungen innerhalb der Mitochondrien zurückzuführen sind (Jakobs et al. 2011). Die Korrelation funktionaler Heterogenität von Mitochondrien mit Proteinverteilungen würde entscheidend zum Verständnis der Funktion von Mitochondrien beitragen. Generell gibt es momentan nur sehr wenige Erkenntnisse über die Heterogenität mitochondrialer ProteinVerteilungen innerhalb einzelner Zellen.

\section{Heterogenität mitochondrialer Proteinverteilungen}

Unter der Annahme, dass Zellen auf unterschiedliche Energieansprüche mit der Änderung des Proteingehalts ihrer Mitochondrien reagieren (Devin et al. 2007), ist es möglich, dass solch eine Anpassung auch für den Haupteintrittsweg, nämlich den Protein-Importkomplexen (z.B. TOMKomplex), in Mitochondrien wahrscheinlich ist. Mittels STED-Mikroskopie wurde die sub- 
mitochondriale Verteilung einer Untereinheit des TOM-Komplexes, Tom20, in den Mitochondrien untersucht (Wurm et al. 2011). Es wurde berichtet, dass dessen Verteilung auf den Mitochondrien in Clustern erfolgt und fein abgestimmt auf zelluläre Wachstumsbedingungen ist. Weiterhin konnte beobachtet werden, dass Tom20 innerhalb einer Fibroblastenzelle eine ungleichmäßige Verteilung aufweist. Seine Verteilung weist einen Gradienten, mit einer hohen Proteindichte in perinukleären Mitochondrien und einer geringen Proteindichte in peripheren Mitochondrien auf. Außerdem wurde gezeigt, dass die Dichte der Tom20-Proteincluster mit dem mitochondrialen Membranpotential korreliert.

Für diese Studie wurden mehr als 1000 kultivierte Zellen mittels quantitativer Bildauswertungsalgorithmen analysiert.

In einer weiteren Untersuchung wurde belegt, dass ein weiteres mitochondriales Protein, nämlich Mitofilin/Mic60, innerhalb einzelner Zellen eine ähnliche heterogene Verteilung aufweist. Die Autoren beobachteten eine dichtere Clusterverteilung dieses mitochondrialen Proteins in perinukleären Mitochondrien im Vergleich zu peripheren Mitochondrien (Jans et al. 2013).

Die Autoren beider Studien stellten die Vermutung auf, dass die Dichte der Tom20- bzw. Mitofilin/Mic60-Cluster größer in den Mitochondrien nahe dem Kern als am Rand der Zelle ist, weil die Mitochondrien dort wahrscheinlich aktiver sind.

Somit geben sie entscheidende Hinweise, dass selbst die innerzelluläre Verteilung mitochondrialer auf die spezifische zelluläre Umgebung Proteine fein abgestimmt wird und mit funktionellen Parametern korreliert.

\subsubsection{Mechanismen und Ursachen der mitochondrialen Heterogenität}

Die Mechanismen, welche zur Entstehung und dem Erhalt mitochondrialer Heterogenität beitragen, sind bislang unbekannt. Es wurde die Vermutung aufgestellt, dass die beobachteten spezifischen Funktionalisierungen individueller Mitochondrien innerhalb einzelner Zellen, möglicherweise durch individuelle Ansprüche und Bedingungen unterschiedlicher Zellregionen, und die daraus resultierende Anpassung der Mitochondrien, verursacht werden könnten (Kuznetsov et al. 2009). Eindeutige Beweise hierfür existieren jedoch nicht.

Ein möglicher Grund für die Entstehung mitochondrialer Heterogenität können lokale Unterschiede der Ionen- bzw. Substrat-Konzentrationen oder des Energie-Bedarfs innerhalb einer Zelle sein (Mironov et al. 2006, Mironov 2007, Kuznetsov et al. 2009). 
Es wird vermutet, dass Prozesse wie mitochondriale Dynamik, also Fusion, Teilung und Bewegung, sowie Mitophagie, das Ausmaß der mitochondrialen Heterogenität kontrollieren und erhalten (Wikstrom et al. 2007, Wikstrom et al. 2009). Ein genaues Verständnis des Einflusses mitochondrialer Dynamik auf die funktionale Heterogenität gibt es bislang nicht. Dies wäre jedoch nötig, um die Entstehung mitochondrialer Heterogenität aufzuklären.

\section{Wie kann mitochondriale Heterogeniät mit mitochondrialer Dynamik koexistieren?}

Ein bekannter Aspekt von Mitochondrien ist ihr hochdynamisches Verhalten. Diese Dynamik wurde unter Verwendung photokonvertierbarer fluoreszierender Proteine (z.B. mtPA-GFP), die in der Matrix von Mitochondrien exprimiert wurden, über längere Zeiträume innerhalb ganzer Zellen untersucht. Verschiedene Forschungsgruppen berichteten von einem kontinuierlichen mitochondrialen Netzwerk. Die Arbeitsgruppe von O. Shirihai (Twig et al. 2008, Twig et al. 2008) beobachtete zum Beispiel, dass nach Photokonversion einer kleinen Menge Mitochondrien in einer Zelle, nach 30 40 min eine komplette Ausbreitung des konvertierten Signals, aufgrund kontinuierlicher Fusions-, Teilungs- und Transportvorgänge, auf die gesamte Mitochondrienpopulation stattgefunden hat. Im Einklang mit diesem Ergebnis, steht die Erkenntnis, dass der Verlust mitochondrialer Fusion die Entstehung einer Heterogenität bezüglich des Membranpotentials individueller Mitochondrien bewirkt (Chen et al. 2005). Diese Beobachtungen stehen jedoch völlig im Gegensatz zu der zuvor berichteten funktionalen Heterogenität von Mitochondrien, denn durch die Vorgänge mitochondrialer Dynamik wäre eine Homogenisierung von Mitochondrien und ihrem Inhalt zu erwarten (Wikstrom et al. 2009). Eine mögliche Erklärung kann die Beobachtung, dass nicht alle Mitochondrien fusionieren können, geben. Der Verlust der Fähigkeit von mitochondrialer Fusion, durch Herunterregulierung von Mfn1 und Mfn2, führt zu einer erwarteten Fragmentierung der Mitochondrien und einer starken Beeinträchtigung des Metabolismus dieser Zellen (Chen et al. 2005). Interessanterweise wurde in diesen Zellen eine eindeutige Heterogenität des MMPs beobachtet. Diese Beobachtung bekräftigt die unter 1.1.3 beschriebene Funktion von mitochondrialer Fusion eine „gesunde“ Mitochondrienpopulation zu erhalten.

Weitere Studien konnten beweisen, dass einzelne depolarisierte Mitochondrien von der Fusion ausgespart wurden und sich somit nicht mehr mit den restlichen Mitochondrien vermischen konnten, wodurch erneut ein gewisses $M a ß$ an Heterogenität innerhalb einer Zelle erzeugt wird (Twig et al. 2008). 


\subsection{Bildgebende Verfahren zur Untersuchung der mitochondrialen}

\section{Proteinlokalisation}

Die Möglichkeit Proteine in ihrer natürlichen Umgebung zu visualisieren ist essentiell, um ein genaues Verständnis von biologischen Vorgängen und zellulären Funktionen zu erlangen. Lichtmikroskope eignen sich insbesondere für die Betrachtung intrazellulärer Prozesse und Strukturen und tragen somit zu ihrem Verständnis bei.

\section{Epifluoreszenz- und Konfokalmikroskopie}

Für die visuelle Untersuchung von biologischen Prozessen wird heutzutage hauptsächlich die Fluoreszenzmikroskopie eingesetzt. Dieses Verfahren erlaubt es, markierte Struktur vor einem dunklen zellulären Hintergrund zu visualisieren. Fluoreszenz ist ein physikalischer Prozess, bei dem ein Fluorophor durch Absorption von Licht bestimmter Wellenlänge angeregt wird, um dann die aufgenommene Energie in Form von langwelligerem Licht zu emittieren. Bei der Fluoreszenzmikroskopie wird ausschließlich das zum Anregungslicht spektral verschobene Fluoreszenzlicht detektiert.

Zwei Methoden der Fluoreszenzmikroskopie sind die Epifluoreszenz- und die Konfokalmikroskopie.

Bei der Epifluoreszenzmikroskopie werden alle Fluorophore des Bildfeldes von einer Fluoreszenzlampe angeregt und emittieren anschließend Fluoreszenzlicht. Hierbei werden auch Fluorophore, die sich nicht in der Schärfeebene befinden angeregt und detektiert.

Die konfokale Fluoreszenzmikroskopie ermöglicht es, Strukturen dreidimensional aufzulösen. Indem eine Lochblende (pinhole) in den Strahlengang eingebracht wird, ist eine punktförmige Detektion von Fluorophoren in der Schärfeebene möglich (Minsky 1961). Somit wird nur das Fluoreszenzlicht aus der Fokusebene abgebildet, wodurch die Möglichkeit besteht, dreidimensionale Bilder von Proben mit dieser Technik anzufertigen.

Die mitochondriale Form, sowie ihre Dynamik können mit konventioneller Fluoreszenz-Mikroskopie gut untersucht werden. Für die Analyse submitochondrialer Proteincluster und ihrer Verteilung besitzen Epifluoreszenzmikroskope und Konfokalmikroskope eine entscheidende Limitation. Wie vom Abbe'schen Gesetz (Abbe 1873) beschrieben, ist die Auflösung von Lichtmikroskopen aufgrund der Welleneigenschaften des Lichtes durch Beugung begrenzt. Die maximal erreichbare Auflösung konventioneller Lichtmikroskope beträgt ca. $600 \mathrm{~nm}$ in axialer Richtung (z) und ca. $200 \mathrm{~nm}$ in lateraler Richtung (xy). Da Mitochondrien einen Durchmesser nahe der Auflösungsgrenze besitzen, können 
Heterogenitäten submitochondrialer Proteinverteilungen nur mit Mikroskopietechniken untersucht werden, die ein unbegrenztes Auflösungsvermögen besitzen (Wurm et al. 2011, Jans et al. 2013).

\section{Nanoskopie}

Verschiedenste Entwicklungen der letzten Jahre konnten die Auflösung der Lichtmikroskopie entscheidend verbessern. Diese beugungsunbegrenzten Nanoskopie-Techniken nutzen Marker, die zwei molekulare Zustände besitzen - einen fluoreszierenden „an“- und einen dunklen „aus"-Zustand (Hell 2003). Der Übergang zwischen diesen Zuständen kann auf verschiedene Arten herbeigeführt werden. In Abhängigkeit davon, wie dieser Übergang stattfindet lassen sich verschiedene Nanoskopie-Verfahren einteilen in gerichtete Schaltverfahren, z.B. STED (STimulated Emission Depletion microscopy) (Hell et al. 1994, Klar et al. 2000), SSIM (Saturated Structured-Illumination Microscopy) (Gustafsson 2005) und RESOLFT (REversible Saturable OpticaL Fluorescence Transitions) (Hell 2003, Brakemann et al. 2011, Grotjohann et al. 2011) sowie zufällige Schaltverfahren, z.B. PALM (PhotoActivated Localization Microscopy) (Betzig et al. 2006), STORM (STochastic Optical Reconstruction Microscopy) (Rust et al. 2006) und GSDIM (Ground State Depletion-Individual Molecule return microscopy) (Folling et al. 2008).

Im Rahmen dieser Arbeit wurde ausschließlich mit der beugungsunbegrenzten STED-Mikroskopie gearbeitet, da diese Technik am besten etabliert ist.

Bei der STED-Mikroskopie wird durch stimulierte Emission eines, durch Lichtabsorption angeregten, Fluorophors mittels Bestrahlung mit einem längerwelligen, energieärmeren Laserpuls der angeregte Zustand entvölkert, noch bevor Fluoreszenz stattfinden kann (Abbildung 1.10). Da die Photonen, die durch stimulierte Emission abgegeben werden, langwelliger sind als das Fluoreszenzlicht, können sie so von der Detektion ausgeschlossen werden.
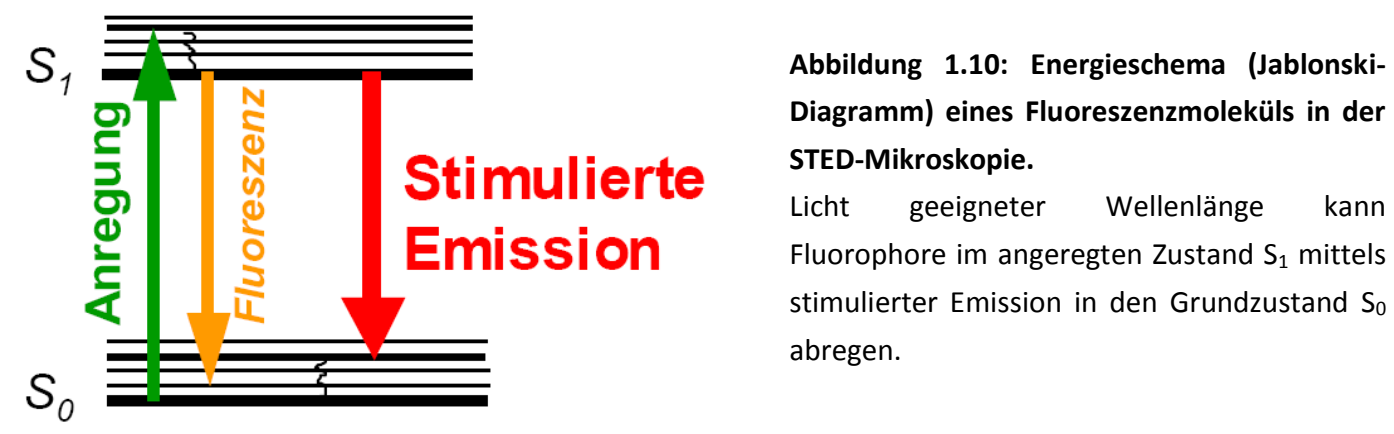
Wie bei der Konfokalmikroskopie werden zunächst die Fluorophore in der Fokusebene durch einen Laser angeregt, wobei die Intensitätsverteilung des Anregungslichtes von Beugung bestimmt wird. Eine Auflösungserhöhung entsteht durch die Reduktion der räumlichen Ausdehnung des effektiven Fokus. Das wird erreicht, indem die Fluoreszenz durch stimulierte Emission in der äußeren Region des Fokus ausgeschaltet wird, sodass Fluoreszenz nur noch im zentralen Punkt stattfindet. Hierzu wird die Anregung mit dem STED-Strahl, dessen Fokus in der Form eines Rings mit einem Intensitätsminimum (idealerweise mit der Lichtintensität von 0) in der Mitte gestaltet wird, überlagert (Abbildung 1.11).

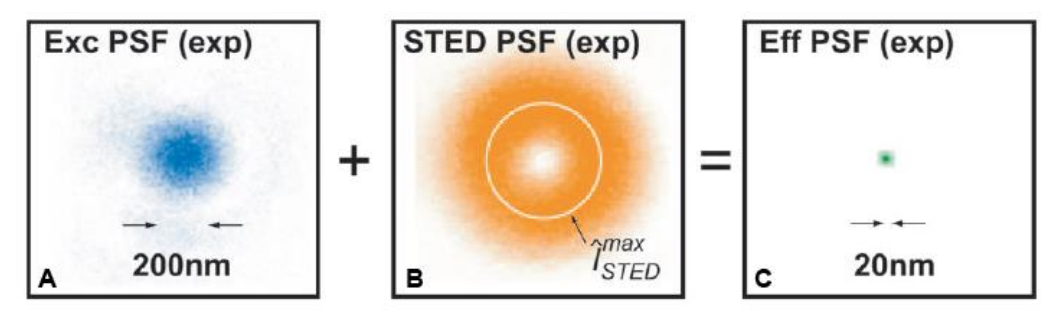

\section{Abbildung 1.11: Prinzip der Auflösungserhöhung bei der STED-Mikroskopie.}

Die PSF (Point-Spread-Function) eines konfokalen Fokus (A) wird überlagert mit einer ringförmigen Intensitätsverteilung des STED-Strahles (B). Durch stimulierte Entvölkerungsprozesse ergibt sich somit eine Intensitätsverteilung der Fluoreszenz (C) mit einer effektiven Breite von ca. $20 \mathrm{~nm}$. Abbildung verändert nach (Donnert et al. 2006).

Mit Hilfe der STED-Mikroskopie konnten bisher Auflösungen von $8 \mathrm{~nm}$ (Rittweger et al. 2009) in nicht-biologischen Proben und $20 \mathrm{~nm}$ in biologischen Proben (Donnert et al. 2006) erreicht werden. Prinzipiell ist die maximale Auflösung nur noch durch die photophysikalischen Eigenschaften des Fluorophors und die Laserintensität limitiert (Hell 2009).

\subsection{Zielsetzung dieser Arbeit}

Mitochondrien besitzen die essentielle Funktion der Energieproduktion in eukaryotischen Zellen. Ihre Dysfunktion wird in den Zusammenhang mit der Entstehung einer Vielzahl verheerender Erkrankungen gebracht. Es gibt Hinweise, dass Mitochondrien sich morphologisch und funktional zwischen verschiedenen Zelltypen und individuellen Zellen unterscheiden. Vermutlich ist diese Heterogenität ein Resultat der Anpassung an unterschiedliche metabolische Bedingungen. Bislang ist jedoch wenig darüber bekannt, ob mitochondriale Proteine eine heterogene Verteilung aufweisen. Für ihre detaillierte Untersuchung eignet sich insbesondere die Fluoreszenzmikroskopie. In einer vorhergehenden Studie wurde die Existenz einer heterogenen Tom20-Verteilung, einer Untereinheit des Importkomplexes kernkodierter mitochondrialer Proteine, in Form eines intrazellulären 
Gradienten innerhalb einzelner Säugerzellen mittels hochauflösender STED-Nanoskopie belegt. Bislang ist unklar, ob diese Beobachtung auch für andere mitochondriale Proteine gültig ist. Dies sollte im Rahmen dieser Arbeit analysiert werden. Die Ergebnisse anderer Studien lassen die Vermutung zu, dass die Prozesse der mitochondrialen Dynamik, also Fusion, Teilung und Bewegung, das Ausmaß der mitochondrialen Heterogenität kontrollieren und erhalten. Welche Auswirkung diese Vorgänge tatsächlich auf die Verteilung mitochondrialer Proteine haben, ist bislang unbekannt und sollte im Rahmen dieser Arbeit untersucht werden. Weiterhin ist bislang unverstanden, wie diese heterogenen mitochondrialen Proteinverteilungen zustande kommen und welche Signale und Moleküle an ihrer Regulierung beteiligt sind. Ziel dieser Arbeit ist somit ein detaillierteres Verständnis der Heterogenität mitochondrialer Proteinverteilungen von Säugerzellen. Durch den Einsatz der Konfokal- und der beugungsunbegrenzten STED-Mikroskopie sollten mögliche Änderungen der Proteinverteilungen nachgewiesen werden. 


\section{Material und Methoden}

\subsection{Verwendete Materialien}

\subsubsection{Chemikalien}

Soweit nicht anders angegeben, wurden die verwendeten Substanzen in entmineralisiertem Wasser gelöst, welches mit Hilfe der Purelab Classic Reinstwasseranlage (Elga, Celle, Deutschland) aufbereitet worden ist.

Alle verwendeten Chemikalien wurden im Reinheitsgrad „zur Analyse“ von folgenden Herstellern bezogen: Sigma-Aldrich (München, Deutschland), Carl Roth (Karlsruhe, Deutschland), Merck (Darmstadt, Deutschland), Applichem (Darmstadt, Deutschland) und Serva (Heidelberg, Deutschland).

\begin{tabular}{|l|}
\hline \multicolumn{1}{|c|}{ Chemikalie } \\
\hline Methanol \\
\hline para-Formaldehyd \\
\hline $\mathrm{KCl}$ \\
\hline $\mathrm{KH}_{2} \mathrm{PO}_{4}$ \\
\hline $\mathrm{NaCl}$ \\
\hline $\mathrm{Na}{ }_{2} \mathrm{HPO}_{4}$ \\
\hline $\mathrm{HCl}$ \\
\hline DMF \\
\hline Tris(hydroxymethyl)-aminomethan (TRIS) \\
\hline NaHCO \\
\hline NaOH \\
\hline DMSO \\
\hline Glyzerin \\
\hline Mowiol 4-88 \\
\hline DABCO (1,4-Diazabicyclo[2.2.2]octan) \\
\hline BSA (Rinder-Serum-Albumin) \\
\hline Isopropanol \\
\hline Triton X-100 \\
\hline Glycin \\
\hline SDS \\
\hline Essigsäure \\
\hline Bromphenolblau \\
\hline Coomassie Brilliant Blau \\
\hline DTT \\
\hline Ponceau S \\
\hline
\end{tabular}




\begin{tabular}{|l|} 
Magermilchpulver \\
\hline $\mathrm{NaOH}$
\end{tabular}

Tabelle 2.1: Auflistung der verwendeten Chemikalien.

\begin{tabular}{|c|c|c|c|}
\hline Name & Wirkung & $\begin{array}{c}\text { Endkon- } \\
\text { zentration }\end{array}$ & Quelle/Hersteller \\
\hline Nocodazol & Depolymerisation von Tubulin & $5 \mu \mathrm{g} / \mathrm{ml}$ & Calbiochem, Merck \\
\hline Oligomycin & $\begin{array}{l}\text { Inhibition F1Fo-ATP-Synthase, } \\
\text { Erhöhung mitochondriales } \\
\text { Membranpotential }\end{array}$ & $10 \mu \mathrm{M}$ & $\begin{array}{l}\text { Selleckchem, Houston, } \\
\text { USA }\end{array}$ \\
\hline Valinomycin & $\begin{array}{l}\mathrm{K}^{+} \text {-Ionophor, Zerstörung } \\
\text { mitochondriales Membranpotential }\end{array}$ & $5 \mu \mathrm{M}$ & Sigma-Aldrich \\
\hline Rotenon & $\begin{array}{l}\text { Inhibition Atmungskettenkomplex I } \\
\text { und Depolymerisation Tubulin }\end{array}$ & $2 \mu \mathrm{M}$ & Sigma-Aldrich \\
\hline Turbofect & Transfektion von Säugerzellen & & $\begin{array}{l}\text { Fermentas, Thermo } \\
\text { Scientific, Waltham, USA }\end{array}$ \\
\hline $\begin{array}{l}\text { DAPI (4',6-Diamidino- } \\
\text { 2-phenylindol) }\end{array}$ & $\begin{array}{l}\text { Fluoreszenzmarkierung von } \\
\text { Nukleinsäuren/ Kernmarkierung }\end{array}$ & $2,5 \mu \mathrm{g} / \mathrm{ml}$ & Sigma-Aldrich \\
\hline $\begin{array}{l}\text { MitoTracker Red CM- } \\
\mathrm{H}_{2} \mathrm{XrOS}\end{array}$ & $\begin{array}{l}\text { Fluoreszenzmarkierung von } \\
\text { Mitochondrien }\end{array}$ & $500 \mathrm{nM}$ & Life Technologies \\
\hline $\begin{array}{l}\text { DiOC }_{6}(3,3 \text { '-Dihexyl- } \\
\text { oxacarbocyaniniodid) }\end{array}$ & $\begin{array}{l}\text { Fluoreszenzmarkierung von } \\
\text { Mitochondrien }\end{array}$ & $0,1 \mathrm{nM}$ & Life Technologies \\
\hline KK114 & Fluorophor & & Dr. K. Kolmakov, MPI-BPC \\
\hline Oregon Green 488 & Fluorophor & & Life Technologies, \\
\hline Atto565 & Fluorophor & & $\begin{array}{l}\text { Atto-Tec, Siegen, } \\
\text { Deutschland }\end{array}$ \\
\hline Bradford-Reagenz & Proteinkonzentrationsbestimmung & & Bio-Rad, Hercules, USA \\
\hline Hygromycin B & $\begin{array}{l}\text { Antibiotikum, Selektion von Drp1- } \\
\text { shRNA-transfizierten Zellen }\end{array}$ & $2 \mathrm{mg} / \mathrm{ml}$ & Sigma-Aldrich \\
\hline Puromycin & $\begin{array}{l}\text { Antibiotikum, Selektion von Mfn2- } \\
\text { shRNA-transfizierten Zellen }\end{array}$ & $40 \mu \mathrm{g} / \mathrm{ml}$ & Sigma-Aldrich \\
\hline Ziegen-Serum & $\begin{array}{l}\text { Blockreagenz bei Immun- } \\
\text { fluoreszenzmarkierung }\end{array}$ & & Sigma-Aldrich \\
\hline $\begin{array}{l}\text { DMEM, high glucose, } \\
\text { GlutaMAX }\end{array}$ & Zellkulturmedium & & $\begin{array}{l}\text { Life Technologies, } \\
\text { Carlsbad, USA }\end{array}$ \\
\hline $\begin{array}{l}\text { fötales Rinderserum } \\
\text { FBS Gold }\end{array}$ & Zellkulturmediumzusatz & & PAA, GE Healthcare \\
\hline $\begin{array}{l}\text { Penicillin/ } \\
\text { Streptomycin }\end{array}$ & Zellkulturmediumzusatz & $\begin{array}{l}10.000 \mathrm{U} / \mathrm{ml} \\
10.000 \mu \mathrm{g} / \mathrm{ml} \\
\end{array}$ & $\begin{array}{l}\text { Biochrom, Berlin, } \\
\text { Deutschland }\end{array}$ \\
\hline $\begin{array}{l}\text { Natrium-Pyruvat } \\
\text { Lösung, } 100 \mathrm{mM}\end{array}$ & Zellkulturmediumzusatz & & Sigma-Aldrich \\
\hline Trypsin/EDTA, 10x & Zellkultur & & Biochrom \\
\hline RC DC Protein Assay & Proteinkonzentrationsbestimmung & & Bio-Rad \\
\hline $\begin{array}{l}\text { PageRuler Prestained } \\
\text { Protein Ladder }\end{array}$ & Größenstandard für SDS-PAGE & & Fermentas \\
\hline Complete tablets mini & Proteaseinhibitor & $\begin{array}{l}1 \text { Tablette } \\
\text { pro } 1 \mathrm{ml} \\
\text { Wasser }\end{array}$ & $\begin{array}{l}\text { Roche, Mannheim, } \\
\text { Deutschland }\end{array}$ \\
\hline Western Lightening & $\begin{array}{l}\text { Chemilumineszenz Western-Blot } \\
\text { Detektionsreagenz }\end{array}$ & & $\begin{array}{l}\text { PerkinElmer, Rodgau, } \\
\text { Deutschland }\end{array}$ \\
\hline
\end{tabular}

Tabelle 2.2: Auflistung der verwendeten Reagenzien. 


\subsubsection{Verbrauchsmaterialien}

\begin{tabular}{|l|l|}
\hline \multicolumn{1}{|c|}{ Verbrauchsmaterial } & \multicolumn{1}{c|}{ Hersteller } \\
\hline $75 \mathrm{~cm}^{2}$-Kultivierungsflaschen & Greiner Bio-One, Frickenhausen, Deutschland \\
\hline Pipettenspitzen & Sarstedt, Nümbrecht, Deutschland \\
\hline Petrischalen (5 und $10 \mathrm{~cm})$ & Sarstedt \\
\hline Mikrotiterplatten (6-, 12-, 24-Well-Platten) & Nunc, Rochester, USA \\
\hline Deckgläser (10, $12 \mathrm{~mm})$ & Menzel, Braunschweig, Deutschland \\
\hline Flaschen & Schott, Mainz, Deutschland \\
\hline Plastikflaschen für Medium & Sarstedt \\
\hline Vakuum-Flaschenaufsatzfilter & Sarstedt \\
\hline Cryotubes & Nunc, Wiesbaden, Deutschland \\
\hline Sephadex G25 Säule (PD-10) & GE Healthcare, Freiburg, Deutschland \\
\hline Spitzen & Sarstedt \\
\hline Transfer-Pipetten & Sarstedt \\
\hline Plastikreaktionsgefäße (1,5; 15 und $50 \mathrm{ml})$ & Sarstedt \\
\hline Zellschaber & Sarstedt \\
\hline Nitrozellulose-Membran Protran & Whatman, Dassel, Deutschland \\
\hline Objektträger & Menzel \\
\hline
\end{tabular}

Tabelle 2.3: Auflistung der verwendeten Verbrauchsmaterialien.

\subsubsection{Geräte}

\begin{tabular}{|l|l|l|}
\hline \multicolumn{1}{|c|}{ Gerät } & \multicolumn{1}{c|}{ Modell } & Hersteller \\
\hline Inkubator & Hera Cell 240 & Heraeus, Hanau, Deutschland \\
\hline Epifluoreszenzmikroskop & DM6000 & Leica Microsystems, Wetzlar, Deutschland \\
\hline Magnetrührer & MR3001 & Heidolph, Kehlheim, Deutschland \\
\hline Absaugpumpe & vacuum gas pump & VWR, Radnor, USA \\
\hline Pipetten & Pipetman & Gilson, Middleton, USA \\
\hline elektrische Pipettierhilfe & Pipetboy acu & Integra, Zizers, Schweiz \\
\hline Zellkulturzentrifuge & Biofuge Primo & Heraeus \\
\hline Absaugpumpe Zellkultur & Integra Vacusafe & Integra, Zizers, Schweiz \\
\hline pH-Meter & PB-11 & Sartorius, Göttingen, Deutschland \\
\hline Konfokalmikroskop & TCS SP5 & Leica Microsystems \\
\hline Konfokalmikroskop & TCS STED & Leica Microsystems \\
\hline STED-Mikroskop & & Eigenanfertigung \\
\hline Proteinblotapparatur & & Serva \\
\hline Lebendzell-Mikroskop mit Heizung & & Eigenanfertigung basierend auf Leica DMIRB \\
\hline
\end{tabular}




\begin{tabular}{|l|l|l|} 
Neubauer Zählkammer & & Brand, Wertheim, Deutschland \\
\hline Zellzähler & Scepter & Millipore, Billerica, USA \\
\hline Einfriergefäß für Säugerzellen & $\begin{array}{l}\text { NALGENE Cryo } \text { }^{\circ} \mathrm{C} \\
\text { Freezing Container }\end{array}$ & Nalgene/Nunc, Penfield, USA \\
\hline Zellkulturmikroskop & Leica DMI3000B & Leica Microsystems \\
\hline Tischschüttler & Thermomixer 5436 & Eppendorf, Wesseling-Berzdorf, Deutschland \\
\hline Tischzentrifuge & Biofuge pico & Heraeus \\
\hline Vortexer & Genie 2 & Bender \& Hobein AG, Zürich, Schweiz \\
\hline Waage & Sartorius universal & Sartorius \\
\hline Feinwaage & AG135 & Mettler Toledo, Greifensee, Schweiz \\
\hline SDS-PAGE Apparatur & Mini-PROTEAN & Bio-Rad \\
\hline Lumineszenz-Detektors & Tetra Cell & Eigenanfertigung \\
\hline Wasserbad & HT M6 & Lauda, Lauda-Königshofen, Deutschland \\
\hline
\end{tabular}

Tabelle 2.4: Auflistung der verwendeten Geräte.

\subsubsection{Zelllinien}

\begin{tabular}{|l|l|l|l|}
\hline \multicolumn{1}{|c|}{ Name } & \multicolumn{1}{|c|}{ Organismus } & \multicolumn{1}{c|}{ Gewebe } & \multicolumn{1}{c|}{ Quelle } \\
\hline Vero & Grüne Meerkatze & Nierenepithel & $\begin{array}{l}\text { European Collection of Cell Cultures (ECACC) } \\
84113001 \text { oder ATCC CCL-81 }\end{array}$ \\
\hline HDFn & Mensch & $\begin{array}{l}\text { primäre neonatale } \\
\text { Fibroblasten }\end{array}$ & Cell Systems, Kirkland, USA \\
\hline HeLa & Mensch & Cervix-Karzinom & $\begin{array}{l}\text { AG Larsson, MPI für Biologie des Alterns, Köln; } \\
\text { (ATCC) }\end{array}$ \\
\hline
\end{tabular}

Tabelle 2.5: Auflistung der verwendeten Zelllinien.

\subsubsection{Plasmide}

\begin{tabular}{|l|l|l|l|l|l|l|}
\hline \multicolumn{1}{|c|}{ Name } & \multicolumn{1}{|c|}{ Insert } & $\begin{array}{l}\text { Plasmid- } \\
\text { Stamm }\end{array}$ & $\begin{array}{l}\text { Fluoreszenz- } \\
\text { protein }\end{array}$ & Resistenz & Promoter & \multicolumn{1}{|c|}{ Quelle } \\
\hline U6-shRNA DRP1 & $\begin{array}{l}\text { shRNA } \\
\text { Drp1 }\end{array}$ & pREP4 & --- & Amp, Hyg & U6 & (Lee et al. 2004) \\
\hline $\begin{array}{l}\text { pGIPZ-shRNA } \\
\text { MFN2 }\end{array}$ & $\begin{array}{l}\text { shRNA } \\
\text { Mfn2 }\end{array}$ & pGIPZ & TurboGFP & $\begin{array}{l}\text { Amp, } \\
\text { Puro }\end{array}$ & hCMV & $\begin{array}{l}\text { Thermo Scientific/ } \\
\text { Open Biosystems, } \\
\text { Waltham, USA }\end{array}$ \\
\hline $\begin{array}{l}\text { pGIPZ-shRNA } \\
\text { RHOT1 }\end{array}$ & $\begin{array}{l}\text { shRNA } \\
\text { Rhot1 }\end{array}$ & pGIPZ & TurboGFP & $\begin{array}{l}\text { Amp, } \\
\text { Puro }\end{array}$ & hCMV & $\begin{array}{l}\text { Thermo Scientific/ } \\
\text { Open Biosystems, }\end{array}$ \\
\hline $\begin{array}{l}\text { pGIPZ-shRNA } \\
\text { TRAK1 }\end{array}$ & $\begin{array}{l}\text { shRNA } \\
\text { Trak1 }\end{array}$ & pGIPZ & TurboGFP & $\begin{array}{l}\text { Amp, } \\
\text { Puro }\end{array}$ & hCMV & $\begin{array}{l}\text { Thermo Scientific/ } \\
\text { Open Biosystems, }\end{array}$ \\
\hline $\begin{array}{l}\text { pGIPZ-shRNA } \\
\text { negative control }\end{array}$ & $\begin{array}{l}\text { non- } \\
\text { silencing } \\
\text { shRNA }\end{array}$ & pGIPZ & TurboGFP & $\begin{array}{l}\text { Amp, } \\
\text { Puro }\end{array}$ & hCMV & $\begin{array}{l}\text { Thermo Scientific/ } \\
\text { Open Biosystems, }\end{array}$ \\
\hline
\end{tabular}




\begin{tabular}{|l|l|l|l|l|l|l|} 
pDsRed1-Mito & mtDsRed & & DsRed & Kan, Neo & hCMV & $\begin{array}{l}\text { CLONTECH, } \\
\text { Mountain View, } \\
\text { USA }\end{array}$ \\
\hline $\begin{array}{l}\text { pcDNA3-mito- } \\
\text { EosFP }\end{array}$ & mtEosFP & pcDNA3 & EosFP & Amp, Neo & hCMV & $\begin{array}{l}\text { MoBiTec, } \\
\text { Göttingen, } \\
\text { Deutschland }\end{array}$ \\
\hline
\end{tabular}

Tabelle 2.6: Auflistung der verwendeten Expressions-Plasmide.

Vektorkarten zu den Plasmiden befinden sich im Anhang (Abschnitt 7.2).

\begin{tabular}{|l|l|}
\hline \multicolumn{1}{|c|}{ Name } & \multicolumn{1}{c|}{ Zielsequenz $\mathbf{5}^{\prime} \rightarrow \mathbf{3} \mathbf{3}^{\prime}$} \\
\hline U6-shRNA DRP1 & TTCAATCCGTGATGAGTATGCTTTTCTTC \\
\hline pGIPZ-shRNA MFN2 & CAGTAGTCCTCAAGGTTTA \\
\hline pGIPZ-shRNA RHOT1 & TGCATGAAGTTAAACAAGA \\
\hline pGIPZ-shRNA TRAK1 & GCCAGATGACTAAGACATA \\
\hline
\end{tabular}

Tabelle 2.7: Auflistung der Zielsequenzen der shRNA-kodierenden Plasmide.

Zellen, die über eine Herunterregulierung eines spezifischen Proteins verfügten, wurden durch Transfektion von Vero-Zellen mit dem entsprechenden shRNA-kodierenden Plasmid erhalten (siehe Tabelle 2.6). Nach Selektion dieser Zellen konnten transfizierte Zellen über GFP-Fluoreszenz (wenn vorhanden) oder einem eindeutigen mitochondrialen Phänotyp identifiziert werden. Eine Immunfluoreszenzmarkierung gegen das zu herunterregulierende Protein ließ weiterhin eine Aussage über seine tatsächliche Mengen-Reduzierung, also ob die Herunterregulation funktioniert hat, zu. Im Folgenden wurden nur Zellen analysiert, die eine deutliche Verringerung der Proteinmenge aufwiesen ( $50 \%$ reduziertes Fluoreszenzsignal).

\subsubsection{Antikörper}

Primärantikörper

\begin{tabular}{|l|l|l|l|}
\hline \multicolumn{1}{|c|}{ Antikörper gegen } & aus Spezies & \multicolumn{1}{c|}{$\begin{array}{c}\text { Verdünnung } \\
\text { 1: }\end{array}$} & \multicolumn{1}{c|}{ Quelle/Hersteller } \\
\hline Tom22 & Maus & 100 & Sigma-Aldrich \\
\hline ds DNA & Maus & 100 & Progen, Heidelberg, Deutschland \\
\hline$\alpha$-Tubulin & Maus & 100 & Sigma-Aldrich \\
\hline Cytochrom C/ CytC & Maus & 300 & BD Biosciences, San Jose, USA \\
\hline Tom20 & Kaninchen & 100 & Santa Cruz Biotechnology, Dallas, USA \\
\hline Tom20 & Maus & 100 & BD Bioscience \\
\hline Mitofilin/ Mic60 & Kaninchen & 100 & Abcam, Cambridge, UK \\
\hline
\end{tabular}




\begin{tabular}{|l|l|l|l|} 
Hsp70 & Maus & 100 & Abcam \\
\hline Cyclophilin D/ CypD & Maus & 100 & MitoSciences/ Abcam \\
\hline ATP-Synthase B/ ATPS & Maus & 100 & Abcam \\
\hline Mfn2 & Kaninchen & 100 & Cell Signaling \\
\hline DnaJC11 & Maus & 100 & Abnova, Taipei, Taiwan \\
\hline CHCHD3/ Mic19 & Kaninchen & 100 & Atlas Antibodies, Stockholm, Schweden \\
\hline Hsp60 & Kaninchen & 100 & Santa Cruz \\
\hline Sam50 & Kaninchen & 100 & Atlas Antibodies \\
\hline Tim23 & Maus & 100 & BD Bioscience \\
\hline Mio10/ Mic10 & Kaninchen & 100 & Abcam \\
\hline mtCoxl & Maus & 100 & MitoSciences/ Abcam \\
\hline Mff & Kaninchen & 100 & Proteintech, Chicago, USA \\
\hline PCNA & Maus & 50 & Santa Cruz \\
\hline Aurora B Kinase & Maus & 50 & BD Bioscience \\
\hline B-Aktin & Maus & $\begin{array}{l}5000 \mathrm{im} \\
\text { Western }\end{array}$ & Sigma-Aldrich \\
\hline Milton/Trak1 & Kaninchen & $\begin{array}{l}500 \mathrm{im} \\
\text { Western }\end{array}$ & Sigma-Aldrich \\
\hline Miro/ Rhot1 & $\begin{array}{l}50 \text { IF } \\
1000 \mathrm{im} \\
\text { Western }\end{array}$ & Sigma-Aldrich \\
\hline
\end{tabular}

Tabelle 2.8: Auflistung der verwendeten Primärantikörper.

Sekundärantikörper

\begin{tabular}{|l|l|l|l|l|}
\hline Antikörper gegen & aus Spezies & Fluorophor & $\begin{array}{c}\text { Verdünnung } \\
\text { 1: }\end{array}$ & \multicolumn{1}{|c|}{ Quelle/Hersteller } \\
\hline Kaninchen & Ziege & KK114 & 50 & $\begin{array}{l}\text { Jackson ImmunoResearch + eigene } \\
\text { Kopplung }\end{array}$ \\
\hline Maus & Schaf & KK114 & 50 & $\begin{array}{l}\text { Jackson ImmunoResearch + eigene } \\
\text { Kopplung }\end{array}$ \\
\hline Maus & Ziege & $\begin{array}{l}\text { Oregon } \\
\text { Green 488 }\end{array}$ & 50 & $\begin{array}{l}\text { Jackson ImmunoResearch + eigene } \\
\text { Kopplung }\end{array}$ \\
\hline Kaninchen & Ziege & $\begin{array}{l}\text { Oregon } \\
\text { Green 488 }\end{array}$ & 50 & $\begin{array}{l}\text { Jackson ImmunoResearch + eigene } \\
\text { Kopplung }\end{array}$ \\
\hline Kaninchen & Ziege & Atto565 & 50 & $\begin{array}{l}\text { Jackson ImmunoResearch + eigene } \\
\text { Kopplung }\end{array}$ \\
\hline Maus & Ziege & HRP & 10000 WB & $\begin{array}{l}\text { Jackson ImmunoResearch + eigene } \\
\text { Kopplung }\end{array}$ \\
\hline Kaninchen & Ziege & HRP & 10000 WB & $\begin{array}{l}\text { Jackson ImmunoResearch + eigene } \\
\text { Kopplung }\end{array}$ \\
\hline & & & $\begin{array}{l}\text { Jackson ImmunoResearch, West } \\
\text { Grove, USA }\end{array}$ \\
\hline
\end{tabular}

Tabelle 2.9: Auflistung der verwendeten Sekundärantikörper. 


\subsubsection{Lösungen und Puffer}

Alle Puffer, Lösungen und Medien wurden, wenn nicht anders angegeben, in entmineralisiertem Wasser angesetzt.

$\begin{array}{rl}\text { PBS-Puffer } & (p H 7,4): \\ 2,68 \mathrm{mM} & \mathrm{KCl} \\ 1,47 \mathrm{mM} & \mathrm{KH}_{2} \mathrm{PO}_{4} \\ 137 \mathrm{mM} & \mathrm{NaCl} \\ 8 \mathrm{mM} & \mathrm{Na}_{2} \mathrm{HPO}_{4}\end{array}$

Formaldehyd-Fixativ Lösung (pH 7,4):

$8 \%(\mathrm{w} / \mathrm{v}) \quad$ para-Formaldehyd in PBS

\section{Extraktions-Lösung}

$0,5 \%(v / v) \quad$ Triton X-100 bzw.

$0,1 \%(v / v) \quad$ Triton $X-100$ in PBS

Block-Lösung

$10 \%(w / v) \quad B S A$ in PBS

1 M TRIS- $\mathrm{HCl}(p H 7,5$ und 8,5):

$1 \mathrm{~mol} / \mathrm{I} \quad$ Tris(hydroxymethyl)-aminomethan (TRIS)

$\underline{1 \mathrm{MNaHCO}_{3}}(\mathrm{pH} \mathrm{8,3-9,0):}$

$1 \mathrm{~mol} / \mathrm{I} \quad \mathrm{NaHCO}_{3}$

Einbett-Medium (Mowiol/DABCO):

$25 \%(w / v) \quad$ Glyzerin

$9 \%(w / v) \quad$ Mowiol 4-88

$0,1 \mathrm{M} \quad$ TRIS-HCl $(\mathrm{pH} \mathrm{8,5)}$

$0,1 \%(w / v) \quad$ DABCO

\section{DMEM-Medium}

$88 \%(v / v) \quad$ DMEM, high glucose, GlutaMAX 


$\begin{array}{ll}10 \%(\mathrm{v} / \mathrm{v}) & \text { Fötales Rinder Serum } \\ 1 \mathrm{mM} & \text { Natrium-Pyruvat } \\ 100 \mathrm{U} / \mathrm{ml} & \text { Penicillin } \\ 100 \mu \mathrm{g} / \mathrm{ml} & \text { Streptomycin }\end{array}$

\section{Einfriermedium}

$70 \%(\mathrm{v} / \mathrm{v}) \quad$ DMEM, high glucose, GlutaMAX

$20 \%(v / v) \quad$ Fötales Rinder Serum

$10 \%(v / v) \quad$ DMSO

$\underline{\text { Trypsin/EDTA }}$

0,05\% (w/v) Trypsin

$0,02 \%(w / v) \quad$ EDTA in PBS

SDS-Probenpuffer $(p H 6,8)$

$\begin{array}{ll}4 \%(\mathrm{w} / \mathrm{v}) & \text { SDS } \\ 200 \mathrm{mM} & \text { DTT } \\ 20 \%(\mathrm{v} / \mathrm{v}) & \text { Glyzerin } \\ 0,02 \% & \text { Bromphenolblau } \\ 100 \mathrm{mM} & \text { TRIS-HCl }\end{array}$

\section{Trenngel $12,5 \%$}

$\begin{array}{ll}6,3 \mathrm{ml} & \text { Wasser } \\ 5 \mathrm{ml} & 1,5 \mathrm{M} \mathrm{TRIS}-\mathrm{HCl} \mathrm{pH} \mathrm{8,8} \\ 8,3 \mathrm{ml} & 30 \% \text { Acrylamid: Bisacrylamid-Lösung (30:1) } \\ 200 \mu \mathrm{l} & 10 \%(\mathrm{w} / \mathrm{v}) \text { SDS } \\ 200 \mu \mathrm{l} & 10 \%(\mathrm{w} / \mathrm{v}) \text { APS } \\ 20 \mu \mathrm{l} & \text { TEMED }\end{array}$

Sammelgel $5 \%$

$\begin{array}{ll}5,6 \mathrm{ml} & \text { Wasser } \\ 2,5 \mathrm{ml} & 0,5 \mathrm{M} \mathrm{TRIS}-\mathrm{HCl} \mathrm{pH} \mathrm{6,8} \\ 1,7 \mathrm{ml} & 30 \%(\mathrm{w} / \mathrm{v}) \text { Acrylamid: Bisacrylamid-Lösung (30:1) } \\ 100 \mu \mathrm{l} & 10 \%(\mathrm{w} / \mathrm{v}) \text { SDS } \\ 100 \mu \mathrm{l} & 10 \%(\mathrm{w} / \mathrm{v}) \text { APS }\end{array}$


$10 \mu \mathrm{l}$

TEMED

Lämmli-Puffer (pH 8,3)

$25 \mathrm{mM} \quad$ TRIS-HCl

$192 \mathrm{mM} \quad$ Glyzin

$0,1 \%(w / v) \quad S D S$

\section{Coomassie Färbelösung}

$10 \%(v / v) \quad$ Essigsäure

$25 \%(\mathrm{v} / \mathrm{v}) \quad$ Isopropanol

0,05\% (w/v) Coomassie Blau R-250

\section{Entfärbelösung}

$10 \%(v / v) \quad$ Essigsäure

$50 \%(v / v) \quad$ Methanol

\section{Transferpuffer}

$4 \mathrm{mM} \quad$ TRIS-HCl

37,5 mM Glycin

$20 \%(v / v) \quad$ Methanol

in Ponceau-Färbelösung

$5 \mathrm{~g} / \mathrm{I}$ Ponceau S

$5 \%(v / v)$ Essigsäure

$40 \%(w / v)$ Methanol

\section{Blocklösung}

$20 \%(w / v)$ Magermilchpulver in PBS

\section{Waschlösung}

$0,5 \%(w / v)$ Magermilchpulver in PBS 


\subsection{Methoden}

\subsubsection{Zellbiologische Methoden}

\section{Kultivierung und Aussaat von Säugerzellen}

Für die Experimente dieser Arbeit wurde nur die adhärent wachsende Vero-Säugerzelllinie verwendet.

Die Säugerzellen wurden in DMEM-Kultivierungsmedium bei $37{ }^{\circ} \mathrm{C}, 5 \% \mathrm{CO}_{2}$-Begasung und einer wassergesättigten Atmosphäre kultiviert. Die Zellen wurden typischerweise einmal wöchentlich, jedoch mindestens bei Erreichen einer 80 \%igen Konfluenz, passagiert. Dazu wurden die Zellen mit PBS gewaschen und anschließend mit Hilfe einer Trypsin-EDTA-Lösung vom Flaschenboden abgelöst (10 min, $5 \mathrm{ml}, 37^{\circ} \mathrm{C}$ ). Anschließend wurden die Zellen in vorgewärmtem DMEM-Medium (5 ml) aufgenommen und in einer Verdünnung von 1:20 in einer neuen Zellkulturflasche ausgesät. Die Kontrolle der Zellen erfolgte mit einem Leica DMI3000B-Mikroskop, das mit einem Leica PL Fluotar (10x/0.3 PH1)-Objektiv ausgestattet war.

Für die Durchführung von Experimenten wurden die Zellen, nachdem sie sich von dem Zellkulturflaschenboden abgelöst hatten und mit Medium versetzt worden sind, direkt zur Transfektion eingesetzt oder in Mikrotiterplatten, sogenannten Well-Platten, beziehungsweise Petrischalen auf mittels Isopropanol sterilisierten Glasdeckgläsern ausgesät und kultiviert.

Um die Vergleichbarkeit der Experimente sicher zu stellen, wurden die verwendeten Säugerzellen nur bis zur 30. Passage für Experimente eingesetzt.

\section{Dauerkulturen/Kryo-Konservierung}

Säugerzellen können in flüssigem Stickstoff bei Tiefsttemperaturen dauerhaft gelagert und anschließend zur weiteren Verwendung aufgetaut werden. Zur Erstellung von Dauerkulturen wurden Säugerzellen bis zu einer Konfluenz von circa 80 \% kultiviert. Zunächst wurden die Zellen wie unter Abschnitt 2.2.1 beschrieben trypsiniert und bei $100 \times \mathrm{g}$ für $5 \mathrm{~min}$ sedimentiert. Das entstandene Zellpellet wurde in Einfriermedium (pro $75 \mathrm{~cm}^{2}$-Flasche 4,5 $\mathrm{ml}$ ) aufgenommen. Daraufhin wurde die Zellsuspension in Kryoröhrchen verteilt. Diese wurden dann mit Hilfe eines mit Isopropanol gefüllten Gefäßes (NALGENE Cryo $1{ }^{\circ} \mathrm{C}$ Freezing Container) bei einer Einfrier-Rate von $-1{ }^{\circ} \mathrm{C} / \mathrm{h}$ bei $-80^{\circ} \mathrm{C}$ eingefroren. Anschließend wurden sie in flüssigem Stickstoff gelagert.

\section{Zellzahlbestimmung}

Die Bestimmung der Zellzahl erfolgte mit Hilfe des automatischen Zellzählers, Scepter'. Die trypsinierten Zellen wurden zu diesem Zweck in DMEM-Medium aufgenommen und $200 \mu \mathrm{l}$ dieser 
Suspension zur Bestimmung der Zellzahl verwendet. Dies wurde nach Angaben des Herstellers durchgeführt.

\section{Transfektion und Selektion von Säugerzellen}

Transfektionen von Säugerzellen wurden typischerweise in 6-Well-Platten durchgeführt.

\section{Transfektion von Vero-Zellen mit Turbofect (Fermentas)}

Zum Einbringen von Fremd-DNA in Vero-Zellen wurde standardmäßig das Transfektionsreagenz Turbofect verwendet. Es beruht auf dem DEAE-Dextran-Prinzip. Dabei handelt es sich um eine wässrige Lösung eines kationischen Polymers, welcher mit Desoxyribonukleinsäure stabile, positiv geladene Komplexe bildet. Diese Polymer-DNA-Komplexe heften sich an die Zelloberfläche und vermitteln anschließend die Aufnahme der DNA in die Zelle durch Endozytose (De Smedt et al. 2000). Die Transfektion wurde gemäß Herstellerangaben durchgeführt.

Für die Transfektion wurden Vero-Zellen einen Tag vor der Transfektion auf Deckgläsern in DMEM ausgesät. Der Ansatz des Transfektionsmixes erfolgte durch Verdünnen von $4 \mu \mathrm{g}$ Plasmid-DNA in $400 \mu \mathrm{l}$ serumfreiem-DMEM und Zugabe von $6 \mu$ l Turbofect Reagenz. Dieser Transfektionsmix wurde gut gemischt und $17 \mathrm{~min}$ bei Raumtemperatur inkubiert. Abschließend wurde der Transfektionsansatz tropfenweise zu den Zellen gegeben und die Platte leicht geschwenkt. Das Ergebnis der Transfektion wurde nach 24 bis $48 \mathrm{~h}$ ausgewertet.

\section{Selektion von transfizierten Zelllen}

Um die Anzahl von nicht transfizierten Zellen pro Well zu reduzieren, wurden die Zellen $24 \mathrm{~h}$ nach der Transfektion mit einem entsprechenden Antibiotikum versetzt.

Für die Selektion auf Vorhandensein des Drp1-shRNA-Plasmides wurden Vero-Zellen zwei Tage mit $2 \mathrm{mg} / \mathrm{ml}$ Hygromycin B inkubiert. Anschließend wurden die Zellen drei weitere Tage ohne Antibiotikum kultiviert.

Zur Selektion auf das Mfn2-shRNA-Plasmides wurden Vero-Zellen zwei Tage mit $40 \mu \mathrm{g} / \mathrm{ml}$ Puromycin inkubiert und anschließend drei weitere Tage ohne Antibiotikum kultiviert.

\section{Behandlungen}

Für die Behandlung von Säugerzellen mit verschiedenen Substanzen wurden diese $24 \mathrm{~h}$ vor der Zugabe der Reagenzien wie unter Abschnitt 2.2.1. beschrieben ausgesät. Anschließend wurden die Substanzen, die zuvor in DMSO gelöst wurden, in der entsprechenden Konzentration zugegeben. Um toxische Effekte zu vermeiden, betrug die maximale DMSO-Konzentration im Zellkulturmedium nie 
mehr als $1 \%$. Nach der gewünschten Inkubationsdauer wurden die Zellen fixiert, mehrmals mit PBS gewaschen und anschließend wie in Abschnitt 2.2.2 beschrieben gefärbt.

\subsubsection{Proteinbiochemische Methoden}

\section{Isolierung von Gesamtzellprotein aus mammalen Zellen}

Zur Isolierung von Gesamtzellprotein aus kultivierten Säugerzellen wurden die Zellen nach Entfernen des Kulturmediums zweimal mit PBS gewaschen und anschließend mit Hilfe eines Zellschabers vom Zellkulturgefäß gelöst. Durch Zentrifugation ( $4696 \times$ g; $4{ }^{\circ} \mathrm{C}$ ) wurden die Zellen sedimentiert und nach zweimaligem Waschen in PBS mit einem Protease-Inhibitor-Gemisch und SDS-Probenpuffer aufgenommen.

\section{Bestimmung der Proteinkonzentration}

Die Proteinkonzentration der Säugerzellextrakte wurde durch den vom Lowry-Verfahren abgeleiteten RC DC Protein Assay nach der Vorschrift des Herstellers bestimmt.

\section{Polyacrylamid-Gelelektrophorese}

Die zu untersuchenden Proteine wurden mit Hilfe der diskontinuierlichen SDS-PolyacrylamidGelelektrophorese (SDS-PAGE) ihrer Größe nach aufgetrennt. Die Acrylamid-Konzentration des Trenngels betrug $12,5 \%(\mathrm{w} / \mathrm{v})$ und die des Sammelgel $5 \%(\mathrm{w} / \mathrm{v})$.

Die in Probenpuffer gelösten Proteinextrakte wurden für fünf Minuten auf $95{ }^{\circ} \mathrm{C}$ erhitzt, kurz zentrifugiert und auf das Polyacrylamid-Gel aufgetragen. Zur Elektrophorese wurde Lämmli-Puffer verwendet. Die elektrophoretische Auftrennung der Proteine wurde bei 15 - $20 \mathrm{~mA} / \mathrm{Gel}$ durchgeführt. Zur Abschätzung der Größe der detektierten Proteine wurde als Referenz ein Proteingrößenstandard verwendet (Anhang 7.xy).

\section{Anfärbung von SDS-Polyacrylamidgelen}

Die Proteine im SDS-Polyacrylamidgel wurden mit Hilfe des Farbstoffs Coomassie Brilliant Blau angefärbt. Hierfür wurde das Gel für 15 - 30 Minuten in eine Färbelösung eingelegt. Anschließend wurde überschüssiger Farbstoff durch Waschen in Entfärbelösung aus der Gelmatrix entfernt.

\section{Transfer von Proteinen}

Um die Proteine immunologisch detektieren zu können, wurden sie mittels Nass-Blot auf Nitrozellulose-Membranen mit einer Porengröße von 0,45 $\mu \mathrm{m}$ transferiert. Dabei wurden die 
Membran und das Proteingel zwischen mehrere mit Transferpuffer getränkte Filterpapiere und Schwämme gelegt. Der Transfer erfolgte erneut elektrophoretisch für 16 Stunden bei $80 \mathrm{~mA}$ / Blot und $4{ }^{\circ} \mathrm{C}$ in einer mit Transferpuffer gefüllten Blotapparatur.

\section{Ponceau-Färbung}

Um die Effizienz des Transfers der Proteine auf die Membran zu überprüfen, wurde eine Färbung mit Ponceau Rot durchgeführt. Hierfür wurde die Membran nach dem Transfer für 15 min in PonceauFärbelösung inkubiert. Nach der anschließenden Entfärbung mit Wasser waren die Proteinbanden deutlich sichtbar und konnten dokumentiert werden. Vor der Fortsetzung der Western-Analyse wurde die Membran zur Entfernung des Farbstoffs mehrfach in PBS gewaschen.

\section{Immunologischer Nachweis von Proteinen auf Membranen}

Zur spezifischen Detektion einzelner Proteine innerhalb dieses komplexen, aufgetrennten Gemisches wurden spezifische, gegen die Zielproteine gerichtete, Antikörper verwendet (Harlow und Lane, 1988). Hierzu wurden zunächst freie Proteinbindungsstellen auf der Membran durch eine 45minütige Inkubation in Blocklösung belegt und anschließend die Membran mehrfach in Waschlösung gewaschen. Danach wurde die Membran für mindestens eine Stunde bei RT mit dem Primärantikörper verdünnt in Waschlösung inkubiert. Nach mehrfachem Waschen in Waschlösung wurde der Primärantikörper durch einstündige Inkubation mit dem Peroxidase-gekoppelten Sekundärantikörper verdünnt in Waschlösung gebunden. Vor der Detektion der Signale mittels eines auf Chemilumineszenz basierenden Detektionssystems wurde die Membran mehrfach in Waschlösung und PBS gewaschen. Durch eine an den sekundären Antikörper gekoppelte Peroxidase (Horseradish Peroxidase, HRP) wurde das in der Detektionslösung enthaltene Luminol enzymatisch umgesetzt. Die hierbei entstehende Chemilumineszenz wurde mittels eines Lumineszenz-Detektors detektiert.

\subsubsection{Lichtmikroskopische Methoden}

\section{Fluorophor-Antikörper-Kopplung}

Die in dieser Arbeit verwendeten Sekundärantikörper wurden durch Kopplung von Fluorophoren an Antikörper hergestellt.

Zur Kopplung von Fluorophoren an Antikörper wurden N-hydroxy-succinimidyl-Ester (NHS-Ester) der zu koppelnden Fluorophore mit den freien primären Aminogruppen von Antikörpern zur Reaktion gebracht (LaRochelle et al. 1986). Hierfür wurde $1 \mathrm{mg}$ des Antikörpers mit $100 \mu \mathrm{l} 1 \mathrm{M} \mathrm{NaHCO}$ 
versetzt. Außerdem wurden $200 \mu \mathrm{g}$ des in DMF gelösten Farbstoffes $(10 \mathrm{mg} / \mathrm{ml})$ unter Rühren langsam zu der Antikörperlösung gegeben. Diese Mischung wurde eine Stunde weiter bei Raumtemperatur gerührt. Danach wurden $100 \mu \mathrm{I} 1 \mathrm{M}$ TRIS-HCl $(\mathrm{pH} 7,5)$ zu der Lösung pipettiert, um freie NHS-Gruppen abzureagieren und weitere 5 min gerührt. Der gekoppelte Antikörper wurde nun mittels Größenausschluss-Chromatographie von freiem Farbstoff befreit (Sephadex-Säule) und in $1,5 \mathrm{ml}$ Fraktionen eluiert. Abschließend wurde die Proteinkonzentration der einzelnen Fraktionen bestimmt, um zu identifizieren, in welcher Fraktion sich der gekoppelte Antikörper befand. Hierzu wurde das Reagenz Bradford von Bio-Rad nach den Angaben des Herstellers verwendet. Die Messung der Absorption der Proben bei $\lambda=600 \mathrm{~nm}$ wurde am Spektrophotometer vorgenommen. Daraufhin wurden alle Antikörperhaltigen Fraktionen vereint, durch Zugabe von BSA (Endkonzentration $5 \mathrm{mg} / \mathrm{ml}$ ) stabilisiert, aliquotiert, schockgefroren und bei $-80^{\circ} \mathrm{C}$ gelagert.

\section{Indirekte Immunfluoreszenz-Markierung (Wurm et al. 2010)}

Eine Methode um die Lokalisation von Makromolekülen in Zellen und Geweben fluoreszenzmikroskopisch nachzuweisen ist die Immunfluoreszenzmikroskopie. Dafür macht man sich die Eigenschaft von Antikörpern, Antigene mit hoher Spezifität zu binden, zum Nutzen. Die für diese Zwecke eingesetzten Antikörper sind der IgG-Klasse zuzuordnen und verfügen über eine Größe von ca. $150 \mathrm{kDa}$.

IgGs bestehen aus zwei identischen schweren $(H)$ und zwei identischen leichten Polypeptidketten, die über Disulfidbrücken miteinander kovalent verknüpft sind.

In dieser Arbeit wurde die indirekte Immunfluoreszenzmarkierung angewandt, da diese eine Signalverstärkung implementiert.

Dabei wird der Primärantikörper nach der Bindung an das nachzuweisende Molekül durch einen spezifischen fluorochromierten sekundären Antikörper detektiert. Für die Immunfluoreszenzmikroskopie werden fixierte Zellen verwendet. Für die Fixierung von Zellen und Geweben wird standardmäßig Formaldehyd verwendet, welches freie Aminogruppen bindet. Zur Strukturerhaltung einiger Zellbestandteile wird die Fixierung mit Methanol bevorzugt. Um die Penetration der Antikörper in intrazelluläre Kompartimente zu gewährleisten, ist eine Permeabilisierung der Membranen mittels Detergenzien nötig. Unspezifische Bindungsstellen werden mit Hilfe von Rinderserumalbumin abgesättigt. Durch Kombination zweier Primärantikörper aus verschiedenen Organismen/Spezies, können sogar zwei Epitope gleichzeitig markiert und mikroskopiert werden (Doppelmarkierung).

Für Immunfluoreszenz-Färbungen wurden die Zellen am Tag vor der Färbung auf Deckgläschen ausgesät. 


\section{Fixierung von Säuger-Zellen}

Herstellung $8 \%(w / v)$ Formaldehyd-Fixativ-Lösung:

Zunächst wurden $8 \mathrm{~g}$ para-Formaldehyd abgewogen und mit $80 \mathrm{ml} \mathrm{PBS}$, sowie einem $\mathrm{NaOH}-\mathrm{Plätzchen}$ versetzt. Diese Suspension wurde gemischt und unter leichtem Erwärmen $\left(60^{\circ} \mathrm{C}\right)$ für 20 min gerührt. Sobald sich das para-Formaldehyd vollständig aufgelöst hatte, wurde der $\mathrm{pH}$-Wert der Lösung mittels $\mathrm{HCl}$ auf 7,5 eingestellt. Abschließend wurde das Volumen der Lösung auf $100 \mathrm{ml}$ mit PBS aufgefüllt. Diese $8 \%$ ige Formaldehyd-Lösung konnte bei $-20^{\circ} \mathrm{C}$ über mehrere Monate und bei $4{ }^{\circ} \mathrm{C}$ über eine Woche gelagert werden.

Für die Färbung von Mitochondrien wurde das Medium von den Zellen abgenommen und diese mit einer vorgewärmten $8 \%$ igen Formaldehyd-Fixativ-Lösung für $10 \mathrm{~min}$ bei $37^{\circ} \mathrm{C}$ inkubiert. Anschließend wurden die Zellen mehrmals mit PBS gewaschen und in PBS bis zu einer Woche gelagert $\left(4^{\circ} \mathrm{C}\right)$.

Zur Mikroskopie von Zytoskelett-Bestandteilen wurde eine Fixierung mit eiskaltem Methanol $\left(-20^{\circ} \mathrm{C}\right)$ für 10 min durchgeführt.

Um eine Markierung von Säugerzellen mit Antikörpern gegen PCNA und Aurora B Kinase zu erreichen und gleichzeitig die Struktur von Mitochondrien zu erhalten, wurde eine Kombination von Methanolmit Formaldehyd-Fixierung eingesetzt. Hierzu wurde zunächst 3 min mit vorgewärmter $8 \%$ iger Formaldehyd-Lösung und direkt danach für 5 min mit eiskaltem Methanol fixiert.

Zur Doppel-Immunmarkierung von Rhot1 und Tom20 wurde eine Fixierung mit einer vorgewärmten 4 \%igen Formaldehyd-Fixativ-Lösung für $15 \mathrm{~min}$ bei $37^{\circ} \mathrm{C}$ durchgeführt. Anschließend wurden die Zellen mehrmals mit PBS gewaschen.

\section{Immunfluoreszenzmarkierung}

Die mit den Säugerzellen beschichteten Deckgläser wurden zunächst einer 10 minütigen Behandlung mit der Extraktionslösung unterzogen. Durch das Vorhandensein des Detergenzes wird die Zellmembran permeabilisiert und cytoplasmatische Epitope können gebunden werden. Im Anschluss wurden unspezifische Bindungsstellen durch 10 min Inkubation mit 10 \%iger Blocklösung abgesättigt. Daraufhin wurden die Zellen für eine Stunde in verdünnten Lösungen der Primärantikörper in Blocklösung (Verdünnungen siehe Tabelle 2.8) inkubiert. Anschließend wurden die Zellen für je 5 min in PBS, in Extraktionspuffer und in Blockpuffer gewaschen. Danach wurden die Zellen eine Stunde in 
verdünnten Lösungen der Fluorophor-gekoppelten-Sekundärantikörper in Blocklösung (Endkonzentration 1-20 $\mu \mathrm{g} / \mathrm{ml}$ ) inkubiert. Alle Inkubationen mit Antikörpern wurden in einer feuchten Kammer bei Raumtemperatur durchgeführt. Schließlich wurden die Zellen mehrmals in PBS für insgesamt 30 min gewaschen.

Für die Doppel-Immunfluoreszenzmarkierung von Rhot1 und Tom20 wurde das Färbeprotokoll in einer abgewandelten Form durchgeführt. Zunächst erfolgte eine Permeabilisierung mit 0,1 \% Triton X-100/ PBS für 5 min. Nach einem Waschschritt in PBS wurden unspezifische Bindungsstellen mit 100 \% Ziegen-Serum für 30 min abgesättigt. Anschließend erfolgte eine einstündige Inkubation mit den Rhot1- und Tom20-Primärantikörpern, verdünnt in $100 \%$ Ziegenserum, gefolgt von einem Waschschritt mit PBS. Daraufhin wurden die Zellen eine Stunde mit den Sekundärantikörpern, verdünnt in $100 \%$ Ziegenserum, inkubiert und abschließend mit PBS gewaschen.

\section{Einbetten der Proben in Mowiol}

Immunfluoreszenzmarkierte Säugerzellen wurden in Mowiol mit DABCO eingebettet (Zusammensetzung siehe 2.1.8; Herstellung: (Wurm et al. 2010)). Vor der Mikroskopie ließ man das Mowiol für mehrere Stunden aushärten.

\section{Farbstoffe}

Die DNA im Zellkern wurde mit dem blau fluoreszierenden Farbstoff DAPI (4',6-Diamidino-2phenylindol) in einer Konzentration von $2,5 \mu \mathrm{g} / \mathrm{ml}$ angefärbt. Die Färbung mit DAPI wurde beim Einbetten der Proben durch Einbringen von DAPI in das Einbettmedium Mowiol durchgeführt.

Des Weiteren wurden Farbstoffe verwendet, die die Mitochondrien in lebenden Zellen anfärben (Mitotracker). Hierfür kam der grün fluoreszierende Farbstoff DIOC 6 (3,3'-Dihexyloxacarbocyaninlodid) (Matzke 1986, Liu et al. 1987) in einer Konzentration von 0,1 nM im Kulturmedium zum Einsatz, sowie der rot fluoreszierende, fixierbare Farbstoff MitoTracker Red CM- $\mathrm{H}_{2} \mathrm{Xros}$ (500 nM) (Carlini et al. 2013).

Zur Markierung wurde der Farbstoff direkt in das Medium der Säugerzellen pipettiert. Daraufhin wurde dieser Ansatz $30 \mathrm{~min}$ bei Raumtemperatur inkubiert und anschließend ohne weitere Waschschritte mikroskopiert oder fixiert.

\section{Epifluoreszenz- und Durchlichtmikroskopie}

Die Epifluoreszenz- und Durchlicht-Mikroskopie wurde mit dem Leica DM6000-Mikroskop durchgeführt. Dieses war mit einem 10x (0,3 NA), 20x (0,5 NA) und 40x (0,75 NA) Luft-Objektiv, einem 63x (1,2 NA) Wasser-Immersionsobjektiv und einem 100x (1,4 NA) Öl-Immersionsobjektiv 
ausgestattet. Für die Mikroskopie von Säugerzellen wurde ausschließlich das Objektiv mit 63x Vergrößerung verwendet. Als Lichtquelle für die Durchlichtmikroskopie diente eine Halogenlampe. Die Beleuchtung für die Fluoreszenzmikroskopie wurde mittels einer Metallhalogenidlampe (120 W), in deren Strahlengang verschiedene Filter platziert wurden, durchgeführt. DAPI wurde mit einem A4Filterwürfel (Anregung 360/40 nm, Emission 470/40 nm), GFP, DiOC 6 und OregonGreen488 mit einem GFP-Filterwürfel (Anregung 470/40 nm, Emission 525/50 nm), MitoTracker Red $\mathrm{CM}^{-} \mathrm{H}_{2}$ Xros bzw. Atto565 mit einem N3-Filterwürfel (Anregung 546/12, Emission 600/40 nm) und KK114 wurde mit einem Spectrum FRED-Filterwürfel (Anregung 630/20, Emission 667/30 nm) detektiert. Die Detektion erfolgte mittels einer zum System gehörenden CCD-Kamera.

\section{Konfokale Fluoreszenzmikroskopie}

Zur Betrachtung und Dokumentation der Immunfluoreszenzmarkierten Säugerzellen kamen die konfokalen Laser-Raster Mikroskope (confocal laser scanning microscope, CLSM) Leica SP5 zum Einsatz. Die Aufnahmen wurden typischerweise bei einem Lochblenden-Durchmesser von einer AiryEinheit und einer Raster-Geschwindigkeit von 400 Zeilen pro Sekunde durchgeführt. Die Bilder wurden mit einer Voxel-Größe von (X x Y x Z) $50 \mathrm{~nm}$ x $50 \mathrm{~nm}$ x $150 \mathrm{~nm}$ (nach den Vorgaben des Nyquist-Theorems) aufgenommen. Außerdem wurden die Photomultiplier im dynamischen Bereich betrieben. Die Anregung der Fluorophore erfolgte in der Nähe ihrer Absorptionsmaxima. Die Anregung erfolgte mit $405 \mathrm{~nm}$ (für DAPI, Diodenlaser), $488 \mathrm{~nm}$ (für GFP und Oregon Green 488, Argonlaser), $561 \mathrm{~nm}$ (für MitoTracker Red $\mathrm{CM}-\mathrm{H}_{2}$ Xros und Atto565, Diodenlaser) und $647 \mathrm{~nm}$ (für KK114, HeNe-Laser). Die Detektion der Fluoreszenz erfolgte in einem breiten Bereich um die Emissionswellenlänge der Fluorophore. Die Breite des Detektionsfensters wurde für DAPI von 410435 nm, für GFP/Oregon Green 488 von $495-520$ nm, für Mitotracker Red CM- ${ }_{2} X_{\text {Xros/Atto565von }}$ 570-650 nm und für KK114 von 651-773 nm gewählt. Für Mehr-Farben-Aufnahmen wurde das Mikroskop im sequenziellen Modus benutzt und in Abhängigkeit von der Fragestellung wurden zStapel aufgenommen. Um das Signal-zu-Rausch-Verhältnis der gewonnenen Bilder zu verbessern, wurde jeder optische Schnitt mehrfach aufgenommen (typischerweise 4 Mal) und gemittelt. Alle Aufnahmen entstanden bei einer Raumtemperatur von $\sim 22^{\circ} \mathrm{C}$.

Es wurde das Öl-Immersionsobjektiv (PL APO 63x/1.4-0.6 oil) verwendet.

Mit diesem Mikroskop wurden zudem die Lebendzellexperimente mit mtEosFP-transfizierten Zellen durchgeführt.

Zur Betrachtung und Dokumentation der immunfluoreszenzmarkierten Säugerzellen kam außerdem das konfokale Laser-Raster Mikroskop (confocal laser scanning microscope, CLSM) Leica TCS STED zum Einsatz. Dieses unterscheidet sich nur folgendermaßen vom TCS SP5: Es verfügte über ein 
Wasser-Immersionsobjektiv (HCX PL APO CS 63x/1.2 water). Die Anregung erfolgte mit $488 \mathrm{~nm}$ (für GFP und Oregon Green488, Argonlaser) und 633 nm (für KK114, gepulster Diodenlaser).

\section{Lebendzell-Mikroskopie}

DsRed

Für diesen Ansatz wurde DsRed in der mitochondrialen Matrix von Vero-Zellen exprimiert. Ein bis zwei Tage nach der Transfektion wurden die transfizierten Zellen an einem speziellen, für die LebendMikroskopie von Säugerzellen geeigneten Epifluoreszenzmikroskop (Leica DMIRB), untersucht. Dieses verfügte über eine temperierbare, thermisch isolierte Klimakammer, wodurch es möglich war, lebende Zellen über längere Zeiträume $(1 \mathrm{~h})$ kontinuierlich zu beobachten, ohne eine Schädigung der Zellen hervorzurufen. Die Zellen wurden auf Deckgläschen kultiviert und in einer speziell angefertigten Lebendzellkammer invers mikroskopiert. Über den Zellen befand sich ständig ein vorgewärmtes Volumen an farblosem Säugerzellmedium (HDMEM).

Das Mikroskop war mit einem 63x (1,2 NA) Öl-Immersionsobjektiv ausgestattet. Die Beleuchtung für die Fluoreszenzmikroskopie erfolgte mittels einer LED (light-emitting-diode) bei $530 \mathrm{~nm}$, in deren Strahlengang ein N3-Filterwürfel (Anregung 546/12, Emission 600/40 nm) platziert wurde. Die Detektion erfolgte mittels einer CCD-Kamera. Ein spezielles Programm (Imspector) realisierte eine Bildaufnahme in Abständen von 30 Sekunden, wodurch Videosequenzen entstanden. Verschiebungen des Z-Fokus wurden manuell korrigiert.

\section{$\underline{E S F P}$}

Für einen weiteren Ansatz zur Untersuchung der Dynamik von Mitochondrien wurde EosFP in der mitochondrialen Matrix von Vero-Zellen exprimiert. Es zeichnet sich durch seine Eigenschaft aus, die ursprüngliche Fluoreszenz im grünen Wellenlängenbereich nach Bestrahlung mit Licht aus dem UVBereich $(405 \mathrm{~nm}$ ), in Fluoreszenz des roten Wellenlängenbereichs zu schalten (Wiedenmann et al. 2004). Somit ermöglicht es die Beobachtung der Verteilung der roten Fluoreszenz des geschalteten Proteins innerhalb kleiner, abgegrenzter Bereiche über längere Zeiträume. Für die Untersuchung im Rahmen dieser Arbeit wurde ein Plasmid, welches für mtEosFP kodierte, in Vero-Zellen transfiziert. Nach ein bis zwei Tagen wurden die Zellen mikroskopiert. Die mitochondriale Dynamik in transfizierten lebenden Zellen, welche sich durch grüne Fluoreszenz in den Mitochondrien identifizeren ließen, wurde nun an einem Konfokalmikroskop (Leica TCS SP5) mit Hilfe des FRAPWizards untersucht. Die Zellen wurden hierzu auf Deckgläschen kultiviert und in einer speziell angefertigten Lebendzellkammer invers mikroskopiert. Über den Zellen befand sich ständig ein vorgewärmtes Volumen an farblosem Säugerzellmedium (HDMEM). Die Mikroskopie erfolgt bei Raumtemperatur. 
Zunächst wurden kleine Bereiche von Mitochondrien innerhalb einer Zelle mit einem UV-Laser lokal begrenzt bestrahlt (10 x $10 \mu \mathrm{m}$ region-of-interest ROI; Einstellungen: 50 \% UV-Laserintensität; set background to zero; 15 frames). Dadurch kam es zunächst zur Konvertierung der grünen Fluoreszenz des EosFP zu einer Fluoreszenz im roten Wellenlängenbereich (Intensität 488 nm Laser: 30 \%; 561 nm Laser: $100 \%$ ). Nachfolgend wurde die Verteilung der roten Fluoreszenz innerhalb der Zelle untersucht. Aufgrund von mitochondrialer Dynamik konnte bereits 5 min nach dem UV-Schalten eine gewisse Verbreiterung der roten Fluoreszenz des ursprünglich geschalteten Bereichs auf umliegende Mitochondrien beobachtet werden. Daraufhin wurden die Zellen wieder zur Erhaltung ihrer Lebensfähigkeit bei Standardbedingungen kultiviert. 50 min nach dem ursprünglichen Schalten der Fluoreszenz wurden sie erneut mikroskopiert und die Verteilung der roten geschalteten Fluoreszenz nach diesem langen Zeitraum innerhalb der Zelle untersucht.

\section{STED-Mikroskopie}

Die Bildaufnahme mittels STED-Mikroskopie erfolgte an einem nicht-kommerziellen mikroskopischen Aufbau (Harke et al. 2008) (eine Schema-Zeichnung des Mikroskops findet sich in Abbildung 2.1).

Das eingesetzte STED-Mikroskop bot eine Auflösung von $\sim 40 \mathrm{~nm}$. Es war mit einem ÖlImmersionsobjektiv (NA 1.4 Oil immersion, 100x PL APO) ausgestattet.

In diesem STED-Mikroskop erfolgte die Anregung der Fluorophore bei $640 \mathrm{~nm}$ mittels einer LaserDiode. Die Auslöschung der Fluoreszenz fand durch einen Laser-Impuls bei 760 nm statt (MIRA 900, Coherent, Santa Clara, CA, USA). Die Leistung dieses STED-Lasers betrug in der Rückapertur ca. $200 \mathrm{~mW}$ und er hatte eine Repititionsrate von $76 \mathrm{MHz}$. Die Donut-Form des STED-Strahls wurde mit einer Vortex-Phasenplatte (RPC Photonics, Rochester, NY, USA), die zu einer helikalen Phasenverschiebung des STED-Strahls führt, erzeugt. Zur Detektion wurde das Emissionslicht der Wellenlängen von 650 bis $690 \mathrm{~nm}$ auf vier APDs (avalanche photodiode) verteilt.

Alle Proben, die an diesem Aufbau gemessen wurden, sind mit dem Infrarot-Fluoreszenzfarbstoff KK114 markiert worden. 


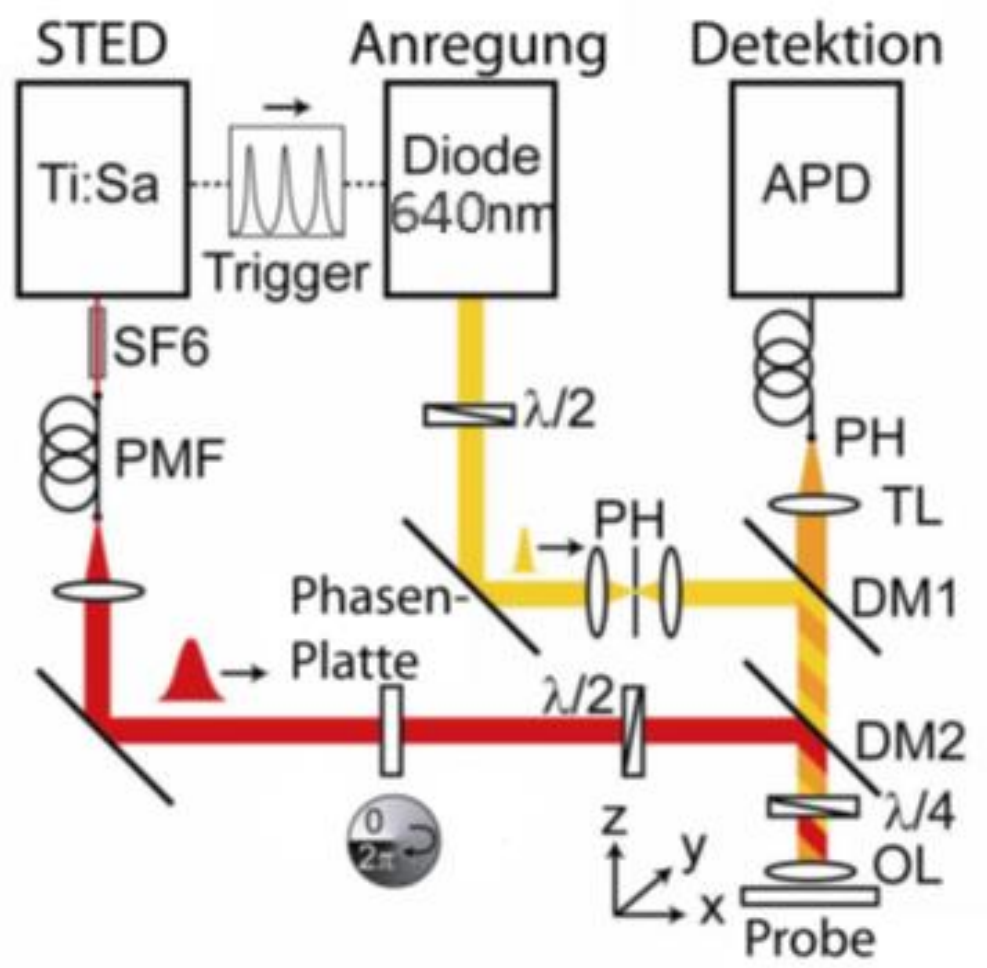

Abbildung 2.1: Schematische Darstellung des Aufbaus, der für die Ein-Farben-STEDMikroskopie verwendet wurde:

PMF: Polarisations-erhaltende Faser; APD: Avalanche Photo-Diode; $\mathrm{PH}$ : pinhole; TL: Tubus-Linse; DM: dichroitischer Spiegel; OL: Objektiv-Linse; SF6: Glas-Stäbe Abbildung aus (Harke et al. 2008).

2.2.4 Nachbearbeitung, Auswertung und Simulation mikroskopischer Daten

\section{Verwendete EDV-Programme}

\begin{tabular}{|l|l|}
\hline Software & Hersteller \\
\hline Excel & Microsoft, Redmont, USA \\
\hline Imspector & $\begin{array}{l}\text { Schönle A., 2006. Imspector Image Acquisition \& Analysis } \\
\text { Software, v0.10; http://www.imspector.de }\end{array}$ \\
\hline LAS AF & Leica Microsystems, Mannheim, Deutschland \\
\hline $\begin{array}{l}\text { Adobe Photoshop CS3, } \\
\text { Adobe Illustrator CS3 }\end{array}$ & ADOBE, San Jose, USA \\
\hline MATLAB & Mathworks, Natick, USA \\
\hline Fiji & Open source \\
\hline Origin 9.0 & OriginLab, Northampton, USA \\
\hline
\end{tabular}

Tabelle 2.10: Auflistung aller verwendeten Datenverarbeitungsprogramme

Zur Bearbeitung der aufgenommenen mikroskopischen Bilder wurden die Programme Imspector und Adobe Photoshop CS3 (Tabelle 2.10) verwendet. Üblicherweise wurden ausschließlich Kontrastanpassungen an den Rohdaten vorgenommen. Die STED-mikroskopischen Aufnahmen wurden zusätzlich geglättet. 
Zur Darstellung der aufgenommenen Strukturen wurden sowohl lineare als auch nicht-lineare Farbtabellen verwendet (siehe Anhang 7.1).

\section{Tracking von Mitochondrien}

Die Verfolgung der Positionsänderung einzelner Mitochondrien im Rahmen der lebendzellmikroskopischen Untersuchung mitochondrialer Beweglichkeit, erfolgte mit dem Bildauswertungsprogramm Fiji. Hierzu wurde die Position und somit die Bewegung einzelner Mitochondrien von Bild zu Bild verfolgt (Funktion: manual tracking). Hierfür wurde immer die Mittelposition eines Mitochondriums angewählt (auch nach Fusions- und Teilungsvorgängen der beobachteten Mitochondrien). Somit erfolgt die Analyse der Positionsänderung unabhängig von der Länge der einzelnen Mitochondrien. Das Programm erstellte Trajektorien, die den Weg des Mitochondriums über die gesamte Zeit darstellen. Außerdem wurden von dem Programm verschiedene Parameter wie z.B. die Entfernung zum letzten Punkt, die Entfernung zum Ausgangspunkt, in Form eines Excel-Dokumentes ausgegeben.

\section{Analyse submitochondrialer Proteinverteilungen}

\section{Konfokale Daten}

Die Analyse der Fluoreszenzintensitätsverteilung mitochondrialer Proteine auf konfokalen Bilddaten wurde in Zusammenarbeit mit Dr. C. Wurm etabliert. Sie basiert auf selbst geschriebenen Algorithmen in dem Programm MATLAB. Hierzu wurden Maximalprojektionen konfokaler z-Stapel, die nach den Vorgaben des Nyquist Theorems aufgenommen wurden, untersucht. Die Maximalprojektion wurde anstatt der Aufaddierung des Signals aller z-Ebenen gewählt, weil bei ihr additive Effekte der Überlagerung von Mitochondrien, welche die Auswertung verfälschen könnten, am geringsten sind. Um die Mitochondrien einer Zelle von denen einer anderen Zelle abzugrenzen, musste manuell eine Zellmaske gezeichnet werden. Zusätzlich wurde die Position des Zellkerns manuell festgelegt.

Anschließend ermittelte die Auswertung die Position der Mitochondrien innerhalb einer Zelle. Hierzu erstellte der Analysealgorithmus binäre Mitochondrienmasken, wodurch die Mitochondrien vom Zellhintergrund getrennt wurden. Dies erfolgte folgendermaßen (Abbildung 2.2): Zunächst wurden die konfokalen Bilddaten im Rahmen des Schwellwertverfahren (thresholding) mit einer Gaussfunktion ( $2 \mu \mathrm{m}$ Durchmesser) geglättet. Anschließend wurden die geglätteten Bilddaten von Rohdaten abgezogen. Dies diente dazu, große Inhomogenitäten der Fluoreszenzintensität abzumildern, während mittlere und kleine Strukturen erhalten blieben. Negative Intensitätswerte wurden dann auf 0 gesetzt. Um eine Mitochondrienmaske zu erzeugen, wurde nun das Differenz-Bild binärisiert, indem ein (lokaler) 'isodata'-Schwellwert angewandt wurde. Daraufhin wurde die 
Mittellinie der Mitochondrien identifiziert und diese um $200 \mathrm{~nm}$ verbreitert. Nur diese Mitochondrienmittellinie, und nicht das gesamte Mitochondrium, wurde im Rahmen dieser Auswertung analysiert. Anhand dieser Mittellinienmaske wurde anschließend die Fluoreszenzintensität jedes Pixels innerhalb dieser bestimmt.
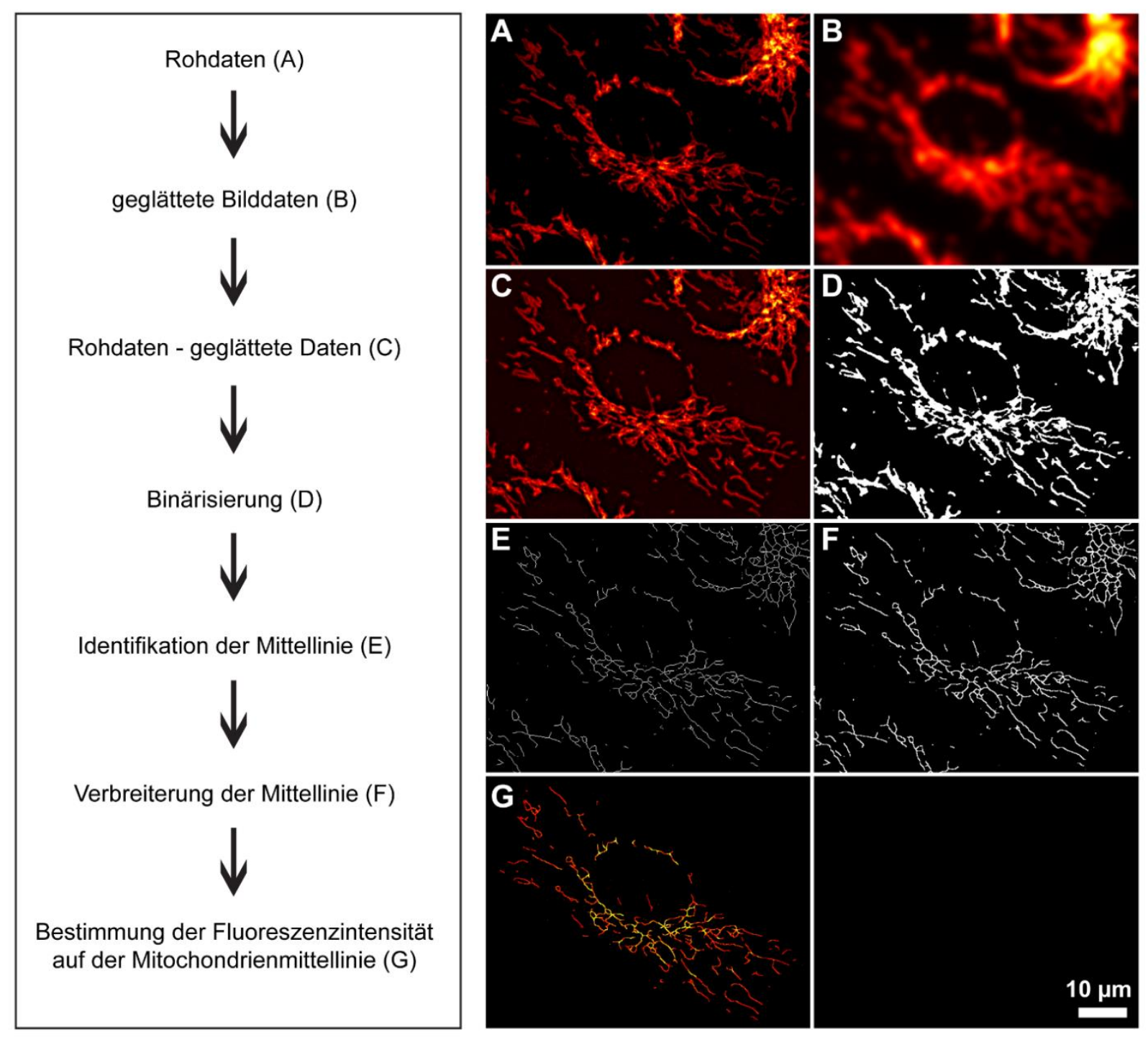

Abbildung 2.2: Arbeitsschema der Mitochondrienerkennung im Rahmen der Fluoreszenzintensitätsanalyse mitochondrialer Proteinverteilungen.

Linke Spalte: Übersicht des Arbeitsablaufs. Rechts: Beispiel für die Bestimmung der mitochondrialen Mittellinie von Tom20-markierten Vero-Zellen. Die Rohdaten (A) wurden im ersten Schritt geglättet (B) und anschließend die geglätteten Daten von den Rohdaten subtrahiert (C). Das erhaltene Differenzbild wurde danach binärisiert (D), um die Mitochondrien vom Bildhintergrund zu trennen. Daraufhin wurde die mitochondriale Mittellinie identifiziert (E) und diese um $200 \mathrm{~nm}$ verbreitert (F). Abschließend wurde die Fluoreszenzintensität auf dieser Mitochondrienmittellinie innerhalb einer Zelle ermittelt. 
Abschließend wird die Intensität jedes Pixels innerhalb der Mitochondrien gegen seine Entfernung zum Zellmittelpunkt, dem Kern, aufgetragen. Generell wurde der Mittelwert der Fluoreszenzintensität der Mitochondrien über alle Richtungen einer bestimmten Entfernung zum Zellkern errechnet.

Die Auftragung des Abstand zum Zellkern gegen die Fluoreszenzintensität ergibt im Falle von Tom20 häufig eine heterogene Verteilung seiner Fluoreszenzintensität über die Zelle, die gut mit einer Regressionsgeraden linearisiert werden kann. Diese besitzt oftmals eine negative Steigung und entspricht somit also einer hohen Fluoreszenzintensität in kernnahen Mitochondrien und einer geringeren Fluoreszenzintensität in Mitochondrien, die sich in der Zellperipherie befinden. Der Wert dieser Steigung $(\Delta \mathrm{lnt} / \mu \mathrm{m})$ eignet sich gut, um das Ausmaß der Heterogenität mitochondrialer Proteinverteilungen innerhalb ganzer Zellen zu beschreiben und ermöglicht somit einen Vergleich zwischen verschiedenen Bedingungen.

Auswertung mit Normalisierung auf Gesamtzellausdehnung

Die Größe von Säugerzellen kann sich aufgrund verschiedenster Einflüsse deutlich unterscheiden. Um Protein-Gradienten in Zellen unterschiedlicher Größe besser miteinander vergleichen zu können, wurde ein weiterer Wert zum Vergleich des Ausmaßes der Heterogenität der Verteilung mitochondrialer Proteine innerhalb ganzer Zellen verwendet. Hierzu wurde eine Normalisierung der Fluoreszenzintensität auf die Gesamtzellgröße eingeführt. Das Ergebnis dieser Normalisierung ist der Wert der Gesamtänderung der Fluoreszenzintensität über die ganze Zelle, also vom kernnächsten Mitochondrium bis zum Mitochondrium, das am Entferntesten in der Zelle vorliegt ( $\Delta$ Int). Hiermit wird der maximale Unterschied der Fluoreszenzintensität von mitochondrialer Proteindichte einer Zelle, unabhängig von der Größe der Zelle, angegeben.

\section{Auswertung mit Ausschluss bestimmter Zellbereiche}

Für die Analyse der Fluoreszenzintensitätsverteilung mitochondrialer Proteine wurden zwar Maximalprojektionen konfokaler z-Stapel verwendet, dennoch können additive Effekte aufgrund überlagernder Mitochondrien, insbesondere im kernnahen Zellbereich, wo die Mitochondrien sehr dicht aggregiert lokalisieren, nicht gänzlich ausgeschlossen werden (Abbildung 3.4). Diese könnten die Fluoreszenzintensität an Kreuzungspunkten von Mitochondrien künstlich erhöhen und eine dichtere Proteinverteilung suggerieren. Um den Einfluss dieses Effekts beurteilen und inn ausschließen zu können, wurde die Intensitätsauswertung konfokaler Mikroskopaufnahmen weiter entwickelt. Hierzu wurden die überlappenden Bereiche von Mitochondrien von der Analyse ausgespart und nur noch nicht-überlappende Mitochondrien ausgewertet. Außerdem war es mit dieser Auswertung möglich, speziell den Zellkern von der Auswertung auszuschießen. Das war nötig, 
wenn der Zellkern bei einer mitochondrialen Immunfluoreszenzmarkierung unspezifisch angefärbt wurde.

Auswertung ohne mitochondriale Mittellinie

Für die Auswertung der Fluoreszenzintensitätsverteilung mitochondrialer DNA und fragmentierter Mitochondrien eignete sich die Analyse mit der mitochondrialen Mittellinie nicht, weil hiermit die Erkennung der kugeligen (und nicht tubulären) Struktur der mtDNA nicht effektiv funktionierte. Hierzu wurde dementsprechend der Schritt der Identifikation und Verbreiterung der mitochondrialen Mittellinie des Auswertungsalgorithmus weg gelassen.

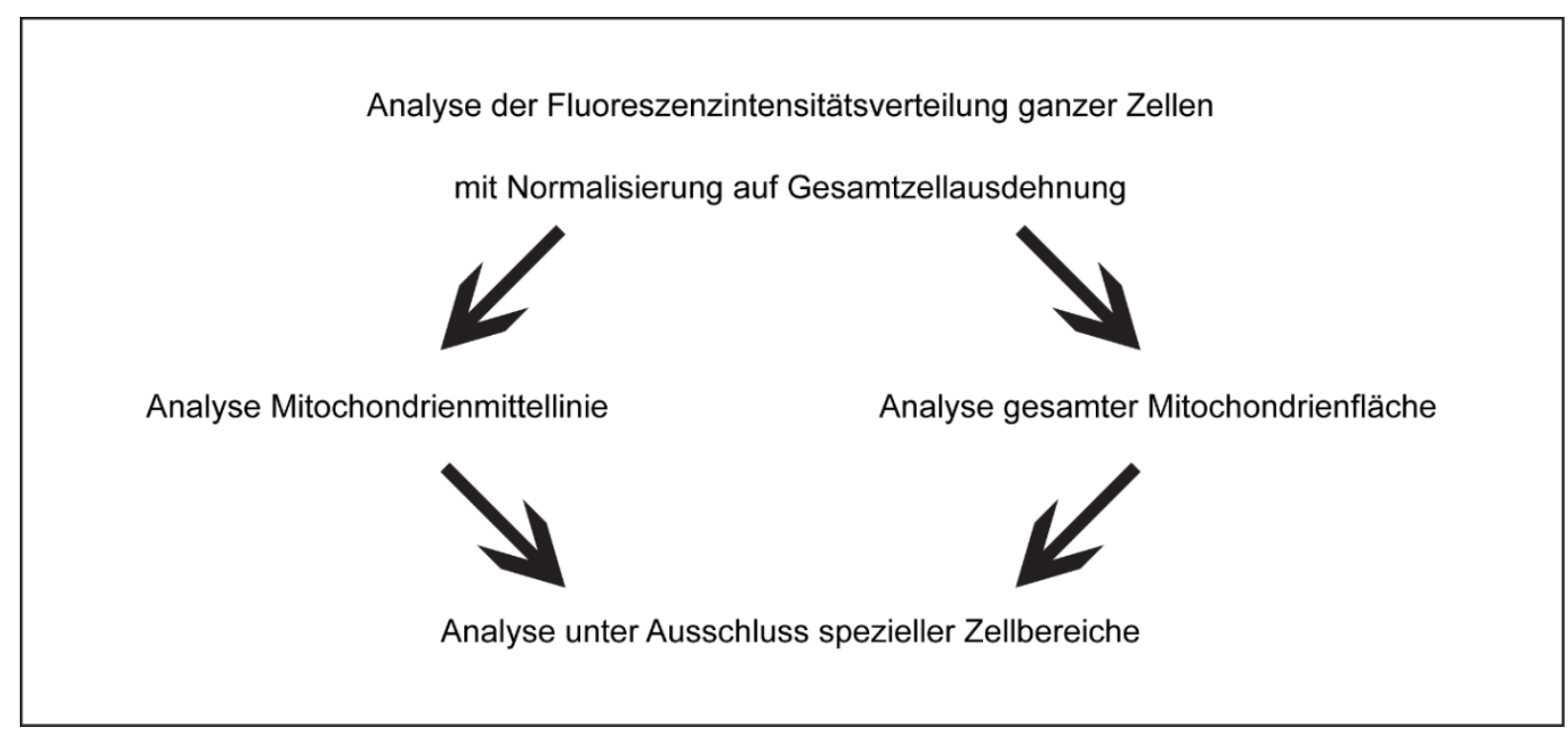

Abbildung 2.3: Übersicht über die im Rahmen dieser Arbeit erstellten Bildauswertungsalgorithmen zur Analyse der Fluoreszenzintensitätsverteilung von konfokalen Bilddaten.

Im Rahmen dieser Arbeit wurden verschiedene Bildauswertungsalgorithmen etabliert, welche die Analyse der Fluoreszenzintensität unter diversen Bedingungen ermöglichten.

\section{STED-Daten (Wurm et al. 2011)}

Die Berechnung der Clusterdichte auf STED-mikroskopischen Aufnahmen in Form der normalisierten Varianz der Fluoreszenzintensität wurde wie bereits beschrieben durchgeführt (Wurm et al. 2011). Dabei ist anzumerken, dass hohe normalisierte Varianzwerte einer geringen Clusterdichte und kleine normalisierte Varianzwerte einer hohen Clusterdichte entsprechen.

\section{Statistische Methoden}

Zur Validierung der erhaltenen Ergebnisse wurden alle Experimente generell mindestens drei Mal durchgeführt. 
Die Signifikanz der Abweichung zweier Datensätze voneinander (z.B. wt gegenüber behandelte Zellen), wurde mittels Durchführung des t-Tests bei zwei unabhängigen Stichproben für Mittelwerte unter Verwendung des Datenverarbeitungsprogrammes Origin berechnet. Dabei galt eine Überschreitungswahrscheinlichkeit von 0,05 (*), 0,01 (**) sowie 0,001 (***) als signifikante Veränderung.

\section{Simulation mikroskopischer Daten}

Durch Simulationen mit dem Programm Imspector wurden Ergebnisse mikroskopischer Daten überprüft.

Die Simulation zur Eignung der Konfokalmikroskopie und der Fluoreszenzintensität zur Unterscheidung mitochondrialer Proteindichten (Abbildung 3.1) erfolgte anhand selbstbestimmter Parameter.

Hierzu wurde eine vereinfachte Version der Mitochondrien und der sich darauf befindenden Proteincluster untersucht. Mitochondrien wurden als Röhren mit einem Durchmesser 300 nm, einer Länge von $3 \mu \mathrm{m}$ und einer Randdicke von 2 Pixeln angenommen. Eine Pixelgröße von $10 \mathrm{~nm}$ wurde vorgegeben. Proteincluster wurden als kugelförmige Strukturen dargestellt. Ihre Verteilung erfolgte mittels einer Poisson-Statistik. Die Zahl der Kugeln, also Proteincluster pro Bild bzw. Mitochondrium, wurde anschließend variiert (1: 2510, 2: 1398, 3: 1015, 4: 703, 5: 589). Die Annahme der Ausdehnung der PSF waren wie folgt: $40 \mathrm{~nm} \times 40 \mathrm{~nm} \times 600 \mathrm{~nm}$ Gauss-Profil für STED-Mikroskopie und $230 \mathrm{~nm} \times 230 \mathrm{~nm} \times 600 \mathrm{~nm}$ Gauss-Profil im Falle der Konfokalmikroskopie.

Für die Simulation des Einflusses überlappender Mitochondrien (Abbildung 3.3) wurden folgende Parameter verwendet. Hierzu wurde erneut eine vereinfachte Version der Mitochondrien in Form einer Röhre angenommen. Der Durchmesser der Röhre betrug $300 \mathrm{~nm}$, ihre Länge $3 \mu \mathrm{m}$, ihre Randdicke 2 Pixel und die Pixelgröße $10 \mathrm{~nm}$. Anschließend wurde simuliert, welchen Effekt eine Überlappung zweier Mitochondrien, also Röhren, auf die Proteinclusterdichte und die Fluoreszenzintensität hat. Dabei wurde der Abstand beider Röhren voneinander $(240 \mathrm{~nm}$ und $840 \mathrm{~nm}$ ), sowie die räumliche Ausrichtung zueinander (Grad der Überlappung) variiert. Proteincluster wurden als kugelförmige Strukturen dargestellt. Ihre Verteilung erfolgte mittels einer PoissonStatistik. Die Annahme der Ausdehnung der PSF waren wie folgt: 40 nm x 40 nm x 600nm Gauss-Profil für STED-Mikroskopie und 230 nm x 230 nm x 600 nm Gauss-Profil im Falle der Konfokalmikroskopie. 


\section{Ergebnisse}

Ziel dieser Arbeit war die Analyse der Verteilung mitochondrialer Proteine in kultivierten Säugerzellen. Hierzu wurde nicht nur Konfokalmikroskopie verwendet, sondern auch die beugungsunbegrenzte STED-Mikroskopie.

\subsection{Untersuchung mitochondrialer Proteinverteilungen in unbehandelten} Zellen

Im Rahmen dieser Arbeit wurden alle Untersuchungen mit Vero-Zellen durchgeführt. Dabei handelt es sich um eine immortalisierte Zelllinie, die aus Nierenepithelzellen von grünen Meerkatzen (African Green Monkey) gewonnen wurde. Aufgrund ihrer flachen, fibroblastenähnlichen Morphologie eignen sie sich insbesondere für die mikroskopische Analyse mitochondrialer Proteinverteilungen, wodurch die Mitochondrien ausgebreitet in der Zelle liegen. Außerdem wurde die submitochondriale Proteinverteilung von Tom 20 bereits in Vero-Zellen untersucht und eine Verteilung in diskreten Clustern auf der Mitochondrienoberfläche, sowie eine Heterogenität in deren Verteilung, in Form eines intrazellulären Gradienten, festgestellt (Wurm et al. 2011).

Zur fluoreszenzmikroskopischen Visualisierung mitochondrialer Proteine gibt es verschiedene Techniken. Üblicherweise werden hierfür entweder die direkte Markierung eines Proteins mit einem Fluoreszenzmarker, z.B. durch genetische Fusionierung mit einem fluoreszierenden Protein, oder eine indirekte Detektion über Immunfluoreszenzmarkierungen mit Antikörpern, eingesetzt. Die direkte Markierung von Proteinen durch genetische Fusionierung mit Fluoreszenzproteinen erfordert ihre transiente Expression. Diese birgt den Nachteil einer Überexpression des Zielproteins, da das Zielprotein zusätzlich zum endogenen Protein exprimiert wird. Dadurch kann die Proteinlokalisation verändert werden. Somit eignet sich die Expression von Fusionsproteinen folglich nicht für die Untersuchung nativer submitochondrialer Proteinlokalisationen mit hochauflösender Mikroskopie. Mittlerweise wurden Methoden entwickelt, welche eine genomische Markierung von Säugerzellen erlauben, wodurch keine Überexpression des Fusionsproteins stattfindet. Hierzu zählen die Technologien der Zink-Finger-Nukleasen, der TALENs (transcription activator-like effector nuclease) oder des CRISPR/Cas-Systems (clustered regularly interspaced short palindromic repeats). Diese Systeme befinden sich jedoch noch in der Entwicklungsphase und sind deshalb ungeeignet für einen 
breiten Einsatz. Aus diesem Grund wurden im Rahmen dieser Arbeit Proteinverteilungen ausschließlich über Immunfluoreszenzmarkierungen analysiert, wie es auch in der bisherigen Studie zur Analyse mitochondrialer Proteinverteilungen mittels STED-Mikroskopie der Fall war (Wurm et al. 2011).

\subsubsection{Konfokalmikroskopie als Instrument zur Analyse mitochondrialer} Heterogenität

Ausgangspunkt dieser Arbeit waren die Ergebnisse von Wurm et al. 2011. In der Studie wurde die STED-Mikroskopie und ein entsprechender quantitativer Bildanalysealgorithmus zur Untersuchung der Verteilung mitochondrialer Proteincluster innerhalb ganzer Zellen (Auswertung der Varianz der Fluoreszenzintensität) verwendet. Um die Proteindichte und Verteilung des mitochondrialen Proteins Tom20 zu analysieren war der Einsatz der hochauflösenden STED-Mikroskopie nötig. Die Auflösung konventioneller Lichtmikroskope ist nicht ausreichend, um einzelne Proteincluster aufzulösen. Dies gelingt nur mit hochauflösenden beugungsunbegrenzten Mikroskopietechniken, wie z.B. der STEDMikroskopie. Die im Rahmen der Studie präsentierten Bildanalysealgorithmen ermöglichten eine automatisierte quantitative Untersuchung mitochondrialer Proteinverteilungen STEDmikroskopischer Aufnahmen.

Im Rahmen der vorliegenden Arbeit sollten mitochondriale Proteinverteilungen hinsichtlich einer vorliegenden Heterogenität näher untersucht werden. Hierzu war die Analyse großer Mengen an Zellen nötig, um den Einfluss biologischer Variabilität auf die Proteinverteilungen zu minimieren. Um die Analyse von Proteinverteilungen in hochdurchsatzweise zu ermöglichen, wurde das AuswertungsKonzept von Wurm et al. im Rahmen dieser Arbeit weiter entwickelt. Die STED-Mikroskopie besitzt eine Reihe von Vorteilen gegenüber der klassischen Konfokalmikroskopie, aktuell stellt ihr Zeitaufwand eine Limitation für die Hochdurchsatzanalyse von Proteinverteilungen dar. Dies gilt insbesondere, wenn ganze Zellen analysiert werden sollen. Im Rahmen dieser Arbeit wurde deshalb eine Methode zur automatisierten quantitativen Analyse mitochondrialer Proteinverteilungen mittels Konfokalmikroskopie etabliert.

Die Eignung der Konfokalmikroskopie zur Unterscheidung verschiedener mitochondrialer Proteinmengen wurde mit Hilfe einer Simulation untersucht (Abbildung 3.1), bei der Mitochondrien als Röhren mit einem Durchmesser von $300 \mathrm{~nm}$ angenommen wurden. Anschließend wurde eine variable Menge an Proteinclustern auf der Mitochondrienfläche statistisch verteilt, welche sowohl mit dem theoretischen Fokus eines STED- und Konfokalmikroskops aufgelöst wurden. Anhand der Simulation wurde gezeigt, dass eine dichtere Proteinclusterverteilung (welche mittels STED- 
Mikroskopie aufgelöst werden könnte) und somit eine höhere Proteinmenge zu einer höheren Fluoreszenzintensität bei konfokalmikroskopischer Analyse führt (Abbildung 3.1).

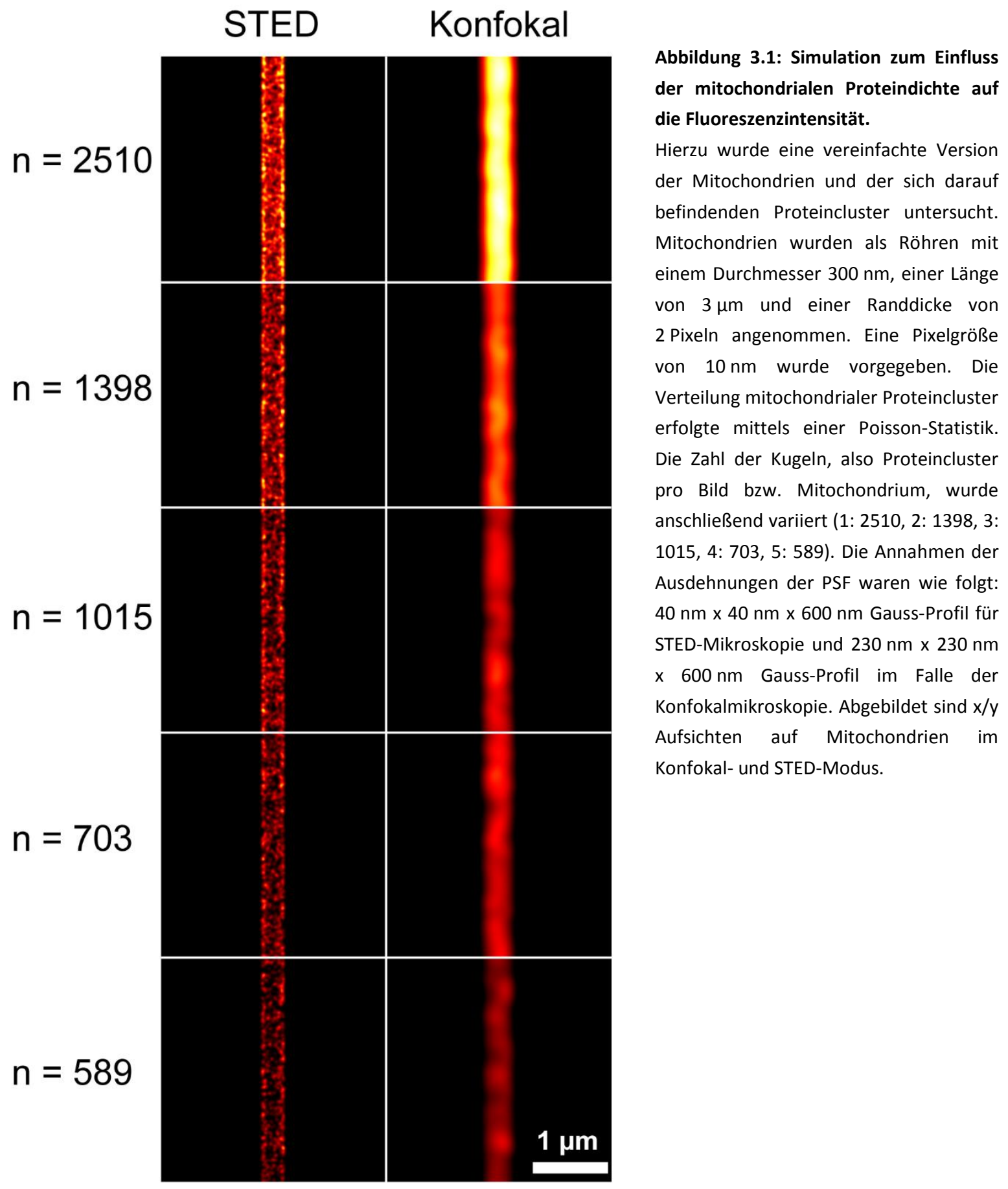

Weiterhin wurde mikroskopisch untersucht, ob diese Annahme korrekt ist. Hierzu wurden parallel STED- und konfokalmikroskopische Aufnahmen von Vero-Zellen, in denen Tom20 mittels Immunfluoreszenz markiert wurde (wie unter 2.2.3 beschrieben), angefertigt. Die Detektion der Markierung erfolgte an einem STED-Mikroskop parallel im Konfokal- und STED-Modus (Aufbau unter 
2.2.3 beschrieben). Bei Betrachtung der STED-Aufnahmen war eine heterogene Verteilung von Tom20-Proteinclustern, in Form eines Gradienten, auf Mitochondrien innerhalb einer Vero-Zelle sichtbar. So zeigten perinukleäre Mitochondrien eine dichtere Verteilung der Proteincluster im Vergleich zu peripheren Mitochondrien (Abbildung 3.2 A). Im entsprechenden konfokalmikroskopischen Bild war zu beobachten, dass die Fluoreszenzintensität in den perinukleären Mitochondrien höher ist als in den peripheren Mitochondrien (Abbildung 3.2 B). Dies zeigte sich in einer Vielzahl von Zellen.
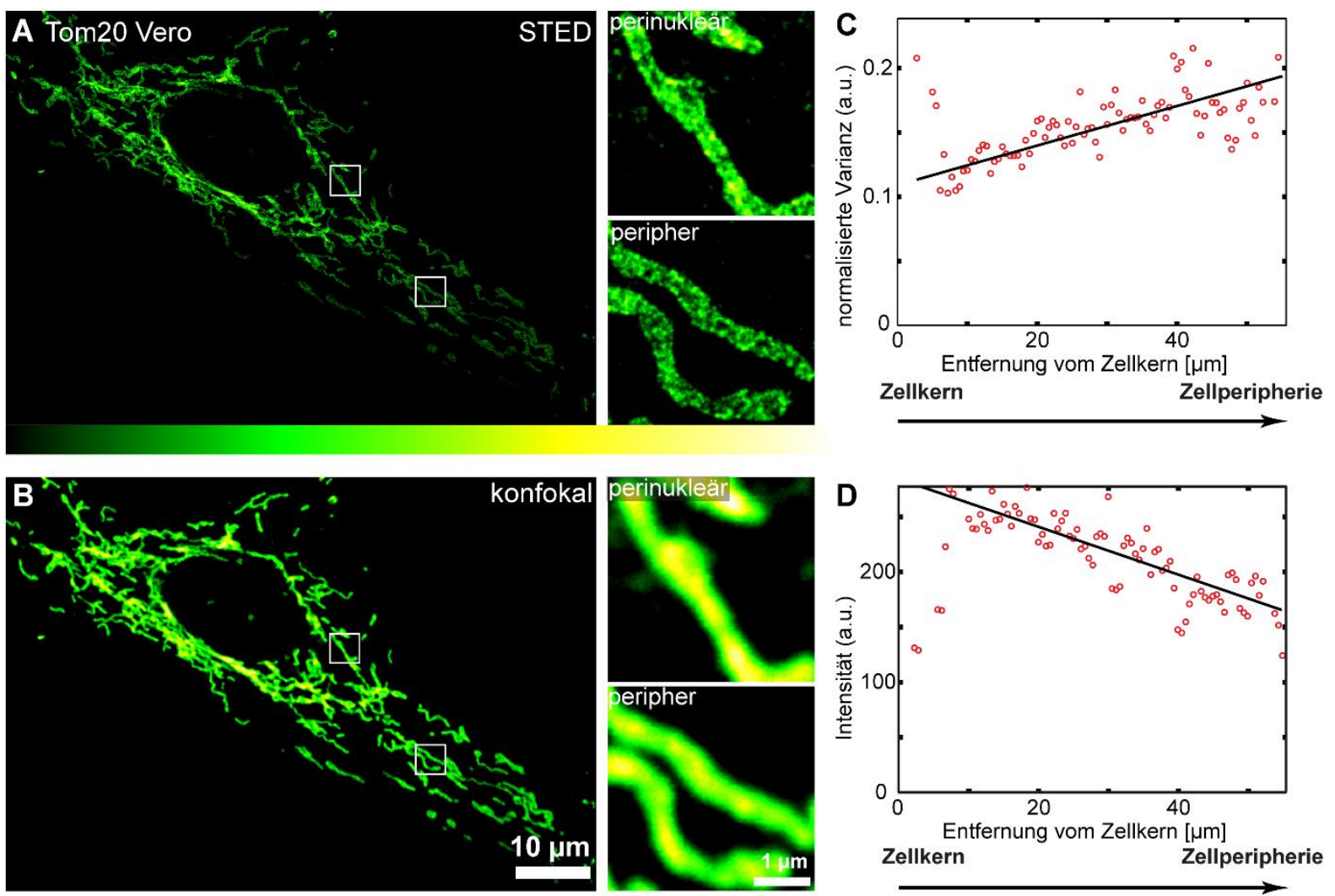

Abbildung 3.2: Die Verteilung des mitochondrialen Proteins Tom20 ist heterogen und weist einen intrazellulären Gradienten auf.

Die Heterogenität von Tom20-Proteinverteilungen kann mittels STED-Mikroskopie und Konfokalmikroskopie immunfluoreszenzmarkierter Zellen untersucht werden. (A) STED-Mikroskopie erlaubt die Auflösung von Tom20Proteinclustern in Vero-Zellen. In perinukleären Mitochondrien sind sie dichter verteilt sind als in peripheren. (B) Entsprechende Beobachtungen lassen sich mittels Konfokalmikroskopie machen. Die Aufnahme zeigt, dass die Fluoreszenzintensität von Tom20 höher in perinukleären Mitochondrien als in peripheren Mitochondrien ist. Die Bilder wurden nachträglich geglättet. $(C+D)$ Die Unterschiede der Verteilung von Tom20 auf Mitochondrien innerhalb einer Zelle, werden durch quantitative Bildanalysealgorithmen (C) der Varianz der Fluoreszenz-Intensität (STED-Mikroskopie) und (D) der Fluoreszenz-Intensität (Konfokal-Mikroskopie) bestätigt. Die Farbtabellen peripherer und perinukleärer Mitochondrien sind identisch.

Somit korrelierte die Anzahl der Proteincluster, welche mittels STED-Mikroskopie visualisiert wird, mit der Fluoreszenzintensität, die mittels Konfokalmikroskopie erhalten wird. Das bedeutet, dass sich die Konfokalmikroskopie zur Untersuchung der Heterogenität mitochondrialer Proteine eignet. 
Um diese Beobachtungen quantitativ darstellen zu können, wurden die Bilder anschließend mittels automatischer Bildanalysealgorithmen ausgewertet. Zum einen wurde die normalisierte Varianz der Fluoreszenzintensität (STED-Mikroskopie) ermittelt, welche ein indirektes Maß für die Dichte von Proteinclustern darstellt, zum anderen wurde die Fluoreszenzintensität (Konfokalmikroskopie) von Tom20 innerhalb ganzer Zellen analysiert (siehe Material \& Methoden 2.2.4).

Die Berechnung der normalisierten Varianz der Fluoreszenzintensität wurde bereits erfolgreich zur Analyse mitochondrialer Proteinverteilungen eingesetzt und ist gut charakterisiert (Wurm et al. 2011). Die normalisierte Varianz spiegelt nicht nur die Verteilung und Größe der Proteincluster wieder, sondern auch das Verhältnis des Cluster-Signals zum mitochondrialen Hintergrundsignal. Hierzu ist anzumerken, dass hohe normalisierte Varianzwerte einer geringen Clusterdichte und kleine normalisierte Varianzwerte einer hohen Clusterdichte entsprechen. In Abbildung 3.2 B ist die Verteilung der normalisierten Varianzwerte der Tom20-Cluster in Abhängigkeit von der Position innerhalb der Zelle exemplarisch für die abgebildete Zelle aufgetragen. Die graphische Darstellung zeigte, dass in Kernnähe geringere normalisierte Varianzwerte vorliegen als in der Zellperipherie. Die Anwendung des Bildanalysealgorithmus auf die Zelle aus Abbildung 3.2 A (und einer Vielzahl weiterer Zellen) ergab, dass die Regressionsgerade durch die Varianzwerte dieser Zelle eine negative Steigung aufweist. Das bestätigte, dass die Cluster von Tom20 in Zellkernnähe dichter verteilt sind als in der Zellperipherie.

Zur Untersuchung der Intensitätsverteilung des Tom20-Fluoreszenzsignals konfokaler Bilddaten mittels quantitativer Bildanalysealgorithmen, ermittelte die Auswertung die Mitochondrien und bestimmt die Fluoreszenzintensität jedes Pixels innerhalb dieser (siehe Material \& Methoden 2.2.4). Die Auftragung der Intensität jedes Pixels innerhalb der Mitochondrien gegen seine Entfernung zum Zellmittelpunkt, dem Kern, ergab für die Zelle aus Abbildung 3.2 (und einer Vielzahl weiterer Zellen) eine heterogene Verteilung (in Form eines Gradienten) der Tom20-Fluoreszenzintensität über die Zelle. Für die Verteilung der Werte wurde eine Regressionsgerade bestimmt, die eine negative Steigung besitzt, also einer hohen Fluoreszenzintensität in perinukleären Mitochondrien und einer geringeren Fluoreszenzintensität in peripheren Mitochondrien (Abbildung 3.2 A+B), entspricht. Der Wert dieser Steigung konnte verwendet werden, um das Ausmaß der Gradientenverteilung mitochondrialer Proteine innerhalb ganzer Zellen zu beschreiben und ermöglichte somit einen Vergleich zwischen verschiedenen Bedingungen.

Somit ist festzustellen, dass die Beobachtung der Existenz einer heterogenen Verteilung in Form eines Gradienten des mitochondrialen Tom20-Proteins (perinukleäre Mitochondrien besitzen eine höhere Fluoreszenzintensität als periphere) (Abbildung 3.2 B) mittels der neu entwickelten Fluoreszenzintensitätsanalyse konfokalmikroskopischer Daten (Abbildung 3.2 D) bestätigt wurde. Außerdem ist festzuhalten, dass die Beobachtungen, welche mittels konfokalmikroskopischer Daten 
gemacht wurden mit denen STED-mikroskopischer Daten, inklusive der Varianzanalyse mitochondrialer Proteincluster, korrelierte (Abbildung 3.2 A/C und Wurm et al.).

Im weiteren Verlauf der Arbeit wurde die Konfokalmikroskopie in Kombination mit der Fluoreszenzintensitätsauswertung genutzt, um die Heterogenität mitochondrialer Proteinverteilungen unter verschiedensten Bedingungen in hochdurchsatzweise zu analysieren. Da die Konfokalmikroskopie keine Aussage über die Lokalisation der Proteine in Clustern oder als homogenes Protein zulässt, wurde in Einzelfällen auch die STED-Mikroskopie und die Analyse der Varianz der Fluoreszenzintensität weiterhin eingesetzt.

Die Beobachtung, dass die intrazelluläre Tom20-Verteilung einen Dichtegradienten aufweist bestätigte zwar die Ergebnisse früherer Studien (Wurm et al. 2011), dennoch konnte nicht ausgeschlossen werden, dass diese Gradientenverteilung aufgrund Überlappungseffekte dicht beieinander liegender Mitochondrien entsteht. Im Rahmen dieser Arbeit wurde deshalb kontrolliert, welchen Einfluss überlappende Mitochondrien auf die Fluoreszenzintensiätsauswertung haben.

\subsubsection{Einfluss der Mitochondriendichte auf die Ergebnisse der} Intensitätsanalyse

Ein mögliches Problem bei der der Auswertung der Fluoreszenzintensität birgt das Auflösungsvermögen von Konfokalmikroskopen in axialer Richtung. Dieses beträgt ca. $600 \mathrm{~nm}$. Da Mitochondrien einen Durchmesser von $200-400 \mathrm{~nm}$ haben, könnten somit zwei dicht übereinanderliegende Mitochondrien gleichzeitig aufgenommen werden. Ihr Fluoreszenzsignals würde sich folglich addieren. Davon betroffen sind vor allem perinukleäre Zellbereiche, wo die Mitochondrien sehr dicht aggregiert lokalisiert sind. Anhand einer Simulationen wurde diese Problematik verdeutlicht (Abbildung 3.3). Hierzu wurden Mitochondrien als Röhren mit einem Durchmesser von $300 \mathrm{~nm}$ angenommen. Anschließend wurden zwei Mitochondrientubuli verschieden positioniert (nebeneinander- und übereinander liegend). Eine gleichbleibende Menge Proteincluster wurden auf den Mitochondrienoberflächen statistisch verteilt, welche sowohl mittels einer STED- und einer konfokalen PSF (point-spread-function) aufgelöst wurden. Anschließend wurden die Mitochondrientubuli in zwei unterschiedlichen Abständen zueinander angeordnet: $240 \mathrm{~nm}$ (< axialer Auflösung) und $840 \mathrm{~nm}$ (> axialer Auflösung). Es konnte beobachtet werden, dass im Falle der Überlagerung zweier mitochondrialer Tubuli, mit einem Abstand von 240 nm zueinander, ihr Fluoreszenzsignal zusammen aufgenommen wurde und es sich quasi addiert. Im Falle der 
Überlagerung zweier mitochondrialer Tubuli mit einem Abstand von $840 \mathrm{~nm}$ zueinander, konnten beide Tubuli voneinander getrennt aufgelöst werden. Ihr Fluoreszenzsignal hatte sich nicht addiert. Anhand der Ergebnisse der Simulation wurde bestätigt, dass eine dichtere Mitochondrienanordnung (insofern Tubuli in einem Abstand von weniger als $840 \mathrm{~nm}$ überlagern), zu einer höheren Fluoreszenzintensität bei konfokalmikroskopischer Analyse führte und somit eine höhere Proteinmenge suggerierte (Abbildung 3.3).

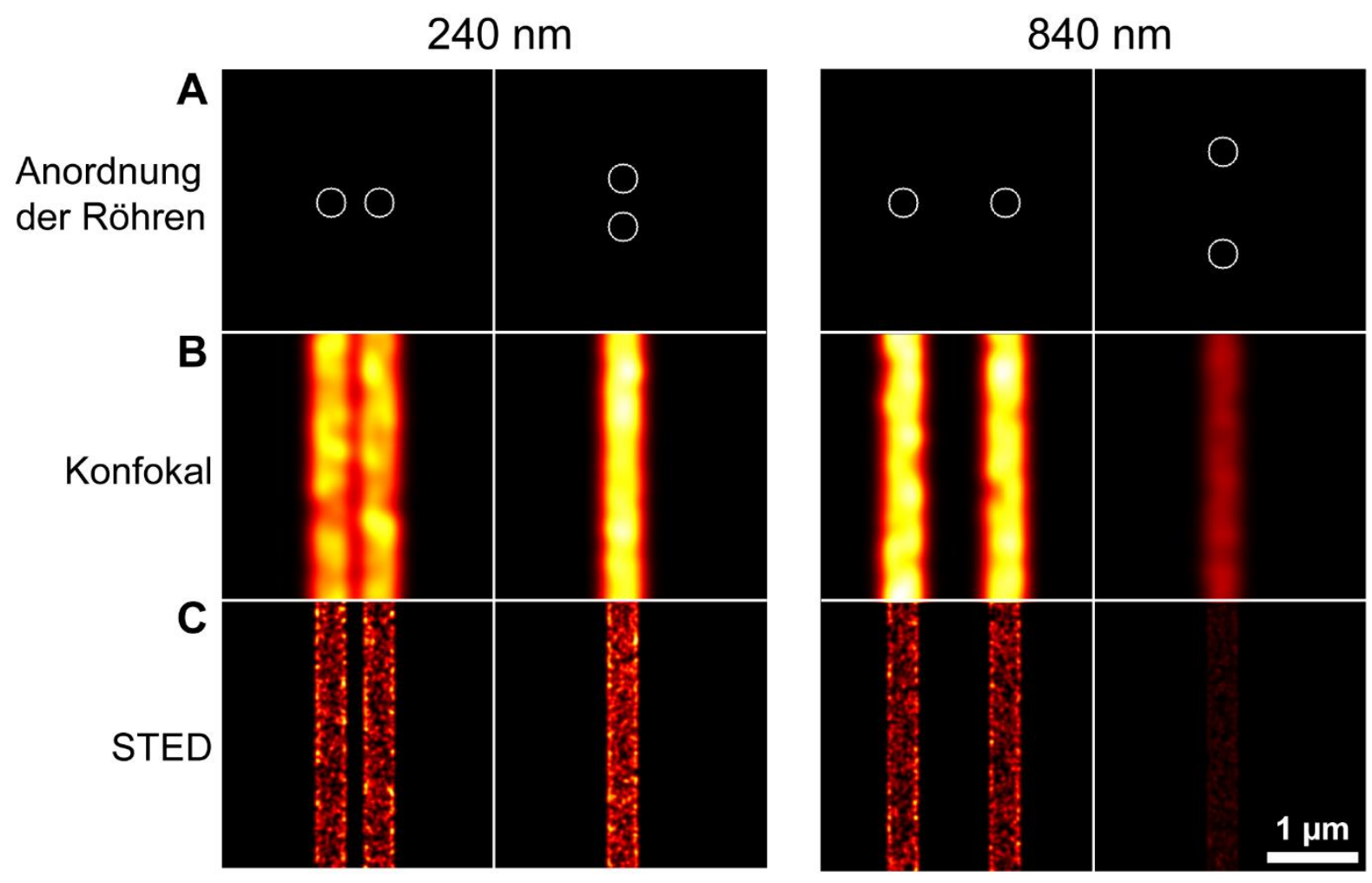

Abbildung 3.3: Simulation zum Einfluss der Überlappung von Mitochondrien auf die Fluoreszenzintensität.

Für die Simulation des Einflusses überlappender Mitochondrien wurden folgende Parameter verwendet: Es wurde eine vereinfachte Version der Mitochondrien in Form einer Röhre angenommen. Der Durchmesser der Röhre betrug $300 \mathrm{~nm}$, ihre Länge $3 \mu \mathrm{m}$, ihre Randdicke 2 Pixel und die Pixelgröße $10 \mathrm{~nm}$. Anschließend wurde simuliert, welchen Effekt eine Überlappung zweier Mitochondrien, also Röhren, auf die Proteindichte und die Fluoreszenzintensität hat. Dabei wurde der Abstand beider Röhren voneinander $(240 \mathrm{~nm} / 840 \mathrm{~nm})$, sowie die räumliche Ausrichtung zueinander (Grad der Überlappung) variiert. Die Verteilung mitochondrialer Proteincluster erfolgte mittels einer Poisson-Statistik. Die Annahmen der Ausdehnungen der PSF waren wie folgt: 40 nm x 40 nm x 600 nm Gauss-Profil für STED-Mikroskopie und $230 \mathrm{~nm} \times 230 \mathrm{~nm} \times 600 \mathrm{~nm}$ Gauss-Profil im Falle der Konfokalmikroskopie. (A) Abgebildet sind x/z Ansichten von Mitochondrien. (B) Abgebildet sind $x / y$ Aufsichten von Mitochondrien (Konfokal-Modus). (C) Abgebildet sind $x / y$ Aufsichten von Mitochondrien (STED-Modus). 
Um den Einfluss dieses Effekts auf Konfokalmikroskopischen Daten beurteilen zu können, wurden die überlappenden Bereiche von Mitochondrien von der Analyse ausgespart und nur noch nichtüberlappende Mitochondrien ausgewertet (Abbildung 3.4 A/B linke Spalte).

\section{A ganze Zelle}
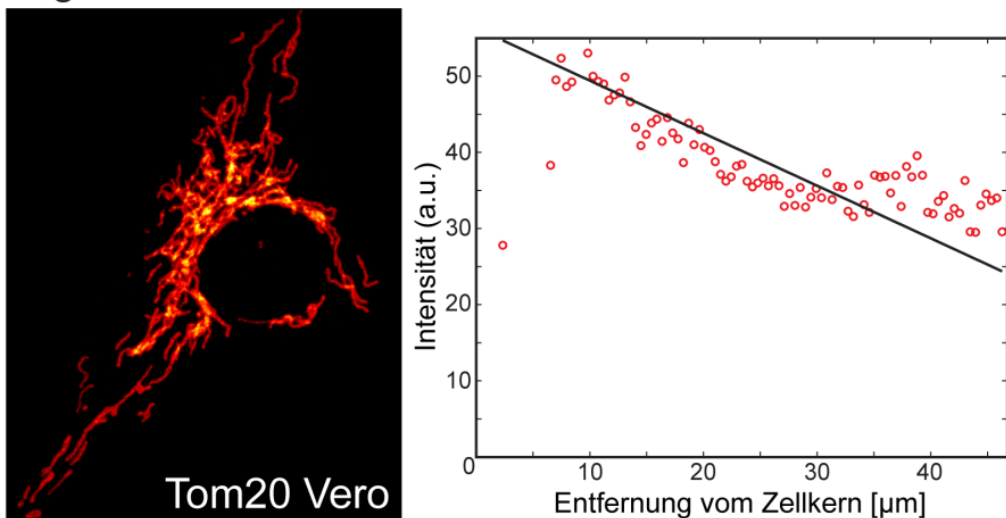

B Mitochondrienausschluss
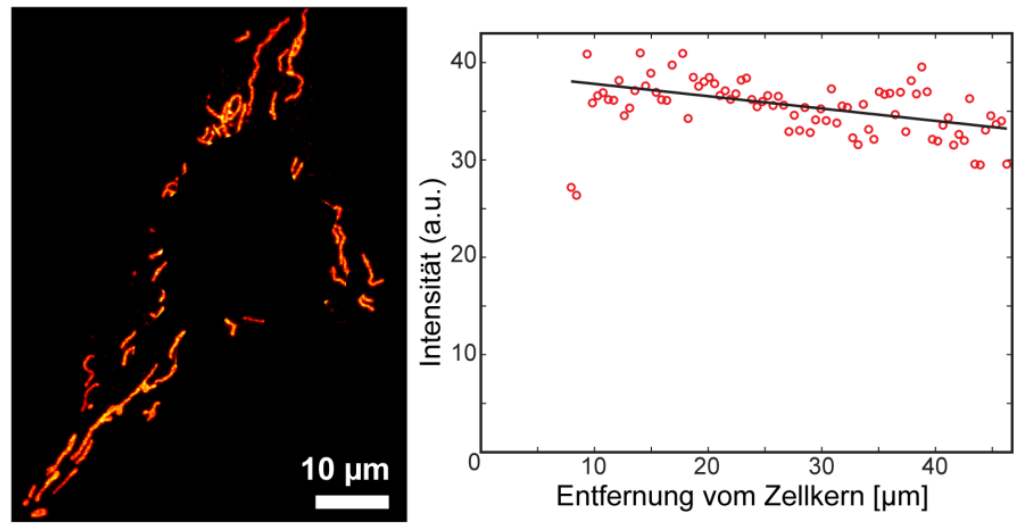

C

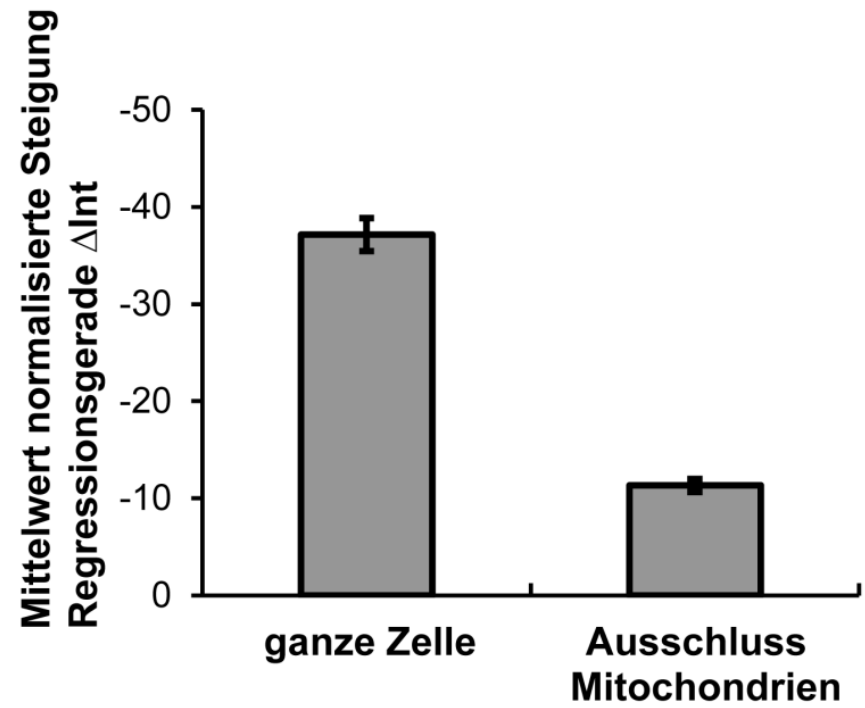

Abbildung 3.4: Die Überlappung von Mitochondrien hat einen Einfluss auf die Fluoreszenzintensitätsauswertung.

(A) Die Analyse des Tom20-FluoreszenzSignals der Gesamtheit der Mitochondrien von Vero-Zellen ergab, dass die Verteilung von Tom20 eine ausgeprägte Heterogenität über die Zelle zeigt. Um störende Effekte überlappender Mitochondrien auszuschließen, wurden diese manuell von der Fluoreszenzintensitätsanalyse ganzer Zellen ausgespart. (B) Nach Ausschluss überlappender Mitochondrien, zeigte die Analyse des Tom20-Fluoreszenz-Signals, dass eine flachere, aber dennoch signifikante Gradientenverteilung von Tom20 entlang einer Zelle existiert. Abgebildet sind Maximalprojektionen konfokaler zStapel. (C) Diese Beobachtung wurde nach Auswertung der Tom20-Verteilung von >100 Zellen mittels Fluoreszenzintensitätsanalyse bestätigt. Gezeigt sind Mittelwerte und Standardfehler.

Anhand einer vergleichenden Auswertung, mit und ohne überlappende Mitochondrien, konnte festgestellt werden, dass die Überlappung einen Beitrag zur Intensitätserhöhung, insbesondere bei 
kernnahen Mitochondrien, hat. Die Intensitätsverteilung von Tom20 in Vero-Zellen war flacher nach Ausschluss überlappender Mitochondrien. Dementsprechend waren die Unterschiede der Fluoreszenzintensität von kernnahen und kernfernen Mitochondrien tatsächlich geringer (Abbildung 3.4. A/B rechte Spalte). Dennoch war selbst nach Ausschluss überlappender Mitochondrien eine Gradientenverteilung von Tom20 innerhalb ganzer Zellen zu erkennen.

Um diese Beobachtung statistisch zu belegen, wurde die Untersuchung für insgesamt $>100$ Zellen durchgeführt. Anschließend wurde der Mittelwert der Steigung der Regressionsgeraden aller Zellen, mit und ohne Ausschluss überlappender Mitochondrien berechnet (Abbildung 3.4 C). Das Ergebnis dieser Berechnung spiegelte die zuvor für eine Zelle beschriebene Beobachtung (Abbildung 3.4 A/B) wieder. Nach Ausschluss überlappender Mitochondrien, war der Mittelwert der Gesamtänderung der Tom20-Fluoreszenzintensität über alle Zellen, geringer als ohne Ausschluss überlappender Mitochondrien, aber dennoch sichtbar.

Die Überlappung von Mitochondrien wurde im weiteren Verlauf der Arbeit berücksichtigt.

Weiterhin bestand die Möglichkeit, dass die Gradientenverteilung des mitochondrialen Tom20Proteins auf einer intrazellulär ungleichmäßigen Färbeeffizienz beruht. Die Immunfluoreszenzmarkierung könnte eventuell in perinukleären Zellbereichen besser funktioniert haben als in peripheren Zellbereichen. Wäre der Gradient auf Unterschiede in der Färbeeffizienz zurückzuführen, müsste dieser bei allen Färbungen auftreten. Deshalb wurde der Auswertungsalgorithmus von Konfokaldaten dahingehend kontrolliert, indem untersucht wurde, ob mitochondriale DNA auch eine Gradientenverteilung innerhalb von Vero-Zellen aufweist.

\subsubsection{Einfluss der Antikörper-Färbungen auf die analysierten} Proteinverteilungen

Um auszuschließen, dass die Gradientenverteilung mitochondrialer Proteine aufgrund einer ungleichmäßigen Färbeeffizienz zustande kommt, wurde die Fluoreszenzintensitätsverteilung von mitochondrialer DNA mit Hilfe des Auswertungsalgorithmus analysiert. Mitochondriale DNA liegt mit Proteinen assoziiert in Clustern vor (Chen et al. 2005). Die Analyse der Fluoreszenzintensitätsverteilung mitochondrialer DNA eignete sich deshalb als Kontrolle des Auswertungsalgorithmus, weil bekannt ist, dass häufig die gleiche Menge mtDNA pro Nukleoid auftritt (Kukat et al. 2011). Folglich wären keine Unterschiede in der Fluoreszenzintensitätsverteilung innerhalb einer Zelle zu erwarten. 
Die mitochondriale DNA wurde mittels eines Antikörpers, der doppelsträngige DNA erkennt, fluoreszenzmarkiert (Abbildung 3.5 A).

Die Auswertung der Fluoreszenzintensitätsverteilung ergab, dass mitochondriale DNA keinen erkennbaren intrazellulären Mengengradienten aufweist, wie er für das Tom20-Protein beobachtet wurde. Für die Analyse wurde der Bereich des Zellkerns ausgeschlossen, da dieser ein extrem hohes Fluoreszenzsignal aufwies und somit die Auswertung der Verteilung mitochondrialer DNA beeinträchtigt hat.

Somit konnte gezeigt werden, dass mitochondriale DNA keine heterogene Intensitäts- und somit Mengenverteilung aufweist. Das zeigt außerdem, dass nicht alle mitochondrialen Komponenten eine Dichtegradientenverteilung besitzen. Somit ließen sich verschiedene Dichteverteilungen von Strukturen mit der etablierten Auswertung unterscheiden.
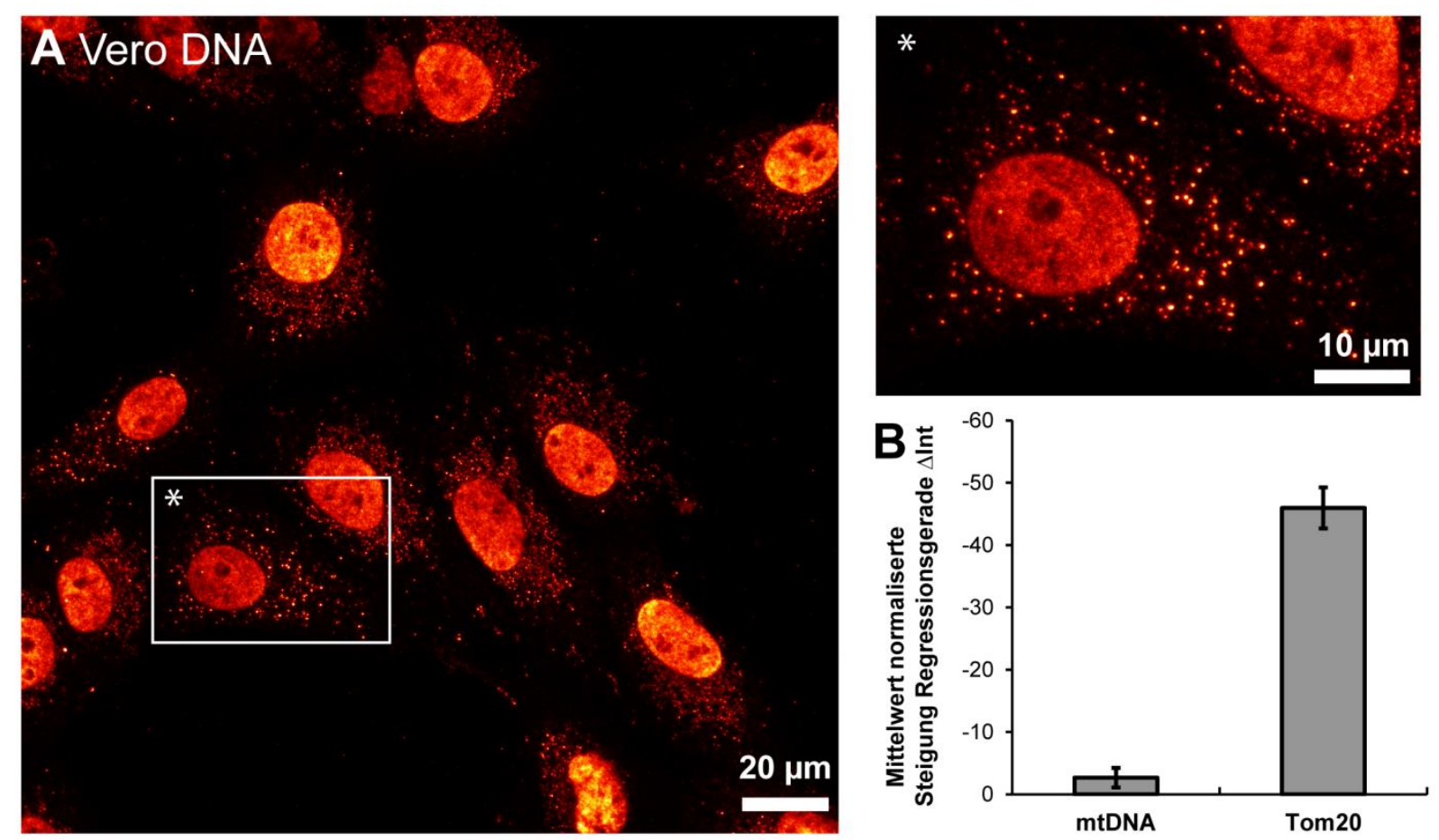

Abbildung 3.5: Die intrazelluläre Fluoreszenzintensitätsverteilung mitochondrialer DNA ist nicht heterogen.

(A) Mitochondriale DNA wurde per Immunfluoreszenzmarkierung gegen dsDNA visualisiert. In Vero-Zellen konnte eine homogene Verteilung seiner Fluoreszenzintensität beobachtet werden. Abgebildet sind Maximalprojektionen konfokaler z-Stapel. (B) Diese Beobachtung bestätigte die Fluoreszenzintensitätsauswertung von insgesamt 77 Vero-Zellen. Im Unterschied zu dem mitochondrialen Protein Tom20 wies die Menge mitochondrialer DNA innerhalb einer Zelle keine Gradientenverteilung auf. Gezeigt sind Mittelwerte und Standardfehler.

Anschließend wurde untersucht, ob andere mitochondriale Proteine außer Tom20 auch eine intrazelluläre Gradientenverteilung aufweisen. Hierzu wurden die Verteilungen einer Vielzahl weiterer mitochondrialer Proteine konfokalmikroskopisch analysiert. 


\subsubsection{Gradientenverteilungen können für weitere mitochondriale Proteine} beobachtet werden

Die Studien von Wurm et al. 2011 und Jans et al. 2013 waren bislang die einzigen Untersuchung, die direkte Erkenntnisse zur heterogenen Verteilung mitochondrialer Proteine innerhalb ganzer Zellen lieferten (Wurm et al. 2011, Jans et al. 2013). Sie beobachteten, dass die Verteilung von Tom20 und Mitofilin/Mic60 einen intrazellulären Gradienten aufweist, mit einer dichteren Proteinverteilung in perinukleären Mitochondrien als in peripheren. Daraus ergab sich die Frage, ob weitere mitochondriale Proteine solche Verteilung aufweisen, welche im Rahmen dieser Arbeit beantwortet werden sollte.

Zunächst wurde die Verteilung der MICOS-Komplex-Komponenten Mic60, Mic10, Mic19 und DnaJC11 analysiert. Dieser Komplex lokalisiert unter anderem an den Cristae Junctions, welche eine Verbindung mitochondrialer Cristae zur inneren Grenzflächenmembran darstellen. Die Verteilung der Komplexproteine kann somit einen Hinweis auf die Verteilung und Dichte mitochondrialer Cristae geben. Außerdem gibt es die Vermutung, dass Cristae Junctions die Zusammensetzung der CristaeMembran kontrollieren und dadurch die ATP-Produktion zu beeinflussen (Mannella 2006). Dementsprechend könnte die Dichte der Cristae mit der Aktivität von Mitochondrien korrelieren. Von großem Interesse wäre die Beantwortung der Frage, ob die Aktivität der Mitochondrien möglicherweise innerhalb von Zellen verschieden ist. Aus demselben Grund, wurde im Rahmen dieser Arbeit auch die Verteilung von Atmungskettenkomplexen (ATP Synthase ( $\beta$-Untereinheit), Cytochrom c und der Cytochrom c-Oxidase I) untersucht.

Weiterhin wurde die Verteilung der Importkomplexproteine Tom20, Tom22, Tim23, Sam50 sowie des Chaperons Hsp70 analysiert. Die Mehrheit mitochondrialer Proteine ist im Zellkern kodiert und muss in Mitochondrien importiert werden. Der Haupteintrittsweg sind die Protein-Importkomplexe der äußeren und inneren mitochondrialen Membran. Die Untersuchung der Verteilung dieser Proteine könnte nicht nur einen Hinweis auf räumliche Unterschiede des Imports mitochondrialer Proteine, sondern möglicherweise auch auf verschiedene metabolische Bedingungen, geben. Dies ist möglich aufgrund der der Annahme, dass Zellen auf unterschiedliche Energieansprüche mit der Änderung des Proteingehalts ihrer Mitochondrien reagieren (Devin et al. 2007). Folglich wäre solch eine Anpassung auch für die Importkomplexproteine wahrscheinlich.

Außerdem wurde im Rahmen dieser Arbeit die Verteilung des mitochondrialen Proteins Cyclophilin D analysiert. Dieses ist Teil der mitochondrialen Permeabilitäts- und Durchgangspore (Mitochondrial permeability transition pore, MPTP), deren Aktivierung vermutlich im Vorgang der Initiierung von Apoptose eine Rolle spielt. Durch die MPTP gelangen Moleküle, z.B. Stoffwechselmetabolite, bis zu einer Größe von 5 kDa in die Mitochondrien. 
Des Weiteren wurde die Verteilung des Chaperons Hsp60, dessen Funktion die Faltung und Zusammensetzung von in Mitochondrien importierter Proteine ist und dem Protein Mff (mitochondrial fission factor), welches eine Funktion bei der mitochondrialen Teilung hat, untersucht. Die Analyse der Verteilung eines Proteins, welches mit dem mitochondrialen Teilungsapparat assoziiert ist, ist von Interesse, weil dies eventuell eine Aussage über zellregionsspezifische Unterschiede mitochondrialer Teilungsvorgänge erlaubt.

Die Analyse der Verteilung dieser Vielzahl mitochondrialer Proteine unterschiedlicher submitochondrialer Kompartimente erfolgte mittels der Intensitätsanalyse konfokalmikroskopischer Bildaufnahmen von 3000 immunfluoreszenzmarkierten Vero-Zellen (beispielhafte Aufnahmen der Immunfluoreszenzmarkierungen aller Proteine befinden sich im Anhang Abschnitt 7.3). Sie lieferte erstaunlicherweise das Ergebnis, dass alle analysierten mitochondrialen Proteine über eine heterogene Verteilung verfügten, die einem Gradienten entsprach (Abbildung 3.6). Dies bedeutet, dass die Fluoreszenzintensität und somit die Proteinmengen aller untersuchten mitochondrialen Proteine in Zellkernnähe größer waren als in der Zellperipherie.

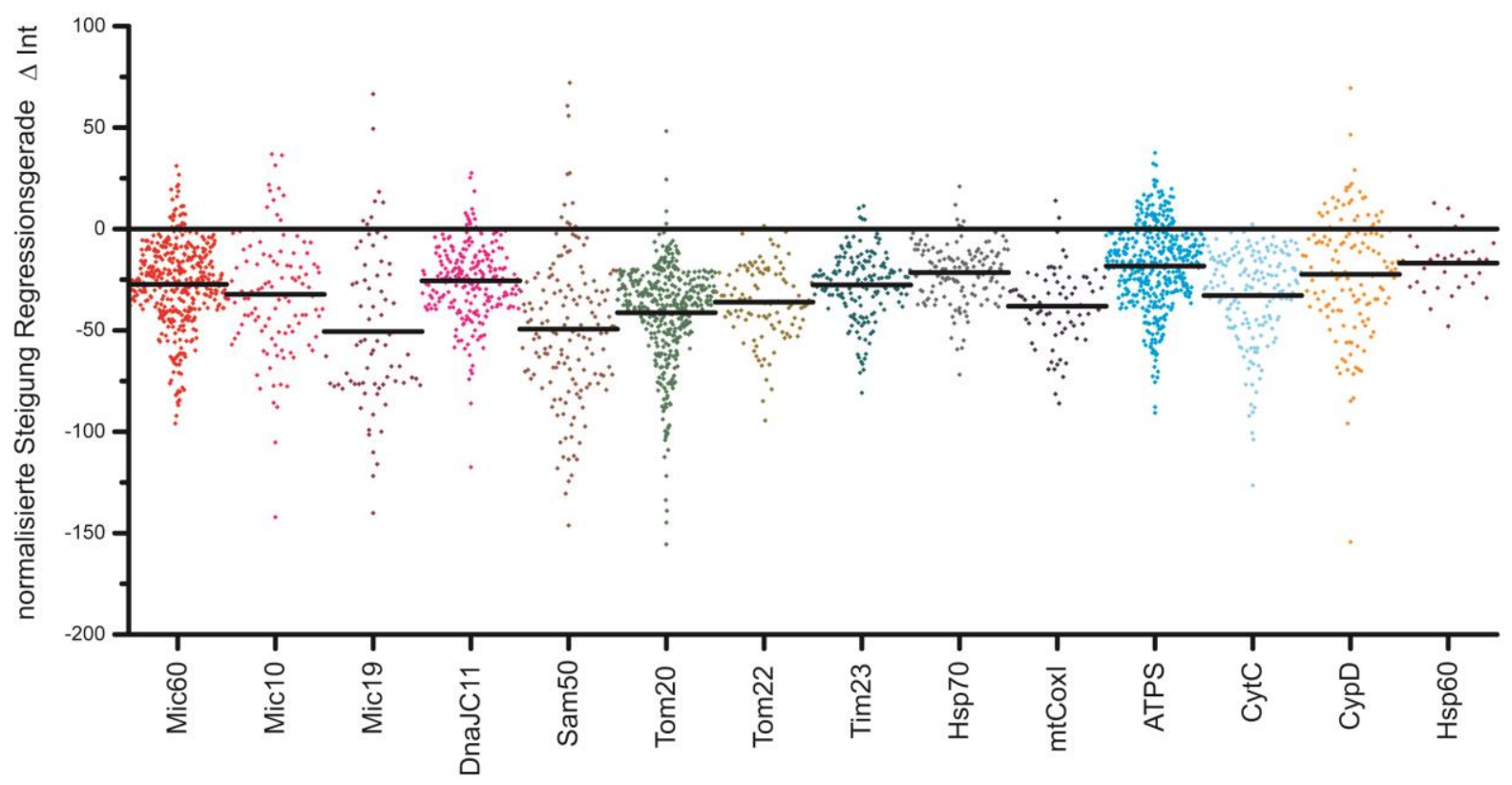

Abbildung 3.6: Subzelluläre Verteilungen einer Vielzahl mitochondrialer Proteine zeigen eine Gradientenverteilung. Im Graphen wurde die Steigung der Regressionsgerade als Gesamtintensitätsänderung der Fluoreszenz pro Zelle, für jede Zelle, geordnet nach den markierten Proteinen, aufgetragen. Die Analyse von 32 bis 445 immunfluoreszenzmarkierten Vero-Zellen pro Protein ergab innerhalb einer Zelle eine hauptsächlich negative Steigung der FluoreszenzIntensitätsänderung. Die Zahl der analysierten Zellen entspricht der Anzahl der Quadrate. Die schwarzen Balken geben den Mittelwert aller Zellen wieder. Verschiedene mitochondriale Proteine, aus unterschiedlichen mitochondrialen Subkompartimenten, besitzen dementsprechend eine Gradientenverteilung innerhalb von Vero-Zellen. 
Das Vorhandensein einer heterogenen Verteilung in Form eines intrazellulären Gradienten mitochondrialer Proteine wurde somit für verschiedenste mitochondriale Proteine, die unterschiedliche Funktionen und sub-mitochondriale Lokalisationen aufwiesen, beobachtet.

Interessanterweise besaßen alle untersuchten Komponenten des MICOS-Komplexes eine Gradientenverteilung. Dies könnte bedeuten, dass die Anzahl der Cristae Junctions in Zellkernnähe höher ist als in der Zellperipherie. Außerdem gibt dies einen Hinweis darauf, dass auch die Dichte und Anzahl mitochondrialer Cristae, und somit wohlmöglich auch die ATP-Produktion, innerhalb einer Zelle ungleich ist. Diese Beobachtung lässt die Vermutung entstehen, dass mitochondriale Proteinverteilungen auf unterschiedliche Energieansprüche innerhalb von Zellen angepasst werden können.

Anhand der Beobachtung, dass alle analysierten Proteine des mitochondrialen Import-Apparates eine Gradientenverteilung aufwiesen, lässt sich vermuten, dass der Import mitochondrialer Proteine innerhalb der Zelle nicht gleichmäßig stattfindet, sondern in der Nähe des Zellkerns eher als am Rand der Zelle erfolgt. Dies könnte zum einen den Erwartungen entsprechen, dass generell mehr Proteinimport in Zellkernnähe stattfindet, weil dort wohlmöglich auch eine höhere Konzentration an mRNA vorliegt und erhöhte Proteintranslation erfolgt. Zum anderen könnte dies auch eine Anpassung an unterschiedliche Energieansprüche darstellen.

Dies bestätigen könnte auch die Beobachtung, dass die analysierten Atmungskettenkomplexproteine eine Gradientenverteilung aufwiesen. Diese verfügten auch über eine größere Proteinmenge in den perinukleären Mitochondrien als in den peripheren.

Des Weiteren wurde eine Gradientenverteilung des Proteins Mff, welches in der mitochondrialen Teilung involviert ist, beobachtet. Auch dieses Ergebnis wäre so nicht zu erwarten gewesen, da bislang keine subzellulären Unterschiede der Menge mitochondrialer Teilungsproteine beobachtet wurden.

Da für alle analysierten mitochondrialen Proteine gleichermaßen eine Gradientenverteilung innerhalb von Zellen beobachtet werden konnte und keine Unterschiede zu erkennen waren, wurden alle weiteren Untersuchungen zur Heterogenität mitochondrialer Proteinverteilungen im Rahmen dieser Arbeit anhand des Proteins Tom20 durchgeführt.

Aus der Erkenntnis, dass eine Vielzahl mitochondrialer Proteine eine heterogene Verteilung in Form von Gradienten besitzt, ergaben sich viele weitere Fragen. Eine bedeutende Frage, die im Rahmen dieser Arbeit beantwortet werden sollte, war wie diese deutlich ausgeprägte Gradientenverteilung trotz der Dynamik dieser Organellen existieren kann. 


\subsection{Untersuchung mitochondrialer Dynamik im Kontext der} Heterogenität von Proteinverteilungen

Mitochondrien sind sehr dynamische Organellen, die sich durch fortwährende Fusions-, Teilungs- und Bewegungsvorgänge auszeichnen. Diese Prozesse tragen maßgeblich zu der schnellen Veränderung der Erscheinung ihres Netzwerks bei.

Mikroskopische Studien zur Untersuchung dieser Dynamik lieferten widersprüchliche Beobachtungen. Zum einen gibt es eine Reihe von Veröffentlichungen, die andeuten, dass sich der mitochondriale Inhalt innerhalb einer Stunde komplett vermischt und das mitochondriale Netzwerk kontinuierlich ist (Karbowski, Arnoult et al. 2004, Karbowski, Jeong et al. 2004, Twig, Elorza et al. 2008). Hierzu wurde eine Vielzahl an Zellinien unter Verwendung des photoaktivierbaren PA-GFPs analysiert. Wäre das mitochondriale Netzwerk kontinuierlich, würde die mitochondriale Dynamik innerhalb kurzer Zeit zu einer Homogenisierung des mitochondrialen Inhalts führen. Es ist schwer vorstellbar, wie die Gradientenverteilung mitochondrialer Proteine trotzdem existieren kann.

Andere Studien machten gegensätzliche Beobachtungen. Sie zeigten mit Hilfe verschiedener Mikroskopieansätze, dass das mitochondriale Netzwerk innerhalb einer Zelle nicht kontinuierlich ist (Collins, Berridge et al. 2002, Ivanchenko, Rocker et al. 2005). Hierzu wurden unterschiedliche Zellen und Methoden, wie z.B. FRAP mit DsRed und das photokonvertierbare EosFP, verwendet. Zu diesen unterschiedlichen Beobachtungen könnte es aufgrund der Verwendung verschiedener Zelllinien und Methoden/fluoreszierender Proteine, sowie Bedingungen bei der Durchführung der Experimente kommen.

Im Rahmen dieser Arbeit sollte dementsprechend der Einfluss mitochondrialer Dynamik auf mitochondriale Proteinverteilungen in Vero-Zellen untersucht werden.

Die mitochondriale Dynamik des gesamten Netzwerks wurde mittels zweier unterschiedlicher Ansätze untersucht. Zum einen wurde die Verteilung von Mitochondrien mit Hilfe des photokonvertierbaren fluoreszierenden Proteins EosFP, zum anderen mit Hilfe des rot fluoreszierenden Proteins DsRed, analysiert. Beide Proteine wurden genetisch an eine kurze Sequenz fusioniert (mitochondriale targeting Sequenz von CoxVIII), wodurch sie in der mitochondrialen Matrix lokalisierten und in Vero-Zellen transient exprimiert wurden. 


\subsubsection{Untersuchung mitochondrialer Dynamik mit EosFP}

Das photokonvertierbare Protein EosFP eignet sich gut um die Dynamik von Mitochondrien lebender Zellen zu analysieren und wurde bereits erfolgreich zu diesem Zweck eingesetzt (Ivanchenko et al. 2005). Es zeichnet sich durch seine Eigenschaft aus, die ursprüngliche Fluoreszenz im grünen Wellenlängenbereich nach Bestrahlung mit Licht aus dem UV-Bereich, in Fluoreszenz des roten Wellenlängenbereichs zu schalten (Wiedenmann et al. 2004). Somit ermöglicht es die Beobachtung der Verteilung der roten Fluoreszenz des geschalteten Proteins innerhalb kleiner, abgegrenzter Bereiche über längere Zeiträume. Für die Untersuchung im Rahmen dieser Arbeit, wurde EosFP in Vero-Zellen mitochondrial exprimiert (siehe M\&M 2.2.3). Die mitochondriale Dynamik in lebenden Zellen, welche sich durch grüne Fluoreszenz in den Mitochondrien identifizieren ließen, wurde nun konfokalmikroskopisch untersucht.

Um beantworten zu können, ob die mitochondriale Dynamik tatsächlich den Inhalt aller Mitochondrien von Vero-Zellen nach ca. einer Stunde durchmischt, wurden kleine Bereiche der Mitochondrien innerhalb der Zelle mit einem UV-Laser lokal begrenzt photokonvertiert. Nachfolgend wurde die Verteilung der roten Fluoreszenz innerhalb der Zelle untersucht. Aufgrund von mitochondrialer Dynamik, konnte bereits nach 5 min nach dem UV-Schalten eine gewisse Verbreiterung der roten Fluoreszenz des ursprünglich geschalteten Bereichs auf umliegende Mitochondrien beobachtet werden (Abbildung 3.7). Daraufhin wurden die Zellen wieder, zur Erhaltung ihrer Lebensfähigkeit, bei Standardbedingungen kultiviert. 50 min nach dem ursprünglichen Schalten der Fluoreszenz wurden sie erneut mikroskopiert und die Verteilung der roten geschalteten Fluoreszenz nach diesem Zeitraum innerhalb der Zelle untersucht. Es konnte beobachtet werden, dass sich die rote Fluoreszenz nur minimal gegenüber dem 5 min Wert verbreitert hat und sich nicht auf die gesamten Mitochondrien der Zelle verteilt hat (Abbildung 3.7). Diese Beobachtung konnte im gleichen Maße für eine Reihe weiterer Zellen gemacht werden. Diese Ergebnisse deuten darauf hin, dass die Dynamik von Mitochondrien in Vero-Zellen derart stattfand, dass die Vermischung von mitochondrialem Inhalt nur innerhalb eines relativ kleinen abgegrenzten Bereiches erfolgte. Sie bewirkte nicht eine vollständige Homogenisierung des Gehalts von Mitochondrien.

Das mitochondriale Netzwerk von Vero-Zellen besitzt folglich eine limitierte Kontinuität. Somit ist es möglich, dass eine ausgeprägte Gradientenverteilung mitochondrialer Proteine trotz mitochondrialer Dynamik existieren kann. 

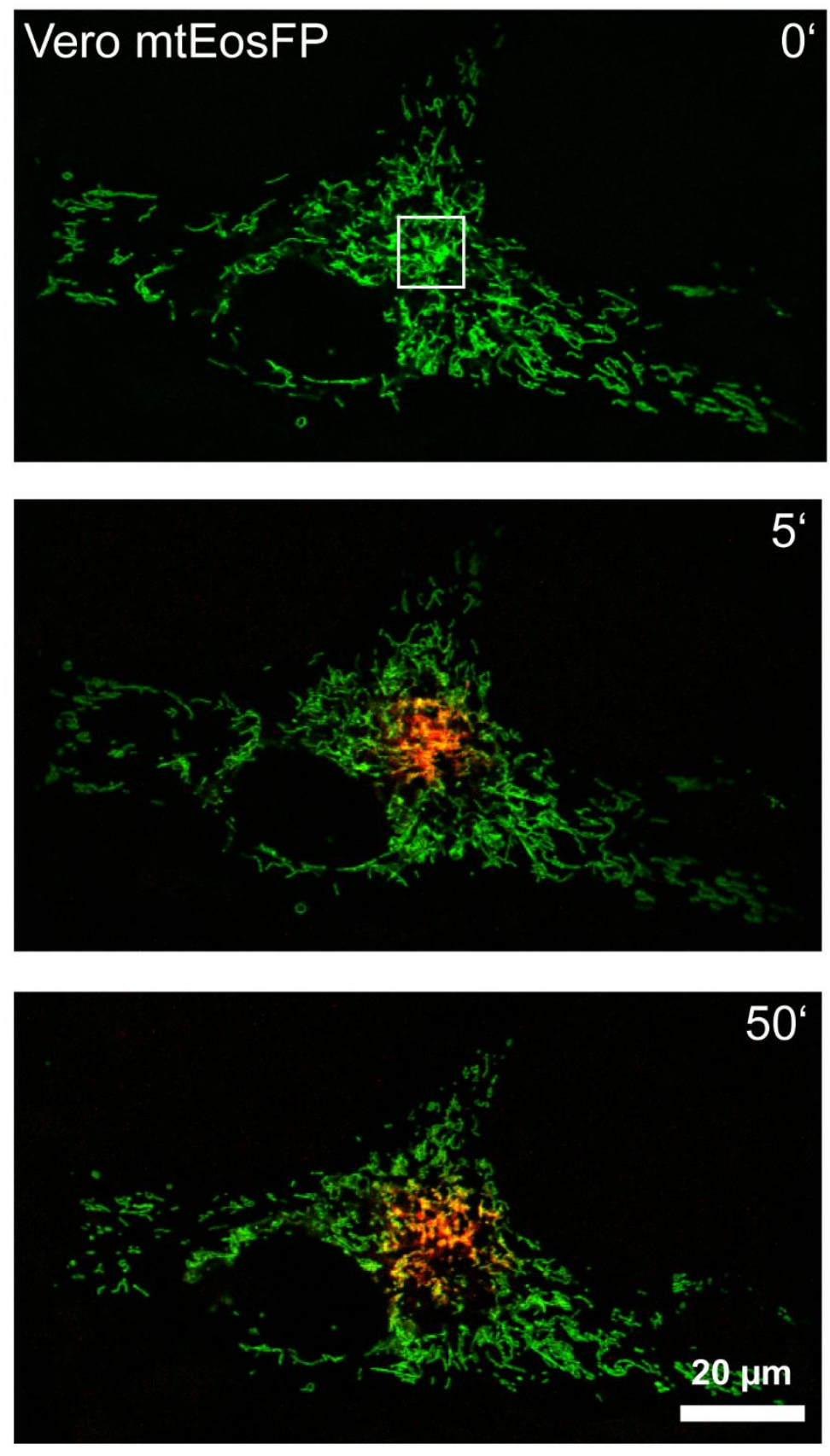

\subsubsection{Untersuchung mitochondrialer Dynamik mit DsRed}

Die Dynamik von Mitochondrien wurde anschließend mit Hilfe des rot fluoreszierenden Proteins DsRed und einer veränderten experimentellen Durchführung analysiert.

Für diesen Ansatz wurde DsRed in der mitochondrialen Matrix von Vero-Zellen exprimiert. Die transfizierten Zellen wurden an einem speziellen, für die Lebend-Mikroskopie von Säugerzellen geeigneten Epifluoreszenzmikroskop, untersucht. Dieses verfügte über eine temperierbare, 
thermisch isolierte Klimakammer, welche die Betrachtung der Veränderungen des mitochondrialen Netzwerks über längere Zeiträume ermöglichte (siehe M\&M 2.2.3). Die Auswertung der Dynamik einzelner Mitochondrien lieferte dabei folgende Ergebnisse:

\begin{tabular}{|l|c|}
\hline & Mittelwert \\
\hline insgesamt zurückgelegte Strecke $(\mu \mathrm{m} / \mathrm{h})$ & 27.2 \\
\hline maximale Entfernung vom Anfangspunkt $(\mu \mathrm{m} / \mathrm{h})$ & 5.4 \\
\hline Strecke Anfangs- bis Endpunkt $(\mu \mathrm{m} / \mathrm{h})$ & 4.6 \\
\hline durschnittliche Entfernung $(\mu \mathrm{m})$ pro 30s & 0.24 \\
\hline $\begin{array}{l}\text { Verhältnis maximal zurückgelegte Strecke eines } \\
\text { Mitochondriums/ Gesamtzellengröße }(\%) \text { pro 1 h }\end{array}$ & 7.4 \\
\hline Maximale Zellausdehnung gesamt $(\mu \mathrm{m})$ & 73.7 \\
\hline
\end{tabular}

Tabelle 3.1: Ergebnisse der Auswertung der Bewegung einzelner Mitochondrien.

Die Bewegung einzelner Mitochondrien $(n=20)$ wurde in $m t D s R e d$ exprimierenden Vero-Zellen über eine Stunde verfolgt. Die Auswertung erfolgte mit dem Manual Tracking-Plugin der Software Fiji. Generell veränderte sich die Position eines Mitochondriums innerhalb des beobachteten Zeitraums nur um ca. 7,4 \% der Gesamtzellfläche und zeigt somit eine lokal begrenzte Beweglichkeit.

Beispielhaft ist solch eine Verfolgung einzelner Mitochondrien über den Verlauf einer Stunde in Abbildung 3.8 dargestellt.

Auch mit dieser Methode, konnte beobachtet werden, dass sich die Positionen von Mitochondrien über den Zeitraum von $1 \mathrm{~h}$ nur lokal begrenzt verändert haben. Es konnte für kein Mitochondrium eine völlig freie Beweglichkeit innerhalb des gesamten Netzwerks oder eine Positionsänderung über die gesamte Zelle festgestellt werden (Abbildung 3.8). Die Mitochondrien veränderten ihre Position nach einer Stunde im Mittel nur um $7,4 \%$ der gesamten Zellfläche, wobei die insgesamt zurückgelegte Strecke immerhin $~ 37 \%$ der Gesamtzellgröße betrug (Tabelle 3.1). Das lässt den Schluss zu, dass die Mitochondrien zwar sehr beweglich wirkten, ihre ursprüngliche Ausgangsposition aber kaum verlassen haben, sondern vielmehr ein "Schwingen“ um den Ausgangspunkt stattgefunden haben muss.

Weiterhin konnte beobachtet werden, dass sich periphere Mitochondrien häufig schneller bewegt haben als perinukleäre Mitochondrien. Außerdem wurden kleine Unterschiede bezüglich der Richtung der Bewegung der Mitochondrien gefunden. In der Nähe des Kerns lokalisierte Mitochondrien vollzogen hauptsächlich laterale Bewegung radial um den Kern herum, wohingegen Mitochondrien der Zellperipherie oftmals auch sehr schnelle orthogonale Bewegung, also senkrecht zum Kern, durchgeführt haben. Diese schnellen Mitochondrien waren jedoch über den gesamten Beobachtungszeitraum vom Netzwerk isoliert. 


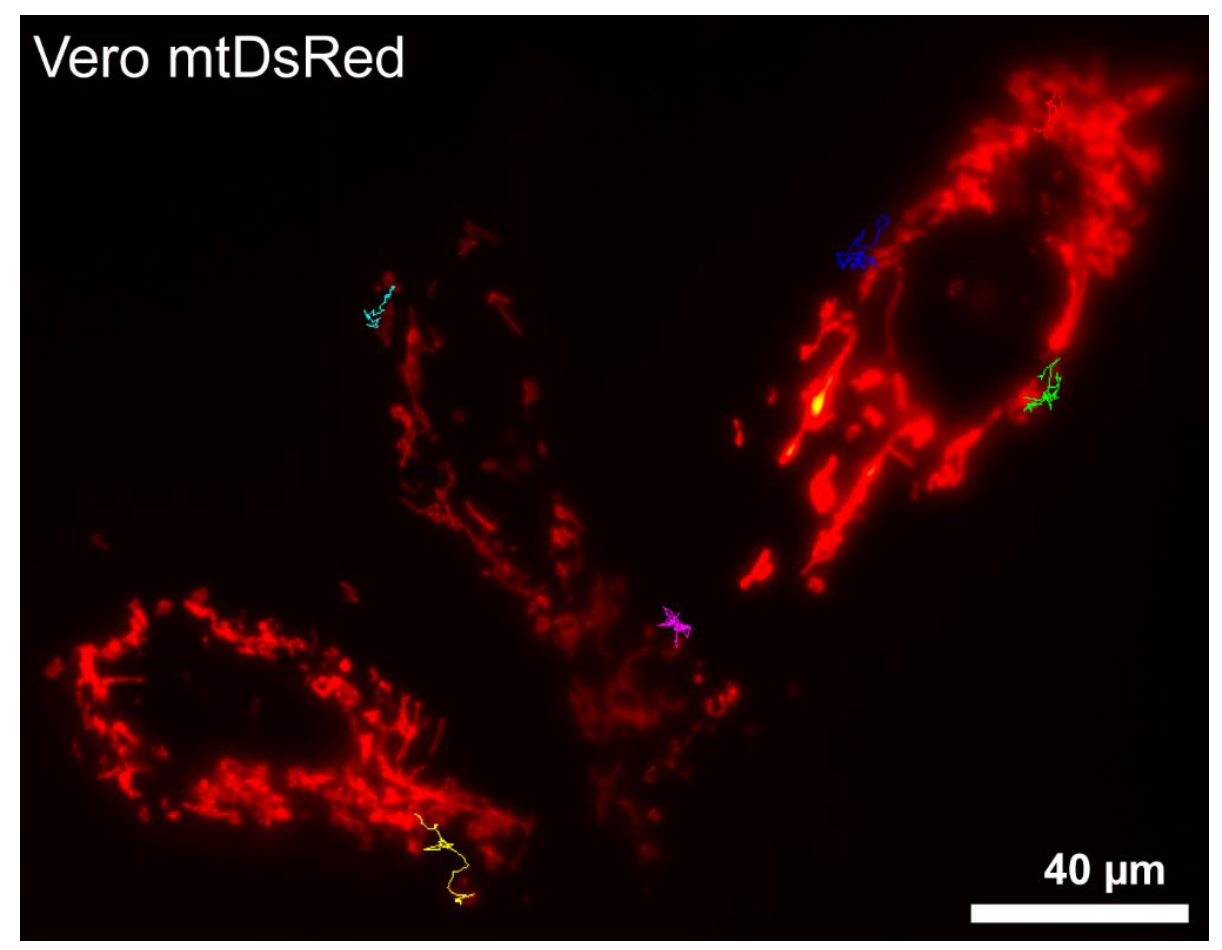

Abbildung 3.8: Einzelne Mitochondrien werden aufgrund mitochondrialer Dynamik nur örtlich begrenzt transloziert. Lebend-Zell-Mikroskopie des mitochondrial exprimierten DsRed-Proteins erlaubte die Verfolgung der Position einzelner Mitochondrien von Vero-Zellen über eine Stunde. Durch die Aufnahme eines Bildes alle 30 Sekunden entstanden Videosequenzen der mitochondrialen Dynamik. Die Position einzelner Mitochondrien wurde über die Zeit verfolgt. Die farblich dargestellten Trajektorien mitochondrialer Ortsveränderungen wurden hier mit der DsRedFluoreszenz überlagert. Deutlich zu sehen ist die örtlich begrenzte Verbreitung der analysierten Mitochondrien. Für die Aufnahme wurde Epifluoreszenzmikroskopie angewandt.

Die Dynamik einzelner Mitochondrien erfolgte in lokal begrenzter Weise. Somit ist es vorstellbar, dass diese Art mitochondrialer Dynamik nicht zu einem Verlust heterogener mitochondrialer Proteinverteilungen führt. Deshalb ist es möglich, dass die Heterogenität mitochondrialer Proteinverteilungen trotz mitochondrialer Dynamik existieren kann.

Die Prozesse der mitochondrialen Fusion und Teilung sind entscheidend an der Formveränderung des mitochondrialen Netzwerkes beteiligt. Mitochondrien können im Laufe ihres Lebenszyklus eine Reihe unterschiedlicher Formen annehmen. Im Extremfall können sie hyperfusionieren oder fragmentieren. Dies geschieht oft als Ergebnis einer Anpassung dieser Organellen an verschiedene Stresssitutationen. Deshalb war ein Ziel dieser Arbeit zu untersuchen, welchen Einfluss die Hyperfusion oder Hyperfragmentierung von Mitochondrien auf die Verteilung mitochondrialer Proteine hat. 


\subsection{Untersuchung des Einflusses mitochondrialer Morphologie auf die}

\section{Heterogenität mitochondrialer Proteinverteilung}

Zur Untersuchung des Einflusses mitochondrialer Elongation und Fragmentierung auf die Heterogenität mitochondrialer Proteine, wurde die Verteilung des mitochondrialen Tom20-Proteins in Fusions- und Teilungs-defizienten Vero-Zellen analysiert.

\subsubsection{Der Verlust mitochondrialer Fusions- und Teilungsfähigkeit hat deutliche} Auswirkungen auf die mitochondriale Morphologie

Die Herunterregulierung des mitochondrialen Teilungsproteins Drp1 führt zu extrem hyperfusionierten und elongierten Mitochondrien (Lee et al. 2004). Entsprechend können fragmentierte Mitochondrien bei Herunterregulierung des mitochondrialen Fusionsproteins Mfn2 beobachtet werden (Chen et al. 2005). Zellen, die fragmentierte bzw. elongierte/hyperfusionierte Mitochondrien besaßen, wurden im Rahmen dieser Arbeit durch Herunterregulierung der Menge des Fusionsproteins Mfn2 (Mitofusin2) beziehungsweise des Teilungsproteins Drp1 (Dynamin related protein 1), erhalten. Dies wurde mit Hilfe der RNA-Interferenz-Technologie (RNAi) erzielt. Hierzu wurden die Zellen jeweils mit einem Plasmid transfiziert, welches eine spezielle shRNA (small-hairpin RNA) kodierte.

Für die Analyse der Drp1-/Teilungsdefizienten Zellen wurde das pREP4-Drp1-shRNA-Plasmid, welches bereits beschrieben und gut charakterisiert wurde (Lee et al. 2004), verwendet. Drp1herunterregulierte Zellen konnten eindeutig durch Immunfluoreszenzmarkierung des mitochondrialen Tom20-Proteins identifiziert werden. Sie wiesen die charakteristische elongierte und hyperfusionierte Mitochondrienmorphologie auf (Abbildung 3.9) (Lee et al. 2004).

Fusions-defiziente Zellen wurden durch Transfektion von Vero-Zellen mit dem pGIPZ-Mfn2-shRNAPlasmid erhalten. Eine Immunfluoreszenzmarkierung gegen das Mfn2-Protein ließ danach eine Aussage über die tatsächliche Reduzierung seiner Proteinmenge, also ob die Herunterregulation funktioniert hat, zu. Des Weiteren konnten Mfn2-herunterregulierte Zellen aufgrund der deutlich veränderten Mitochondrienmorphologie identifiziert werden. Diese wies in Fusions-defizienten Zellen eine starke Fragmentierung des Netzwerks sowie eine deutliche Verkürzung individueller Mitochondrien, wie sie für Mitofusin-defiziente Zellen zu erwarten ist, auf (Abbildung 3.9) (Chen et al. 2003). Weiterhin wurde sowohl für Drp1- und Mfn2-Knockdown eine deutliche Vergrößerung der Zellen beobachtet, was auf eine gestörte Fähigkeit der Zellteilung hindeutet. 

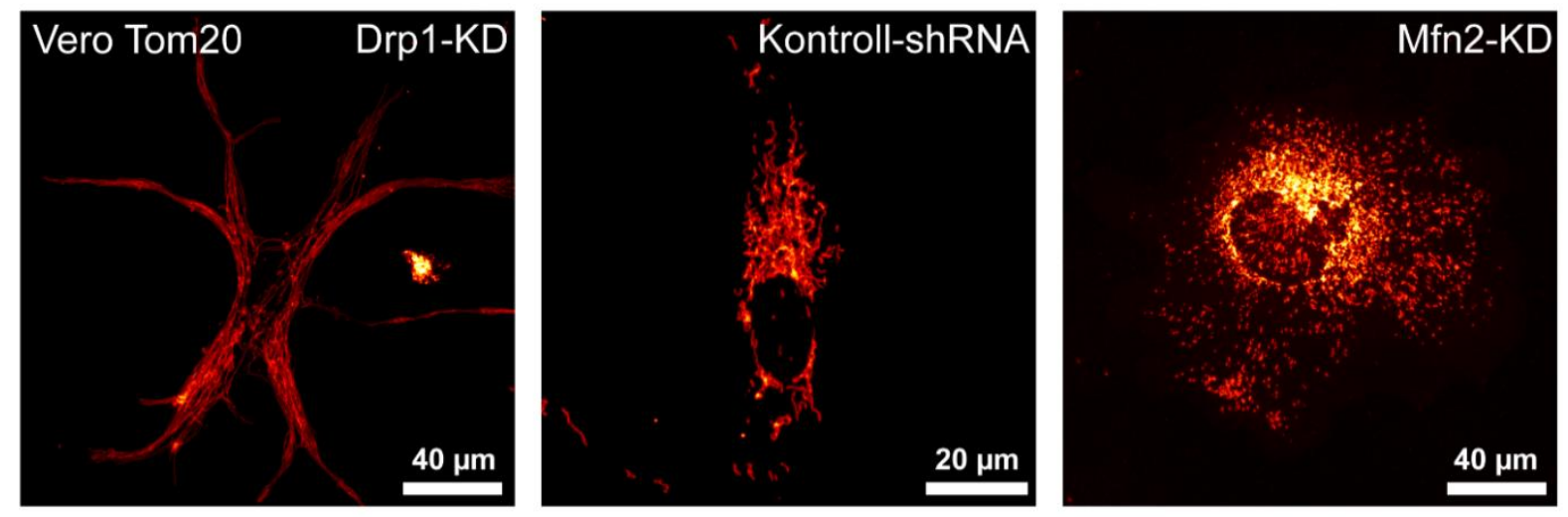

Abbildung 3.9: Inhibierung mitochondrialer Fusion und Teilung verändert die mitochondriale Morphologie.

Der Verlust des Drp1-Proteins führte zu elongierten und hyperfusionierten Mitochondrien in Vero-Zellen. Der Verlust von Mfn2 erzeugte stark fragmentierte und verkürzte Mitochondrien. Die Transfektion von Vero-Zellen mit Negativkontroll-shRNA ergab keine Morphologieänderung von Mitochondrien. Mitochondrien wurden durch Immunfluoreszenzmarkierung von Tom20 sichtbar gemacht. Abgebildet sind Maximalprojektionen konfokaler z-Stapel.

\subsubsection{Die Elongation von Mitochondrien hat Auswirkungen auf die}

\section{Gradientenverteilung eines mitochondrialen Proteins}

Anschließend wurde die Tom20-Proteinverteilung in diesen Zellen auf das Vorhandensein einer Gradientenverteilung untersucht. Dies erfolgte zunächst mit der Intensitätsanalyse auf konfokalmikroskopischen Aufnahmen. Die Auswertung von 79 Drp1-defizienten Zellen (kurz Drp1-KD) bzw. 22 Mfn2-defizienten Zellen (kurz: Mfn2-KD) und der Vergleich mit 35 Negativkontroll-shRNA transfizierten Zellen zeigte, dass der Mittelwert der Steigung der Regressionsgeraden, also der Gesamtintensitätsänderung pro Zelle, über alle Drp1-herunterregulierten Zellen gegenüber Zellen, die mit Negativkontroll-shRNA transfiziert wurden, signifikant verringert war (Abbildung 3.10). Das bedeutet, dass die Drp1-Herunterregulierung und somit die Elongation von Mitochondrien eine Verringerung des Ausmaßes der Gradientenverteilung bewirkt hatte. Beim Vergleich der Mittelwerte der Fluoreszenzintensitätsänderung über alle Mfn2-KD- und Negativkontroll-shRNA-Zellen miteinander, so war zu beobachten, dass die Gesamtänderung der Fluoreszenzintensität in Mfn2-KDZellen mit hyperfragmentierten Mitochondrien unverändert gegenüber den Kontroll-Zellen war (Abbildung 3.10). 


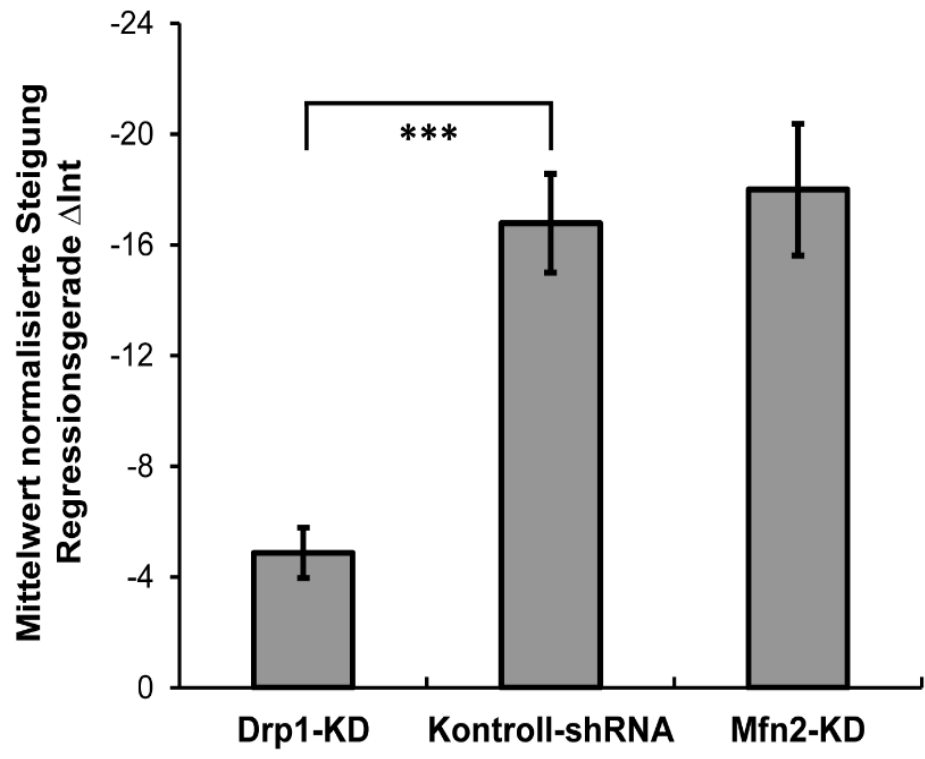

Abbildung 3.10: Die Hyperfusionierung und Elongation von Mitochondrien verändert mitochondriale Proteinverteilungen.

Die Untersuchung der gesamten Tom20Fluoreszenzintensitätsänderung von VeroZellen mit stark elongierten Mitochondrien (Drp1-KD) auf konfokalmikroskopischen Daten ergab eine signifikante Reduzierung der mittleren Intensitätsveränderung über die gesamte Zelle und somit eine Verringerung der intrazellulären Tom20Gradientenverteilung. Im Gegensatz hierzu bewirkte die Fragmentierung von Mitochondrien aufgrund inhibierter mitochondrialer Fusion keine Veränderung des Tom20-Gesamt-Intensitätsunterschiedes in der Zelle (Mfn2-KD). Für die Untersuchung wurden überlappende Mitochondrien von der Auswertung ausgeschlossen. Abgebildet sind Mittelwerte und Standardfehler. ${ }^{* * *} \mathrm{P}=$ 0,001 (t-Test bei zwei unabhängigen Stichproben).

Die Beobachtung der Verringerung der Gradientenverteilung eines mitochondrialen Proteins bei stark elongierten Mitochondrien aufgrund des Verlusts mitochondrialer Teilungsfähigkeit wurde weiterhin mittels der STED-Mikroskopie untersucht. Dies wurde durchgeführt, um die tatsächliche Proteincluster-Verteilung beobachten zu können. Hierzu wurden mehrere Bereiche (mind. 20) einzelner perinukleärer Mitochondrien mit Bereichen einzelner peripherer Mitochondrien von Drp1KD- und untransfizierten Kontroll-Vero-Zellen, hinsichtlich ihrer Tom20-Proteinclusterverteilung, vergleichend betrachtet. Die Kontrollzellen wiesen deutliche Unterschiede in der Dichte der Tom20Proteincluster zwischen perinukleären und peripheren Mitochondrien auf (Abbildung 3.11 linke Spalten). In den Drp1-herunterregulierten Vero-Zellen mit den stark elongierten Mitochondrien wurden kaum Unterschiede der Tom20-Proteinclusterdichte von peripheren und perinukleären Mitochondrien beobachtet (Abbildung 3.11 rechte Spalten). Die Ergebnisse der Intensitätsauswertung konfokalmikroskopischer Bildaufnahmen wurden somit bestätigt. 

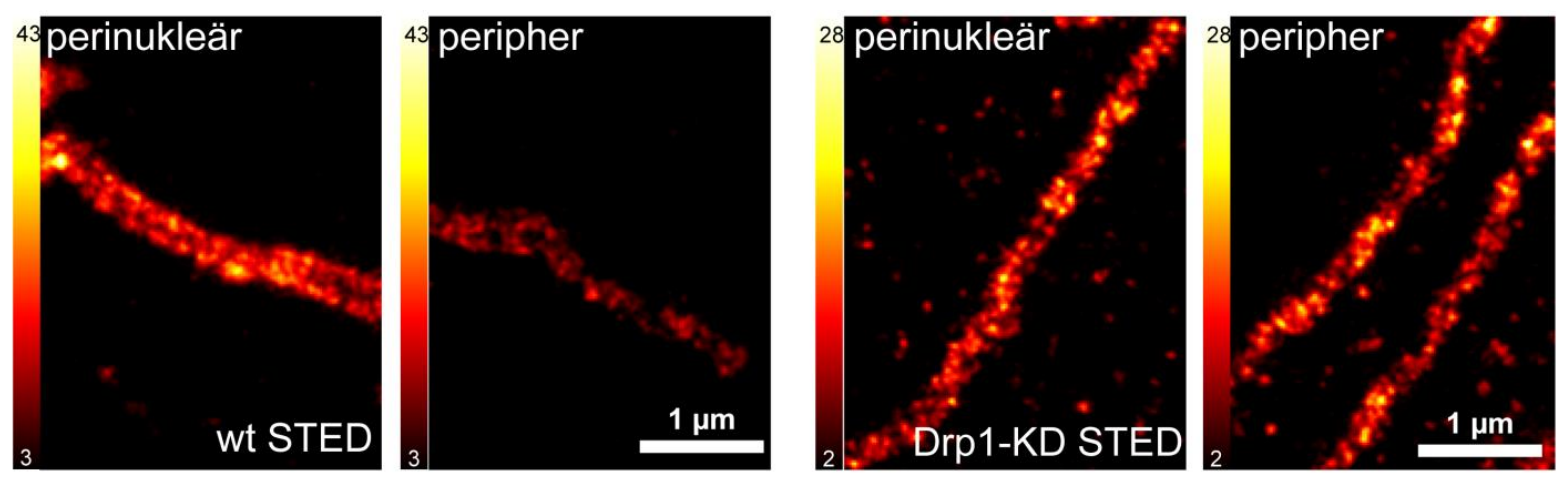

Abbildung 3.11: Die Elongation von Mitochondrien verändert submitochondriale Proteinverteilungen.

Die Reduzierung der Heterogenität von Tom20-Proteincluster-Verteilungen über eine Zelle bei Elongation von Mitochondrien, aufgrund des Verlusts mitochondrialer Teilungsfähigkeit, wurde mittels STED-Mikroskopie visualisiert. In untransfizierten Kontrollzellen (wt) unterschied sich die Dichte mitochondrialer Proteincluster perinukleärer Mitochondrien deutlich von der Dichte in peripheren Mitochondrien, wobei sie in Drp1-KD-Zellen ähnlich ist. Das Experiment wurde insgesamt zwei Mal durchgeführt. Die Bilder wurden nachträglich geglättet. Die Farbtabellen peripherer und perinukleärer Mitochondrien sind identisch.

\subsubsection{Innerhalb einzelner elongierter Mitochondrien existiert keine}

\section{Gradientenverteilung von Tom20}

Der Vergleich der Tom20-Proteindichte perinukleärer Mitochondrien mit der von peripheren Mitochondrien in Zellen mit unterbundener mitochondrialer Teilungsfähigkeit ergab, dass zwischen diesen Bereichen ein nur noch sehr geringer Unterschied besteht. Bedenkt man in diesem Zusammenhang die Tatsache, dass die Drp1-herunterregulierten Zellen über extrem elongierte Mitochondrien verfügen, die oftmals direkt vom Zellkern bis zum Rand der Zelle durchgängig verlaufen, so kommt die Frage auf, ob auf diesen elongierten Drp1-KD-Mitochondrien eine heterogene Verteilung der Tom20-Proteinmenge, in Form eines Dichtegradienten, zu beobachten ist. Diese Frage wurde mit Hilfe konfokaler Mikroskopiedaten untersucht. Bei Betrachtung der Aufnahmen war auf den Drp1-KD-Zellen keine Gradientenverteilung der Tom20-Fluoreszenzintensität zu beobachten (Abbildung 3.12). Das bedeutet, dass durch die starke Elongation aufgrund der Inhibierung mitochondrialer Teilung auch auf einzelnen Mitochondrien eine deutlich reduzierte Heterogenität in der Verteilung des Tom20-Proteins existierte. 


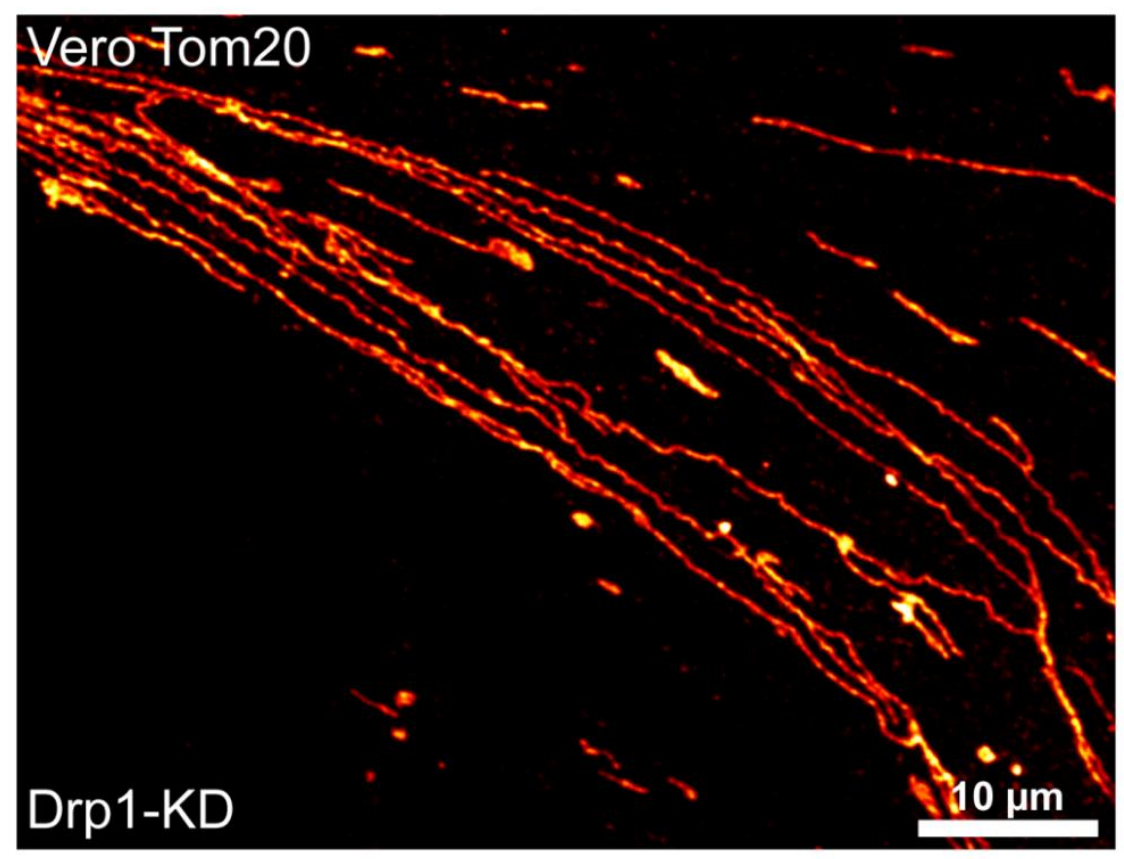

Abbildung 3.12: Auf einzelnen elongierten Mitochondrien von Drp1-KD-Zellen existiert keine Tom20-Gradientenverteilung. Die Verteilung von Tom20 auf einzelnen elongierten Mitochondrien von Teilungsgehemmten Vero-Zellen weist keine deutliche Heterogenität auf. Hierbei handelt es sich um eine Konfokalaufnahme. Untersucht wurden insgesamt mindestens 100 Einzelmitochondrien.

Somit wurde im Rahmen dieser Arbeit gezeigt, dass die Gradientenverteilung von Tom20 innerhalb von Zellen mit hyperfusionierten elongierten Mitochondrien gegenüber normalen Zellen mit intakter mitochondrialer Teilungsfähigkeit entscheidend vermindert ist. Die Hyperfragmentierung von Mitochondrien durch Mfn2-Herunterregulierung veränderte diese Heterogenität nicht.

Daraus lässt sich schlussfolgern, dass mitochondriale Teilung einen Beitrag zur Heterogenität mitochondrialer Proteinverteilungen leistet.

Mitochondriale Fusion und Teilung prägen das äußere Erscheinungsbild von Mitochondrien. Im Verlauf des Zellzyklus kann sich dieses deutlich verändern und hyperfusionierte oder fragmentierte Mitochondrien erzeugen. Deshalb war ein weiteres Ziel dieser Arbeit zu analysieren, ob sich die Heterogenität mitochondrialer Proteinverteilungen während des Zellzyklus verändert.

\subsection{Untersuchung der Heterogenität mitochondrialer Proteinverteilung} im Laufe des Zellzyklus mammaler Zellen

Die mitochondriale Morphologie kann sich im Laufe des Zellzyklus deutlich verändern (Arakaki et al. 2006, Mitra et al. 2009). Es wurde für NRK-Zellen berichtet, dass am Übergang von der G1- zur SPhase ein hyperfusioniertes mitochondriales Netzwerk vorliegt. Mitochondrien, welche die Mitose und die eigentliche Zellteilung vollziehen, weisen eine stark fragmentierte Morphologie auf. Da im Rahmen dieser Arbeit zuvor gezeigt wurde, dass die Inhibierung mitochondrialer Teilung und dadurch 
die Veränderung mitochondrialer Morphologie, die Gradientenverteilung mitochondrialer Proteine modifiziert, sollte im folgenden Experiment untersucht werden, inwiefern die Veränderungen der mitochondrialen Morphologie, aufgrund des geänderten Gleichgewichts mitochondrialer Dynamik während des Zellzyklus, einen Effekt auf die Heterogenität mitochondrialer Proteinverteilungen haben.

Insbesondere interessant war außerdem die Fragestellung, wie sich die Heterogenität mitochondrialer Proteinverteilungen während der direkten Zellteilung, und somit Fragmentierung und anschließender Aufteilung aller Mitochondrien auf die beiden Tochterzellen, verhält.

\subsubsection{Immunfluoreszenzmarkierungen spezifischer Zellzyklusmarker erlauben} die Zuordnung der Zellzyklusphasen

Um diese Fragestellungen zu bearbeiten, war es zunächst im Rahmen dieser Arbeit nötig, eine Methode zu entwickeln, welche optisch die eindeutige Zuordnung der jeweiligen Phase des Zellzyklus, in der sich eine Zelle bei Fixierung befunden hat, erlaubt. Hierzu eignet sich zum Beispiel die Synchronisierung von Zellkulturen, sodass sich alle Zellen anschließend in der der gleichen Zellzyklusphase befinden. Nach Vorversuchen wurde jedoch von chemischen Methoden zur Synchronisation von Zellkulturen abgesehen, da die hierzu verwendeten Substanzen potenziell einen störenden Effekt auf die mitochondriale Proteinverteilung, sowie die Zell-Lebensfähigkeit haben könnten. Die mechanische Form der Synchronisation von Zellkulturen durch Abschütteln mitotischer Zellen könnte diesbezüglich eine Alternative bieten. Im Rahmen dieser Arbeit wurde diese Methode deshalb getestet; doch die Anzahl der synchronisierten Zellen, die damit erhalten wurde, war zu gering für eine statistisch aussagekräftige Untersuchung. Stattdessen wurde eine Methode entwickelt, um unsynchronisierten Zellen, die jeweils spezifische Zellzyklusphase zuordnen zu können. Dies wurde durch Antikörpermarkierungen (Immunfluoreszenz), zusätzlich zu dem mitochondrialen Protein Tom20, realisiert. Hierzu wurden die Zellzyklusmarker PCNA (proliferatingcell-nuclear-antigen) und AuroB (Aurora B-Kinase) eingesetzt. Diese Proteine weisen eine spezifische Lokalisation in Abhängigkeit von der Phase des Zellzyklus auf, welche mittels Immunomarkierung visualisiert wurde. Diese Methode erlaubte eine eindeutige Zuordnung der Zellzyklusphase zu individuellen Zellen der Vero-Linie (Abbildung 3.13). 

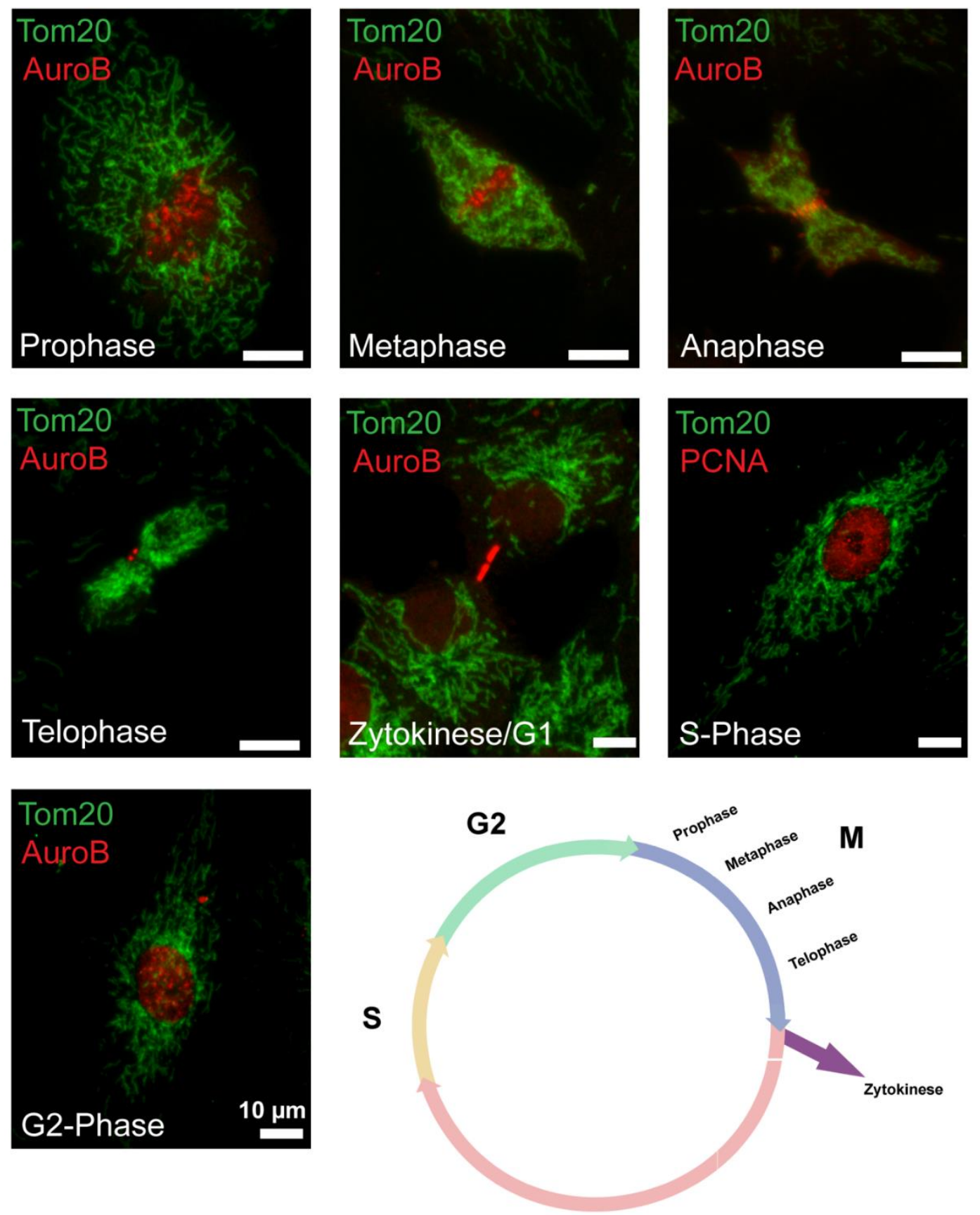

G1

Abbildung 3.13: Die Identifikation der Zellzyklusphase individueller Zellen ist durch Immunfluoreszenzmarkierungen gegen spezifische Zellzyklusmarkerproteine möglich.

Durch Ko-Immunfluoreszenzmarkierungen von Tom20 (grün) und den spezifischen Zellzyklusmarkerproteinen PCNA bzw. AuroB (rot), welche eine bestimmte Lokalisierung in Abhängigkeit von der Zellzyklusphase besitzen, war es möglich individuellen Vero-Zellen die spezifische Zellzyklusphase zuzuordnen. Abgebildet sind Maximalprojektionen konfokaler zStapel. Zur besseren Orientierung ist eine schematische Darstellung des Verlaufs des Zellzyklus dargestellt.

Insbesondere die Zellen in den Phasen der Mitose konnten durch die spezifische Lokalisation von Aurora B-Kinase identifiziert werden (Abbildung 3.13). Während der eigentlichen Zellteilung, also der Trennung beider Tochterzellen voneinander direkt nach der Mitose (auch Zytokinese genannt), 
lokalisierte AuroB im Mittelkörper (midbody). Außerdem assoziierte es während der G2-Phase mit dem Heterochromatin und im Verlauf der Mitose markierte es den Kinetochor. PCNA assoziierte spezifisch während der S-Phase mit den replication foci (Hyde-Dunn et al. 1997, Leonhardt et al. 2000, Murata-Hori et al. 2002, Mora-Bermudez et al. 2007, Mitra et al. 2009, Sagona et al. 2010). Weiterhin konnte mit dieser Methode die deutliche Fragmentierung der Mitochondrien während der Mitose (Metaphase, Anaphase, Telophase) beobachtet werden und somit die Ergebnisse früherer Studien bestätigt werden (Arakaki et al. 2006, Mitra et al. 2009). Es konnte keine deutliche Hyperfusionierung von Mitochondrien am Übergang von der G1- zur S-Phase beobachtet werden. Dies steht im Widerspruch zu der Beobachtung von Mitra et al.. Ein möglicher Grund hierfür kann die Verwendung einer anderen Zelllinie als in dieser Arbeit sein. Eine entscheidende Limitation stellt die Tatsache dar, dass der G1/S-Übergang nicht durch die spezifische Lokalisation eines Zellzyklusmarkers identifiziert werden kann. Somit war es im Rahmen dieser Arbeit nicht möglich Zellen exakt zu diesem Zeitpunkt des Zellzyklus zu beobachten. In der Studie von Mitra et al. wurde eine chemische Synchronisation angewandt, um Zellen im G1/S-Übergang anzureichern, welche im Rahmen der vorliegenden Arbeit vermieden wurde.

Nachdem die Methode zur Identifizierung der Zellzyklusphase individueller Zellen etabliert war, wurde sie verwendet, um die Tom20-Proteinverteilung in Zellen der einzelnen Zellzyklusphasen auf Vorhandensein einer Heterogenität zu untersuchen.

\subsubsection{Mitochondriale Proteine besitzen während der gesamten Interphase eine} heterogene Verteilung

Nach der Zuordnung der spezifischen Zellzyklusphase zu individuellen Zellen, erfolgte die Tom20proteinverteilungsanalyse auf konfokalmikroskopischen Daten, sodass eine Aussage über die mitochondriale Heterogenität zu jeder einzelnen Zellzyklusphase möglich war. Dabei konnte festgestellt werden, dass die Gradientenverteilung des mitochondrialen Tom20-Proteins in allen Phasen der Interphase des Zellzyklus deutlich ausgeprägt war (im gleichen Ausmaß wie sie auch für eine unsynchronisierte Zellkultur beobachtet wurde). Das konnte anhand des Vergleichs der Mittelwerte der Steigung der Regressionsgerade über mindestens 24 Zellen je Zellzyklusphase, beobachtet werden (Abbildung 3.14). 


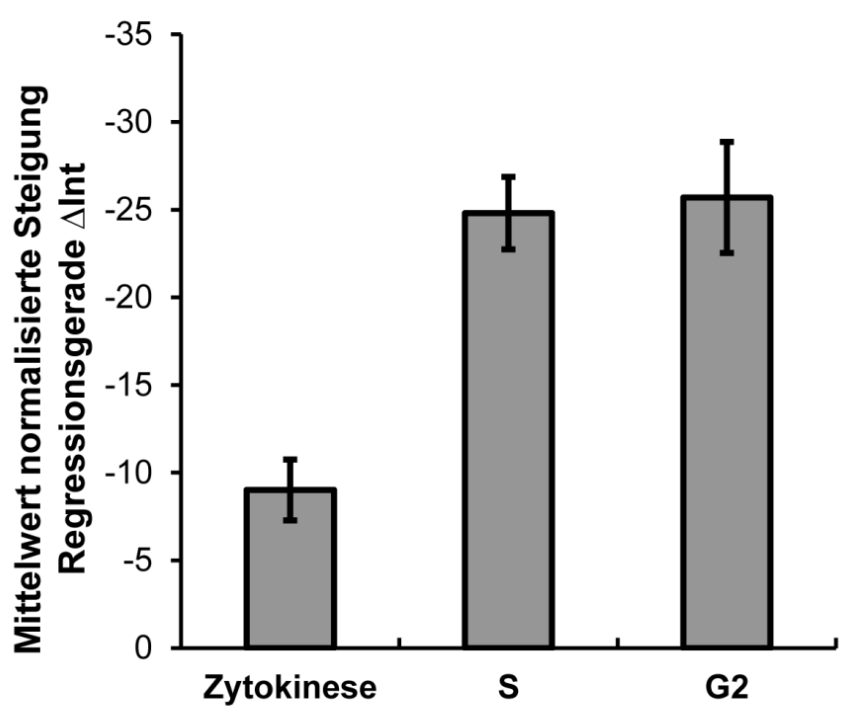

Abbildung 3.14: Die Heterogenität mitochondrialer Proteinverteilungen ist stabil während des gesamten Zellzyklus.

Die Auswertung der Fluoreszenzintensitätsverteilung von je mind. 24 Zellen zeigte, dass eine ausgeprägte Gradientenverteilung von Tom20 während der gesamten Interphase des Zellzyklus vorhanden war. Die Tom20-Proteinverteilung war bereits während der Zytokinese deutlich heterogen. Sie entsprach im Allgemeinen der Heterogenität, wie sie in unsynchronisierten Zellkulturen beobachtet wurde. Für die Analyse wurden überlappende Mitochondrien von der Auswertung ausgeschlossen. Gezeigt sind Mittelwerte und Standardfehler.

Während den einzelnen Phasen der Mitose wurde keine Analyse der Tom20-FluoreszenzIntensitätverteilung durchgeführt. In diesen Phasen wiesen die Mitochondrien eine stark fragmentierte Morphologie sowie eine perinukleäre Aggregierung auf, wodurch keine eindeutige Identifizierung einzelner Mitochondrien möglich war.

Ein interessanter Aspekt dieser Untersuchung, war die Beobachtung, dass in Vero-Zellen, welche sich in der Zytokinese-Phase, also der Trennung von beiden Tochterzellen und somit unmittelbar nach der Aufteilung aller Mitochondrien auf diese Tochterzellen, befunden haben, bereits eine ausgeprägte Gradientenverteilung von Tom20, wie sie normalerweise für eine unsynchronisierte Zellkultur beobachtet wurde, vorhanden war (Abbildungen 3.14).

Diese Beobachtung lässt die Vermutung zu, dass es einen sehr schnellen Mechanismus in Säugerzellen gibt, der direkt nach der Aufteilung aller Mitochondrien auf beide Tochterzellen, aktiv Mitochondrien gezielt spezifisch anordnet und so eine Gradientenverteilung mitochondrialer Proteine erzeugt. Es ist denkbar, dass dies aufgrund der Interaktion von Mitochondrien mit dem Zytoskelett, insbesondere Mikrotubuli, erfolgt. Mitochondrien liegen assoziiert mit Mikrotubuli vor und werden entlang dieses Zytoskelettbestandteils transportiert. Um den Einfluss des mitochondrialen Transports, und somit der Interaktion mit dem Zytoskelett, auf die Heterogenität mitochondrialer Proteinverteilungen zu identifizieren, wurden verschiedene Experimente im Rahmen dieser Arbeit durchgeführt. 


\title{
3.5 Untersuchung des Einflusses der Interaktion von Mitochondrien mit
} Mikrotubuli auf die Verteilung mitochondrialer Proteine

\author{
3.5.1 Die Zerstörung des Mikrotubuli-Zytoskeletts vermindert die \\ Heterogenität mitochondrialer Proteinverteilungen
}

Mitochondrien interagieren vielfältig mit verschiedensten Bestandteilen des Zytoskeletts. Am häufigsten wird eine Assoziation von Mitochondrien mit Mikrotubuli beobachtet (Heggeness et al. 1978, Hollenbeck et al. 2005, Schwarz 2013). Diese Interaktion ermöglicht den Transport von Mitochondrien. Die zuvor erhaltenen Ergebnisse bezüglich der heterogenen Verteilung mitochondrialer Proteine während des Zellzyklus geben eventuell einen Hinweis darauf, dass mitochondrialer Transport ein Aspekt der Entstehung und Aufrechterhaltung dieser Verteilungen ist. Deshalb wurde im Rahmen dieser Arbeit der Einfluss des mitochondrialen Transports über Mikrotubuli auf die Heterogenität mitochondrialer Proteinverteilungen untersucht.

Der mitochondriale Transport wurde zunächst unterbunden, indem die Substanz Nocodazol, welche eine Depolymerisierung von Tubulin-Filamenten bewirkt (Samson et al. 1979), für $48 \mathrm{~h}$ auf VeroZellen inkubiert wurde. Der Verlust von Tubulin-Fasern wurde mittels Immunfluoreszenzmarkierung eindeutig belegt (Abbildung 3.15 A). In unbehandelten Kontrollzellen wiesen die Mitochondrien ein intaktes Netzwerk (sichtbar durch Immunomarkierung gegen Tom20) und Tubulin intakte Filamente (visualisiert durch Immunomarkierung gegen $\alpha$-Tubulin), die über die gesamte Zelle reichten, auf. Nach 48-stündiger Inkubation mit Nocodazol lagen keine Tubulin-Fasern mehr vor, sondern nur noch depolymerisiertes Protein. Des Weiteren waren die Mitochondrien nach dieser Behandlung leicht verkürzt und über die gesamte Zelle verteilt. Sie zeigten nicht mehr die normalerweise zu beobachtende Aggregierung um den Zellkern. Die Nocodazol-behandelten Zellen waren gegenüber den unbehandelten Zellen leicht vergrößert. Durch Nocodazol-Inkubation und somit die Zerstörung der Mikrotubuli werden Zellen am Fortschreiten ihrer Zellteilung gehindert.

Die Analyse der Tom20-Proteinverteilung in diesen Zellen mittels Konfokalmikroskopie und Fluoreszenzintensitätsauswertung ergab, dass das Ausmaß der Gradientenverteilung von Tom20 nach Zerstörung des Mikrotubuli-Zytoskeletts gegenüber unbehandelten Referenzzellen deutlich verringert war (Abbildung $3.15 \mathrm{~B}$ ). 

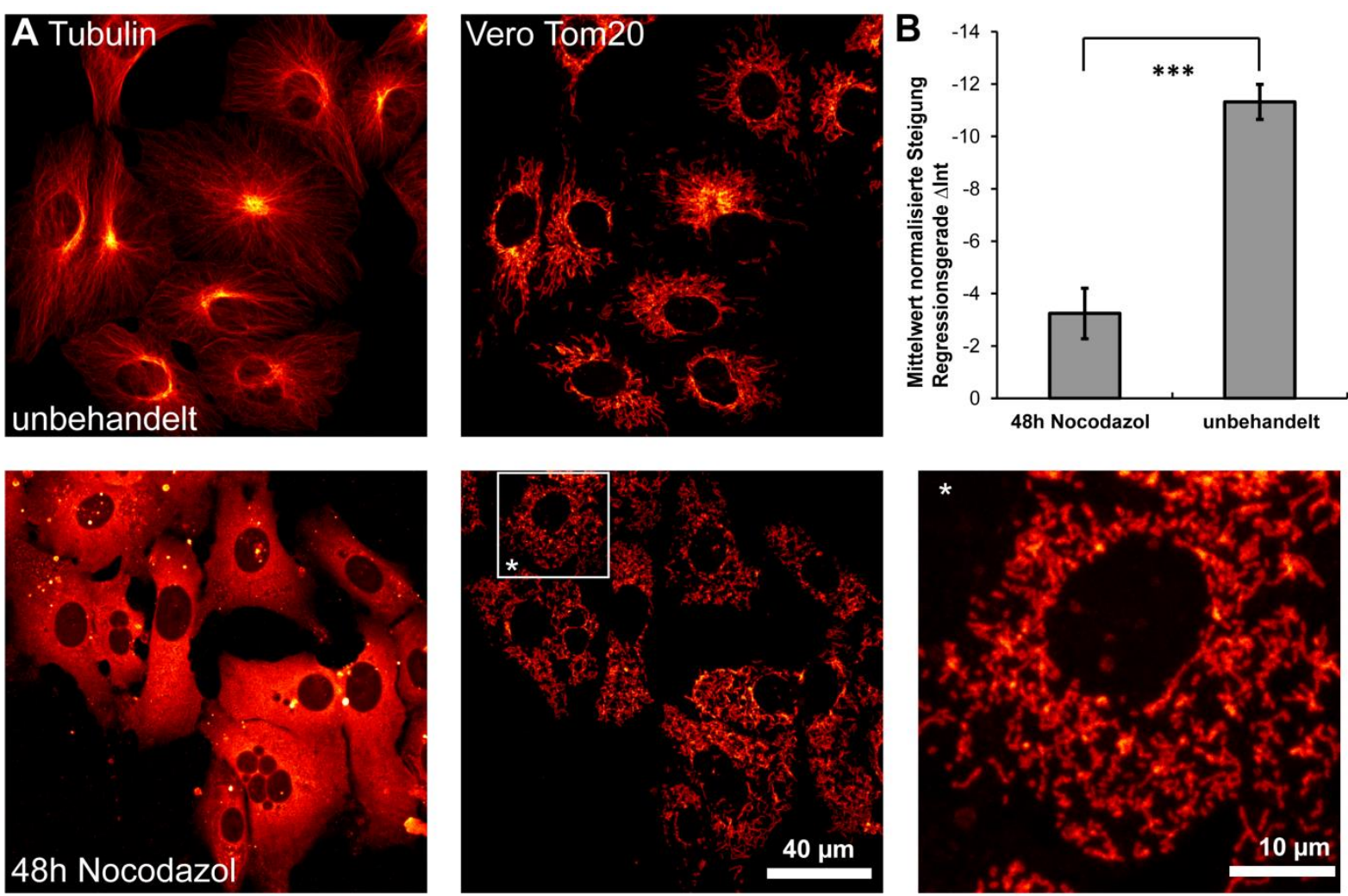

Abbildung 3.15: Die Zerstörung von Mikrotubuli-Filamenten verringert mitochondriale Heterogenität.

(A) Die 48-stündige Inkubation von Vero-Zellen mit der Tubulin-depolymerisierenden Substanz Nocodazol und anschließende Immunfluoreszenzmarkierungen gegen $\alpha$-Tubulin und Tom20 zeigten deutlich den Verlust intakter Tubulin-Filamente und eine Umverteilung der Mitochondrien. Abgebildet sind Maximalprojektionen konfokaler z-Stapel. (B) Die Analyse der Tom20-Fluoreszenzintensität von mindestens 20 Zellen zeigte eine signifikante Reduzierung seiner Heterogenität über die gesamte Zelle nach Nocodazol-Behandlung. Das Experiment wurde mindestens drei Mal durchgeführt. Für die Untersuchung wurden überlappende Mitochondrien ausgeschlossen. Gezeigt sind Mittelwerte und Standardfehler. ${ }^{* * *} \mathrm{P}=0,001$ (t-Test bei zwei unabhängigen Stichproben). Die Farbtabellen der Mitochondrienmarkierungen sind identisch.

Demnach war der Mittelwert der Steigungen der Regressionsgerade aller Zellen nach NocodazolInkubation im Vergleich zu unbehandelten Kontrollzellen signifikant reduziert. Das bedeutet, dass die normalerweise sichtbare Heterogenität der Tom20-Fluoreszenzintensitätsverteilung, in Form eines intrazellulären Dichtegradienten, nach der Depolymerisierung von Tubulin deutlich verringert vorliegt. Die Zerstörung der Mikrotubuli, und somit die Unterbindung mitochondrialen Transports, hat demnach einen Einfluss auf die Heterogenität der Tom20-Proteinverteilung.

Die Beobachtungen, welche mit Hilfe der Analyse der Tom20-Fluoreszenzintensitätsverteilung konfokalmikroskopischer Daten gemacht wurden, wurden in einem weiteren Schritt mittels hochauflösender STED-Mikroskopie nochmals untersucht. 
Hierzu wurden ganze Tom20-immunfluoreszenzmarkierte Vero-Zellen, die sowohl Nocodazol- als auch unbehandelt waren, mit dem STED-Mikroskop aufgenommen (Abbildung 3.16 A). Der Vergleich der Dichte von Tom20-Proteinclustern von perinukleären mit peripheren Mitochondrien ergab in unbehandelten Zellen einen deutlichen Unterschied der Proteindichte (siehe Abbildungen 3.2 und 3.13). Auf $48 \mathrm{~h}$-Nocodazol-behandelten Zellen ergab sich bei diesem Vergleich kein erkennbarer Unterschied der Tom20-Proteindichte (Abbildung 3.16 B). Somit bestätigte die rein optische Beurteilung von Tom20-Proteinverteilungen auf STED-mikroskopischen Aufnahmen die mittels Konfokalmikroskopie und Fluoreszenzintensitätsauswertung erhaltene Reduzierung der Heterogenität nach Zerstörung filamentösem Tubulins.
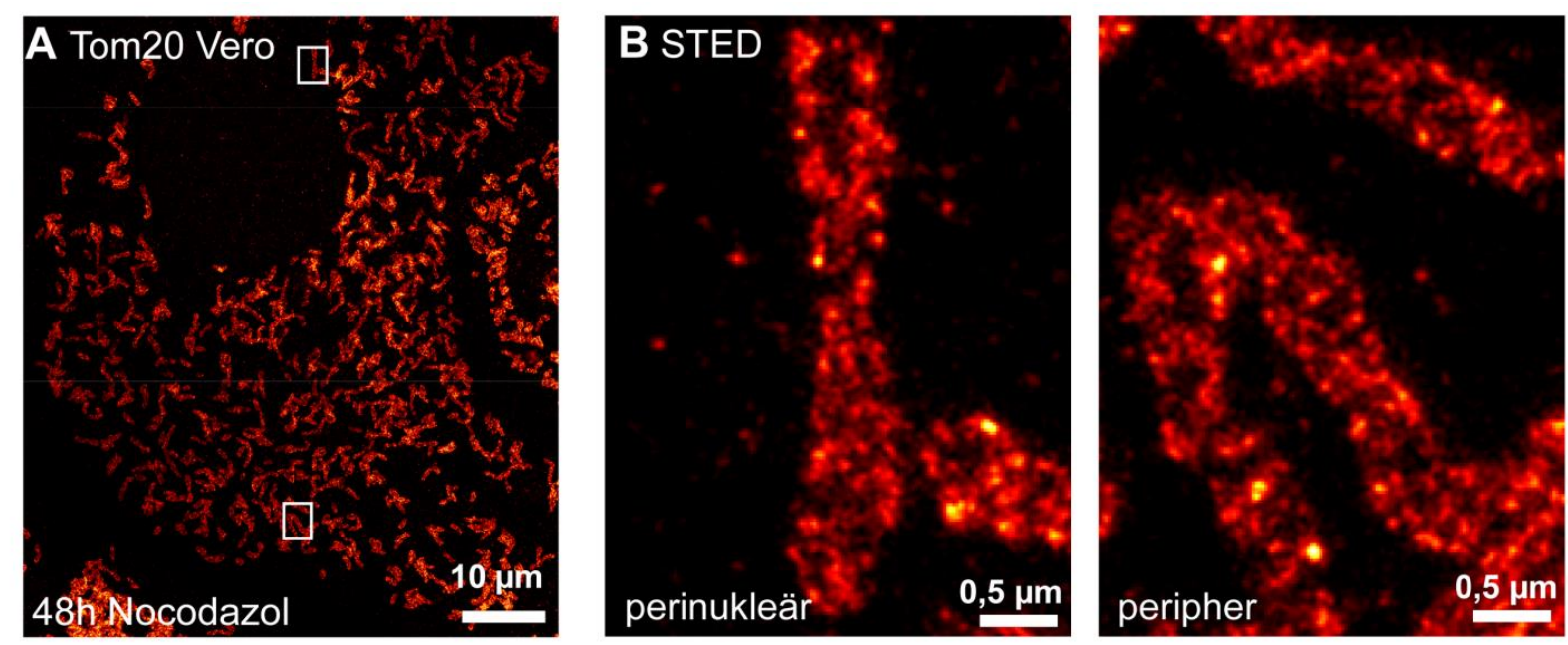

Abbildung 3.16: Die Zerstörung von Mikrotubuli-Filamenten reduziert die Heterogenität der intrazellulären Tom20Proteinverteilung.

(A) 48h-Nocodazol-behandelte Zellen zeigten eine Verringerung der Heterogenität der Tom20-Proteinverteilung nach Depolymerisierung von Tubulin. Abgebildet ist eine STED-mikroskopische Übersichtsaufnahme einer repräsentativen Zelle. (B) Die Dichte von Tom20-Proteinclustern, welche mittels STED-Mikroskopie aufgelöst wurden, unterschied sich innerhalb peripherer und perinukleärer Mitochondrien, anders als in unbehandelten Zellen, nach Nocodazol-Inkubation kaum. Die Bilder wurden nachträglich geglättet. Das Experiment wurde zwei Mal durchgeführt. Die Farbtabellen peripherer und perinukleärer Mitochondrien sind identisch.

Somit wurde, sowohl mittels Konfokal- wie auch STED-Mikroskopie, gezeigt, dass die Heterogenität der Verteilung von Tom20 nach Zerstörung des Mikrotubuli-Zytoskeletts verringert ist. Diese Beobachtung impliziert eine Beteiligung des Transports von Mitochondrien entlang Mikrotubuli am Mechanismus der Aufrechterhaltung der Heterogenität mitochondrialer Proteinverteilungen.

Um weiterhin die Rolle der Interaktion von Mitochondrien mit Mikrotubuli, bei der Aufrechterhaltung der heterogenen Verteilung mitochondrialer Proteine, genauer zu verstehen, wurde direkt der Einfluss des mitochondrialen Transports hierauf untersucht.

Am Transport von Mitochondrien sind Proteinkomplexe beteiligt, von denen eine Vielzahl bereits identifiziert wurde (Lovas and Wang 2013). Der am besten charakterisierte ist der Rhot/Trak/Kinesin- 
Komplex. Er besteht aus dem spezifischen Kinesin-Motorprotein, der die Mikrotubuli bindet, dem mitochondrialen Adapterprotein Rhot (hMiro) und dem Protein Trak (hMilton), welches eine Verbindung zwischen Rhot und dem Kinesin-Motor herstellt. Um eine Aussage über die Rolle des aktiven Kinesin-vermittelten mitochondrialen Transports bei der Entstehung der Heterogenität mitochondrialer Proteinverteilungen zu treffen, wurden Zellen hergestellt und analysiert, die gezielt einen Verlust des mitochondrienspezifischen Kinesin-Adapters, Rhot1, sowie dessen Bindungspartners Trak1 besaßen.

\subsubsection{Die Herunterregulierung von Proteinen des Komplexes für Kinesin-} vermittelten mitochondrialen Transport vermindert die Gradientenverteilung von Tom20

Zur Klärung der Frage, ob spezifischer mitochondrialer Transport an der Entstehung bzw. Aufrechterhaltung der intrazellulären Gradientenverteilung mitochondrialer Proteine beteiligt ist, wurden die Hauptkomponenten eines Proteinkomplexes, die maßgeblich für den mitochondrialen Transport verantwortlich sind, herunterreguliert. Hierbei handelte es sich um Rhot1 (hMiro1) und Trak1 (hMilton1).

Rhot1 ist eines von zwei möglichen mitochondrialen Adapterproteinen (zusammen mit seiner Isoform Rhot2). Ein Verlust dieses Adapterproteins unterbindet spezifisch den mitochondrialen anterograden Transport (Guo et al. 2005).

Wie Rhot verfügt auch Trak über zwei Säugerhomologe: Trak1 und Trak2. Seine Bedeutung für den mitochondrialen Transport wurde anhand von Versuchen mit Neuronen, welche Mutationen dieser Gene aufwiesen, verdeutlicht. Die Mitochondrien verblieben im Soma und wurden nicht in Axonen und ihren Enden beobachtet, was den Schluss zulässt, dass mitochondrialer Transport unterbunden war (Stowers et al. 2002, Gorska-Andrzejak et al. 2003).

Zur Realisierung der Herunterregulierung beider Proteine wurde erneut mit der RNA-InterferenzTechnologie gearbeitet. Hierzu wurden Vero-Zellen mit einem shRNA-Plasmid transfiziert, welches eine RNA-Sequenz kodierte, die spezifisch den Abbau der Rhot1- bzw. der Trak1-mRNA bewirkte und somit zu einer Herunterregulierung der jeweiligen Proteinmenge, führte.

Der Erfolg der spezifischen Herunterregulierung durch die eingesetzten shRNAs wurde mittels SDSPAGE und Western-Blot-Analyse von Gesamtzellextrakten transfizierter und selektierter Vero-Zellen kontrolliert. Diese ergaben, dass eine Herunterregulierung der entsprechenden Proteinmengen um $50-70 \%$ in den Säugerzellextrakten erfolgt ist (Abbildung 3.17) und somit ausreichend für eine weitere Analyse dieser Zellen war. 


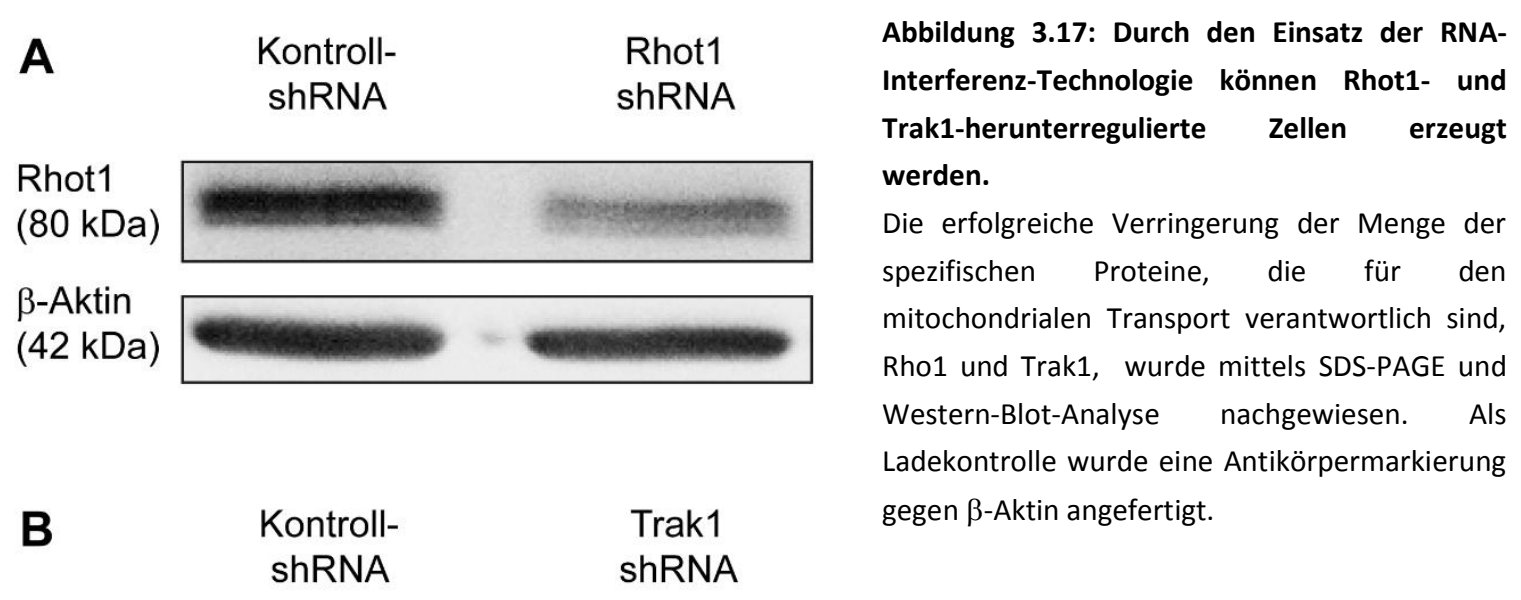

\section{Trak1}

$(115 \mathrm{kDa})$

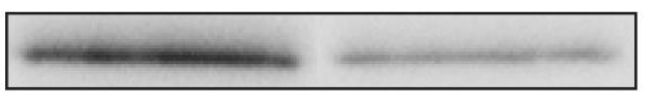

$\beta$-Aktin

$(42 \mathrm{kDa})$

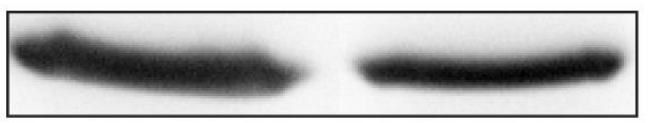

Anschließend wurde die Verteilung des mitochondrialen Tom20 Proteins auf den Rhot1herunterruglierten Zellen mittels Konfokalmikroskopie und Fluoreszenzintensitätsanalyse untersucht. Als zusätzliche Kontrolle wurde der Erfolg der Herunterregulierung von Rhot1 mittels KoImmunfluoreszenzmarkierung auf jeder einzelnen Zelle ermittelt. Dazu wurden die Zellen sowohl mit spezifisch bindenden Antikörpern gegen Rhot1 als auch Tom20 markiert. Als Limitation erwies sich dabei jedoch die Tatsache, dass der verwendete Rhot-Antikörper zwar spezifisch nur mitochondriales Signal detektiert hat, allerdings keine Unterscheidung der beiden Isoformen Rhot1 und Rhot2 zuließ. Dadurch war nie ein vollständiger Verlust des Rhot1-Fluoreszenzsignals zu erwarten, sondern immer nur eine teilweise Verringerung dessen (Abbildung 3.18). Interessanterweise wiesen die Mitochondrien dieser Zellen, oftmals auch eine deutliche Veränderung ihrer Anordnung innerhalb der gesamten Zellen auf, was auf einen gestörten mitochondrialen Transport hindeutet. 

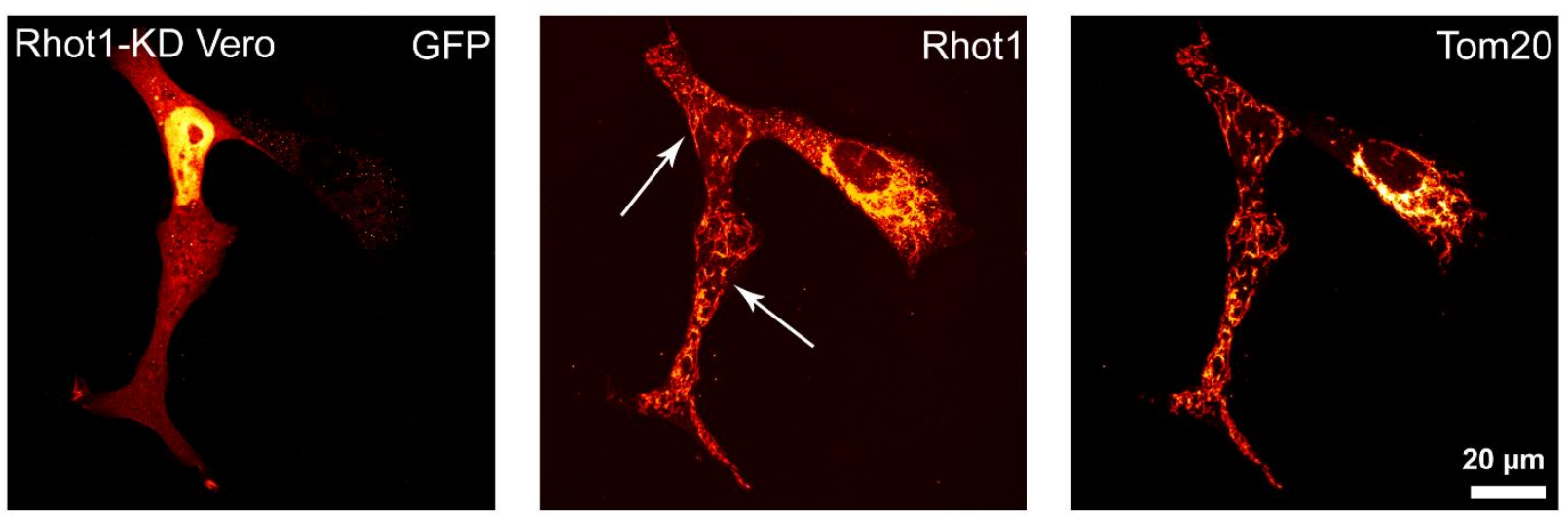

Abbildung 3.18: Die Verringerung des spezifischen Adapterproteins für mitochondrialen Transport Rhot1 kann mittels Immunfluoreszenzmarkierungen detektiert werden.

Die Herunterregulierung von Rhot1 erfolgte per Transfektion eines Plasmides, welches eine spezifische shRNA kodierte, in Vero-Zellen. Transfizierte Zellen zeichneten sich durch GFP-Fluoreszenz aus (linke Zelle, mit Pfeilen markiert). Die tatsächliche Verringerung der Proteinmenge wurde über eine Immunfluoreszenzmarkierung bestätigt. Hierzu wurde das mitochochondriale Rhot-Protein mit einem Antikörper, der beide Isoformen detektiert, markiert. In diesem Fall zeigte sich, dass die linke transfizierte Zelle tatsächlich eine Verringerung des Rhot1-Fluoreszenzsignals, gegenüber der rechten untransfizierten Zelle, aufwies. Weiterhin wurden die Mitochondrien mittels Immunfluoreszenzmarkierung gegen Tom20 markiert. Abgebildet sind Maximalprojektionen konfokaler z-Stapel.

Nachdem die Herunterregulierung des Rhot1-Proteins optisch detektiert werden konnte, erfolgte die Analyse der Tom20-Fluoreszenzintensitätsverteilung auf konfokalmikroskopischen Daten von Rhot1KD-Zellen, sowie auf entsprechenden Negativkontroll-shRNA transfizierten Zellen.

Der Vergleich mit Kontroll-Zellen ergab, dass durch die Herunterregulierung von Rhot1 das Ausmaß der Gradientenverteilung von Tom20 über die Zellen verringert war. Das konnte dadurch gezeigt werden, dass die Mittelwerte der Gesamtintensitätsänderungen aller Zellen bei Rhot1Herunterregulierung gegenüber Negativkontroll-shRNA transfizierten Zellen signifikant verringert waren (Abbildung 3.19). Anschließend wurde untersucht, ob eine weitere Komponente (Trak) des Kinesin-vermittelten Mitochondrientransportkomplexes auch einen entsprechenden Einfluss auf die Heterogenität mitochondrialer Proteinverteilungen hat. 


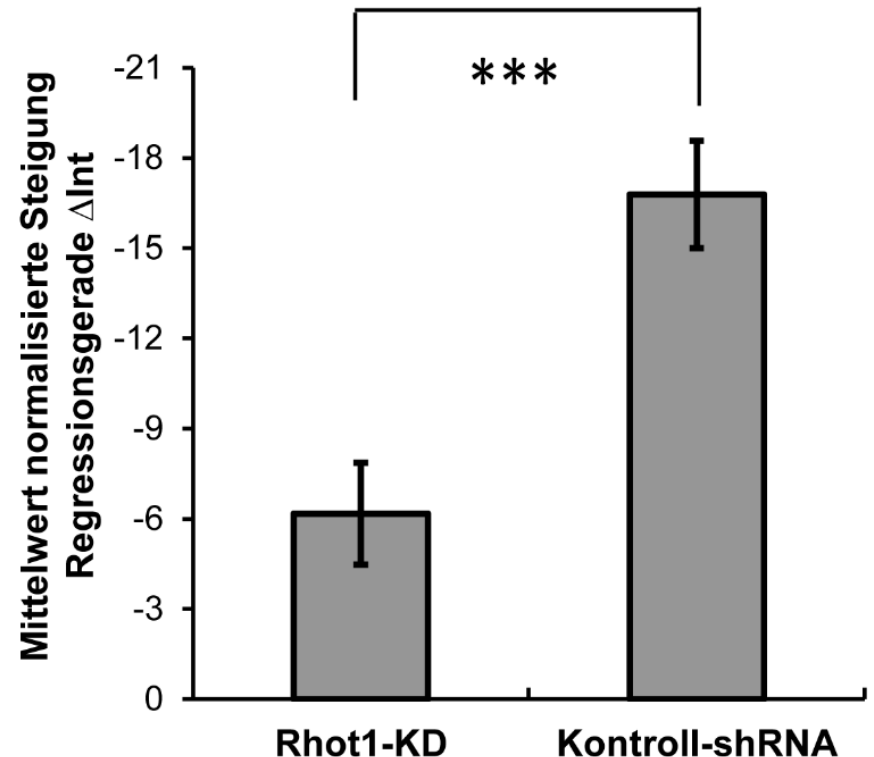

Abbildung 3.19: Der Verlust des Adapterproteins für Kinesin-vermittelten mitochondrialen Transport verringert die intrazelluläre Tom20Heterogenität.

Die Fluoreszenzintensitätsanalyse der Tom20Verteilung in mindestens 20 Rhot1herunterregulierten (Rhot1-KD) und der Vergleich mit Negativkontroll-shRNA transfizierten VeroZellen zeigte eine signifikante Reduzierung seiner Gradientenverteilung über die Zelle. Für die Untersuchung wurden überlappende Mitochondrien von der Berechnung ausgeschlossen. Das Experiment wurde drei Mal durchgeführt. Abgebildet sind Mittelwerte und Standardfehler. ${ }^{* * *} \mathrm{P}=0,001$ (t-Test bei zwei unabhängigen Stichproben).

Der Erfolg der Herunterregulierung auf individuellen Zellen konnte für Trak1 nicht mittels KoImmunfluoreszenzmarkierung ermittelt werden, weil kein entsprechend spezifischer Antikörper verfügbar war. Da jedoch bei Herunterregulierung von Rhot1 beobachtet wurde, dass die Mitochondrien dieser Zellen, oftmals auch eine deutliche Veränderung ihrer Anordnung innerhalb der gesamten Zelle aufwiesen, wurde diese charakteristische Umverteilung der Mitochondrien herangezogen, um Trak1-herunterregulierte Zellen zu identifizieren (Abbildung 3.20 A).

Nach der Identifikation von Trak1-herunterregulierten Zellen, erfolgte die Analyse der Tom20Fluoreszenzintensitätsverteilung auf diesen konfokal-mikroskopischen Daten. Die Mittelwerte der Gesamtintensitätsänderungen von Tom20 aller Zellen bei Trak1-Herunterregulierung waren signifikant verringert gegenüber mit Negativkontroll-shRNA transfizierten Vero-Zellen (Abbildung 3.20 B). Demnach ergab der Vergleich mit Kontrollzellen, dass durch die Herunterregulierung von Trak1 das Ausmaß der Gradientenverteilung von Tom20 über die Zellen verringert wurde.

Die Ergebnisse deuten somit eine direkte Beteiligung des mitochondrialen Transportkomplexes aus Rhot, Trak, Kinesin und Mikrotubuli bei der Aufrechterhaltung der Heterogenität der Tom20Proteinverteilung an. 

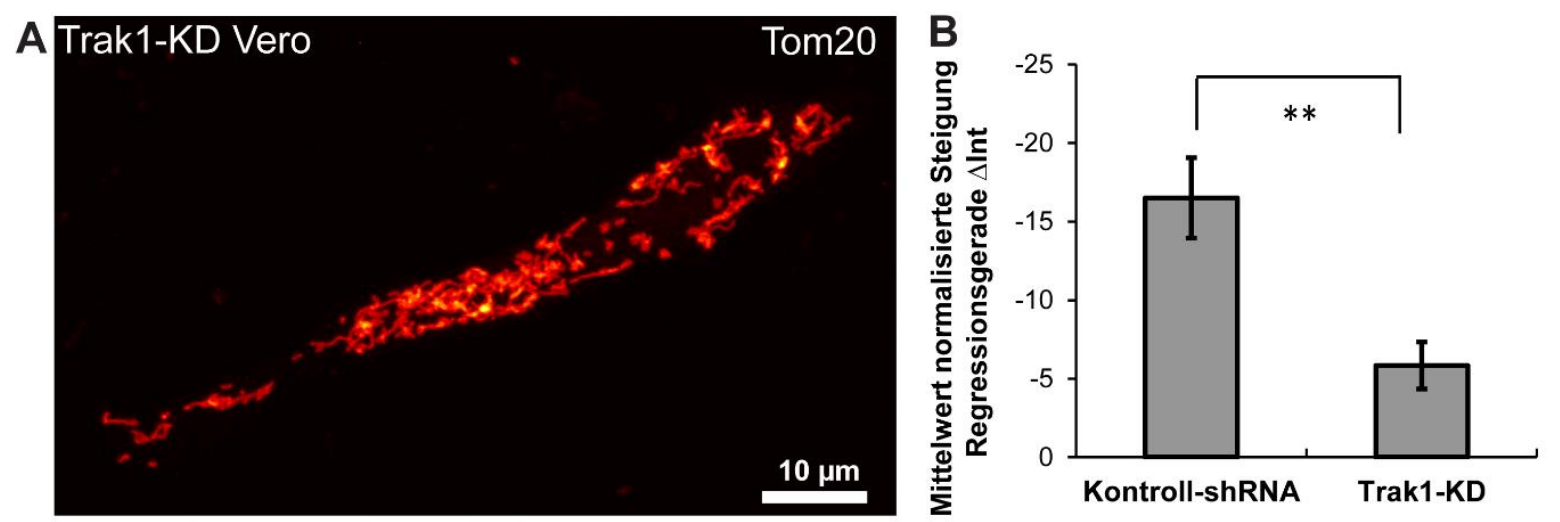

Abbildung 3.20: Die Herunterregulierung von Trak1 verringert die intrazelluläre Gradientenverteilung von Tom20.

(A) Trak1-herunterregulierte Vero-Zellen verfügten innerhalb einer Zelle über eine veränderte Anordnung der gesamten Mitochondrien, die ähnlich der Anordnung, welche durch Rhot1 Herunterregulierung zustande kommt, wart. (B) Die Fluoreszenzintensitätsanalyse der Tom20-Verteilung in mindestens 20 Trak1-herunterregulierten (Trak1-KD) und der Vergleich mit Negativkontoll-shRNA tranfizierten Zellen zeigte, dass seine Gradientenverteilung über die Zelle signifikant reduziert war. Für die Untersuchung wurden überlappende Mitochondrien von der Berechnung ausgeschlossen. Das Experiment wurde drei Mal durchgeführt. Abgebildet sind Mittelwerte und Standardfehler. ${ }^{* *} \mathrm{P}=0,01$ (t-Test bei zwei unabhängigen Stichproben).

Die Ergebnisse dieser Arbeit zeigen folglich, dass die Assoziation von Mitochondrien mit Mikrotubuli für die Existenz heterogener mitochondrialer Proteinverteilungen von Bedeutung ist. Außer Nocodazol gibt es weitere Substanzen, welche die Depolymerisierung von Tubulin-Filamenten bewirken. Dazu zählt zum Beispiel Rotenon (Diaz-Corrales et al. 2005). Interessanterweise wird Rotenon mit der nicht-genetisch-bedingten Entstehung der neurodegenerativen Parkinson Erkrankung in Verbindung gebracht (Schapira 2010). Die Dysfunktion von Mitochondrien ist ein bekannter Aspekt neurodegenerativer Erkrankungen (Nunnari et al. 2012). Somit ist es von Interesse zu untersuchen, ob unter den durch Rotenon hervorgerufenen pathophysiologischen Bedingungen eine Heterogenität mitochondrialer Proteinverteilungen vorliegt.

\subsection{Untersuchung mitochondrialer Proteinverteilung unter} pathophysiologischen Bedingungen

Um zu untersuchen, ob die Verteilung mitochondrialer Proteine unter pathophysiologischen Bedingungen verändert vorliegt, wurde die Substanz Rotenon eingesetzt. Dabei handelt es sich um ein Reagenz, welches sowohl eine Depolymerisierung von Tubulin-Filamenten, als auch eine Inhibierung des mitochondrialen Atmungskettenkomplexes I bewirkt und eine Rolle bei der 
Entstehung der nicht genetisch bedingten Parkinson Erkrankung spielt (Diaz-Corrales et al. 2005, Schapira 2010).

Der Einfluss von Rotenon auf Vero-Zellen wurde nach 48-stündiger Inkubation untersucht. Der mehrheitliche Verlust von Tubulin-Strängen konnte mittels Immunfluoreszenzmarkierung demonstriert werden (Abbildung 3.21). In unbehandelten Kontrollzellen wiesen die Mitochondrien ein intaktes Netzwerk (sichtbar durch Immunomarkierung gegen Tom20) und Tubulin intakte Filamente (visualisiert durch Immunomarkierung gegen $\alpha$-Tubulin), die über die gesamte Zelle reichten, auf. Nach 24-stündiger Inkubation mit Rotenon lagen fast keine intakten Tubulin-Fasern mehr vor, sondern hauptsächlich depolymerisiertes Protein. Des Weiteren waren die Mitochondrien nach dieser Behandlung leicht verkürzt und über die gesamte Zelle verteilt. Sie zeigten nicht mehr die normalerweise zu beobachtende Aggregierung um den Zellkern, was bereits bei NocodazolInkubation beobachtet wurde.
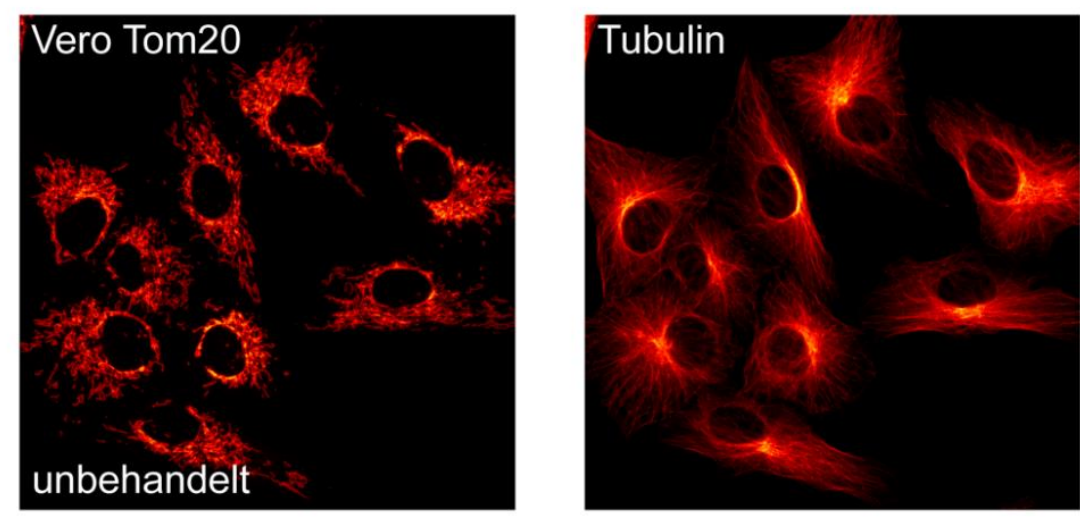

Abbildung 3.21: Durch Inkubation mit Rotenon wird filamentöses Tubulin weitgehend zerstört.

Die Depolymerisierung von Tubulin wurde auf Rotenon- und unbehandelten Vero-Zellen mittels Immunfluoreszenzmarkierung untersucht. Dabei wurden sowohl $\alpha$-Tubulin, als auch das mitochondriale Protein Tom20 mit spezifischen Antikörpern markiert.
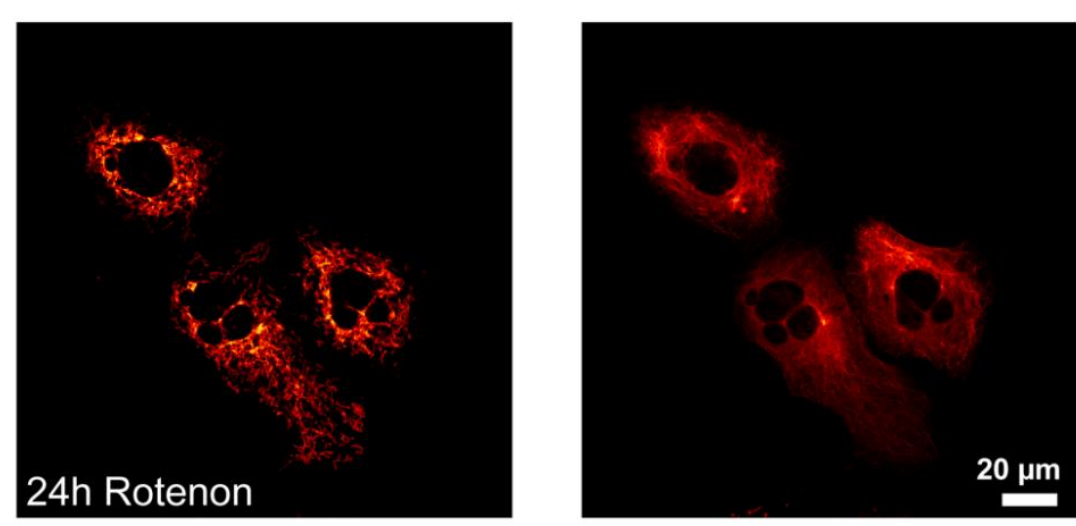
Unbehandelte wt-Zellen wiesen intakte Tubulin-Fasern und ein normales mitochondriales Netzwerk auf, wohingegen eine 24stündige Rotenon-Behandlung den Großteil filamentösem Tubulins zerstörte und die mitochondriale Anordnung innerhalb der Zelle veränderte. Abgebildet sind Maximalprojektionen konfokaler zStapel.

Die Analyse der Tom20-Proteinverteilung in diesen Zellen, mittels Konfokalmikroskopie und Fluoreszenzintensitätsauswertung, ergab, dass das Ausmaß der Gradientenverteilung von Tom20 nach Zerstörung des Mikrotubuli-Zytoskeletts durch Rotenon gegenüber unbehandelten Referenzzellen deutlich verringert war (Abbildung 3.22). Demnach war der Mittelwert der Steigungen der Regressionsgerade aller Zellen nach Rotenon-Inkubation im Vergleich zu unbehandelten Kontrollzellen signifikant reduziert. Das bedeutet, dass auch die durch Rotenon vermittelte 
Depolymerisierung von Tubulin, eine deutliche Verringerung der intrazellulären Gradientenverteilung von Tom20 bewirkt hatte. Die Reduktion des Ausmaßes der Gradientenverteilung eines mitochondrialen Proteins könnte somit ein Merkmal der Dysfunktion von Mitochondrien bei beispielsweise neurodegenerativen Erkrankungen sein.

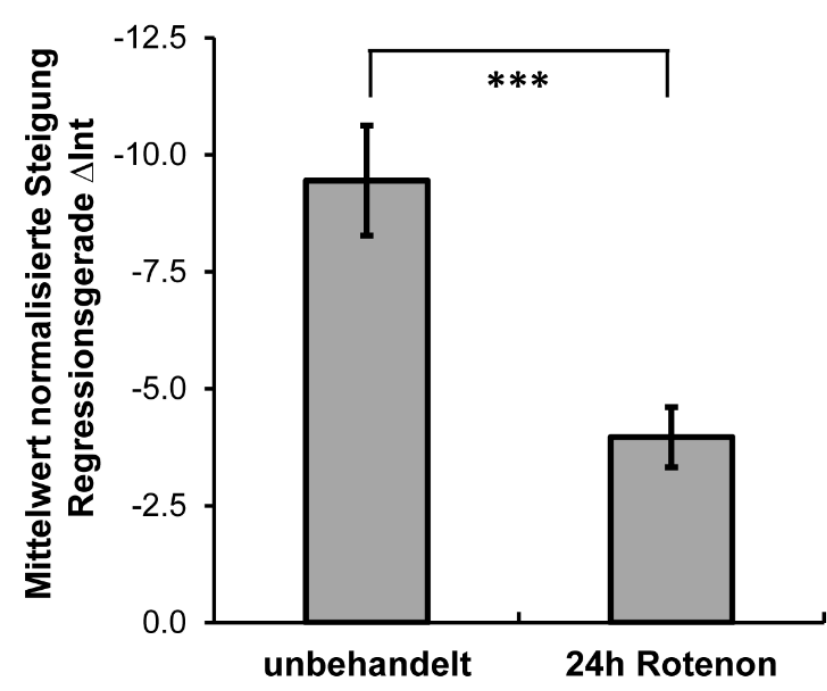

Die Beobachtungen, welche mit Hilfe der Analyse der Tom20-Fluoreszenzintensitätsverteilung konfokalmikroskopischer Daten gemacht wurden, wurden in einem weiteren Schritt mittels hochauflösender STED-Mikroskopie nochmals untersucht.

Hierzu wurden ganze Tom20-immunfluoreszenzmarkierte Vero-Zellen, die sowohl Rotenon- als auch unbehandelt waren, mit dem STED-Mikroskop aufgenommen. Der Vergleich der Dichte von Tom20Proteinclustern von perinukleären mit peripheren Mitochondrien zeigte in unbehandelten Zellen einen deutlichen Unterschied der Proteindichte (siehe Abbildungen 3.2 und 3.13). Auf 24 h-Rotenonbehandelten Zellen ergab sich bei diesem Vergleich kein erkennbarer Unterschied der Tom20Proteindichte (Abbildung 3.23). Somit bestätigte die rein optische Beurteilung von Tom20Proteinverteilungen auf STED-mikroskopischen Aufnahmen die mittels Konfokalmikroskopie und Fluoreszenzintensitätsauswertung beobachtete Reduzierung der Gradientenverteilung nach Zerstörung der Mikrotubuli.

Somit wurde, sowohl mittels Konfokal- wie auch STED-Mikroskopie, gezeigt, dass die Heterogenität der mitochondrialen Tom20-Verteilung nach Zerstörung des Mikrotubuli-Zytoskeletts auch durch Rotenon, wie bereits durch Nocodazol, deutlich verringert ist. Diese Beobachtung impliziert eine Beteiligung der Assoziation von Mitochondrien mit Mikrotubuli am Mechanismus der Aufrechterhaltung der Gradientenverteilung mitochondrialer Proteine. 


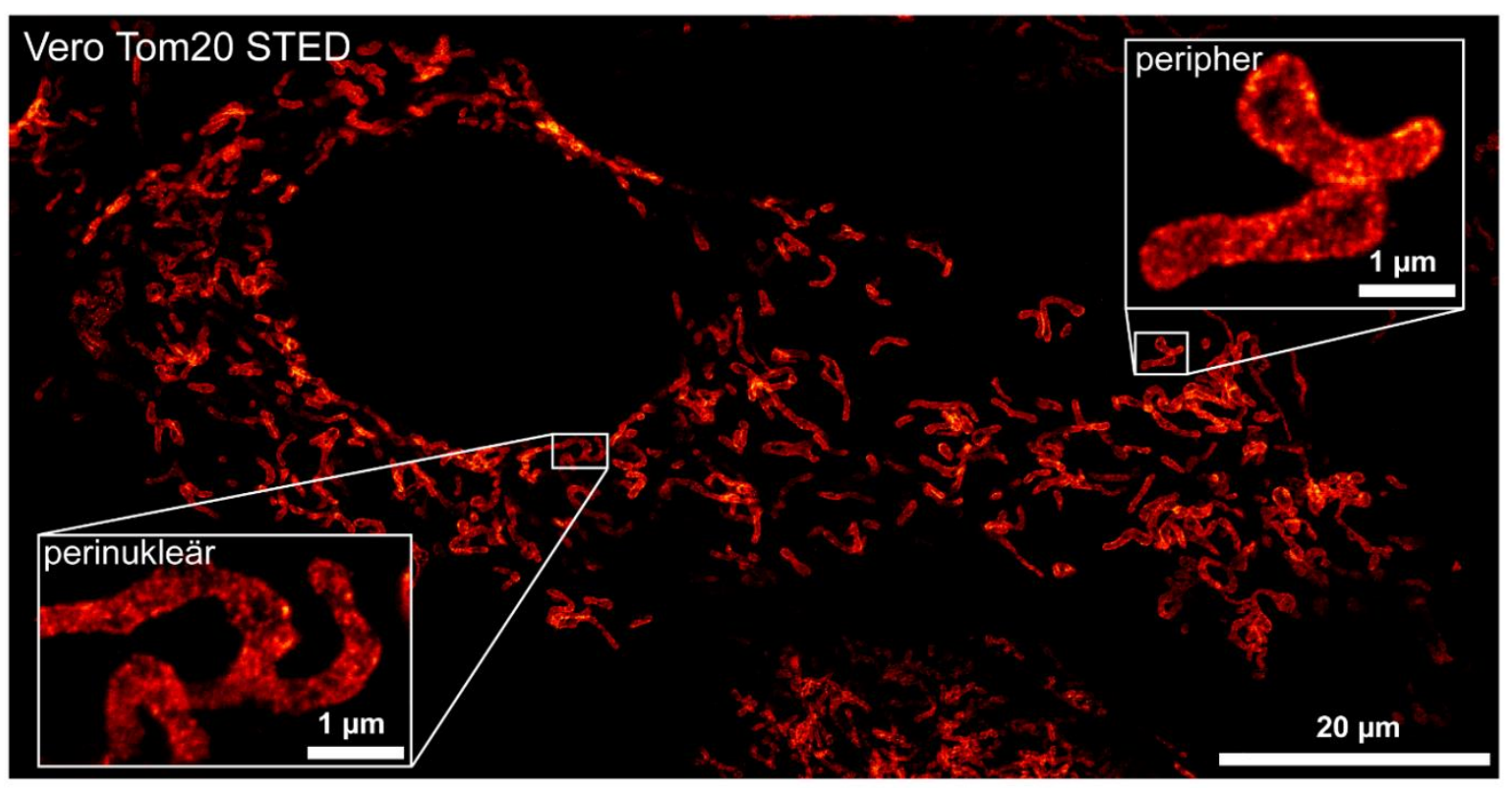

Abbildung 3.23: Die Zerstörung von Mikrotubuli durch Rotenon reduziert die Heterogenität der Tom20Proteinverteilung.

Die STED-Mikroskopie von 24h-Rotenon- und unbehandelten Zellen ermöglichte die Beobachtung einer Verringerung des Ausmaßes der Gradientenverteilung von Tom20 nach Depolymerisierung von Tubulin. Die Tom20Proteinclusterdichten peripherer und perinukleärer Mitochondrien unterscheiden sich, anders als in unbehandelten Zellen, nach Rotenon-Inkubation kaum. Die Farbtabellen peripherer und perinukleärer Mitochondrien sind identisch.

Rotenon hat nicht nur den Effekt der Depolymerisierung von Tubulin, sondern auch der Inhibierung des mitochondrialen Atmungskettenkomplexes I. Um zu untersuchen, ob diese weitere Funktion ursächlich für die Beobachtungen der Veränderung mitochondrialer Proteinverteilung bei Inkubation mit Rotenon war, wurden Vero-Zellen mit einer Substanz inkubiert, die spezifisch den Komplex I inhibierte.

Hierbei handelte es sich um Piericidin A (Acton et al. 2004). Dieses hatte das mitochondriale Membranpotential (aufgrund der Inhibierung des Atmungskettenkomplexes I) verringert. Weiterhin konnte beobachtet werden, dass nach 48-stündiger Inkubation mit Piericidin A, die Mitochondrienmorphologie leicht fragmentiert und verkürzt war (Abbildung 3.24 A). Die Analyse der Proteinverteilung von Tom20 auf $48 \mathrm{~h}$-Piericidin A-behandelten Zellen und der Vergleich mit entsprechenden unbehandelten Kontrollzellen zeigte, dass die Heterogenität seiner Verteilung bei Piericidin A-Inkubation unverändert blieb (Abbildung 2.24 B). 

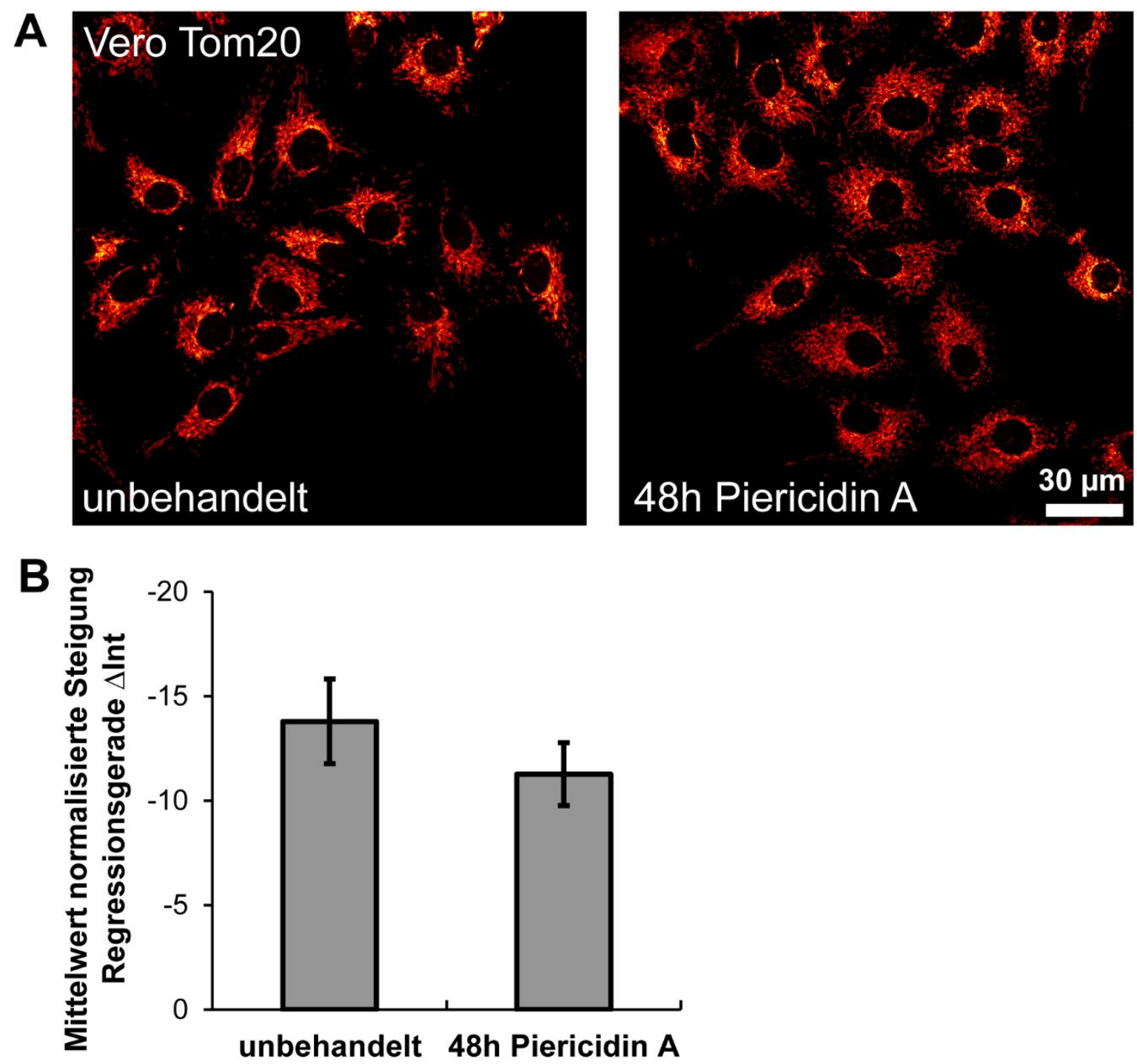

Abbildung 3.24: Die Inhibierung des Atmungskettenkomplexes I durch Piericidin A verändert nicht die heterogene Tom20-Proteinverteilung.

(A) Vero-Zellen, die $48 \mathrm{~h}$ mit Piericidin A inkubiert wurden, wiesen eine leicht fragmentierte und verkürzte Mitochondrienmorphologie gegenüber unbehandelten Zellen auf. (B) Die fluoreszenzmikroskopische Analyse von Tom20-Intensitätsverteilungen in Piericidin A- und unbehandelten Vero-Zellen (je 20 Zellen), ergab, dass die Gradientenverteilung nach Piericidin A-Behandlung für $48 \mathrm{~h}$ unverändert war. Dies konnte anhand der ähnlichen Mittelwerte der Steigungen der Regressionsgeraden bei Piericidin A-behandelten Zellen und Kontroll-Zellen gezeigt werden. Für die Analyse wurden überlappende Mitochondrien ausgeschlossen. Das Experiment wurde drei Mal durchgeführt. Gezeigt werden Mittelwerte und Standardfehler.

Auf die Gradientenverteilung von Tom20 hatte Piericidin A folglich keinen Effekt. Dies bedeutet, dass die Ursache für die Verringerung der heterogenen Verteilung von Tom20 bei Inkubation mit Rotenon letztlich hauptsächlich auf seine depolymerisierende Wirkung auf Tubulin zurückzuführen ist. 
Im Rahmen dieser Arbeit konnte demnach der Einfluss der Assoziation von Mitochondrien mit Mikrotubuli, und somit der Transport von Mitochondrien, als essentiell für die Aufrechterhaltung der Heterogenität mitochondrialer Proteinverteilungen gezeigt werden. Den Versuchen vorausgegangen war die Erkenntnis, dass direkt nach der Zellteilung, während der Zytokinese, eine geordnete Aufteilung aller Mitochondrien auf beide Tochterzellen und eine Ausbildung einer deutlichen Gradientenverteilung von Tom20 zu beobachten ist. Diese Anordnung kann möglicherweise über Mikrotubuli-basierte Transportmechanismen erfolgen.

Unklar ist jedoch welche Signale in bzw. auf den Mitochondrien zu dieser spezifischen Sortierung führen. Um diese zu identifizieren, wurde im Rahmen dieser Arbeit die Auswirkung einer Vielzahl von Bedingungen auf die intrazelluläre Gradientenverteilung des mitochondrialen Tom20-Proteins untersucht.

\subsection{Untersuchungen zur Identifikation von Signalen, welche zur}

\section{Entstehung der Gradientenverteilung mitochondrialer Proteine beitragen}

Die vorangegangen Ergebnisse dieser Arbeit geben einen Hinweis darauf, dass es einen aktiven Mechanismus zur spezifischen intrazellulären Anordnung von Mitochondrien gibt. Signale, welche die mitochondrialen Proteinverteilungen beeinflussen, könnten aufgrund der vielfältigen Funktionen von Mitochondrien und Interaktionen mit anderen Zellorganellen unterschiedlichen Ursprungs sein: ATP/ADP-Verhältnis, Substrat- bzw. Proteingehalt, $\mathrm{Ca}^{2+}-$ Konzentration, Nähe zu anderen Organellen. Vermutlich sind an diesem Mechanismus weitere Proteine beteiligt, die bislang nicht identifiziert sind.

Um zu erfahren, wie mitochondriale Proteinverteilungen reguliert werden, wurde im Rahmen dieser Arbeit der Einfluss einer Vielzahl verschiedener Bedingungen auf die Gradientenverteilung des mitochondrialen Tom20-Proteins untersucht.

Es wurde zunächst untersucht, ob das mitochondriale Membranpotential ein Faktor, der zur Entstehung heterogener mitochondrialer Proteinverteilungen führt, ist. Es könnte deshalb als Signal für die spezifische Anordnung von Mitochondrien dienen, weil es ein Indikator der Aktivität für die ATP-Produktion von Mitochondrien ist. Hierzu wurde der Effekt einer Vielzahl von Atmungskettenkomplexinhibitoren, Entkopplern des mitochondrialen Membranpotentials, Ionophoren, sowie der mtDNA-Defizienz auf die mitochondrialen Proteinverteilungen untersucht.

Nachfolgend werden beispielhaft die Ergebnisse, welche für die Behandlung von Zellen mit Oligomycin und Valinomycin erhalten wurden beschrieben. 


\subsubsection{Untersuchung des Einflusses der Veränderung des mitochondrialen} Membranpotentials auf die Gradientenverteilung von Tom 20

Die Heterogenität des mitochondrialen Membranpotentials wurde in einigen Studien gezeigt (Smiley et al. 1991, Diaz et al. 1999, Collins et al. 2002, Wikstrom et al. 2007, Wikstrom et al. 2009). Eine Untersuchung konnte sogar eine Gradientenverteilung des Membranpotentials, die dem Gradienten mitochondrialer Proteinverteilungen entsprach, beobachten (Wurm et al. 2011). Ferner wurde bereits beobachtet, dass die Depolarisation von Mitochondrien ihren Transport in Axonen arretiert (Schwarz 2013).

Weiterhin ist das mitochondriale Membranpotential notwendig für die ATP-Produktion über die Atmungskette. Sollten mitochondriale Proteine tatsächlich heterogen verteilt sein, um unterschiedliche energetische Ansprüche innerhalb von Zellen zu decken, könnte eine Veränderung des mitochondrialen Membranpotentials und somit der ATP-Produktion eventuell die Grundlage der Proteingradienten zerstören.

Deshalb wurde im Rahmen dieser Arbeit überprüft, ob ein Verlust des mitochondrialen Membranpotentials zu einer Equilibrierung der Tom20-Proteinverteilungen und die Erhöhung des mitochondrialen Membranpotentials zu einer Verschärfung der Gradientenverteilung von Tom20 führen. Dies wäre zu erwarten, wenn das mitochondriale Membranpotential tatsächlich ein Signal für die Entstehung der Heterogenität mitochondrialer Proteinverteilungen ist.

Um den Einfluss des mitochondrialen Membranpotentials auf die Heterogenität der Tom20Proteinverteilung bzw. seine Rolle als Signal für die Entstehung dieser Heterogenität zu untersuchen, wurden zwei Substanzen verwendet, welche auf unterschiedliche Weise das mitochondriale Membranpotential verändern.

Zum einen wurde Valinomycin verwendet, ein Kalium-lonophor, der das mitochondriale Membranpotential rasch und vollständig abbaut (Moore et al. 1964). Zum anderen wurde Oligomycin eingesetzt, welches eine Erhöhung des mitochondrialen Membranpotentials bewirkt (Johnson et al. 1981). Zu dieser Erhöhung kommt es, weil Oligomycin die Funktion der ATP-Synthase, also Komplex V der Atmungskette, inhibiert, indem es den Protonenkanal blockiert (Penefsky 1985). Dadurch ist der Protonenfluss entlang der $\mathrm{F}_{1} \mathrm{~F}_{0}$-ATPase unterbunden.

Der Erfolg der spezifischen Veränderungen des mitochondrialen Membranpotentials, aufgrund der Einwirkungen der Substanzen, wurde über die Färbung mit dem Membranpotential-sensitiven Fluoreszenzfarbstoff MitoTracker Red $\mathrm{CM}^{-} \mathrm{H}_{2}$ Xros kontrolliert. Nach $48 \mathrm{~h}$ Inkubation mit $5 \mu \mathrm{M}$ Valinomycin war erwartungsgemäß keine mitochondriale Markierung mit dem Mitotracker-Farbstoff mehr zu beobachten (Abbildung 3.25), was auf einen Verlust des mitochondrialen 
Membranpotentials hindeutet. Nach $48 \mathrm{~h}$ Inkubation mit $10 \mu \mathrm{M}$ Oligomycin hingegen, war eine deutliche mitochondriale Lokalisierung des Mitotracker-Fluoreszenzsignals zu beobachten. Ferner war dessen Intensität deutlich gegenüber der Markierung von DMSO-behandelten Kontrollzellen erhöht (Abbildung 3.25).
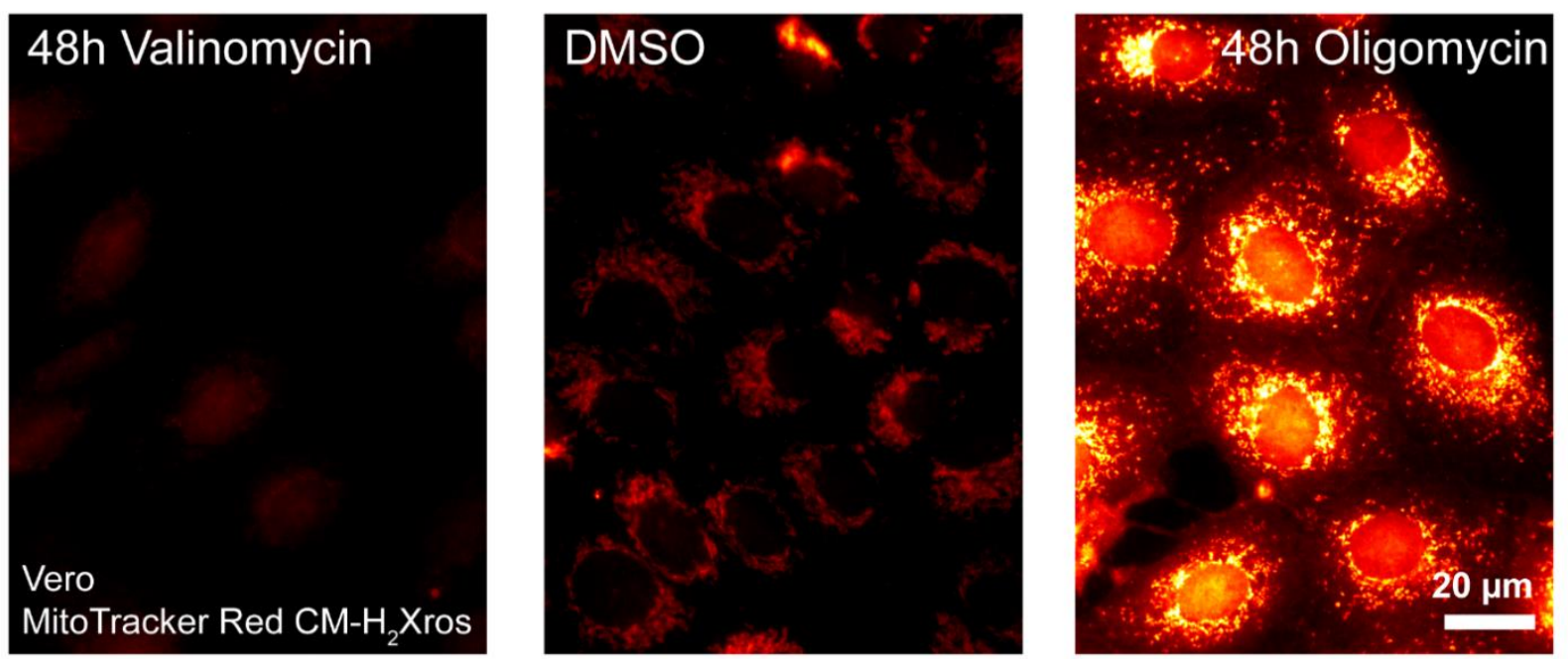

Abbildung 3.25: Das mitochondriale Membranpotential lässt sich durch Einwirkung verschiedener Substanzen gezielt verändern.

Das mitochondriale Membranpotential wurde durch 48-stündige Applikation von $5 \mu \mathrm{M}$ Valinomycin auf Vero-Zellen zerstört bzw. mittels $10 \mu \mathrm{M}$ Oligomycin gegenüber DMSO-behandelten Kontroll-Zellen erhöht. Diese Veränderung wurde durch die Markierung mit dem Membranpotential-sensitiven Farbstoff MitoTracker Red $\mathrm{CM}-\mathrm{H}_{2}$ Xros sichtbar. Abgebildet sind Epifluoreszenzaufnahmen. Die Aufnahmebedingungen und Farbtabelle sind für alle Aufnahmen konstant.

Die 48-stündige Behandlung von Vero-Zellen mit den Membranpotential-manipulierenden Substanzen Valinomycin bzw. Oligomycin (gleiche Konzentrationen wie zuvor) fragmentierte die mitochondriale Morphologie (Abbildung 3.26 A). Das bestätigte die Beobachtungen, dass das mitochondriale Membranpotential einen entscheidenden Einfluss auf das Gleichgewicht mitochondrialer Fusions- und Teilungsvorgänge hat (Legros et al. 2002).

Anschließend wurde der Einfluss dieser induzierten Veränderungen des mitochondrialen Membranpotentials auf die intrazelluläre Verteilung des mitochondrialen Tom20-Proteins untersucht.

Die Analyse der Heterogenität der Tom20-Proteinverteilungen in Zellen mit einem verringerten oder einem erhöhten Membranpotential erfolgte durch die Fluoreszenzintensitätsanalyse konfokalmikroskopischer Daten. Insgesamt ließ sich keine Veränderung der Heterogenität der Tom20-Proteinverteilungen durch die Beeinträchtigung des mitochondrialen Membranpotentials 
feststellen. Die Mittelwerte der Steigungen der Regressionsgeraden über alle Zellen pro Behandlung wichen nicht von DMSO-behandelten Kontroll-Zellen ab (Abbildung 3.26 B).
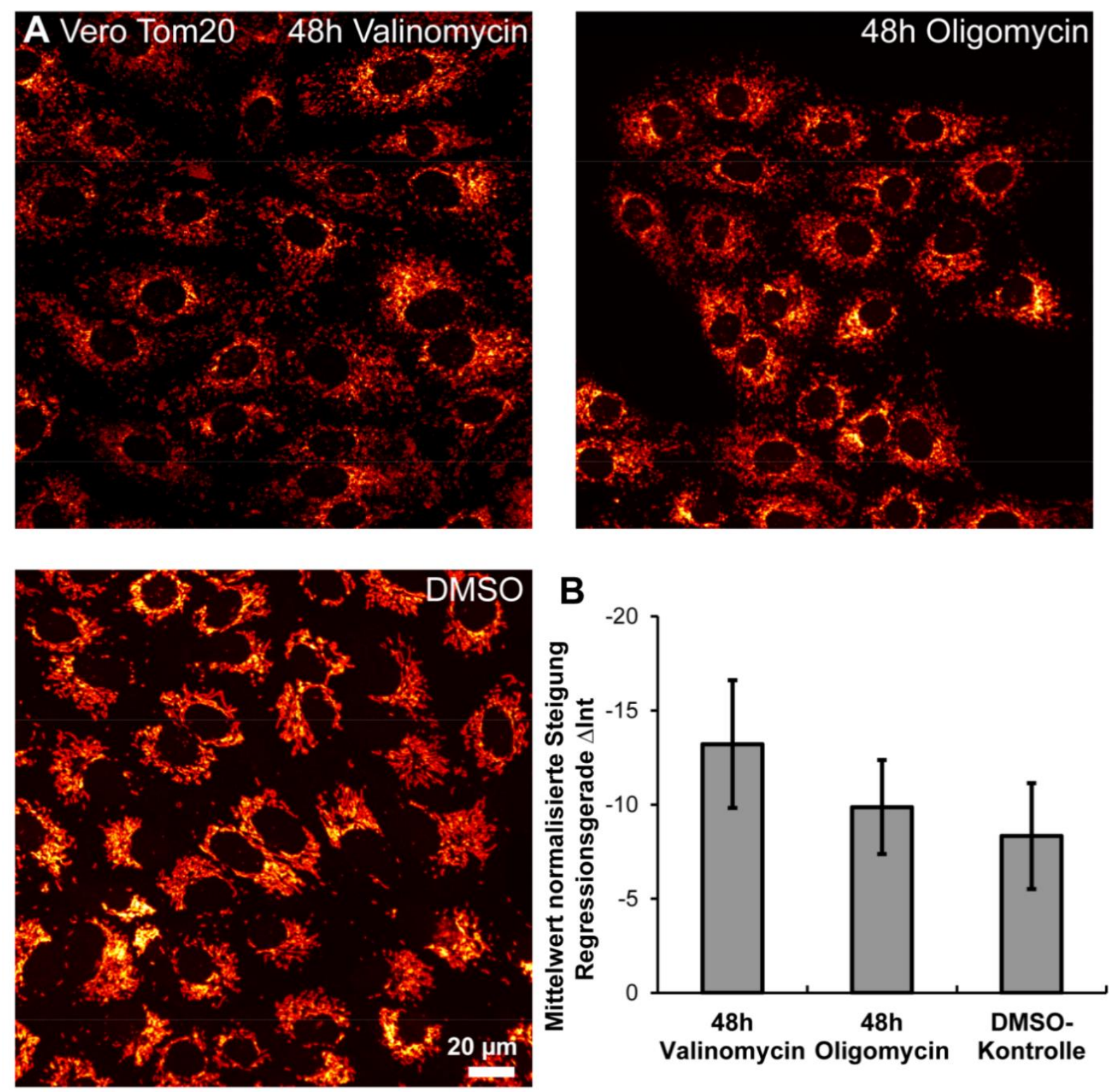

Abbildung 3.26: Veränderungen des mitochondrialen Membranpotentials haben keinen Einfluss auf die Heterogenität der Tom20-Proteinverteilung.

Sowohl die 48-stündige Inkubation mit $5 \mu \mathrm{M}$ Valinomycin, als auch mit $10 \mu \mathrm{M}$ Oligomycin, induzierten eine Fragmentierung des mitochondrialen Netzwerks, welche durch die Immunfluoreszenzmarkierung gegen Tom20 auf Vero-Zellen beobachtet werden kann. Gezeigt werden Maximalprojektionen konfokaler z-Stapel. (B) Die FluoreszenzIntensitätsanalyse von Tom20 auf entweder Valinomycin- oder Oligomycin-behandelten Zellen, ergab, dass die Gradientenverteilung von Tom20, unverändert gegenüber DMSO-behandelten Kontroll-Zellen vorlag. Für die Analyse wurden mindestens 20 Zellen pro Bedingung analysiert und überlappende Mitochondrien wurden von der Auswertung ausgespart. Das Experiment wurde drei Mal durchgeführt. Gezeigt sind Mittelwerte und Standardfehler. Die Farbtabellen der Mitochondrienmarkierungen sind identisch 
Dementsprechend ist festzustellen, dass weder die Verminderung noch die Erhöhung des mitochondrialen Membranpotentials einen Einfluss auf die heterogene Verteilung des mitochondrialen Proteins Tom20 hatte.

Der Einfluss der Veränderung des mitochondrialen Membranpotentials wurde im Rahmen dieser Arbeit durch Einsatz weiterer Substanzen untersucht. Hierzu zählen Atmungskettenkomplexinhibitoren, Ionophore, sowie Ethidiumbromid, welches die mitochondriale DNA zerstört (siehe Tabelle Anhang Tabelle 7.1). Diese Bedingungen veränderten die Gradientenverteilung von Tom20 in Vero-Zellen jedoch nicht. Somit fungiert das mitochondriale Membranpotential vermutlich nicht als Signal für die Entstehung der Heterogenität mitochondrialer Proteinverteilungen.

Deshalb wurden weitere Untersuchungen durchgeführt, um einen Faktor, welcher die heterogene mitochondriale Proteinverteilung reguliert, zu identifizieren.

\subsubsection{Untersuchung des Einflusses verschiedenster Bedingungen auf die} Gradientenverteilung von Tom 20

Im Rahmen dieser Arbeit wurde der Einfluss einer Vielzahl verschiedener Bedingungen auf die Heterogenität mitochondrialer Proteinverteilungen untersucht (siehe Anhang Tabellen 7.1 und 7.2). Ziel dieser Experimente war die Identifikation eines Faktors, welcher die Heterogenität mitochondriale Proteinverteilungen reguliert.

Es besteht die Vermutung, dass die heterogene Verteilung mitochondrialer Protein existiert, weil sie die Folge eines Anpassungsmechanismus auf unterschiedliche metabolische Anforderungen (Energiebedarf) darstellen. Dies ist denkbar, weil Mitochondrien hauptsächlich für die zelluläre ATPProduktion verantwortlich sind. Um diese Hypothese näher zu untersuchen, wurde nicht nur das mitochondriale Membranpotential manipuliert und Atmungskettenkomplexproteine inhibiert (siehe 3.7.1), sondern Säugerzellen auch unter verschiedensten Nährstoffbedingungen kultiviert (viel und wenig Glukose, Desoxyglukose, Überschuss an ATP). Die Intention dieser Experimente war generell die Untersuchung der Reaktion von Säugerzellen auf eine veränderte Abhängigkeit bzw. Notwendigkeit von Mitochondrien zur ATP-Produktion. Es konnten zwar Veränderungen der gesamten mitochondrialen Morphologie aufgrund der veränderten Kultivierungsbedingungen beobachtet werden, jedoch keine Modifikationen der Heterogenität mitochondrialer Proteinverteilungen. 
Darüber hinaus wurde der Effekt der Überexpression sowie Inhibierung bzw. Herunterregulierung von Proteinen auf die Tom20-Proteinverteilung untersucht, zu denen es bereits Hinweise gab, dass sie über die Funktion der Wahrnehmung des energetischen Status verfügen oder die mitochondriale Aktivität regulieren können. Hierzu zählten zum Beispiel die AMP-Kinase, die Caseinkinase und die Proteinkinase A. Generell ist anzunehmen, dass Proteinkinasen möglicherweise eine Rolle bei der Regulierung mitochondrialer Proteinverteilungen spielen könnten, weil sie eine posttranslationale Regulierung von Proteinaktivität vermitteln. Ferner wurde die Auswirkung der Inhibierung aller Proteinkinasen durch Staurosporin auf die mitochondrialen Proteinverteilungen erprobt. Da dies keine Veränderungen bewirkte, wurde anschließend der Einfluss der Inhibition der Translation (zytoplasmatisch, mitochondrial), also der Neusynthese aller Proteine, auf die heterogene Verteilung mitochondrialer Proteine analysiert. Das Ergebnis dieses Experiments könnte einen Hinweis darauf geben, ob die Ausbildung heterogener Proteinverteilungen in Mitochondrien überhaupt auf die Wirkung eines Proteins zurückzuführen ist. Es konnte keine eindeutige Veränderung mitochondrialer Proteinverteilungen nach 48-stündiger Inkubation mit den entsprechenden Substanzen beobachtet werden. Problematisch erwies sich bei der Analyse jedoch die Tatsache, dass die Zellen oftmals zu diesem Zeitpunkt bereits in die Apoptose übergingen. Da die zuvor beschriebenen Ergebnisse einen Hinweis darauf geben, dass vermutlich kein unbekanntes Protein verantwortlich für die Regulierung mitochondrialer Proteinverteilungen ist, besteht noch die Möglichkeit, dass ein gezielter Abbau mitochondrialer Proteine die Ursache für die Heterogenität mitochondrialer Proteinverteilungen ist. Um dies zu untersuchen, wurde die Funktion des Proteasoms unterbunden. Das Proteasom ist ein Enzymkomplex, welcher den Abbau von polyubiquitinierten Protein ausführt. Es wurde mittels MG 132 inhibiert; dies zeigte jedoch keinen Effekt auf die Verteilung mitochondrialer Proteine, wobei die starke Morphologieveränderung der Mitochondrien die Auswertung ihrer Proteinverteilungen beeinträchtigte.

Im Rahmen dieser Arbeit wurde bereits gezeigt, dass mitochondriale Dynamik eine gewisse Rolle bei der Gradientenverteilung mitochondrialer Proteine spielt. Deshalb wurde der Einfluss der Überexpression oder Inhibierung weiterer Proteine des mitochondrialen Fusions-, Teilungs- und Transportapparates analysiert. Hierzu zählte zum Einen die Zerstörung von filamentösem Aktin, aber auch die Überexpression verschiedenster Proteine, die entweder an der mitochondrialen Dynamik beteiligt sind (Opal, Mfn1/2, Drp1) oder Teile der mitochondrialen Transportkomplexe sind (Syntabulin, Syntaphilin, Kinesin-light-chain-1, cytoplasmic-dynein-heavy-chain-1). Keine der untersuchten Bedingungen ergaben signifikante Veränderungen der mitochondrialen Proteinverteilungen, wobei teilweise die Untersuchung aufgrund stark veränderter mitochondrialer Morphologie oder apoptotischer Vorgänge erschwert war. 
Zusammenfassend wurde im Rahmen dieser Arbeit erfolgreich gezeigt, dass die Herunterregulierung des mitochondrialen Teilungsproteins Drp1, sowie der Verlust des Transports von Mitochondrien entlang Mikrotubuli die Gradientenverteilung mitochondrialer Proteine beeinflussen. 


\section{Diskussion und Ausblick}

\subsection{Ursachen für die Heterogenität mitochondrialer Proteinverteilungen}

Innerhalb der letzten Jahre ist die Zahl der Studien, welche eine morphologische oder funktionale Heterogenität von Mitochondrien zwischen verschiedenen Zelltypen und Geweben belegen, deutlich angewachsen (Kuznetsov et al. 2009, Wikstrom et al. 2009, Jakobs et al. 2011). Ferner wurde gezeigt, dass diese Heterogenität auch innerhalb einzelner Zellen existiert (Bowser et al. 1998, Collins et al. 2002, Wikstrom et al. 2007, Wurm et al. 2011).

Mitochondrien sind von entscheidender Bedeutung für die Energiebereitstellung innerhalb eukaryotischer Zellen (McBride et al. 2006). Darüber hinaus besitzen sie wichtige Funktionen bei einer Reihe zellulärer Prozesse wie Stoffwechselvorgängen und Ionenhomöostase (Kennedy et al. 1950, Artom et al. 1951, Birt et al. 1960, Craddock et al. 1961, Maier et al. 1974, Scheffler 2001). Das Zusammenspiel aller mitochondrialer Funktionen könnte zu mitochondrialer Heterogenität führen, denn verschiedene mitochondriale Subpopulationen oder sogar einzelne Mitochondrien könnten unterschiedliche Funktionen erfüllen. Die Heterogenität könnte somit einen Mechanismus der Spezialisierung von Mitochondrien zur Erfüllung ihrer diversen Funktionen innerhalb der Zelle darstellen.

Weiterhin wird Mitochondrien eine entscheidende Rolle bei der Entstehung verschiedener Krankheiten, u.a. Diabetes mellitus, neurodegenerativer Erkrankungen und Krebs, zugeschrieben (Nunnari et al. 2012). Interessanterweise wurde ein erhöhtes Maß mitochondrialer Heterogenität unter pathophysiologischen Bedingungen, wie z.B. ischämischer Reperfusion und Diabetes (in BetaZellen), beobachtet (Wikstrom et al. 2009). Weiterhin verändern Stressbedingungen, die den Stoffwechsel betreffen, sowie Apoptose die Heterogenität von Mitochondrien (Kuznetsov et al. 2009, Wikstrom et al. 2009). Deshalb könnte das Verständnis mitochondrialer Heterogenität zur Aufklärung der Integration mitochondrialer Funktion in die Physiologie gesamter Zellen und Geweben sowie der Bedeutung ihrer Dysfunktion für pathophysiologische Zustände beitragen.

\subsubsection{Mitochondriale Heterogenität beruht auf einem aktiven Mechanismus}

Eine heterogene Verteilung ist für viele Proteine in verschiedenen Organismen und Geweben bekannt (De Camilli et al. 1986, Song et al. 2000, Gatti et al. 2001, Reeves et al. 2012, Saunders et al. 2012, Matsuoka et al. 2013). 
Bislang ist wenig darüber bekannt, ob auch die Verteilung mitochondrialer Proteine eine Heterogenität aufweist. In einer Studie wurde die Existenz einer unterschiedlichen Menge bzw. Aktivität der $\mathrm{F}_{1} \mathrm{~F}_{\mathrm{O}}$-ATPase oder des Adenin-Nukleotid-Transporters in verschiedenen Mitochondrien zwar postuliert, der Beweis durch Mikroskopie dieser Proteinheterogenität fehlte bislang (Cossarizza et al. 1996, Wikstrom et al. 2007). Kürzlich ergaben Studien unter Verwendung höchstauflösender Mikroskopietechniken, dass die Dichte mitochondrialer Proteincluster tatsächlich innerhalb von Säugerzellen ungleich ist. Hierzu wurden die nanoskaligen Proteinverteilungen der mitochondrialen Proteine Tom20 und Mitofilin/Mic60 mit Hilfe der STED-Mikroskopie aufgelöst und untersucht (Wurm et al. 2011, Jans et al. 2013). Im Rahmen beider Studien wurde eine höhere Proteindichte in perinukleären Mitochondrien als in peripheren Mitochondrien beobachtet. Im Fall von Tom20 korrelierte diese sogar mit einem physiologischen Parameter, nämlich dem mitochondrialen Membranpotential. Im Rahmen der vorliegenden Arbeit wurde belegt, dass verschiedene mitochondriale Proteine, die unterschiedliche Funktionen und submitochondriale Lokalisationen aufweisen, eine heterogene Verteilung über die gesamte Zelle, in Form eines intrazellulären Gradienten, besitzen.

Da eine heterogene intrazelluläre Verteilung für eine Vielzahl mitochondrialer Proteine und auch für Proteine anderer zellulärer Kompartimente beobachtet werden kann, stellt sich die Frage, ob diese heterogenen Verteilungen zufällig entstehen oder das Ergebnis eines aktiven Mechanismus sind. Aufgrund der Tatsache, dass mRNA im Zellkern produziert wird, könnte man annehmen, dass in Zellkernnähe auch eine höhere Konzentration an mRNA vorliegt und eine erhöhte Proteintranslation erfolgt. Deshalb wäre zu erwarten, dass generell mehr Proteinimport in Mitochondrien in Zellkernnähe stattfindet, wodurch die Gradientenverteilung mitochondrialer Proteine passiv entstehen könnte. Im Rahmen dieser Arbeit konnte jedoch gezeigt werden, dass bereits zu einem Zeitpunkt kurz nach der Zellteilung (während der Zytokinese) eine Gradientenverteilung von Tom20 erkennbar ist (siehe Abschnitt 3.4.2). Diese Beobachtung lässt die Vermutung zu, dass es einen sehr schnellen Mechanismus in der Zelle geben muss, der Mitochondrien auf beide Tochterzellen aufteilt und aktiv gezielt anordnet und so eine Gradientenverteilung mitochondrialer Proteine erzeugt.

\subsubsection{Energiebedarf als mögliche Ursache für mitochondriale Heterogenität}

Welche Signale und molekularen Mechanismen diese Verteilung der Mitochondrien regulieren und wozu letztendlich die Heterogenität existiert, ist bislang unbekannt. Es ist denkbar, dass die mitochondriale Heterogenität eine Anpassung an unterschiedliche subzelluläre Anforderungen und Bedingungen (Ionen- und Metabolit-Konzentrationen), vor allem Stoffwechselzustände, darstellt. 
Dementsprechend könnte die mitochondriale Organisation und Funktion hochspezialisiert sein, um die individuellen Bedürfnisse von Zellen (und ihrer distinkten Regionen) zu erfüllen.

Es besteht die Möglichkeit, dass die Gradientenverteilung mitochondrialer Proteine mit der Regulierung der Aktivität von Mitochondrien zusammenhängt. Denn im Rahmen einer Studie wurde die Hypothese aufgestellt, dass die perinukleäre Aggregierung von Mitochondrien einen Mechanismus darstellt, der dazu dient große Mengen ATP in der Nähe des Zellkerns zu erzeugen (Bruce et al. 2004). Dies wurde damit begründet, dass der Zellkern aufgrund verschiedener Prozesse wie dem nukleären Import, der Regulation von Kinasen, der Kontrolle des Zellzyklus, der DNAReplikation sowie der Funktion von lonenkanälen und -Transportern ein Organell mit einem hohem Bedarf an ATP ist. Somit könnte die Gradientenverteilung mitochondrialer Proteine ein Resultat unterschiedlicher Energieanforderungen innerhalb Zellen sein. Diese Hypothese wird durch die Beobachtung unterstützt, dass ADP die mitochondriale Beweglichkeit verringert. In Zellbereichen mit hohem ATP-Bedarf ist die Menge an ADP höher. Die Arretierung von Mitochondrien in diesen Zellregionen stellt somit eine Anpassung an den erhöhten ATP-Bedarf dar (Schwarz 2013).

Die Ergebnisse einiger Studien unterstützen die Hypothese, dass mitochondriale Heterogenität aufgrund unterschiedlicher Energiebedarfe entsteht. Hierfür spricht beispielsweise die Heterogenität des mitochondrialen Membranpotentials. Das mitochondriale Membranpotential ist ein Indikator der Aktivität für die ATP-Produktion von Mitochondrien. Allerdings existieren widersprüchliche Beobachtungen über die heterogene Verteilung des mitochondrialen Membranpotentials. Wurm et al. beobachteten in Ptk2-Zellen, unter Verwendung des Membranpotentialsensitiven-Farbstoffs DioC $_{6}$, eine Gradientenverteilung des mitochondrialen Membranpotentials, mit einem höheren Membranpotential in perinukleären Mitochondrien als in peripheren Mitochondrien (Wurm et al. 2011). Im Rahmen der vorliegenden Arbeit wurden die gleichen Beobachtungen über das mitochondriale Membranpotential in Vero-Zellen gemacht. Im Gegensatz hierzu wurde im Rahmen anderer Studien, unter Verwendung von JC-1, ein höheres Membranpotential in peripheren Mitochondrien als in perinukleären Mitochondrien für Astrozyten, Hep-2- und endotheliale Zellen beschrieben (Bereiter-Hahn et al. 1983, Smiley et al. 1991, Diaz et al. 1999). Eine andere Studie zeigte, dass in Astrozyten der Großteil der untersuchten Zellen über ein höheres Membranpotential in der Zellperipherie als in Zellkernnähe verfügt, wohingegen andere Zellen keine regionalen Unterschiede des mitochondrialen Membranpotentials oder sogar ein erhöhtes Membranpotential in Zellkernnähe aufwiesen (Keil et al. 2011). Weitere Studien, die mittels TMRE/TMRM die Verteilung des Membranpotentials in humanen Astrozyten, humanen Fibroblasten und pankreatischen BetaZellen analysiert haben, konnten wiederum keine Unterschiede des mitochondrialen Membranpotentials zwischen perinukleären und peripheren Mitochondrien feststellen (Diaz et al. 2000, Wikstrom et al. 2007). 
Es ist möglich, dass diese widersprüchlichen Beobachtungen auf unterschiedlichen experimentellen Bedingungen (u.a. aufgrund der Verwendung verschiedener Farbstoffe und /oder Kultivierungsbedingungen) und der Untersuchung verschiedener Zelllinien beruhen. Wahrscheinlich unterscheiden sich die Membranpotentialverteilungen zwischen verschiedenen Zelllinien aufgrund ihrer hochspezialisierten Funktionen. Diese Vermutung wird durch die Ergebnisse einer Studie unterstützt, die zeigte, dass sich der Mittelwert des mitochondrialen Membranpotentials von verschiedenen Zelllinien unterscheidet (Huang et al. 2004). Als möglichen Grund hierfür wurden unterschiedliche Energiebedarfe der analysierten Zelllinien angeführt.

Somit gibt es Hinweise darauf, dass die Aktivität für ATP-Produktion von Mitochondrien innerhalb einzelner Zellen, aufgrund der Beobachtung der Heterogenität des mitochondrialen Membranpotentials, unterschiedlich ist. Weitere Anhaltspunkte dafür, dass die Ursache mitochondrialer Heterogenität die Anpassung an unterschiedliche Energieanforderungen innerhalb Zellen ist, sind die heterogenen Verteilungen einer Vielzahl im Rahmen dieser Arbeit belegten mitochondrialen Proteine (siehe 3.1.4).

Hierzu zählen beispielsweise die Proteine des mitochondrialen Import-Apparates. Bis auf 13 hydrophobe Proteine sind alle mitochondrialen Proteine im Zellkern kodiert. Mitochondrien verfügen über spezielle Komplexe in der äußeren und inneren mitochondrialen Membran zum Import des Großteils ihrer Proteine. Die Verteilung der Bestandteile Tom20, Tom22, Tim23, Sam50 sowie des Chaperons Hsp70 dieser Importkomplexe wurde im Rahmen dieser Arbeit analysiert. Es wurde beobachtet, dass alle diese analysierten Proteine des mitochondrialen Import-Apparates eine Gradientenverteilung zeigen (siehe 3.1.4). Daraus kann man vermuten, dass der Import mitochondrialer Proteine nicht gleichmäßig innerhalb der Zelle stattfindet, sondern in der Nähe des Zellkerns eher als am Rand der Zelle erfolgt. Diese Beobachtung kann eine Anpassung an unterschiedliche Energiebedarfe bedeuten. Denn unter der Annahme, dass Zellen auf unterschiedliche Energieansprüche mit der Änderung des Proteingehalts ihrer Mitochondrien reagieren (Devin et al. 2007), ist es möglich, dass solch eine Anpassung auch für die Haupteintrittspore und somit die Importkomplexproteine existiert.

Weiterhin wurde im Rahmen dieser Arbeit die Verteilung der MICOS-Komplex-Komponenten Mic60, Mic10, Mic19, DnaJC11 und des Komplex-assoziierten Proteins Sam50 analysiert. Dieser Komplex lokalisiert u.a. an den Cristae Junctions, welche eine Verbindung mitochondrialer Cristae zur inneren Grenzflächenmembran darstellen (Pfanner et al. 2014). Es wurde gezeigt, dass alle analysierten Komponenten des MICOS-Komplexes eine heterogene Verteilung innerhalb einer Zelle, in Form eines intrazellulären Gradienten, aufweisen (siehe 3.1.4).

Dies kann somit bedeuten, dass auch die Verteilung und Dichte mitochondrialer Cristae innerhalb Zellen heterogen ist. Die Dichte der Cristae Junctions kann ein Maß für die Aktivität von 
Mitochondrien sein, weil sie nicht nur die Dichte mitochondrialer Cristae widerspiegelt sondern die Cristae Junctions auch die Zusammensetzung der Cristae-Membran kontrollieren und dadurch die ATP-Produktion beeinflussen (Mannella 2006). Im Einklang mit dieser Annahme steht die Beobachtung dieser Arbeit, dass auch die Verteilungen von Untereinheiten der Atmungskettenkomplexe (ATP Synthase, Cytochrom c und der Cytochrom c-Oxidase) eine Gradientenverteilung innerhalb von Zellen besitzen (siehe 3.1.4). Dies gibt einen weiteren Hinweis darauf, dass womöglich auch die ATP-Produktion innerhalb einer Zelle räumlich ungleich verteilt ist. Somit weisen die Beobachtungen dieser Arbeit darauf hin, dass die Aktivität der Mitochondrien innerhalb von Zellen verschieden ist was auf unterschiedliche Proteinverteilungen, die an die lokalen Energieansprüche innerhalb von Zellen angepasst werden können, zurückzuführen ist.

Für die weitere Aufklärung der Ursache mitochondrialer Heterogenität wäre zudem die Analyse mitochondrialer Proteinverteilungen in Zellen, die polarisiert sind und eine hochspezialisierte Funktion erfüllen, hilfreich. Beispielsweise könnte die Untersuchung von mitochondrialen Proteinverteilungen in Muskelzellen weitere Belege dafür, dass ein unterschiedlicher intrazellulärer Energiebedarf die Ursache der Heterogenität von Mitochondrien ist, geben. Muskelzellen sind deshalb von Bedeutung, weil ihre Funktion der Muskelkontraktion große Mengen an Energie in Form von ATP benötigt. Unter der Annahme, dass die Heterogenität mitochondrialer Proteinverteilungen deshalb existiert, weil ein erhöhter ATP-Bedarf in bestimmten Zellregionen gedeckt werden muss, ist zu vermuten, dass in Muskelzellen keine Gradientenverteilung mitochondrialer Proteine beobachtbar ist. Dies ist deshalb wahrscheinlich, weil die Fibrillen, welche die Energie für die Kontraktion benötigen, sich überall in den Muskelzellen befinden. Die Muskelfibrillen wären die Strukturen in der Zelle mit dem höchsten Energiebedarf und nicht der Zellkern, was möglicherweise für Fibroblastenzellen gilt. Im Rahmen dieser Arbeit wurde deshalb die Verteilung von Tom20 in Herzmuskelzellen von Ratten untersucht (präpariert wurden diese von Dr. Eva Wagner, UMG). Die Immunfluoreszenzmarkierung von Tom20 ergab eine vollständige Färbung innerhalb der Zellen. Es wurde kein distinktes Netzwerk, wie es in den meisten Säugerzelltypen zu beobachten ist, sondern eine hochgeordnete Struktur sichtbar (Abbildung 4.1). Dies deutete bereits darauf hin, dass keine Heterogenität der Dichteverteilung des mitochondrialen Tom20 Proteins, wie sie in Vero-Zellen zu beobachten ist, in Kardiomyozyten existiert. 


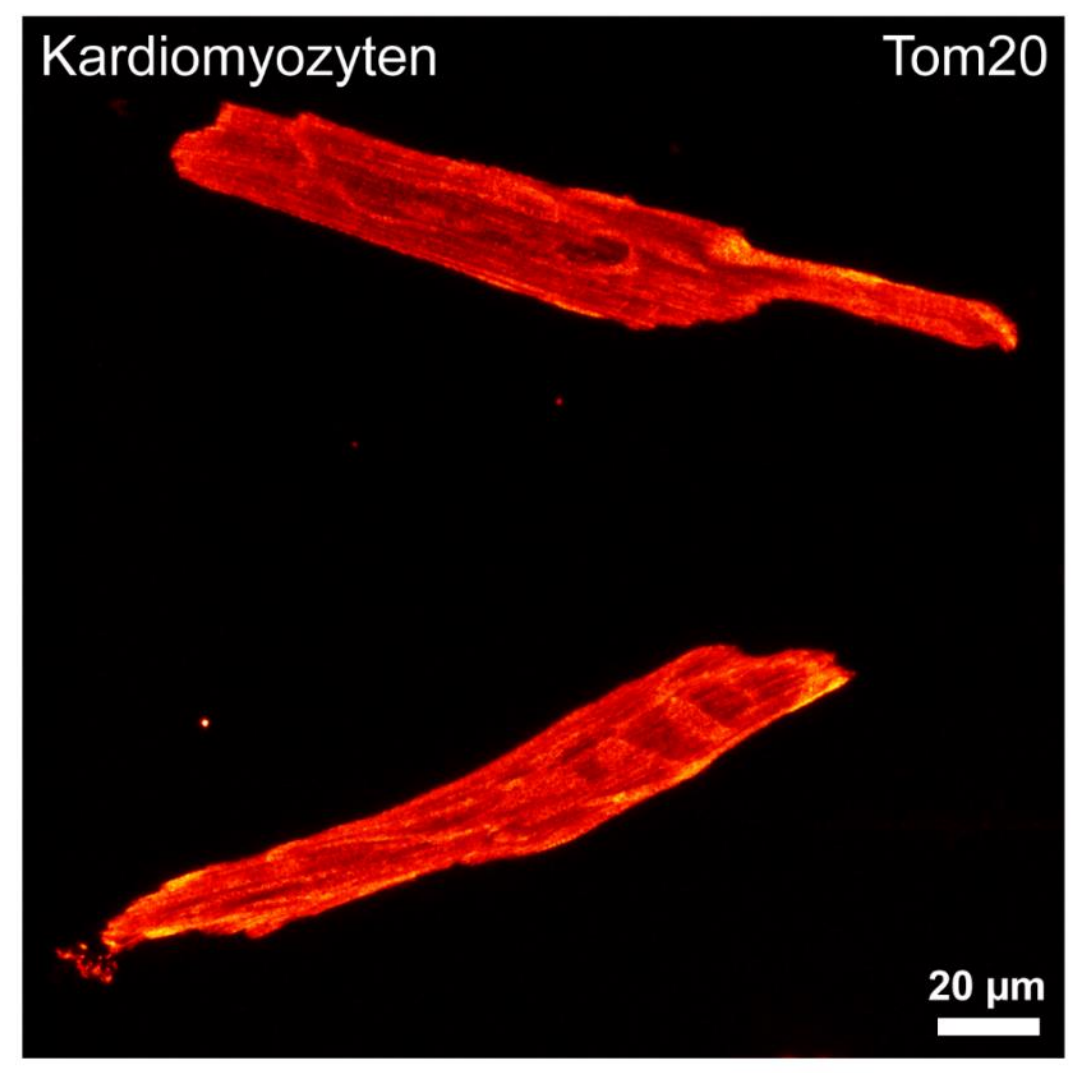

Abbildung 4.1: Untersuchung mitochondrialer Proteinverteilungen in Herzmuskelzellen von Ratten.

Die Immunfluoreszenzmarkierung von Tom20 auf Herzmuskelzellen von Ratten zeigt, dass die Mitochondrien auf die gesamte Zelle ausgebreitet vorliegen. Dabei verändert sich die Tom20-Fluoreszenzintensität innerhalb der Zelle kaum. Lediglich in der Nähe der Plasmamembran ist sie leicht erhöht. Abgebildet ist eine Maximalprojektion konfokaler z-Stapel.

Eine Auswertung der Proteinverteilung von Tom20 in diesen Zellen bestätigte diese Beobachtung. Es war sogar ein leichter Anstieg der Proteindichte in der Nähe der Plasmamembran sichtbar (Abbildung 4.2).

Dies stimmt gut überein mit den Ergebnissen einer früheren Studie (Kuznetsov et al. 2009), in welcher auch eine Erhöhung der Proteindichte in Plasmamembrannähe beobachtet wurde. Dies könnte auf einen Mechanismus der Energiebereitstellung für ATP-getriebene lonenkanäle (z.B. für $\mathrm{Ca}^{2+}$-Eintritt) zurückzuführen sein (Lawrie et al. 1996). Somit geben diese Erkenntnisse einen Hinweis darauf, dass die Verteilung mitochondrialer Proteine tatsächlich einen Mechanismus der Anpassung der Zelle an unterschiedliche Energiebedarfe darstellt. 


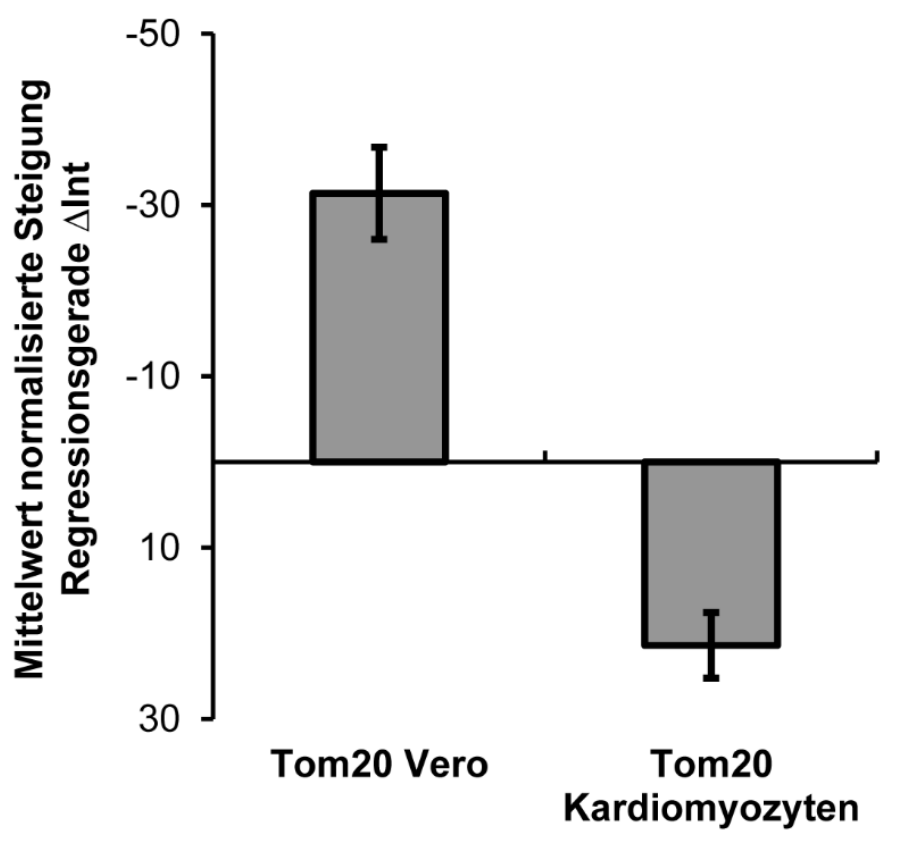

Abbildung 4.2: Untersuchung mitochondrialer Proteinverteilungen in Herzmuskelzellen von Ratten.

Die Auswertung der Fluoreszenzintensitätsverteilung von Tom20 in je mind. 16 Vero-Zellen oder Kardiomyozyten zeigte, dass in Kardiomoyzyten eine deutlich veränderte Heterogenität exisitiert. Kardiomozyten wiesen eine inverse intrazelluläre Gradientenverteilung von Tom20 im Vergleich zu Vero-Zellen auf. Für die Analyse von Kardiomozyten wurde der Auswertungsalgorithmus ohne mitochondriale Mittellinie verwendet. Gezeigt sind Mittelwerte und Standardfehler.

Weiterhin könnte auch die Analyse der Verteilung mitochondrialer Proteine in endothelialen Zellen, die über Zilien verfügen, Hinweise dazu liefern, ob mitochondriale Heterogenität existiert um unterschiedliche Energiebedarfe innerhalb Zellen zu erfüllen. Zilien befinden sich direkt an der Plasmamembran. Für ihre Bewegung muss Energie aufgebracht werden. Unter der Annahme, dass dieser Unterschied im Energiebedarf von der Zelle kompensiert werden muss, wäre die Untersuchung der mitochondrialen Proteinverteilung hier von Bedeutung. Möglicherweise verfügen diese Zellen über eine inverse Proteinverteilung im Vergleich zu Vero-Zellen, da anzunehmen ist, dass die Zilien an der Plasmamembran das Organell mit dem höchsten Energiebedarf darstellen.

In Zukunft wäre insbesondere die Analyse mitochondrialer Heterogenität in Neuronen von Interesse. Aufgrund ihrer komplexen und individuellen Struktur und Funktion, ist die korrekte Funktion und Bewegung von Mitochondrien in diesen Zellen essentiell. Die Synapsen, welche den höchsten Bedarf an ATP und $\mathrm{Ca}^{2+}$-Pufferkapazität innerhalb einer Nervenzelle besitzen, befinden sich häufig in weit vom Soma entfernten Endregionen. Die meisten mitochondrialen Proteine sind jedoch im Kern kodiert. Die Mitochondrien müssen demnach eine lange Strecke vom Kern bis zu den Nervenenden zurücklegen. Dieser Transport muss streng reguliert sein. Jegliche Störung kann verheerende Auswirkungen haben. Mitochondriale Dysfunktion in Neuronen steht im Zusammenhang mit der Entstehung neurodegenerativer Erkrankungen wie Parkinson, Demenz oder Alzheimer. Dementsprechend wäre es von großem Interesse zu erforschen, in welchem Ausmaß eine Gradientenverteilung mitochondrialer Proteine in Neuronen existiert und ob sie bei 
neurodegenerativen Erkrankungen verändert ist. Dies kann weitere Erkenntnisse darüber liefern, welche funktionelle Relevanz mitochondriale Heterogenität besitzt.

Es gibt bereits erste Hinweise auf eine Heterogenität des Membranpotentials zwischen Mitochondrien in Neuronen. Interessanterweise wurde sogar eine Korrelation zwischen Membranpotential und Transportrichtung von Mitochondrien beobachtet. So konnte gezeigt werden, dass $90 \%$ der Mitochondrien mit einem hohen Membranpotential in die Richtung des Wachstumskegels eines Neurons transportiert wurden und sich $80 \%$ der Mitochondrien mit einem geringen Membranpotential in die entgegengesetzte Richtung zum Zellkörper hin bewegt haben (Miller et al. 2004). Es wäre möglich, dass diese Beobachtung auch mit einer Heterogenität mitochondrialer Proteinverteilungen korreliert.

Die Ergebnisse dieser Arbeit geben deutliche Hinweise darauf, dass die mitochondriale Heterogenität das Ergebnis einer Anpassung der Mitochondrien an unterschiedliche subzelluläre Anforderungen und Bedingungen, insbesondere Energiebedarfe und Ionen- bzw. Metabolitkonzentrationen, ist. Das bedeutet, dass die Organisation von Mitochondrien hochspezialisiert sein muss, um die individuellen Bedürfnisse von Zellen bzw. distinkten Zellbereichen zu erfüllen.

\subsection{Faktoren, die zur Entstehung und Aufrechterhaltung der} mitochondrialen Heterogenität beitragen

Welche molekularen Mechanismen der Entstehung und Aufrechterhaltung mitochondrialer Heterogenität zugrunde liegen war vor Beginn der vorliegenden Arbeit nicht bekannt. Im Rahmen dieser Arbeit sollten diese Mechanismen identifiziert werden.

\subsubsection{Das mitochondriale Netzwerk von Vero-Zellen ist nicht kontinuierlich}

Mitochondrien sind hochdynamische Organellen, die sich durch fortwährende Fusions-, Teilungs- und Bewegungsvorgänge auszeichnen. Diese Prozesse tragen maßgeblich zu der schnellen Veränderung der Erscheinung ihres Netzwerks bei (Ferree et al. 2012).

Hierbei stellt sich die Frage, wie die Gradientenverteilung mitochondrialer Proteine trotz kontinuierlicher Dynamik dieser Organellen existieren kann. Dies wäre möglich, wenn das mitochondriale Netzwerk diskontinuierlich ist und mitochondriale Translokation räumlich begrenzt erfolgt. 
Mikroskopische Studien zur Untersuchung der mitochondrialen Kontinuität unter Verwendung fluoreszierender Proteine lieferten widersprüchliche Beobachtungen. Zum einen gibt es eine Reihe von Veröffentlichungen, die darauf hinweisen, dass sich der mitochondriale Inhalt innerhalb einer Stunde komplett vermischt, was auf eine Kontinuität des Netzwerks hindeutet (Karbowski et al. 2004, Karbowski et al. 2004, Twig et al. 2008) (Abbildung 4.3). Dies würde zu einer Homogenisierung des mitochondrialen Inhalts führen. Wenn dies so wäre, dann wäre eine Gradientenverteilung mitochondrialer Proteine unwahrscheinlich.

A HeLa

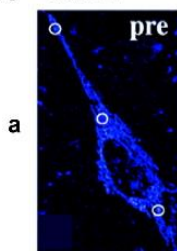

Cos-7

b
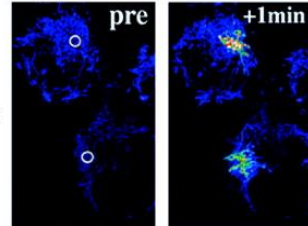

Hippocampal neurons

c
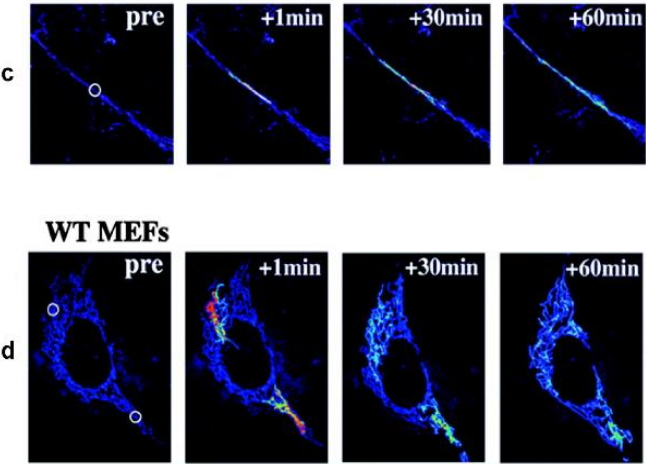
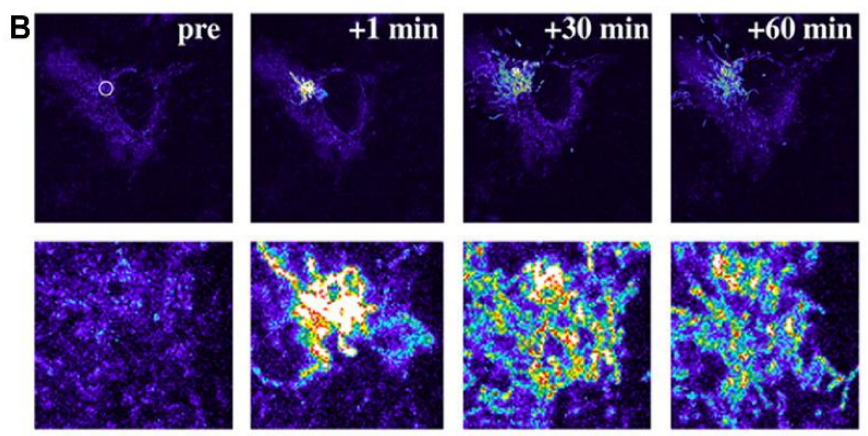

C
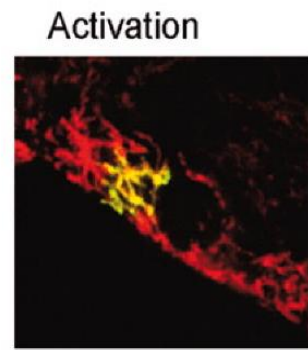

PAGFPmt
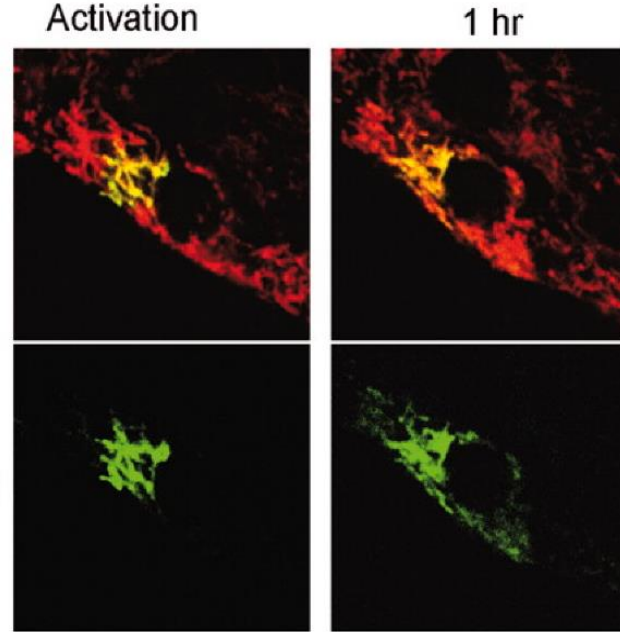

Abbildung 4.3: Ergebnisse der Studien, die eine Kontinuität des mitochondrialen Netzwerks belegen.

(A) Untersuchung der Kontinuität von Mitochondrien in a) HeLa-Zellen, b) COS-7-Zellen, c) Neuronen des Hippocampus und d) MEF-Zellen unter Verwendung des mitochondrial exprimierten photoaktivierbaren PA-GFPs (RegenbogenFarbtabelle). Die Beobachtung der Ausbreitung des Fluoreszenzsignals des aktivierten Proteins erfolgte über einen Zeitraum von 60 min. Abgebildet sind z-Projektionen. Abbildung verändert aus (Karbowski et al. 2004)

(B) HeLa-Zellen, welche das photoaktivierbare PA-GFP mitochondrial exprimierten (Regenbogen-Farbtabelle), wurden photoaktiviert. Die Beobachtung der Ausbreitung des Fluoreszenzsignals des aktivierten Proteins erfolgte über einen Zeitraum von $60 \mathrm{~min}$. Abbildung verändert aus (Karbowski et al. 2004)

(C) In einer ?2-Zelle innerhalb einer intakten Pankreasinsel kommt es zu einer Verbreitung des mtPA-GFP-Signals nach einer Stunde aufgrund mitochondrialer Dynamik. Abbildung verändert aus (Molina et al. 2009).

In anderen Studien wurden jedoch gegensätzliche Beobachtungen gemacht. Mit Hilfe verschiedener Mikroskopieansätze wurde gezeigt, dass sich der Inhalt von Mitochondrien nicht unbegrenzt auf das gesamte Netzwerk ausbreiten kann. Dies gibt einen Hinweis darauf, dass keine Kontinuität aller 
Mitochondrien innerhalb einer Zelle besteht (Collins et al. 2002, Ivanchenko et al. 2005) (Abbildung 4.4).

A

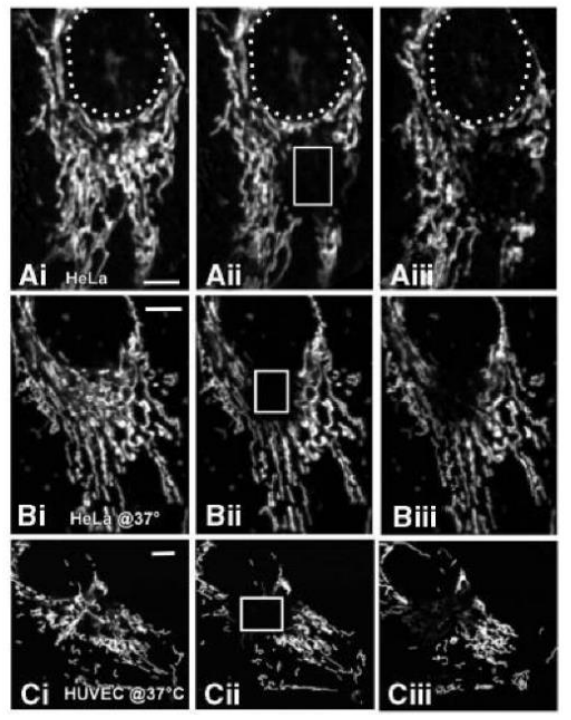

B

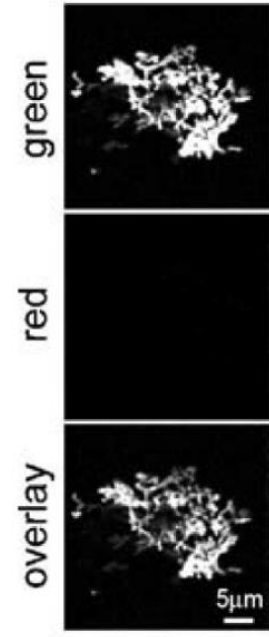

before
2

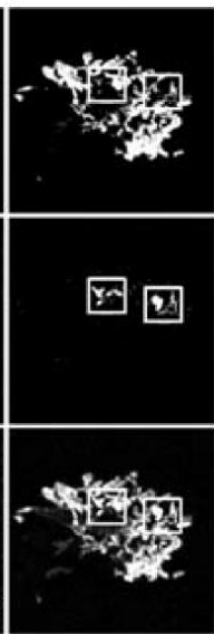

$1 \mathrm{~min}$
3

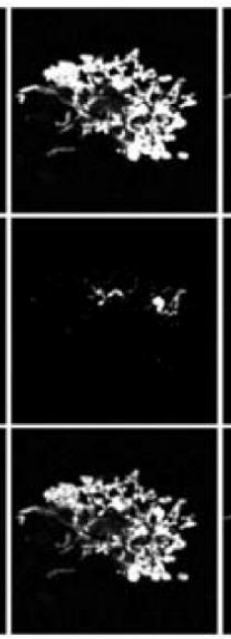

$9 \min$
4

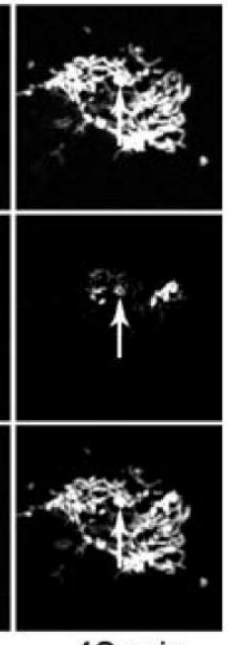

$42 \mathrm{~min}$

Abbildung 4.4: Ergebnisse der Studien, die keine Kontinuität des mitochondrialen Netzwerks zeigen.

(A) Untersuchung der Kontinuität von Mitochondrien in a) HeLa-Zellen bei $22^{\circ} \mathrm{C}$, b) HeLa-Zellen bei $37^{\circ} \mathrm{C}$ und $\mathrm{C}$ ) $\mathrm{HUVEC}$ Zellen bei $37^{\circ} \mathrm{C}$ unter Verwendung des mitochondrial exprimierten DsRed und der FRAP-Methode(Graustufen). DsRed in Mitochondrien innerhalb eines ROIs (weißes Quadrat) wurde zunächst gebleicht und nach 10 sek (A,B,C ii) sowie nach 20 min (A,B,C iii) mikroskopiert. Größenbalken: $5 \mu \mathrm{m}$. Abbildung verändert aus (Collins et al. 2002).

(B) Die Untersuchung der mitochondrialen Kontinuität erfolgte in HeLa-Zellen, die das photoaktivierbare Protein d2EosFP mitochondrial exprimierten. d2EosFP wurde zunächst in kleinen Bereichen der Zelle photokonvertiert. Anschließend wurde die Verbreitung der roten, geschalteten Fluoreszenz nach bestimmten Zeitpunkten (1, 9 und 42 min) verfolgt. Keine Größenbalken vorhanden. Abbildung verändert aus (Ivanchenko et al. 2005).

Somit war es nötig zu untersuchen, ob das Netzwerk von Mitochondrien speziell in Vero-Zellen kontinuierlich ist.

Im Rahmen dieser Arbeit wurde anhand zweier unterschiedlicher Methoden beobachtet, dass innerhalb ca. einer Stunde die Vermischung von mitochondrialem Inhalt und die Positionsänderung von Mitochondrien nur innerhalb eines relativ kleinen abgegrenzten Bereiches erfolgten (siehe 3.2). Diese Experimente zeigten, dass die mitochondriale Dynamik in den untersuchten Zellen lokal begrenzt stattfindet und keine unbegrenzte Beweglichkeit einzelner Mitochondrien existiert. Das lässt den Schluss zu, dass die Mitochondrien ihre ursprüngliche Ausgangsposition kaum verlassen, sondern vielmehr ein ,Schwingen' um den Ausgangspunkt stattfindet. Kleine oszillierende Bewegungen des mitochondrialen Netzwerks wurden bereits im Rahmen anderer Studien in humanen Pankreaszellen (Kuznetsov et al. 2010) und in Ptk2-Zellen (Saunter et al. 2009) beobachtet. Auch hier wurde gezeigt, dass Mitochondrien eher um ihren Ausgangspunkt verharren und im Allgemeinen „vor-zurück“-Bewegungen vollziehen. 
Außerdem geben die Ergebnisse der vorliegenden Arbeit einen Hinweis darauf, dass das mitochondriale Netzwerk von Vero-Zellen nicht kontinuierlich ist. Es findet somit keine vollständige Homogenisierung des Gehalts von Mitochondrien statt, was zu einem Verlust der Gradientenverteilung mitochondrialer Proteine führen würde. Es stellt sich die Frage, wie es zu den oben genannten abweichenden Forschungsergebnissen kommen kann.

Es kann sich dabei zum einen um ein unterschiedliches Verhalten aufgrund der Verwendung verschiedener Zelllinien handeln. Es ist denkbar, dass einige Zelllinien aufgrund ihrer hochspezialisierten Funktion (gegenüber Vero-Zellen) auch ein anderes Verhalten mitochondrialer Dynamik und Kontinuität aufweisen. Es ist wahrscheinlich, dass die widersprüchlichen Beobachtungen aufgrund unterschiedlicher Bedingungen während des Experimentes bzw. der Mikroskopie (z.B. Temperatur, verschiedene fluoreszierende Proteine) entstanden sind.

Im Rahmen dieser Arbeit wurden die Ergebnisse der Studien, die keine komplette Vermischung des mitochondrialen Inhalts beobachteten bestätigt (Studien von: (Collins et al. 2002, Ivanchenko et al. 2005).

Da die mitochondriale Dynamik scheinbar selektiv und begrenzt erfolgt, kann eine Heterogenität mitochondrialer Funktionalität und Proteinverteilungen dennoch existieren.

Somit kann für die Beweglichkeit von Mitochondrien in Vero-Zellen im Kontext der Heterogenität mitochondrialer Proteinverteilungen ein Modell beschrieben werden: die Gradientenverteilung mitochondrialer Proteine geht durch die Dynamik des gesamten mitochondrialen Netzwerks nicht verloren. Die Beweglichkeit von mitochondrialen Filamenten erlaubt zwar Fusions- und Teilungsvorgänge und somit einen Austausch ihres Inhalts in einem lokal begrenztem Zellbereich, dennoch erfolgt die Homogenisierung nicht in dem Ausmaß, dass sich der Inhalt jedes Mitochondriums über die gesamte Zelle verteilen könnte. Hierdurch können Gradientenverteilungen mitochondrialer Proteine bestehen bleiben. Es besteht demnach keine Kontinuität des mitochondrialen Netzwerks in Vero-Zellen.

Wie anhand der Experimente dieser Arbeit festgestellt wurde, führt mitochondriale Dynamik in VeroZellen nicht zu einer vollständigen Homogenisierung des mitochondrialen Inhalts. Eine mögliche Erklärung für diese Beobachtung kann die individuelle Regulierung mitochondrialer Fusion oder Teilung darstellen. Außerdem formen diese Prozesse entscheidend das Erscheinungsbild der gesamten Mitochondrienpopulation. Dementsprechend wäre es vorstellbar, dass die mitochondriale Fusion und Teilung eine Rolle bei der Entstehung und Erhaltung mitochondrialer Heterogenität besitzen. 


\subsubsection{Die Elongation von Mitochondrien vermindert die intrazelluläre} Gradientenverteilung mitochondrialer Proteine

Weitere Erkenntnisse über den molekularen Mechanismus der Erhaltung der Heterogenität mitochondrialer Proteinverteilungen wurden im Rahmen dieser Arbeit erhalten, indem untersucht wurde, welchen Einfluss die Änderung der Morphologie von Mitochondrien, aufgrund inhibierter mitochondrialer Fusion oder Teilung, auf die Verteilung eines mitochondrialen Proteins ausübt.

Mittels Konfokal- und STED-Mikroskopie wurde gezeigt, dass das Ausmaß der Gradientenverteilung von Tom20 innerhalb von Zellen, in denen das mitochondriale Teilungsprotein Drp1 herunterreguliert ist, deutlich gegenüber normalen Zellen mit intakter mitochondrialer Teilungsfähigkeit verringert ist. Die Unterbindung mitochondrialer Fusion durch Mfn2-Herunterregulierung führte indes zu keiner Veränderung dieser Heterogenität (siehe 3.3). Das gibt einen Hinweis darauf, dass mitochondriale Teilung einen erheblichen Beitrag zur Heterogenität mitochondrialer Proteinverteilungen leistet.

Im Rahmen dieser Arbeit wurde belegt, dass die Hyperfusionierung und somit eine Elongation von Mitochondrien das Ausmaß der Gradientenverteilung mitochondrialer Proteine deutlich verringert. Das kann zwei Ursachen haben. Zum einen kann diese Beobachtung generell auf die Elongation der Mitochondrien zurückgeführt werden, wodurch die Proteine innerhalb der gesamten Mitochondrien frei diffundieren könnten und sich der Gradient mit der Zeit auflöst. Auf der anderen Seite könnte es sein, dass die Teilung von Mitochondrien ein Prozess ist, der heterogene Mitochondrien erzeugt. Das könnte bedeuten, dass mitochondriale Teilung tatsächlich sehr selektiv stattfindet und somit zur Entstehung und Erhaltung mitochondrialer Proteingradienten beiträgt.

\subsubsection{Mitochondriale Proteine besitzen während der gesamten Interphase des}

\section{Zellzyklus eine heterogene Verteilung}

Mitochondriale Fusion und Teilung prägen das äußere Erscheinungsbild von Mitochondrien. Im Verlauf des Zellzyklus kann sich dieses, aufgrund eines veränderten Gleichgewichts mitochondrialer Fusions- und Teilungsvorgänge, deutlich verändern und hyperfusionierte oder fragmentierte Mitochondrien erzeugen (Arakaki et al. 2006, Mitra et al. 2009). Da im Rahmen dieser Arbeit belegt wurde, dass eine Hyperfusionierung von Mitochondrien die Verteilung ihrer Proteine verändert (siehe 3.3), wurde untersucht, ob es während des Zellzyklus zu Modifikationen der Gradientenverteilung mitochondrialer Proteine kommt. Die Ergebnisse dieser Experimente können weitere Hinweise auf den Mechanismus der Erhaltung mitochondrialer Heterogenität geben. 
In einer Studie wurde für NRK-Zellen beobachtet, dass am Übergang von der G1- zur S-Phase, vermehrt Zellen mit einem hyperfusionierten mitochondrialem Netzwerk vorlagen während die Mitochondrien, welche die Mitose vollzogen, eine stark fragmentierte Morphologie aufwiesen (Mitra et al. 2009).

Im Rahmen der vorliegenden Arbeit konnte mittels Immunfluoreszenzmarkierungen gegen die Zellzyklusmarkerproteine Aurora B-Kinase und PCNA jeder Zelle ihre individuelle Zellzyklusphase zugeordnet werden. Es konnte eine leichte Fragmentierung und Aggregierung der Mitochondrien während der Mitose (Metaphase, Anaphase, Telophase) beobachtet werden und somit die Ergebnisse früherer Studien teilweise bestätigt werden (Arakaki et al. 2006, Mitra et al. 2009). Die Fragmentierung der Mitochondrien während der Mitose scheint in Vero-Zellen nicht so ausgeprägt zu sein, wie in den NRK-Zellen einer anderen Studie (Mitra et al. 2009). Weiterhin war keine deutliche Hyperfusionierung der Mitochondrien am Übergang von der G1- zur S-Phase sichtbar, die in der zuvor genannten Studie gezeigt wurde (Mitra et al. 2009) (Abbildung 4.5).
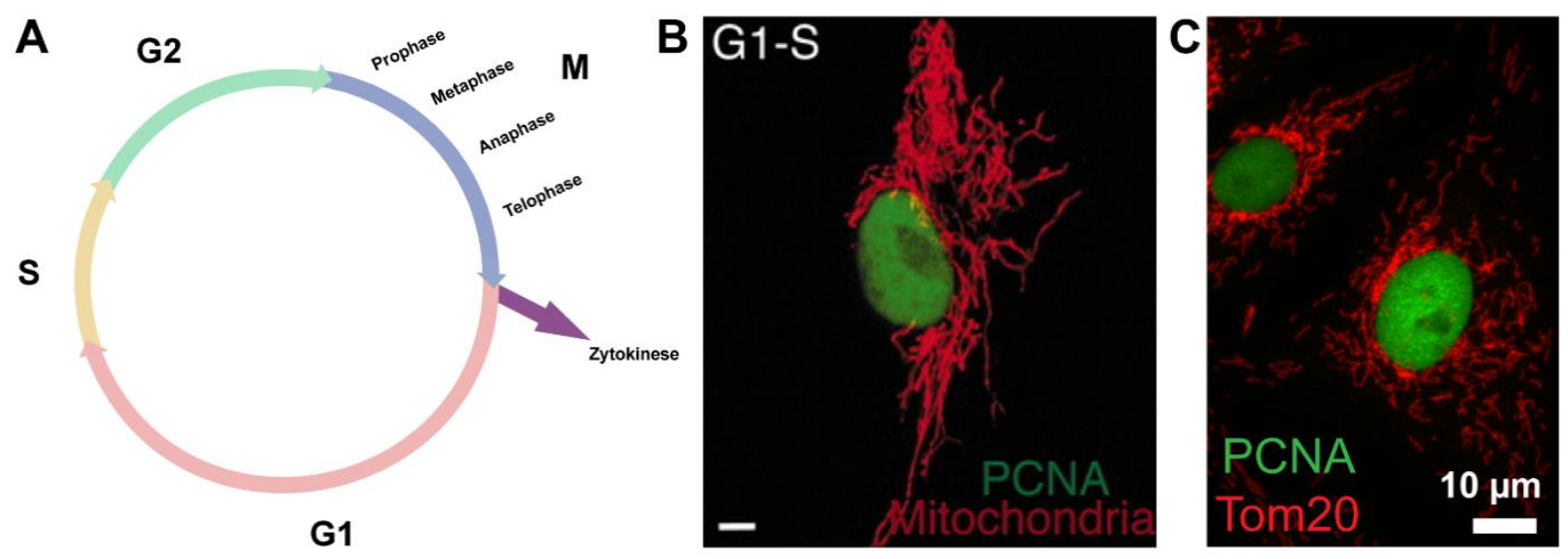

Abbildung 4.5: Mitochondriale Fusion und Teilung während des Zellzyklus.

(A) Schematische Darstellung des Verlaufs des Zellzyklus von Säugerzellen. B) Die Hyperfusionierung von Mitochondrien kann am Übergang von G1- zur S-Phase in NRK-Zellen beobachtet werden. (beide Markierungen resultieren aus Überexpression von fluoreszierenden Fusionsproteinen). Größenbalken: 5 mm. Abbildung verändert aus (Mitra et al. 2009) C) Im Rahmen dieser Arbeit wurde in Vero-Zellen keine Hyperfusionierung von Mitochondrien am Übergang von der G1zur S-Phase beobachtet (beides Immunfluoreszenzmarkierungen).

In einer weiteren Untersuchung zur Morphologie von Mitochondrien wurde in HeLa-Zellen auch keine offensichtliche Hyperfusionierung von Mitochondrien am Übergang von der G1- zur S-Phase beobachtet (Arakaki et al. 2006). Es ist möglich, dass die stärkeren Veränderungen der mitochondrialen Form, sowohl während der Mitose, als auch während dem G1/S-Übergang spezifische Eigenschaften der NRK-Zelllinie sind.

Eine entscheidende experimentelle Limitation ist die Tatsache, dass der G1/S-Übergang nicht durch die spezifische Lokalisation eines Zellzyklusmarkers identifiziert werden kann. Somit ist es nicht 
möglich Zellen exakt zu diesem Zeitpunkt des Zellzyklus zu beobachten. In der früheren Studie von Mitra et al. wurde eine chemische Synchronisation angewandt, um Zellen im G1/S-Übergang anzureichern. Dies könnte auch einen Einfluss auf die Mitochondrienmorphologie haben.

Da in Vero-Zellen der Interphase keine starken Veränderungen der mitochondrialen Morphologie beobachtet wurden, könnte man annehmen, dass sich auch die Gradientenverteilung mitochondrialer Proteine wenig ändert. Tatsächlich wurde im Rahmen dieser Arbeit belegt, dass während der Stadien der Interphase (frühe G1/Zytokinese, S, G2) eine Gradientenverteilung von Tom20 existiert. Die Phasen der Mitose (Prophase, Metaphase, Anaphase, Telophase) konnten nicht analysiert werden, weil die Mitochondrien zu diesem Zeitpunkt sehr stark aggregiert vorliegen. Da Mitochondrien nicht de novo erzeugt werden, sondern sich kontinuierlich während des Zellzyklus vermehren, bedeutet dies auch, dass der molekulare Mechanismus, der die Gradientenverteilung mitochondrialer Proteine aufrechterhält, konstant aktiv sein muss, unabhängig von der Zellzyklusphase. Allerdings ergibt sich daraus auch die Frage, zu welchem Zeitpunkt nach der Mitose, also der Zellteilung, die Gradientenverteilung mitochondrialer Proteine entsteht. Denn während der Mitose ist es nötig, die Mitochondrien der Ausgangszellen, welche teilweise fragmentiert vorliegen, auf beide Tochterzellen aufzuteilen und das mitochondriale Netzwerk anschließend wieder herzustellen. Interessanterweise konnte im Rahmen der vorliegenden Arbeit bereits zu dem Zeitpunkt der Zytokinese, also der endgültigen Teilung beider Tochterzellen, eine Gradientenverteilung von Tom20, in Form eines intrazellulären Gradienten, beobachtet werden (siehe 3.4.2). Diese Beobachtung deutet darauf hin, dass es einen sehr schnellen Mechanismus in der Zelle geben muss, der direkt nach der Aufteilung aller Mitochondrien auf beide Tochterzellen, aktiv zu einer gezielten spezifischen Anordnung der Mitochondrien mit dem Resultat einer Gradientenverteilung mitochondrialer Proteine, führt.

Die Aufklärung dieses Mechanismus kann entscheidende Informationen darüber liefern, wie die Heterogenität mitochondrialer Proteinverteilungen entsteht. Ein möglicher Teil des Mechanismus, der zu diesem raschen Aufbau der Gradientenverteilung mitochondrialer Proteine in Säugerzellen führt, könnte nicht nur die mitochondriale Teilung darstellen, sondern auch die spezifische Aufhängung von Mitochondrien an Mikrotubuli. Vorhergehende Studien zeigten bereits, dass die mitochondriale Vererbung (also die Aufteilung der Mitochondrien von der Mutterzelle auf beide Tochterzellen) ein koordinierter Prozess ist, der einen aktiven Transport entlang der Bestandteile des Zytoskeletts beinhaltet (Yaffe 1999, Fuchs et al. 2002). Denkbar wäre, dass Mitochondrien, die sich in der Mutterzelle beispielsweise in Zellkernnähe mit einem Mikrotubuli assoziiert befanden, während der Mitose an diesem Filament weiterhin gebunden blieben und nach Aufteilung der Mitochondrien auf beide Tochterzellen so erneut in Zellkernnähe positioniert würden. Dies würde nach der 
Zellteilung einen raschen Aufbau der Gradientenverteilung mitochondrialer Proteine erlauben. Um dies zu untersuchen, könnten mikroskopische Studien unter Verwendung photokonvertierbarer fluoreszierender Proteine, über den Verlauf der Mitose angefertigt werden. Hierzu könnten einzelne Mitochondrien, z.B. in der Nähe des Zellkern, von Zellen, die sich in der späten G2-Phase befinden, photokonvertiert und anschließend die Fluoreszenz des Mitochondriums während der Mitose verfolgt werden. Nach Abschluss der Zellteilung wäre zu untersuchen, wo sich das photokonvertierte Mitochondrium befindet. Wäre es wieder in Zellkernnähe lokalisiert, würde dies die Annahme unterstützen, dass die subzelluläre Position von Mitochondrien nach der Zellteilung erhalten bleibt. Um Mitochondrien gezielt zu transportieren und anzuordnen, sodass nach der Mitose in beiden Tochterzellen eine Gradientenverteilung mitochondrialer Proteine vorliegt, müssten Mitochondrien in irgendeiner Weise unterschieden werden, z.B. aufgrund Proteinkonzentrationen, Membranpotential oder Metabolit-Konzentrationen. Welches spezifische mitochondriale Signal hierfür ursächlich ist und über welchen Mechanismus dieses erkannt wird und die Mitochondrienanordnung reguliert wird ist bislang völlig unbekannt.

In der Bäckerhefe Saccharomyces cerevisiae ist ein Mechanismus bekannt, der im Rahmen dieser Untersuchungen von großem Interesse ist. Die Bäckerhefe vermehrt sich durch Knospung (Feldmann 2009). Hierzu müssen Mitochondrien in der Tochterhefe platziert werden. Die Vererbung von Mitochondrien erfolgt sehr spezifisch (Vevea et al. 2014). Es werden nur die gesunden Mitochondrien an die Tochterhefe weitergegeben (Steinkraus et al. 2008, Westermann 2014). Mitochondrien mit geringem Redoxpotential und erhöhter ROS-Menge verbleiben in der Mutterzelle (McFaline-Figueroa et al. 2011, Vevea et al. 2014). Somit entsteht eine Asymmetrie zwischen Mutter- und Tochterhefe bezüglich ihres Alters (Abbildung 4.6). Demnach ist die Bäckerhefe in der Lage, Mitochondrien anhand ihres metabolischen Zustands zu unterscheiden und selektiv zu transportieren. 


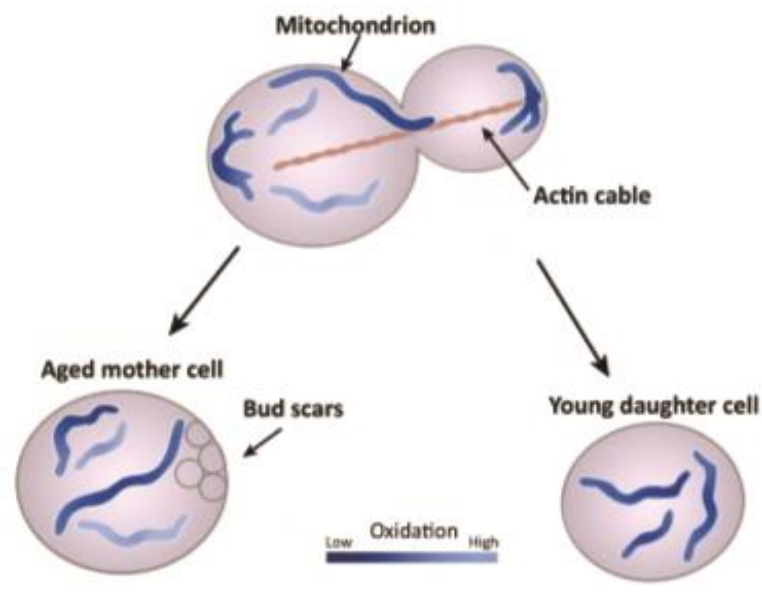

Abbildung 4.6: Mitochondriale Qualitätskontrolle
während der Zellteilung in der Bäckerhefe
Saccharomyces cerevisiae.
Gesündere Mitochondrien, mit einem größeren
reduzierenden Potential, werden bevorzugt an den
Zellpolen verankert und zurückgehalten. Die Tochterzelle
erhält immer gesunde Mitochondrien, welche über Aktin-
Filamente transportiert werden. Die Mitochondrien der
Mutterzelle verfügen unter anderem über erhöhte
Mengen reaktiver Sauestoffspezies, welche eine
Schädigung der Zelle erzeugen können.
Abbildung aus (Vevea et al. 2014).

Der Mechanismus der zu dieser Qualitätskontrolle von Mitochondrien in der Bäckerhefe und somit der selektiven Vererbung der gesündesten Mitochondrien führt, sowie die Kriterien, die den Zustand der Mitochondrien definieren, sind bislang weitgehend unbekannt (Vevea et al. 2014). Der Transport von Mitochondrien erfolgt in der Hefe anders als in Säugerzellen entlang von Aktin-Strängen. Die gesunden Mitochondrien der Tochterhefe werden am Ende dieser Zytoskelettelemente verankert. Wird dieser Vorgang inhibiert, geht die Asymmetrie von Tochter- und Muttermitochondrien verloren (Westermann 2014). Diese Beobachtung gibt einen Hinweis zur Regulation der Vererbung intakter Mitochondrien in der Hefe. Die vollständige Aufklärung dieses Mechanismus könnte von großer Bedeutung für das Verständnis des Aufbaus mitochondrialer Proteingradienten in Säugerzellen sein.

Im Rahmen der vorliegenden Arbeit wurde beobachtet, dass eine heterogene Verteilung eines mitochondrialen Proteins, in Form eines intrazellulären Gradienten, direkt nach der Zellteilung existiert. Es ist zu vermuten, dass hierfür die Interaktion der Mitochondrien mit dem Zytoskelett eine Rolle spielt (Westermann 2014).

\subsubsection{Die Zerstörung des Mikrotubuli-basierten mitochondrialen Transports} vermindert die Heterogenität mitochondrialer Proteinverteilungen

Mitochondrien von Säugerzellen werden hauptsächlich über Interaktionen mit den Mikrotubuli transportiert. Im Rahmen dieser Arbeit wurde deshalb der Zusammenhang von mitochondrialem Transport, entlang der Mikrotubuli, und der Gradientenverteilung mitochondrialer Proteine, untersucht.

Mittels STED- und Konfokalmikroskopie wurde gezeigt, dass die Depolymerisierung von TubulinFasern und somit der Verlust der Interaktion mit Mitochondrien, zu einer deutlichen Verringerung 
des Ausmaßes der intrazellulären Tom20-Gradientenverteilung führt (siehe 3.5.1). Dies bedeutet, dass die Interaktion von Mitochondrien mit Mikrotubuli und der dadurch ermöglichte mitochondriale Transport oder die Aufhängung von Mitochondrien, zur Entstehung und/oder Aufrechterhaltung der Heterogenität mitochondrialer Proteinverteilungen beiträgt. Diese Ergebnisse weisen darauf hin, dass der Transport von Mitochondrien ein Teil des Mechanismus der zur Entstehung und Aufrechterhaltung der Gradientenverteilung mitochondrialer Proteine führt ist.

Interessanterweise sind die Mitochondrien in Zellen, in denen Tubulin depolymerisiert vorliegt, anderes angeordnet als in unbehandelten Zellen (siehe auch: (Legros et al. 2002)). Sie sind in diesen Zellen über die gesamte Zelle verteilt und kommen nicht gehäuft in Zellkernnähe vor. Das belegt, dass das Mikrotubuli-Zytoskelett für die typische intrazelluläre Anordnung von Mitochondrien mit einer leichten Tendenz zur Aggregierung in Kernnähe verantwortlich ist und somit eventuell auch eine räumliche Positionsinformation innerhalb der Zelle vermittelt.

Die Verringerung der Gradientenverteilung eines mitochondrialen Proteins wurde nicht nur durch die Substanz Nocodazol belegt, sondern auch mittels Rotenon (siehe 3.6). Es bewirkt nicht nur die Depolymerisierung von Tubulin, sondern übt auch den Effekt der Inhibierung der Atmungskettenkomplex I-Aktivität aus (Diaz-Corrales et al. 2005). Im Rahmen dieser Arbeit wurde gezeigt, dass allein der Effekt der Zerstörung der Tubulin-Filamente durch Rotenon und nicht die Inhibierung der Atmungskettenkomplex I-Aktivität einen Einfluss auf die mitochondrialen Proteinverteilungen ausübt. Interessanterweise wird Rotenon mit der Entstehung von neurodegenerativen Erkrankungen wie z.B. Parkinson in Verbindung gebracht (Schapira 2010). Dies deutet auf eine pathophysiologische Relevanz der Gradientenverteilung mitochondrialer Proteine hin.

Um die Rolle der Interaktion von Mitochondrien mit Mikrotubuli, bei der Aufrechterhaltung der Gradientenverteilung mitochondrialer Proteine, genauer zu verstehen, wurde direkt der Einfluss des mitochondrialen Transports hierauf untersucht. Eine Vielzahl möglicher Komplexe, die für den mitochondrialen Transport verantwortlich sind, wurde identifiziert (Lovas et al. 2013). Der am besten charakterisierte ist der Rhot/Trak/Kinesin-Komplex. Er besteht aus dem spezifischen KinesinMotorprotein, der die Mikrotubuli bindet, dem mitochondrialen Adapterprotein Rhot und dem Protein Trak, welches eine Verbindung zwischen Rhot und dem Kinesin-Motor herstellt. Eine Vielzahl an Studien belegt, dass ein Verlust dieser Proteine des mitochondrialen Transportkomplexes spezifisch den anterograden Transport von Mitochondrien unterbindet und somit zu einer Umverteilung der Mitochondrien in der Zelle führt (siehe Einleitung 1.1.4) (Schwarz 2013). Im Rahmen dieser Arbeit wurde gezeigt, dass bei Verlust von Rhot1 und Trak1 und dem damit 
einhergehenden spezifischen Verlust des mitochondrialen Transports das Ausmaß der Gradientenverteilung von Tom20 über die Zellen verringert ist (siehe 3.5.2).

Somit konnte die direkte Beteiligung des mitochondrialen Transportkomplexes aus Rhot/Trak/Kinesin/Tubulin bei der Entstehung und/oder Aufrechterhaltung der intrazellulären Gradientenverteilung von Tom 20 bewiesen werden.

Im Rahmen dieser Arbeit konnte somit ein Einfluss der mitochondrialen Teilung und Bewegung über das Mikrotubuli-Zytoskelett auf die intrazelluläre Verteilung mitochondrialer Proteine identifiziert werden. Welche Signale und molekulare Mechanismen diese Verteilung regulieren, ist bislang unbekannt.

Ein ungeklärter Punkt ist demnach, wie die individuellen Eigenschaften der Mitochondrien von der Zelle erkannt werden und es anschließend zu einer Anordnung der Mitochondrien, anhand ihrer Proteindichte, (z.B. direkt nach der Zellteilung) kommt. Ein potentielles mitochondriales Signal könnte das mitochondriale Membranpotential darstellen, welches ein Indikator der Aktivität der Mitochondrien ist. Im Rahmen einer Studie wurde eine Korrelation des mitochondrialen Membranpotentials mit der mitochondrialen Tom20-Proteindichte angedeutet (Wurm et al. 2011). Ferner wurde beobachtet, dass die Depolarisation von Mitochondrien ihren Transport in Axonen arretiert (Schwarz 2013). Weiterhin ist das mitochondriale Membranpotential notwendig für die ATPProduktion über die Atmungskette. Sollten mitochondriale Proteine tatsächlich heterogen verteilt sein, um unterschiedliche energetische Ansprüche innerhalb Zellen zu decken, könnte eine Veränderung des mitochondrialen Membranpotentials und somit der ATP-Produktion eventuell die Grundlage der Proteingradienten zerstören.

Im Rahmen dieser Arbeit wurde jedoch festgestellt, dass weder die Verminderung noch die Erhöhung des mitochondrialen Membranpotentials einen Einfluss auf die Gradientenverteilung des mitochondrialen Proteins Tom 20 hat (siehe 3.7.1) und somit das mitochondriale Membranpotential vermutlich nicht als Signal für die Entstehung mitochondrialer Proteingradienten fungiert. Möglicherweise könnte die relative Veränderung des Membranpotentials durch Manipulation einzelner Mitochondrien und nicht die Veränderung des gesamten Netzwerks weitere Erkenntnisse darüber liefern, ob das mitochondriale Membranpotential als Signal für die heterogene Verteilung mitochondrialer Proteine fungiert. Dieses Experiment ist jedoch schwierig zu realisieren. Somit verbleibt die Frage, wie Mitochondrien unterschieden werden und ihr Transport reguliert wird, sodass dieser nur lokal stattfindet und nach der Zellteilung derart erfolgt, dass Mitochondrien mit einer hohen Proteindichte in Kernnähe angeordnet werden, ungeklärt. Für die Zukunft wäre die Beantwortung der Frage, welche Signale und Proteine tatsächlich für die Regulierung mitochondrialer Proteinverteilung verantwortlich sind, von großer Bedeutung. Hierbei müsste insbesondere die Rolle 
des Rhot/TRAK/Kinesin-Transportkomplexes als Teil eines möglichen Regulationsmechanismus mitochondrialer Proteinverteilungen untersucht werden.

Zusammengefasst lässt sich anhand der im Rahmen dieser Arbeit erhaltenen Ergebnisse folgendes Modell zur Entstehung und Aufrechthaltung mitochondrialer Heterogenität postulieren: Mitochondriale Bewegung und Teilung erfolgen derart, dass ein Gradient der mitochondrialen Proteindichte in einer Zelle erhalten bleibt. Im Rahmen der Zellteilung existiert ein spezifischer Mechanismus, der Mitochondrien zunächst anhand ihrer Eigenschaften (wie beispielsweise dem Inhalt individueller Mitochondrien) unterscheidet und anschließend aktiv die spezifische Aufteilung und Anordnung aller Mitochondrien auf beiden Tochterzellen bewirkt. An diesen Transportprozessen sind Mikrotubuli und der Transportkomplex aus Rhot1/Trak1 beteiligt.

Die Ergebnisse dieser Arbeit tragen somit zum Verständnis der mitochondrialen Heterogenität bei, insbesondere über welchen Mechanismus diese entsteht und aufrechterhalten wird. Es konnte gezeigt werden, dass eine Vielzahl mitochondrialer Proteine eine intrazelluläre heterogene Verteilung in Form eines Dichtegradienten besitzen, welche direkt nach der Zellteilung in beiden Tochterzellen zu beobachten ist. Im Rahmen dieser Arbeit wurde außerdem gezeigt, dass die mitochondriale Teilung und Bewegung Vorgänge sind, welche die Heterogenität mitochondrialer Proteinverteilungen beeinflussen. Darüber hinaus wurde eine veränderte Gradientenverteilung von Tom20 in dysfunktionalen Mitochondrien beobachtet. In Zukunft ist es von enormer Bedeutung weitere Details des intrazellulären Mechanismus, der die mitochondriale Heterogenität erzeugt, aufzuklären, um die Regulation mitochondrialer Funktionen und ihre Integration in die Physiologie von gesamten Zellen noch besser $\mathrm{zu}$ verstehen. Dies könnte insbesondere wichtig sein für das Verständnis pathophysiologischer Bedingungen mitochondrialer Dysfunktion. Hierzu ist es außerdem notwendig aufzuklären, welche zellulären Faktoren die mitochondriale Heterogenität bedingen. 


\section{Abkürzungsverzeichnis}

\begin{tabular}{|c|c|}
\hline ADP & Adenosin-Diphosphat \\
\hline Amp & Ampicillin \\
\hline APD & avalanche photo diode \\
\hline ATP & Adenosin-Triphosphat \\
\hline BSA & Rinderserumalbumin \\
\hline bzw. & beziehungsweise \\
\hline CMV & Cytomegalovirus \\
\hline $\mathrm{Da}$ & Dalton \\
\hline $\mathrm{DABCO}$ & 1,4-Diazabicyclo[2.2.2]octan \\
\hline DAPI & 4',6-Diamidino-2-phenylindol \\
\hline DEAE & Diethylaminoethanol \\
\hline DMEM & Dulbecco's Modified Eagle Medium \\
\hline DMSO & Dimethylsulfoxid \\
\hline DNA & Deoxyribonucleic acid \\
\hline Drp1 & dynamin related protein \\
\hline DsRed & Discosoma striata red fluorescent protein \\
\hline EDTA & Ethylendiamintetraessigsäure \\
\hline ER & endoplasmatisches Retikulum \\
\hline FBS & fetal bovine serum \\
\hline GFP & grün fluoreszierendes Protein \\
\hline $\mathrm{h}$ & hour \\
\hline Hsp & heat shock protein \\
\hline Hyg & Hygromycin B \\
\hline Kann & Kanamycin \\
\hline LED & light-emitting-diode \\
\hline MICOS & mitochondrial contact site and cristae organizing system \\
\hline $\min$ & Minute \\
\hline MMP & mitochondriales Membranpotential \\
\hline mtDNA & mitochondriale Desoxyribonukleinsäure \\
\hline mtGFP/DsRed/EosFP & fluoreszierende Proteine in der mitochondrialen Matrix \\
\hline NA & numerische Apertur \\
\hline
\end{tabular}




$\begin{array}{ll}\text { Neo } & \text { Neomycin } \\ \text { NHS } & \text { N-Hydroxysuccinimid } \\ \text { PAM } & \text { presequence translocase-associated motor } \\ \text { PBS } & \text { phosphate buffered saline } \\ \text { PCNA } & \text { proliferating cell nuclear antigen } \\ \text { PSF } & \text { Point-Spread-Function } \\ \text { PTP } & \text { permeability transition pore } \\ \text { Puro } & \text { Puromycin } \\ \text { RNAi } & \text { ribobucleic acid interference } \\ \text { ROI } & \text { region-of-interest } \\ \text { SAM } & \text { sorting and assembly machinery } \\ \text { ShRNA } & \text { small/short hairpin ribonucleic acid } \\ \text { STED } & \text { Stimulated Emission Depletion Microscopy } \\ \text { TE } & \text { Tris-EDTA } \\ \text { TIM } & \text { translocase of the mitochondrial inner membrane } \\ \text { TOM } & \text { translocase of the outer mitochondrial membrane } \\ \text { TRIS } & \text { Tris(hydroxymethyl9-aminomethan } \\ \text { UV } & \text { Ultraviolett } \\ \text { z.B. } & \text { zum Beispiel } \\ & \end{array}$




\section{Literaturverzeichnis}

Abbe, E. (1873). "Beiträge zur Theorie des Mikroskops und der mikroskopischen Wahrnehmung." Arch.f.

Mikroskop. Anat. 9: 413-420.

Acton, B. M., A. Jurisicova, I. Jurisica and R. F. Casper (2004). "Alterations in mitochondrial membrane potential during preimplantation stages of mouse and human embryo development." Mol Hum Reprod 10(1): 23-32.

Aizawa, H., Y. Sekine, R. Takemura, Z. Zhang, M. Nangaku and N. Hirokawa (1992). "Kinesin family in murine central nervous system." J Cell Biol 119(5): 1287-1296.

Alberts, B., A. Johnson, J. Lewis, M. Raff, K. Roberts and P. Walter (2008). Molecular Biology of the Cell, Garland Science, Taylor \& Francis Group.

Alexander, C., M. Votruba, U. E. Pesch, D. L. Thiselton, S. Mayer, A. Moore, M. Rodriguez, U. Kellner, B. Leo-Kottler, G. Auburger, S. S. Bhattacharya and B. Wissinger (2000). "OPA1, encoding a dynamin-related GTPase, is mutated in autosomal dominant optic atrophy linked to chromosome 3q28." Nat Genet 26(2): 211-215.

Alkhaja, A. K., D. C. Jans, M. Nikolov, M. Vukotic, O. Lytovchenko, F. Ludewig, W. Schliebs, D. Riedel, H. Urlaub, S. Jakobs and M. Deckers (2012). "MINOS1 is a conserved component of mitofilin complexes and required for mitochondrial function and cristae organization." Mol Biol Cell 23(2): 247-257.

Anderson, S., A. T. Bankier, B. G. Barrell, M. H. de Bruijn, A. R. Coulson, J. Drouin, I. C. Eperon, D. P. Nierlich, B. A. Roe, F. Sanger, P. H. Schreier, A. J. Smith, R. Staden and I. G. Young (1981). "Sequence and organization of the human mitochondrial genome." Nature 290(5806): 457465.

Arakaki, N., T. Nishihama, H. Owaki, Y. Kuramoto, M. Suenaga, E. Miyoshi, Y. Emoto, H. Shibata, M. Shono and T. Higuti (2006). "Dynamics of mitochondria during the cell cycle." Biol Pharm Bull 29(9): 1962-1965. 
Artom, C. and M. A. Swanson (1951). "Incorporation of labeled phosphate into the lipides of liver slices." J Biol Chem 193(2): 473-480.

Aspenstrom, P., A. Ruusala and D. Pacholsky (2007). "Taking Rho GTPases to the next level: The cellular functions of atypical Rho GTPases." Experimental Cell Research 313(17): 3673-3679.

Balaban, R. S., S. Nemoto and T. Finkel (2005). "Mitochondria, oxidants, and aging." Cell 120(4): 483495.

Benard, G., N. Bellance, D. James, P. Parrone, H. Fernandez, T. Letellier and R. Rossignol (2007). "Mitochondrial bioenergetics and structural network organization." J Cell Sci 120(Pt 5): 838848.

Benard, G. and R. Rossignol (2008). "Ultrastructure of the mitochondrion and its bearing on function and bioenergetics." Antioxid Redox Signal 10(8): 1313-1342.

Benda, C. (1898). Ueber die Spermatogenese der Vertebraten und höherer Evertebraten, II. Theil: Die Histogenese der Spermien. Arch Anat Physiol. 73: 393-398.

Beraud, N., S. Pelloux, Y. Usson, A. V. Kuznetsov, X. Ronot, Y. Tourneur and V. Saks (2009). "Mitochondrial dynamics in heart cells: very low amplitude high frequency fluctuations in adult cardiomyocytes and flow motion in non beating HI-1 cells." J Bioenerg Biomembr 41(2): 195-214.

Bereiter-Hahn, J. (1990). "Behavior of mitochondria in the living cell." Int Rev Cytol 122: 1-63.

Bereiter-Hahn, J., K. H. Seipel, M. Voth and J. S. Ploem (1983). "Fluorimetry of mitochondria in cells vitally stained with DASPMI or rhodamine 6 GO." Cell Biochem Funct 1(3): 147-155.

Bereiter-Hahn, J. and M. Voth (1994). "Dynamics of mitochondria in living cells: shape changes, dislocations, fusion, and fission of mitochondria." Microsc Res Tech 27(3): 198-219.

Berg, J. S., B. C. Powell and R. E. Cheney (2001). "A millennial myosin census." Mol Biol Cell 12(4): 780-794. 
Betzig, E., G. H. Patterson, R. Sougrat, O. W. Lindwasser, S. Olenych, J. S. Bonifacino, M. W. Davidson, J. Lippincott-Schwartz and H. F. Hess (2006). "Imaging intracellular fluorescent proteins at nanometer resolution." Science 313(5793): 1642-1645.

Birt, L. M. and W. Bartley (1960). "The pyridine nucleotide metabolism of mitochondria incubated with and without added substrates and metabolic inhibitors." Biochem J 76(3): 427-438.

Bowser, D. N., T. Minamikawa, P. Nagley and D. A. Williams (1998). "Role of mitochondria in calcium regulation of spontaneously contracting cardiac muscle cells." Biophys J 75(4): 2004-2014.

Brakemann, T., A. C. Stiel, G. Weber, M. Andresen, I. Testa, T. Grotjohann, M. Leutenegger, U. Plessmann, H. Urlaub, C. Eggeling, M. C. Wahl, S. W. Hell and S. Jakobs (2011). "A reversibly photoswitchable GFP-like protein with fluorescence excitation decoupled from switching." Nat Biotechnol 29(10): 942-947.

Brickley, K., M. J. Smith, M. Beck and F. A. Stephenson (2005). "GRIF-1 and OIP106, members of a novel gene family of coiled-coil domain proteins: association in vivo and in vitro with kinesin." J Biol Chem 280(15): 14723-14732.

Brickley, K. and F. A. Stephenson (2011). "Trafficking kinesin protein (TRAK)-mediated transport of mitochondria in axons of hippocampal neurons." J Biol Chem 286(20): 18079-18092.

Bridgman, P. C. (2004). "Myosin-dependent transport in neurons." J Neurobiol 58(2): 164-174.

Bruce, J. I., D. R. Giovannucci, G. Blinder, T. J. Shuttleworth and D. I. Yule (2004). "Modulation of [Ca2+]i signaling dynamics and metabolism by perinuclear mitochondria in mouse parotid acinar cells." J Biol Chem 279(13): 12909-12917.

Buckman, J. F. and I. J. Reynolds (2001). "Spontaneous changes in mitochondrial membrane potential in cultured neurons." J Neurosci 21(14): 5054-5065.

Cai, Q., C. Gerwin and Z. H. Sheng (2005). "Syntabulin-mediated anterograde transport of mitochondria along neuronal processes." J Cell Biol 170(6): 959-969. 
Carlini, L. and S. Manley (2013). "Live intracellular super-resolution imaging using site-specific stains." ACS Chem Biol 8(12): 2643-2648.

Chan, D. C. (2006). "Mitochondrial fusion and fission in mammals." Annu Rev Cell Dev Biol 22: 79-99.

Chen, H., A. Chomyn and D. C. Chan (2005). "Disruption of fusion results in mitochondrial heterogeneity and dysfunction." J Biol Chem 280(28): 26185-26192.

Chen, H., S. A. Detmer, A. J. Ewald, E. E. Griffin, S. E. Fraser and D. C. Chan (2003). "Mitofusins Mfn1 and Mfn2 coordinately regulate mitochondrial fusion and are essential for embryonic development." J Cell Biol 160(2): 189-200.

Chen, X. J. and R. A. Butow (2005). "The organization and inheritance of the mitochondrial genome." Nat Rev Genet 6(11): 815-825.

Cho, K. I., Y. Cai, H. Yi, A. Yeh, A. Aslanukov and P. A. Ferreira (2007). "Association of the kinesinbinding domain of RanBP2 to KIF5B and KIF5C determines mitochondria localization and function." Traffic 8(12): 1722-1735.

Collins, T. J., M. J. Berridge, P. Lipp and M. D. Bootman (2002). "Mitochondria are morphologically and functionally heterogeneous within cells." EMBO J 21(7): 1616-1627.

Cossarizza, A., D. Ceccarelli and A. Masini (1996). "Functional heterogeneity of an isolated mitochondrial population revealed by cytofluorometric analysis at the single organelle level." Exp Cell Res 222(1): 84-94.

Craddock, V. M. and M. V. Simpson (1961). "Amino acid-activating enzymes in rat-liver mitochondria." Biochem J 80: 348-352.

Cuperus, R., R. Leen, G. A. Tytgat, H. N. Caron and A. B. van Kuilenburg (2010). "Fenretinide induces mitochondrial ROS and inhibits the mitochondrial respiratory chain in neuroblastoma." Cell Mol Life Sci 67(5): 807-816.

De Camilli, P., M. Moretti, S. D. Donini, U. Walter and S. M. Lohmann (1986). "Heterogeneous distribution of the CAMP receptor protein RII in the nervous system: evidence for its 
intracellular accumulation on microtubules, microtubule-organizing centers, and in the area of the Golgi complex." J Cell Biol 103(1): 189-203.

De Smedt, S. C., J. Demeester and W. E. Hennink (2000). "Cationic polymer based gene delivery systems." Pharm Res 17(2): 113-126.

Delettre, C., G. Lenaers, J. M. Griffoin, N. Gigarel, C. Lorenzo, P. Belenguer, L. Pelloquin, J. Grosgeorge, C. Turc-Carel, E. Perret, C. Astarie-Dequeker, L. Lasquellec, B. Arnaud, B. Ducommun, J. Kaplan and C. P. Hamel (2000). "Nuclear gene OPA1, encoding a mitochondrial dynamin-related protein, is mutated in dominant optic atrophy." Nat Genet 26(2): 207-210.

Devin, A. and M. Rigoulet (2007). "Mechanisms of mitochondrial response to variations in energy demand in eukaryotic cells." Am J Physiol Cell Physiol 292(1): C52-58.

Diaz-Corrales, F. J., M. Asanuma, I. Miyazaki, K. Miyoshi and N. Ogawa (2005). "Rotenone induces aggregation of gamma-tubulin protein and subsequent disorganization of the centrosome: relevance to formation of inclusion bodies and neurodegeneration." Neuroscience 133(1): 117-135.

Diaz, G., A. M. Falchi, F. Gremo, R. Isola and A. Diana (2000). "Homogeneous longitudinal profiles and synchronous fluctuations of mitochondrial transmembrane potential." FEBS Lett 475(3): 218224.

Diaz, G., M. D. Setzu, A. Zucca, R. Isola, A. Diana, R. Murru, V. Sogos and F. Gremo (1999). "Subcellular heterogeneity of mitochondrial membrane potential: relationship with organelle distribution

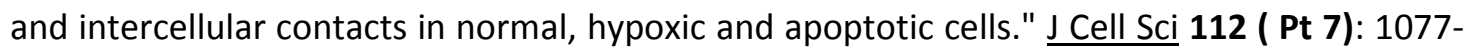
1084.

Distelmaier, F., W. J. Koopman, E. R. Testa, A. S. de Jong, H. G. Swarts, E. Mayatepek, J. A. Smeitink and P. H. Willems (2008). "Life cell quantification of mitochondrial membrane potential at the single organelle level." Cytometry A 73(2): 129-138.

Donnert, G., J. Keller, R. Medda, M. A. Andrei, S. O. Rizzoli, R. Luhrmann, R. Jahn, C. Eggeling and S. W. Hell (2006). "Macromolecular-scale resolution in biological fluorescence microscopy." Proc Natl Acad Sci U S A 103(31): 11440-11445. 
Egan, D. F., D. B. Shackelford, M. M. Mihaylova, S. Gelino, R. A. Kohnz, W. Mair, D. S. Vasquez, A. Joshi, D. M. Gwinn, R. Taylor, J. M. Asara, J. Fitzpatrick, A. Dillin, B. Viollet, M. Kundu, M. Hansen and R. J. Shaw (2011). "Phosphorylation of ULK1 (hATG1) by AMP-activated protein kinase connects energy sensing to mitophagy." Science 331(6016): 456-461.

Egner, A., S. Jakobs and S. W. Hell (2002). "Fast 100-nm resolution three-dimensional microscope reveals structural plasticity of mitochondria in live yeast." Proc Natl Acad Sci U S A 99(6): 3370-3375.

Faelber, K., S. Gao, M. Held, Y. Posor, V. Haucke, F. Noe and O. Daumke (2013). "Oligomerization of dynamin superfamily proteins in health and disease." Prog Mol Biol Transl Sci 117: 411-443.

Feldmann, H. (2009). Yeast: Molecular and Cell Biology, Wiley-Blackwell.

Ferree, A. and O. Shirihai (2012). "Mitochondrial dynamics: the intersection of form and function." Adv Exp Med Biol 748: 13-40.

Folling, J., M. Bossi, H. Bock, R. Medda, C. A. Wurm, B. Hein, S. Jakobs, C. Eggeling and S. W. Hell (2008). "Fluorescence nanoscopy by ground-state depletion and single-molecule return." Nat Methods 5(11): 943-945.

Fransson, A., A. Ruusala and P. Aspenstrom (2003). "Atypical Rho GTPases have roles in mitochondrial homeostasis and apoptosis." J Biol Chem 278(8): 6495-6502.

Fransson, S., A. Ruusala and P. Aspenstrom (2006). "The atypical Rho GTPases Miro-1 and Miro-2 have essential roles in mitochondrial trafficking." Biochem Biophys Res Commun 344(2): 500510.

Frazier, A. E., C. Kiu, D. Stojanovski, N. J. Hoogenraad and M. T. Ryan (2006). "Mitochondrial morphology and distribution in mammalian cells." Biol Chem 387(12): 1551-1558.

Frey, T. G. and C. A. Mannella (2000). "The internal structure of mitochondria." Trends Biochem Sci 25(7): 319-324. 
Friedman, J. R., L. L. Lackner, M. West, J. R. DiBenedetto, J. Nunnari and G. K. Voeltz (2011). "ER tubules mark sites of mitochondrial division." Science 334(6054): 358-362.

Friedman, J. R. and J. Nunnari (2014). "Mitochondrial form and function." Nature 505(7483): 335-343.

Fuchs, F., H. Prokisch, W. Neupert and B. Westermann (2002). "Interaction of mitochondria with microtubules in the filamentous fungus Neurospora crassa." J Cell Sci 115(Pt 9): 1931-1937.

Fujita, T., A. D. Maturana, J. Ikuta, J. Hamada, S. Walchli, T. Suzuki, H. Sawa, M. W. Wooten, T. Okajima, K. Tatematsu, K. Tanizawa and S. Kuroda (2007). "Axonal guidance protein FEZ1 associates with tubulin and kinesin motor protein to transport mitochondria in neurites of NGF-stimulated PC12 cells." Biochem Biophys Res Commun 361(3): 605-610.

Gabaldon, T. and M. A. Huynen (2004). "Shaping the mitochondrial proteome." Biochim Biophys Acta 1659(2-3): 212-220.

Gatti, G., S. Trifari, N. Mesaeli, J. M. Parker, M. Michalak and J. Meldolesi (2001). "Head-to-tail oligomerization of calsequestrin: a novel mechanism for heterogeneous distribution of endoplasmic reticulum luminal proteins." J Cell Biol 154(3): 525-534.

Glater, E. E., L. J. Megeath, R. S. Stowers and T. L. Schwarz (2006). "Axonal transport of mitochondria requires milton to recruit kinesin heavy chain and is light chain independent." $\underline{\mathrm{J} \text { Cell Biol }}$ 173(4): 545-557.

Gorska-Andrzejak, J., R. S. Stowers, J. Borycz, R. Kostyleva, T. L. Schwarz and I. A. Meinertzhagen (2003). "Mitochondria are redistributed in Drosophila photoreceptors lacking milton, a kinesin-associated protein." Journal of Comparative Neurology 463(4): 372-388.

Gray, M. W. (1999). "Evolution of organellar genomes." Curr Opin Genet Dev 9(6): 678-687.

Griparic, L. and A. M. van der Bliek (2001). "The many shapes of mitochondrial membranes." Traffic 2(4): 235-244. 
Grotjohann, T., I. Testa, M. Leutenegger, H. Bock, N. T. Urban, F. Lavoie-Cardinal, K. I. Willig, C. Eggeling, S. Jakobs and S. W. Hell (2011). "Diffraction-unlimited all-optical imaging and writing with a photochromic GFP." Nature 478(7368): 204-208.

Guo, X., G. T. Macleod, A. Wellington, F. Hu, S. Panchumarthi, M. Schoenfield, L. Marin, M. P. Charlton, H. L. Atwood and K. E. Zinsmaier (2005). "The GTPase dMiro is required for axonal transport of mitochondria to Drosophila synapses." Neuron 47(3): 379-393.

Gustafsson, M. G. (2005). "Nonlinear structured-illumination microscopy: wide-field fluorescence imaging with theoretically unlimited resolution." Proc Natl Acad Sci U S A 102(37): 1308113086.

Harbauer, A. B., R. P. Zahedi, A. Sickmann, N. Pfanner and C. Meisinger (2014). "The protein import machinery of mitochondria-a regulatory hub in metabolism, stress, and disease." Cell Metab 19(3): 357-372.

Harke, B., J. Keller, C. K. Ullal, V. Westphal, A. Schonle and S. W. Hell (2008). "Resolution scaling in STED microscopy." Opt Express 16(6): 4154-4162.

Harner, M., C. Korner, D. Walther, D. Mokranjac, J. Kaesmacher, U. Welsch, J. Griffith, M. Mann, F. Reggiori and W. Neupert (2011). "The mitochondrial contact site complex, a determinant of mitochondrial architecture." EMBO J 30(21): 4356-4370.

Heggeness, M. H., M. Simon and S. J. Singer (1978). "Association of mitochondria with microtubules in cultured cells." Proc Natl Acad Sci U S A 75(8): 3863-3866.

Hell, S. W. (2003). "Toward fluorescence nanoscopy." Nat Biotechnol 21(11): 1347-1355.

Hell, S. W. and J. Wichmann (1994). "Breaking the diffraction resolution limit by stimulated emission: stimulated-emission-depletion fluorescence microscopy." Opt Lett 19(11): 780-782.

Hirokawa, N. and Y. Noda (2008). "Intracellular transport and kinesin superfamily proteins, KIFs: structure, function, and dynamics." Physiol Rev 88(3): 1089-1118. 
Hollenbeck, P. J. and W. M. Saxton (2005). "The axonal transport of mitochondria." J Cell Sci 118(Pt 23): 5411-5419.

Hoppins, S., S. R. Collins, A. Cassidy-Stone, E. Hummel, R. M. Devay, L. L. Lackner, B. Westermann, M. Schuldiner, J. S. Weissman and J. Nunnari (2011). "A mitochondrial-focused genetic interaction map reveals a scaffold-like complex required for inner membrane organization in mitochondria." J Cell Biol 195(2): 323-340.

Hoppins, S., L. Lackner and J. Nunnari (2007). "The machines that divide and fuse mitochondria." Annu Rev Biochem 76: 751-780.

Huang, H. M., C. Fowler, H. Zhang and G. E. Gibson (2004). "Mitochondrial heterogeneity within and between different cell types." Neurochem Res 29(3): 651-658.

Hyde-Dunn, J. and G. E. Jones (1997). "Visualization of cell replication using antibody to proliferating cell nuclear antigen." Methods Mol Biol 75: 341-347.

Hyde, B. B., G. Twig and O. S. Shirihai (2010). "Organellar vs cellular control of mitochondrial dynamics." Semin Cell Dev Biol 21(6): 575-581.

Ivanchenko, S., C. Rocker, F. Oswald, J. Wiedenmann and G. U. Nienhaus (2005). "Targeted GreenRed Photoconversion of EosFP, a Fluorescent Marker Protein." J Biol Phys 31(3-4): 249-259.

Jakobs, S. (2006). "High resolution imaging of live mitochondria." Biochim Biophys Acta 1763(5-6): 561-575.

Jakobs, S., N. Martini, A. C. Schauss, A. Egner, B. Westermann and S. W. Hell (2003). "Spatial and temporal dynamics of budding yeast mitochondria lacking the division component Fis1p." $\underline{J}$ Cell Sci 116(Pt 10): 2005-2014.

Jakobs, S., S. Stoldt and D. Neumann (2011). "Light microscopic analysis of mitochondrial heterogeneity in cell populations and within single cells." Adv Biochem Eng Biotechnol 124: 1-19. 
James, D. I., P. A. Parone, Y. Mattenberger and J. C. Martinou (2003). "hFis1, a novel component of the mammalian mitochondrial fission machinery." J Biol Chem 278(38): 36373-36379.

Jans, D. C., C. A. Wurm, D. Riedel, D. Wenzel, F. Stagge, M. Deckers, P. Rehling and S. Jakobs (2013). "STED super-resolution microscopy reveals an array of MINOS clusters along human mitochondria." Proc Natl Acad Sci U S A 110(22): 8936-8941.

Johnson, L. V., M. L. Walsh, B. J. Bockus and L. B. Chen (1981). "Monitoring of relative mitochondrial membrane potential in living cells by fluorescence microscopy." J Cell Biol 88(3): 526-535.

Kanai, Y., Y. Okada, Y. Tanaka, A. Harada, S. Terada and N. Hirokawa (2000). "KIF5C, a novel neuronal kinesin enriched in motor neurons." J Neurosci 20(17): 6374-6384.

Karbowski, M., D. Arnoult, H. Chen, D. C. Chan, C. L. Smith and R. J. Youle (2004). "Quantitation of mitochondrial dynamics by photolabeling of individual organelles shows that mitochondrial fusion is blocked during the Bax activation phase of apoptosis." I Cell Biol 164(4): 493-499.

Karbowski, M., S. Y. Jeong and R. J. Youle (2004). "Endophilin B1 is required for the maintenance of mitochondrial morphology." J Cell Biol 166(7): 1027-1039.

Keil, V. C., F. Funke, A. Zeug, D. Schild and M. Muller (2011). "Ratiometric high-resolution imaging of JC-1 fluorescence reveals the subcellular heterogeneity of astrocytic mitochondria." Pflugers Arch 462(5): 693-708.

Kennedy, E. P. and A. L. Lehninger (1950). "The products of oxidation of fatty acids by isolated rat liver mitochondria." J Biol Chem 185(1): 275-285.

King, S. J. and T. A. Schroer (2000). "Dynactin increases the processivity of the cytoplasmic dynein motor." Nat Cell Biol 2(1): 20-24.

Klar, T. A., S. Jakobs, M. Dyba, A. Egner and S. W. Hell (2000). "Fluorescence microscopy with diffraction resolution barrier broken by stimulated emission." Proc Natl Acad Sci U S A 97(15): 8206-8210. 
Komatsu, M., S. Waguri, T. Ueno, J. Iwata, S. Murata, I. Tanida, J. Ezaki, N. Mizushima, Y. Ohsumi, Y. Uchiyama, E. Kominami, K. Tanaka and T. Chiba (2005). "Impairment of starvation-induced and constitutive autophagy in Atg7-deficient mice." J Cell Biol 169(3): 425-434.

Kornmann, B., E. Currie, S. R. Collins, M. Schuldiner, J. Nunnari, J. S. Weissman and P. Walter (2009). "An ER-mitochondria tethering complex revealed by a synthetic biology screen." Science 325(5939): 477-481.

Krebs, H. A. (1940). "The citric acid cycle and the Szent-Gyorgyi cycle in pigeon breast muscle." Biochem J 34(5): 775-779.

Kroemer, G. (1998). "The mitochondrion as an integrator/coordinator of cell death pathways." Cell Death Differ 5(6): 547.

Kukat, C., C. A. Wurm, H. Spahr, M. Falkenberg, N. G. Larsson and S. Jakobs (2011). "Super-resolution microscopy reveals that mammalian mitochondrial nucleoids have a uniform size and frequently contain a single copy of mtDNA." Proc Natl Acad Sci U S A 108(33): 13534-13539.

Kuznetsov, A. V., M. Hermann, V. Saks, P. Hengster and R. Margreiter (2009). "The cell-type specificity of mitochondrial dynamics." Int J Biochem Cell Biol 41(10): 1928-1939.

Kuznetsov, A. V., M. Hermann, J. Troppmair, R. Margreiter and P. Hengster (2010). "Complex patterns of mitochondrial dynamics in human pancreatic cells revealed by fluorescent confocal imaging." J Cell Mol Med 14(1-2): 417-425.

Kuznetsov, A. V. and R. Margreiter (2009). "Heterogeneity of mitochondria and mitochondrial function within cells as another level of mitochondrial complexity." Int J Mol Sci 10(4): 19111929.

Kuznetsov, A. V., S. Schneeberger, R. Seiler, G. Brandacher, W. Mark, W. Steurer, V. Saks, Y. Usson, R. Margreiter and E. Gnaiger (2004). "Mitochondrial defects and heterogeneous cytochrome $c$ release after cardiac cold ischemia and reperfusion." Am J Physiol Heart Circ Physiol 286(5): H1633-1641. 
Kuznetsov, A. V., J. Troppmair, R. Sucher, M. Hermann, V. Saks and R. Margreiter (2006). "Mitochondrial subpopulations and heterogeneity revealed by confocal imaging: possible physiological role?" Biochim Biophys Acta 1757(5-6): 686-691.

Kuznetsov, A. V., Y. Usson, X. Leverve and R. Margreiter (2004). "Subcellular heterogeneity of mitochondrial function and dysfunction: evidence obtained by confocal imaging." Mol Cell Biochem 256-257(1-2): 359-365.

LaRochelle, W. J. and S. C. Froehner (1986). "Determination of the tissue distributions and relative concentrations of the postsynaptic $43-\mathrm{kDa}$ protein and the acetylcholine receptor in Torpedo." J Biol Chem 261(12): 5270-5274.

Lawrie, A. M., R. Rizzuto, T. Pozzan and A. W. Simpson (1996). "A role for calcium influx in the regulation of mitochondrial calcium in endothelial cells." J Biol Chem 271(18): 10753-10759.

Lee, H. and Y. Yoon (2012). Mitochondrial Dynamics: Mechanisms and Pathologies, eLS. John Wiley \& Sons.

Lee, Y. J., S. Y. Jeong, M. Karbowski, C. L. Smith and R. J. Youle (2004). "Roles of the mammalian mitochondrial fission and fusion mediators Fis1, Drp1, and Opa1 in apoptosis." Mol Biol Cell 15(11): 5001-5011.

Legros, F., A. Lombes, P. Frachon and M. Rojo (2002). "Mitochondrial fusion in human cells is efficient, requires the inner membrane potential, and is mediated by mitofusins." Mol Biol Cell 13(12): 4343-4354.

Legros, F., F. Malka, P. Frachon, A. Lombes and M. Rojo (2004). "Organization and dynamics of human mitochondrial DNA." J Cell Sci 117(Pt 13): 2653-2662.

Leist, M., B. Single, A. F. Castoldi, S. Kuhnle and P. Nicotera (1997). "Intracellular adenosine triphosphate (ATP) concentration: a switch in the decision between apoptosis and necrosis." J Exp Med 185(8): 1481-1486.

Lemasters, J. J. and V. K. Ramshesh (2007). "Imaging of mitochondrial polarization and depolarization with cationic fluorophores." Methods Cell Biol 80: 283-295. 
Leonhardt, H., H. P. Rahn, P. Weinzierl, A. Sporbert, T. Cremer, D. Zink and M. C. Cardoso (2000). "Dynamics of DNA replication factories in living cells." J Cell Biol 149(2): 271-280.

Li, C. and R. M. Jackson (2002). "Reactive species mechanisms of cellular hypoxia-reoxygenation injury." Am J Physiol Cell Physiol 282(2): C227-241.

Ligon, L. A. and O. Steward (2000). "Role of microtubules and actin filaments in the movement of mitochondria in the axons and dendrites of cultured hippocampal neurons." J Comp Neurol 427(3): 351-361.

Liu, X., C. N. Kim, J. Yang, R. Jemmerson and X. Wang (1996). "Induction of apoptotic program in cellfree extracts: requirement for dATP and cytochrome c." Cell 86(1): 147-157.

Liu, Z., W. R. Bushnell and R. Brambl (1987). "Pontentiometric cyanine dyes are sensitive probes for mitochondria in intact plant cells : kinetin enhances mitochondrial fluorescence." Plant Physiol 84(4): 1385-1390.

Logan, D. C. (2006). "Plant mitochondrial dynamics." Biochim Biophys Acta 1763(5-6): 430-441.

Lovas, J. R. and X. Wang (2013). "The meaning of mitochondrial movement to a neuron's life." Biochim Biophys Acta 1833(1): 184-194.

Maier, K. P., C. Helbig, G. Hoppe-Seyler, J. Frohlich, P. Schollmeyer, W. Gerok and H. Talke (1974). "Extractability and intracellular localisation of urea cycle enzymes from rat liver." $\underline{Z \text { Klin Chem }}$ Klin Biochem 12(12): 524-529.

Mannella, C. A. (2006). "Structure and dynamics of the mitochondrial inner membrane cristae." Biochim Biophys Acta 1763(5-6): 542-548.

Margineantu, D. H., W. Gregory Cox, L. Sundell, S. W. Sherwood, J. M. Beechem and R. A. Capaldi (2002). "Cell cycle dependent morphology changes and associated mitochondrial DNA redistribution in mitochondria of human cell lines." Mitochondrion 1(5): 425-435. 
Margulis, L. (1970). "Recombination of non-chromosomal genes in Chlamydomonas: assortment of mitochondria and chloroplasts?" J Theor Biol 26(2): 337-342.

Matsuoka, S., T. Shibata and M. Ueda (2013). "Asymmetric PTEN distribution regulated by spatial heterogeneity in membrane-binding state transitions." PLoS Comput Biol 9(1): e1002862.

Matzke, M. A. (1986). "Visualization of mitochondria and nuclei in living plant cells by the use of a potential-sensitive fluorescent dye." Plant, Cell and Environment 9: 73-77.

McBride, H. M., M. Neuspiel and S. Wasiak (2006). "Mitochondria: more than just a powerhouse." Curr Biol 16(14): R551-560.

McFaline-Figueroa, J. R., J. Vevea, T. C. Swayne, C. Zhou, C. Liu, G. Leung, I. R. Boldogh and L. A. Pon (2011). "Mitochondrial quality control during inheritance is associated with lifespan and mother-daughter age asymmetry in budding yeast." Aging Cell 10(5): 885-895.

Meeusen, S., J. M. McCaffery and J. Nunnari (2004). "Mitochondrial fusion intermediates revealed in vitro." Science 305(5691): 1747-1752.

Meisinger, C., A. Sickmann and N. Pfanner (2008). "The mitochondrial proteome: from inventory to function." Cell 134(1): 22-24.

Miller, K. E. and M. P. Sheetz (2004). "Axonal mitochondrial transport and potential are correlated." $\underline{\mathrm{J}}$ Cell Sci 117(Pt 13): 2791-2804.

Minsky, M. (1961). "Microscopy apparatus: US Patent 3013467."

Mironov, S. L. (2007). "ADP regulates movements of mitochondria in neurons." Biophys J 92(8): 29442952.

Mironov, S. L. and N. Symonchuk (2006). "ER vesicles and mitochondria move and communicate at synapses." J Cell Sci 119(Pt 23): 4926-4934. 
Mitra, K., C. Wunder, B. Roysam, G. Lin and J. Lippincott-Schwartz (2009). "A hyperfused mitochondrial state achieved at G1-S regulates cyclin E buildup and entry into S phase." Proc Natl Acad Sci U S A 106(29): 11960-11965.

Molina, A. J., J. D. Wikstrom, L. Stiles, G. Las, H. Mohamed, A. Elorza, G. Walzer, G. Twig, S. Katz, B. E. Corkey and O. S. Shirihai (2009). "Mitochondrial networking protects beta-cells from nutrient-induced apoptosis." Diabetes 58(10): 2303-2315.

Moore, C. and B. C. Pressman (1964). "Mechanism of action of valinomycin on mitochondria." Biochemical and Biophysical Research Communications 15(6): 562-567.

Mora-Bermudez, F., D. Gerlich and J. Ellenberg (2007). "Maximal chromosome compaction occurs by axial shortening in anaphase and depends on Aurora kinase." Nat Cell Biol 9(7): 822-831.

Morris, R. L. and P. J. Hollenbeck (1993). "The regulation of bidirectional mitochondrial transport is coordinated with axonal outgrowth." J Cell Sci 104 ( Pt 3): 917-927.

Morris, R. L. and P. J. Hollenbeck (1995). "Axonal transport of mitochondria along microtubules and Factin in living vertebrate neurons." J Cell Biol 131(5): 1315-1326.

Murata-Hori, M., M. Tatsuka and Y. L. Wang (2002). "Probing the dynamics and functions of aurora B kinase in living cells during mitosis and cytokinesis." Mol Biol Cell 13(4): 1099-1108.

Nangaku, M., R. Sato-Yoshitake, Y. Okada, Y. Noda, R. Takemura, H. Yamazaki and N. Hirokawa (1994). "KIF1B, a novel microtubule plus end-directed monomeric motor protein for transport of mitochondria." Cell 79(7): 1209-1220.

Navarro, A. and A. Boveris (2007). "The mitochondrial energy transduction system and the aging process." Am J Physiol Cell Physiol 292(2): C670-686.

Nicholls, D. G. and M. W. Ward (2000). "Mitochondrial membrane potential and neuronal glutamate excitotoxicity: mortality and millivolts." Trends Neurosci 23(4): 166-174.

Nunnari, J. and A. Suomalainen (2012). "Mitochondria: in sickness and in health." Cell 148(6): 11451159. 
Ochoa, S. (1940). "Nature of oxidative phosphorylation in brain tissue." Nature 146(267).

Okamoto, K. and J. M. Shaw (2005). "Mitochondrial morphology and dynamics in yeast and multicellular eukaryotes." Annu Rev Genet 39: 503-536.

Omura, T. (1998). "Mitochondria-targeting sequence, a multi-role sorting sequence recognized at all steps of protein import into mitochondria." J Biochem 123(6): 1010-1016.

Palade, G. E. (1952). "The fine structure of mitochondria." Anat Rec 114(3): 427-451.

Palmer, J. W., B. Tandler and C. L. Hoppel (1977). "Biochemical properties of subsarcolemmal and interfibrillar mitochondria isolated from rat cardiac muscle." J Biol Chem 252(23): 8731-8739.

Palmer, J. W., B. Tandler and C. L. Hoppel (1985). "Biochemical differences between subsarcolemmal and interfibrillar mitochondria from rat cardiac muscle: effects of procedural manipulations." Arch Biochem Biophys 236(2): 691-702.

Park, M. K., M. C. Ashby, G. Erdemli, O. H. Petersen and A. V. Tepikin (2001). "Perinuclear, perigranular and sub-plasmalemmal mitochondria have distinct functions in the regulation of cellular calcium transport." EMBO J 20(8): 1863-1874.

Pathak, D., K. J. Sepp and P. J. Hollenbeck (2010). "Evidence that myosin activity opposes microtubule-based axonal transport of mitochondria." J Neurosci 30(26): 8984-8992.

Penefsky, H. S. (1985). "Mechanism of inhibition of mitochondrial adenosine triphosphatase by dicyclohexylcarbodiimide and oligomycin: relationship to ATP synthesis." Proc Natl Acad Sci U SA 82(6): 1589-1593.

Perkins, G., C. Renken, M. E. Martone, S. J. Young, M. Ellisman and T. Frey (1997). "Electron tomography of neuronal mitochondria: three-dimensional structure and organization of cristae and membrane contacts." J Struct Biol 119(3): 260-272.

Pfanner, N., M. van der Laan, P. Amati, R. A. Capaldi, A. A. Caudy, A. Chacinska, M. Darshi, M. Deckers, S. Hoppins, T. Icho, S. Jakobs, J. Ji, V. Kozjak-Pavlovic, C. Meisinger, P. R. Odgren, S. 
K. Park, P. Rehling, A. S. Reichert, M. S. Sheikh, S. S. Taylor, N. Tsuchida, A. M. van der Bliek, I. J. van der Klei, J. S. Weissman, B. Westermann, J. Zha, W. Neupert and J. Nunnari (2014). "Uniform nomenclature for the mitochondrial contact site and cristae organizing system." ్ㅡ Cell Biol 204(7): 1083-1086.

Pilling, A. D., D. Horiuchi, C. M. Lively and W. M. Saxton (2006). "Kinesin-1 and Dynein are the primary motors for fast transport of mitochondria in Drosophila motor axons." Mol Biol Cell 17(4): 2057-2068.

Qian, W., S. Choi, G. A. Gibson, S. C. Watkins, C. J. Bakkenist and B. Van Houten (2012). "Mitochondrial hyperfusion induced by loss of the fission protein Drp1 causes ATMdependent G2/M arrest and aneuploidy through DNA replication stress." J Cell Sci 125(Pt 23): 5745-5757.

Quintero, O. A., M. M. DiVito, R. C. Adikes, M. B. Kortan, L. B. Case, A. J. Lier, N. S. Panaretos, S. Q. Slater, M. Rengarajan, M. Feliu and R. E. Cheney (2009). "Human Myo19 is a novel myosin that associates with mitochondria." Curr Biol 19(23): 2008-2013.

Rambold, A. S., B. Kostelecky, N. Elia and J. Lippincott-Schwartz (2011). "Tubular network formation protects mitochondria from autophagosomal degradation during nutrient starvation." Proc Natl Acad Sci U S A 108(25): 10190-10195.

Rambold, A. S., B. Kostelecky and J. Lippincott-Schwartz (2011). "Together we are stronger: fusion protects mitochondria from autophagosomal degradation." Autophagy 7(12): 1568-1569.

Reeves, G. T., N. Trisnadi, T. V. Truong, M. Nahmad, S. Katz and A. Stathopoulos (2012). "Dorsalventral gene expression in the Drosophila embryo reflects the dynamics and precision of the dorsal nuclear gradient." Dev Cell 22(3): 544-557.

Rittweger, E., K. Y. Han, S. E. Irvine, C. Eggeling and S. W. Hell (2009). "STED microscopy reveals crystal colour centres

with nanometric resolution." Nature Photonics 3: 144-147. 
Rolland, S. G., E. Motori, N. Memar, J. Hench, S. Frank, K. F. Winklhofer and B. Conradt (2013). "Impaired complex IV activity in response to loss of LRPPRC function can be compensated by mitochondrial hyperfusion." Proc Natl Acad Sci U S A 110(32): E2967-2976.

Romashko, D. N., E. Marban and B. O'Rourke (1998). "Subcellular metabolic transients and mitochondrial redox waves in heart cells." Proc Natl Acad Sci U S A 95(4): 1618-1623.

Rossignol, R., R. Gilkerson, R. Aggeler, K. Yamagata, S. J. Remington and R. A. Capaldi (2004). "Energy substrate modulates mitochondrial structure and oxidative capacity in cancer cells." Cancer Res 64(3): 985-993.

Rust, M. J., M. Bates and X. Zhuang (2006). "Sub-diffraction-limit imaging by stochastic optical reconstruction microscopy (STORM)." Nat Methods 3(10): 793-795.

Sagona, A. P. and H. Stenmark (2010). "Cytokinesis and cancer." FEBS Lett 584(12): 2652-2661.

Samson, F., J. A. Donoso, I. Heller-Bettinger, D. Watson and R. H. Himes (1979). "Nocodazole action on tubulin assembly, axonal ultrastructure and fast axoplasmic transport." J Pharmacol Exp Ther 208(3): 411-417.

Saunders, T. E., K. Z. Pan, A. Angel, Y. Guan, J. V. Shah, M. Howard and F. Chang (2012). "Noise reduction in the intracellular pom1p gradient by a dynamic clustering mechanism." Dev Cell 22(3): 558-572.

Saunter, C. D., M. D. Perng, G. D. Love and R. A. Quinlan (2009). "Stochastically determined directed movement explains the dominant small-scale mitochondrial movements within non-neuronal tissue culture cells." FEBS Lett 583(8): 1267-1273.

Scaduto, R. C., Jr. and L. W. Grotyohann (1999). "Measurement of mitochondrial membrane potential using fluorescent rhodamine derivatives." Biophys J 76(1 Pt 1): 469-477.

Schapira, A. H. (2010). "Complex I: inhibitors, inhibition and neurodegeneration." Exp Neurol 224(2): 331-335.

Scheffler, I. E. (2001). "Mitochondria make a come back." Adv Drug Deliv Rev 49(1-2): 3-26. 
Schmidt, O., N. Pfanner and C. Meisinger (2010). "Mitochondrial protein import: from proteomics to functional mechanisms." Nat Rev Mol Cell Biol 11(9): 655-667.

Schwarz, T. L. (2013). "Mitochondrial trafficking in neurons." Cold Spring Harb Perspect Biol 5(6).

Sjostrand, F. S. (1953). "Electron microscopy of mitochondria and cytoplasmic double membranes." Nature 171(4340): 30-32.

Smiley, S. T., M. Reers, C. Mottola-Hartshorn, M. Lin, A. Chen, T. W. Smith, G. D. Steele, Jr. and L. B. Chen (1991). "Intracellular heterogeneity in mitochondrial membrane potentials revealed by a J-aggregate-forming lipophilic cation JC-1." Proc Natl Acad Sci U S A 88(9): 3671-3675.

Smirnova, E., L. Griparic, D. L. Shurland and A. M. van der Bliek (2001). "Dynamin-related protein Drp1 is required for mitochondrial division in mammalian cells." Mol Biol Cell 12(8): 22452256.

Sollner, T., J. Rassow, M. Wiedmann, J. Schlossmann, P. Keil, W. Neupert and N. Pfanner (1992). "Mapping of the protein import machinery in the mitochondrial outer membrane by crosslinking of translocation intermediates." Nature 355(6355): 84-87.

Song, J., N. F. Worth, B. E. Rolfe, G. R. Campbell and J. H. Campbell (2000). "Heterogeneous distribution of isoactins in cultured vascular smooth muscle cells does not reflect segregation of contractile and cytoskeletal domains." J Histochem Cytochem 48(11): 1441-1452.

Steinkraus, K. A., M. Kaeberlein and B. K. Kennedy (2008). "Replicative aging in yeast: the means to the end." Annu Rev Cell Dev Biol 24: 29-54.

Stevens, B. J. (1977). "Variation in number and volume of the mitochondria in yeast according to growth conditions: a study based on serialsectioning and computer graphics reconstitution." Biol. Cell 28: 37-56.

Stowers, R. S., L. J. Megeath, J. Gorska-Andrzejak, I. A. Meinertzhagen and T. L. Schwarz (2002). "Axonal transport of mitochondria to synapses depends on milton, a novel Drosophila protein." Neuron 36(6): 1063-1077. 
Sturmer, K., O. Baumann and B. Walz (1995). "Actin-dependent light-induced translocation of mitochondria and ER cisternae in the photoreceptor cells of the locust Schistocerca gregaria." J Cell Sci 108 ( Pt 6): 2273-2283.

Suen, D. F., K. L. Norris and R. J. Youle (2008). "Mitochondrial dynamics and apoptosis." Genes Dev 22(12): 1577-1590.

Tanaka, K., Y. Sugiura, R. Ichishita, K. Mihara and T. Oka (2011). "KLP6: a newly identified kinesin that regulates the morphology and transport of mitochondria in neuronal cells." J Cell Sci 124(Pt 14): $2457-2465$.

Tanaka, Y., Y. Kanai, Y. Okada, S. Nonaka, S. Takeda, A. Harada and N. Hirokawa (1998). "Targeted disruption of mouse conventional kinesin heavy chain, kif5B, results in abnormal perinuclear clustering of mitochondria." Cell 93(7): 1147-1158.

Tatsuta, T. and T. Langer (2008). "Quality control of mitochondria: protection against neurodegeneration and ageing." EMBO J 27(2): 306-314.

Twig, G., A. Elorza, A. J. Molina, H. Mohamed, J. D. Wikstrom, G. Walzer, L. Stiles, S. E. Haigh, S. Katz, G. Las, J. Alroy, M. Wu, B. F. Py, J. Yuan, J. T. Deeney, B. E. Corkey and O. S. Shirihai (2008). "Fission and selective fusion govern mitochondrial segregation and elimination by autophagy." EMBO J 27(2): 433-446.

Twig, G., B. Hyde and O. S. Shirihai (2008). "Mitochondrial fusion, fission and autophagy as a quality control axis: the bioenergetic view." Biochim Biophys Acta 1777(9): 1092-1097.

Van Blerkom, J., H. Cox and P. Davis (2006). "Regulatory roles for mitochondria in the periimplantation mouse blastocyst: possible origins and developmental significance of differential DeltaPsim." Reproduction 131(5): 961-976.

Van Blerkom, J. and P. Davis (2006). "High-polarized (Delta Psi m(HIGH)) mitochondria are spatially polarized in human oocytes and early embryos in stable subplasmalemmal domains: developmental significance and the concept of vanguard mitochondria." Reprod Biomed Online 13(2): 246-254. 
Van Blerkom, J., P. Davis and S. Alexander (2003). "Inner mitochondrial membrane potential (DeltaPsim), cytoplasmic ATP content and free Ca2+ levels in metaphase II mouse oocytes." Hum Reprod 18(11): 2429-2440.

van Spronsen, M., M. Mikhaylova, J. Lipka, M. A. Schlager, D. J. van den Heuvel, M. Kuijpers, P. S. Wulf, N. Keijzer, J. Demmers, L. C. Kapitein, D. Jaarsma, H. C. Gerritsen, A. Akhmanova and C. C. Hoogenraad (2013). "TRAK/Milton motor-adaptor proteins steer mitochondrial trafficking to axons and dendrites." Neuron 77(3): 485-502.

Vevea, J. D., T. C. Swayne, I. R. Boldogh and L. A. Pon (2014). "Inheritance of the fittest mitochondria in yeast." Trends Cell Biol 24(1): 53-60.

Vogel, F., C. Bornhovd, W. Neupert and A. S. Reichert (2006). "Dynamic subcompartmentalization of the mitochondrial inner membrane." J Cell Biol 175(2): 237-247.

von der Malsburg, K., J. M. Muller, M. Bohnert, S. Oeljeklaus, P. Kwiatkowska, T. Becker, A. Loniewska-Lwowska, S. Wiese, S. Rao, D. Milenkovic, D. P. Hutu, R. M. Zerbes, A. SchulzeSpecking, H. E. Meyer, J. C. Martinou, S. Rospert, P. Rehling, C. Meisinger, M. Veenhuis, B. Warscheid, I. J. van der Klei, N. Pfanner, A. Chacinska and M. van der Laan (2011). "Dual role of mitofilin in mitochondrial membrane organization and protein biogenesis." Dev Cell 21(4): 694-707.

Westermann, B. (2014). "Mitochondrial inheritance in yeast." Biochim Biophys Acta 1837(7): 10391046.

Whatley, J. M., P. John and F. R. Whatley (1979). "From extracellular to intracellular: the establishment of mitochondria and chloroplasts." Proc R Soc Lond B Biol Sci 204(1155): 165187.

Wiedenmann, J., S. Ivanchenko, F. Oswald, F. Schmitt, C. Rocker, A. Salih, K. D. Spindler and G. U. Nienhaus (2004). "EosFP, a fluorescent marker protein with UV-inducible green-to-red fluorescence conversion." Proc Natl Acad Sci U S A 101(45): 15905-15910. 
Wikstrom, J. D., S. M. Katzman, H. Mohamed, G. Twig, S. A. Graf, E. Heart, A. J. Molina, B. E. Corkey, L. M. de Vargas, N. N. Danial, S. Collins and O. S. Shirihai (2007). "beta-Cell mitochondria exhibit membrane potential heterogeneity that can be altered by stimulatory or toxic fuel levels." Diabetes 56(10): 2569-2578.

Wikstrom, J. D., G. Twig and O. S. Shirihai (2009). "What can mitochondrial heterogeneity tell us about mitochondrial dynamics and autophagy?" Int J Biochem Cell Biol 41(10): 1914-1927.

Wurm, C. A. and S. Jakobs (2006). "Differential protein distributions define two sub-compartments of the mitochondrial inner membrane in yeast." FEBS Lett 580(24): 5628-5634.

Wurm, C. A., D. Neumann, M. A. Lauterbach, B. Harke, A. Egner, S. W. Hell and S. Jakobs (2011). "Nanoscale distribution of mitochondrial import receptor Tom20 is adjusted to cellular conditions and exhibits an inner-cellular gradient." Proc Natl Acad Sci U S A 108(33): 1354613551.

Wurm, C. A., D. Neumann, R. Schmidt, A. Egner and S. Jakobs (2010). "Sample preparation for STED microscopy." Methods Mol Biol 591: 185-199.

Yaffe, M. P. (1999). "The machinery of mitochondrial inheritance and behavior." Science 283(5407): 1493-1497.

Yoon, Y., E. W. Krueger, B. J. Oswald and M. A. McNiven (2003). "The mitochondrial protein hFis1 regulates mitochondrial fission in mammalian cells through an interaction with the dynaminlike protein DLP1." Mol Cell Biol 23(15): 5409-5420.

Youle, R. J. and M. Karbowski (2005). "Mitochondrial fission in apoptosis." Nat Rev Mol Cell Biol 6(8): 657-663.

Youle, R. J. and A. M. van der Bliek (2012). "Mitochondrial fission, fusion, and stress." Science 337(6098): 1062-1065.

Zorov, D. B., C. R. Filburn, L. O. Klotz, J. L. Zweier and S. J. Sollott (2000). "Reactive oxygen species (ROS)-induced ROS release: a new phenomenon accompanying induction of the mitochondrial permeability transition in cardiac myocytes." J Exp Med 192(7): 1001-1014. 
Zuchner, S., I. V. Mersiyanova, M. Muglia, N. Bissar-Tadmouri, J. Rochelle, E. L. Dadali, M. Zappia, E. Nelis, A. Patitucci, J. Senderek, Y. Parman, O. Evgrafov, P. D. Jonghe, Y. Takahashi, S. Tsuji, M. A. Pericak-Vance, A. Quattrone, E. Battaloglu, A. V. Polyakov, V. Timmerman, J. M. Schroder and J. M. Vance (2004). "Mutations in the mitochondrial GTPase mitofusin 2 cause CharcotMarie-Tooth neuropathy type 2A." Nat Genet 36(5): 449-451. 


\title{
7. Anhang
}

\subsection{Verwendete Farbtabellen}

\begin{abstract}
A
B

\section{Abbildung 7.1: Verwendete Farbtabellen}

Im Rahmen dieser Arbeit wurden alle mikroskopischen Aufnahmen in nichtlinearen Farbtabellen dargestellt. Es wurde hauptsächlich die (A) fire-Farbtabelle gewählt. Lediglich in Abbildung 3.2 wurde die Farbtabelle (B) delta angewendet.
\end{abstract}

\subsection{Verwendete Plasmide für die Expression in Säugerzellen}

\section{PREP4-U6-shRNA DRP1}

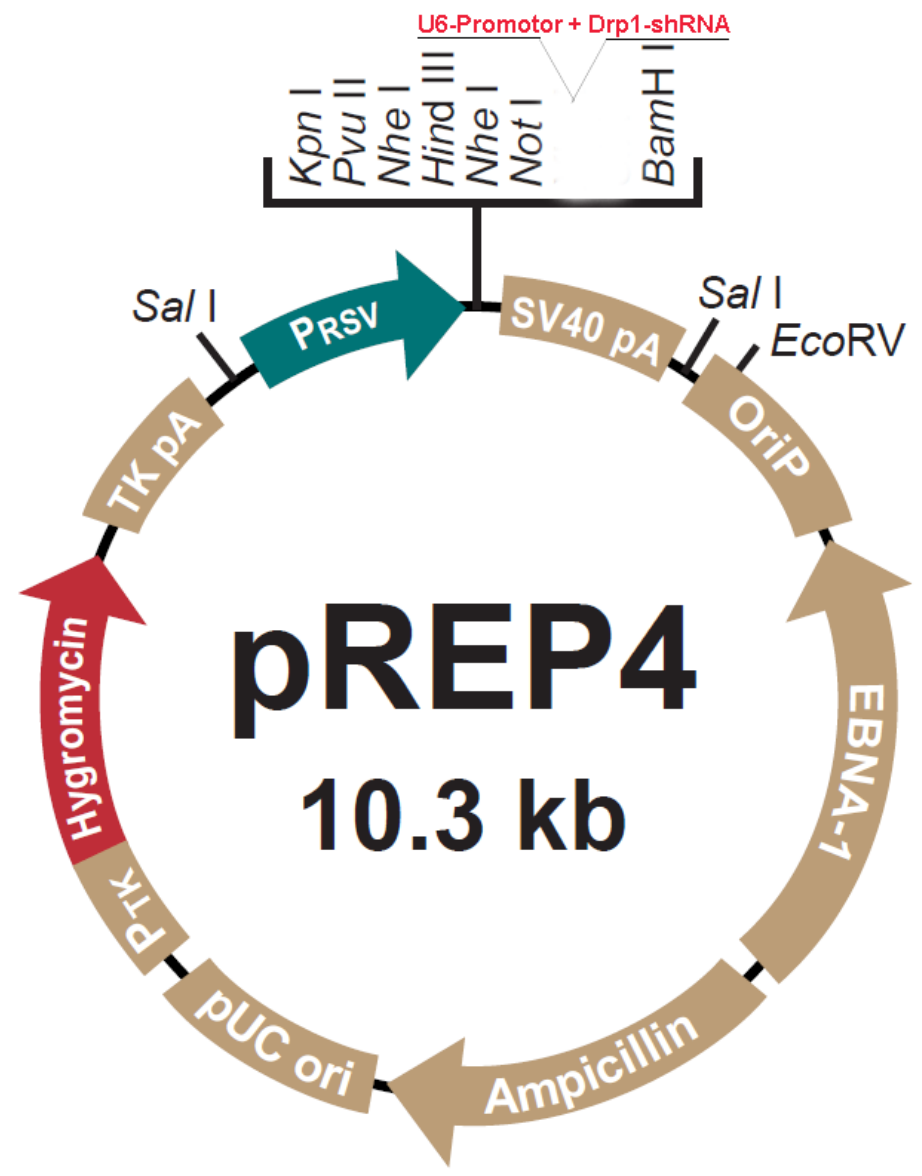

\begin{abstract}
Abbildung 7.2: Plasmidkarte von pREP4-U6-Drp1-shRNA

Zur Herunterregulierung von Drp1 wurde im Rahmen dieser Arbeit ein Plasmid (auf der Basis von pREP4) verwendet, welches eine spezifische shRNA kodierte, die unter dem U6-Promoter exprimiert wurde. Das Plasmid kodiert zusätzlich für eine HygromycinResistenz, die eine Selektionierung auf transfizierte Säugerzellen ermöglicht. Plasmid aus (Lee et al. 2004). Abbildung verändert von http://tools.lifetechnologies. com/content/sfs/manuals/prep4_ man.pdf.
\end{abstract}


pGIPZ-shRNA (Mfn2, Rhot1, Trak1, Negativkontrolle)

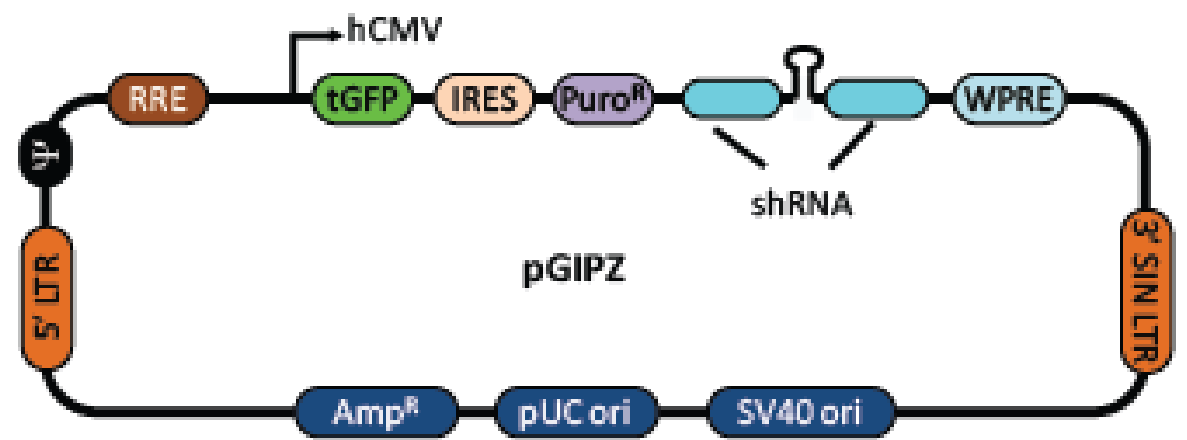

Abbildung 7.3: Plasmidkarte von pGIPZ

Die Menge der Proteine Mfn2 und Rhot1 wurden im Rahmen dieser Arbeit unter Verwendung von shRNA-kodierenden Plasmiden (auf Basis von pGIPZ) herunterreguliert. Ein Kontrollplasmid, das keine Herunterregulierung eines Proteins bewirken sollte, hatte ebenfalls den pGIPZ-Hintergrund. Das Plasmid kodiert außerdem TurboGFP und eine PuromycinResistenz durch die sich transfizierte Zellen selektieren lassen. Abbildung aus: http://dharmacon.gelifesciences.com.

\section{pDsRed1-Mito}

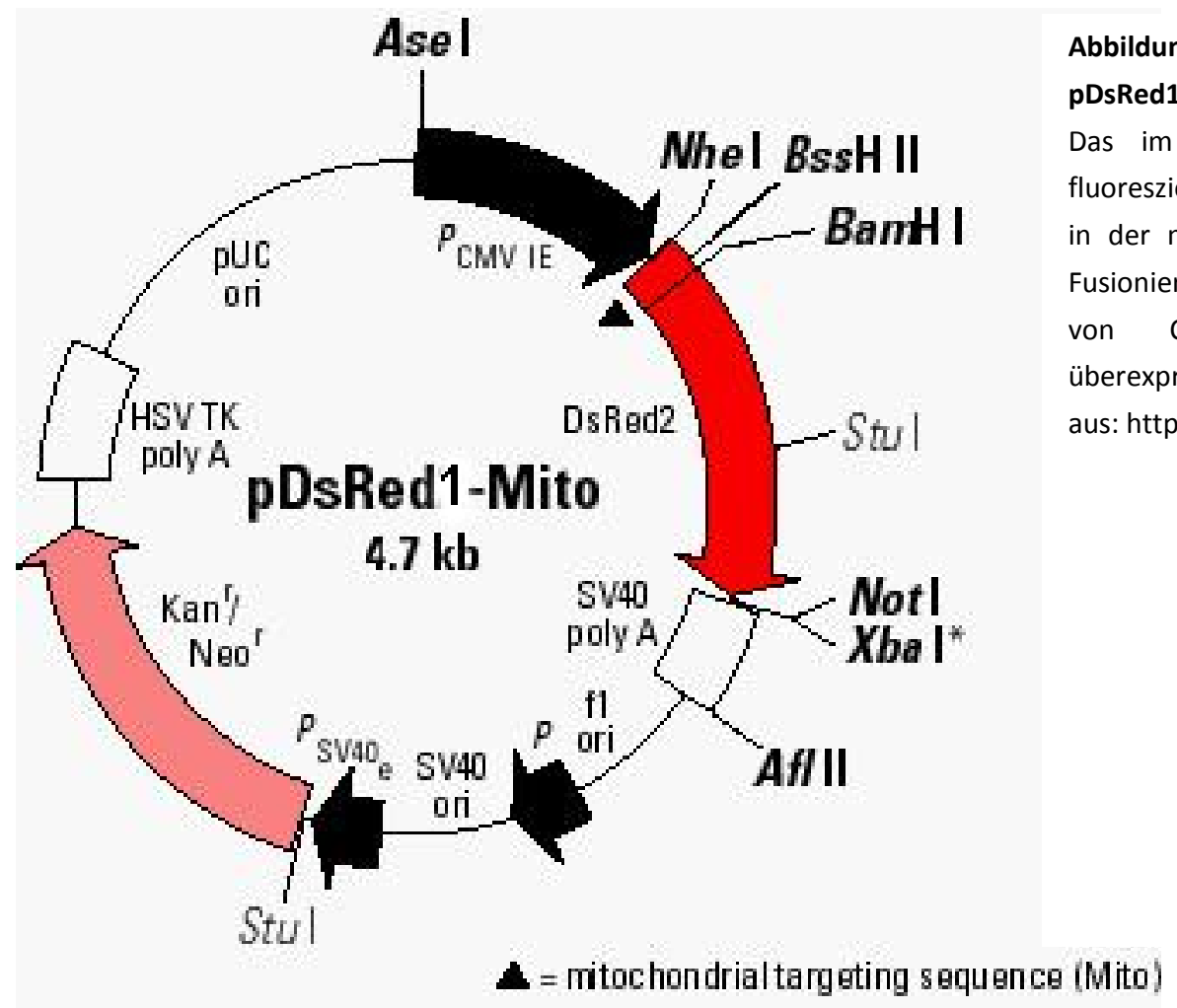




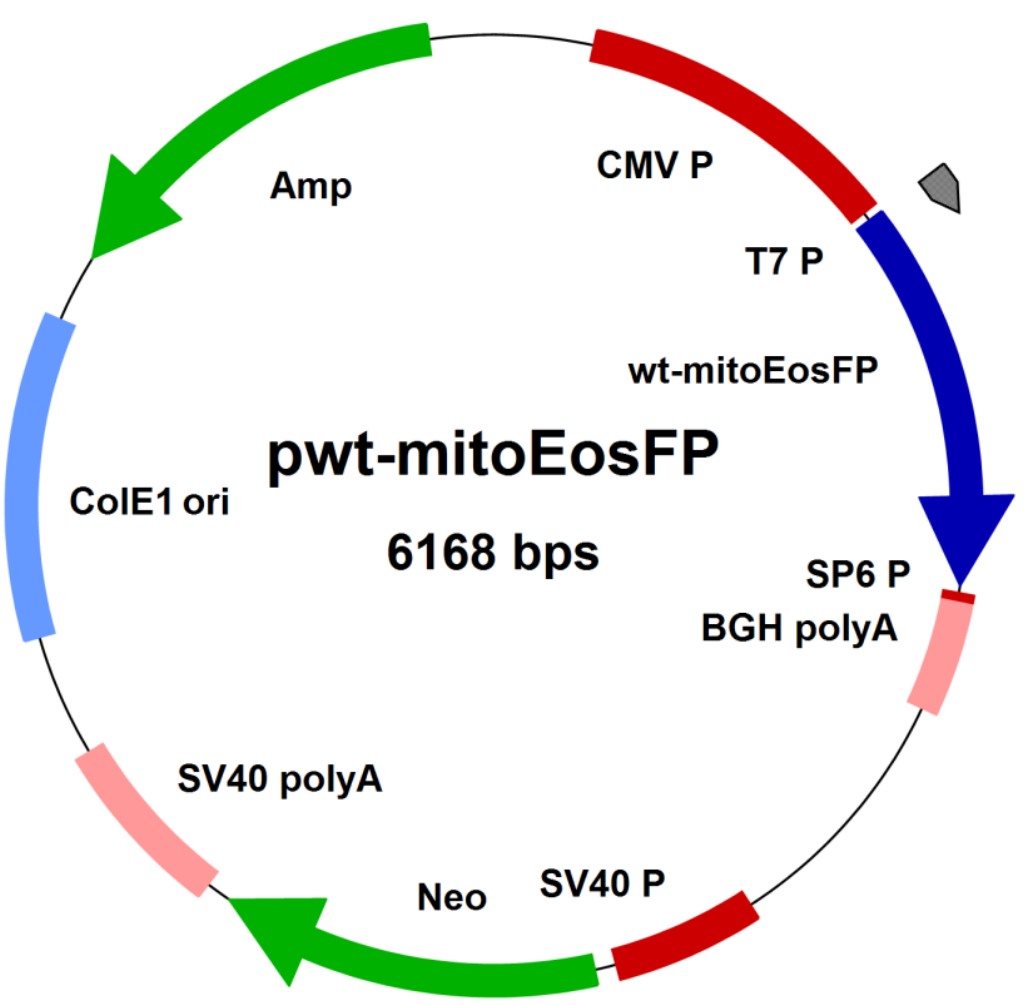

Abbildung 7.5: Plasmidkarte von pcDNA3-mito-EosFP

Das schaltbare fluoreszierende Protein EosFP wurde in der mitochondrialen Matrix durch Fusionierung an die Targeting-Sequenz von CoxVIIIa in Säugerzellen überexprimiert.

Abbildung aus: http://www.mobitec.com/cms/bilder/products/vector_sys/pwt-mitoEosFP.PNG 


\subsection{Immunfluoreszenzmarkierungen diverser mitochondrialer Proteine}
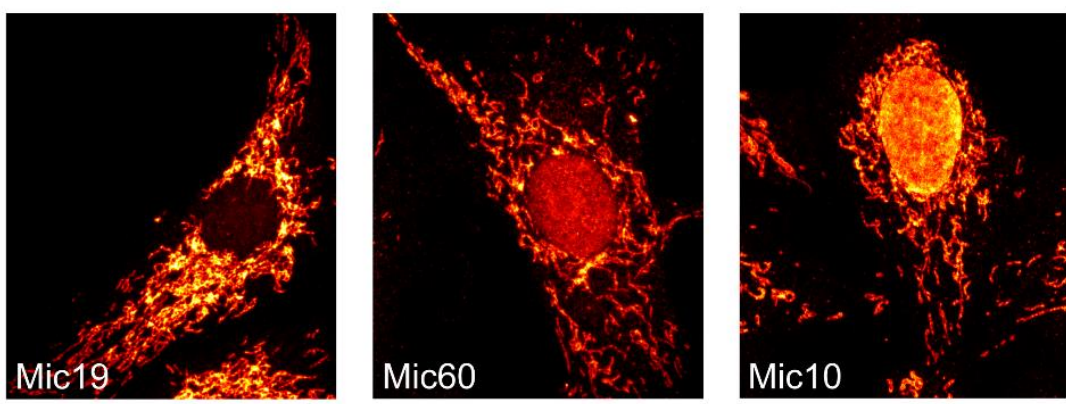

Abbildung 7.6: Immunfluoreszenzmarkierungen einer Vielzahl mitochondrialer Proteine.

Exemplarisch sind konfokalmikroskopische Aufnahmen von Immunfluoreszenzmarkierungen mitochondrialer Proteine, deren

Dichteverteilungen ausgewertet
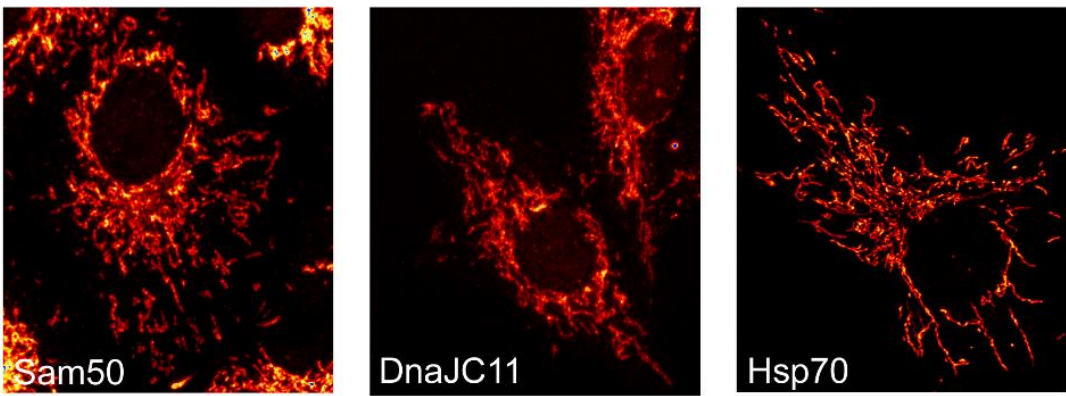

wurden und in Abbildung 3.6

dargestellt sind, abgebildet.

Einige Antikörper haben unspezifisch den Zellkern markiert. Bei diesen Markierungen wurde bei der Auswertung der Fluoreszenzintensität der Bereich des Zellkerns zusätzlich ausgeschlossen.

Abgebildet sind Maximalpro-
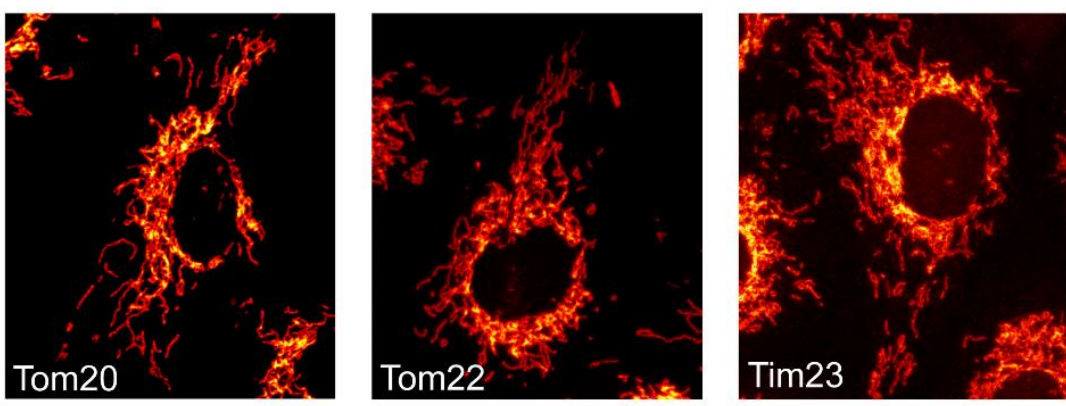

jektionen konfokaler z-Stapel.
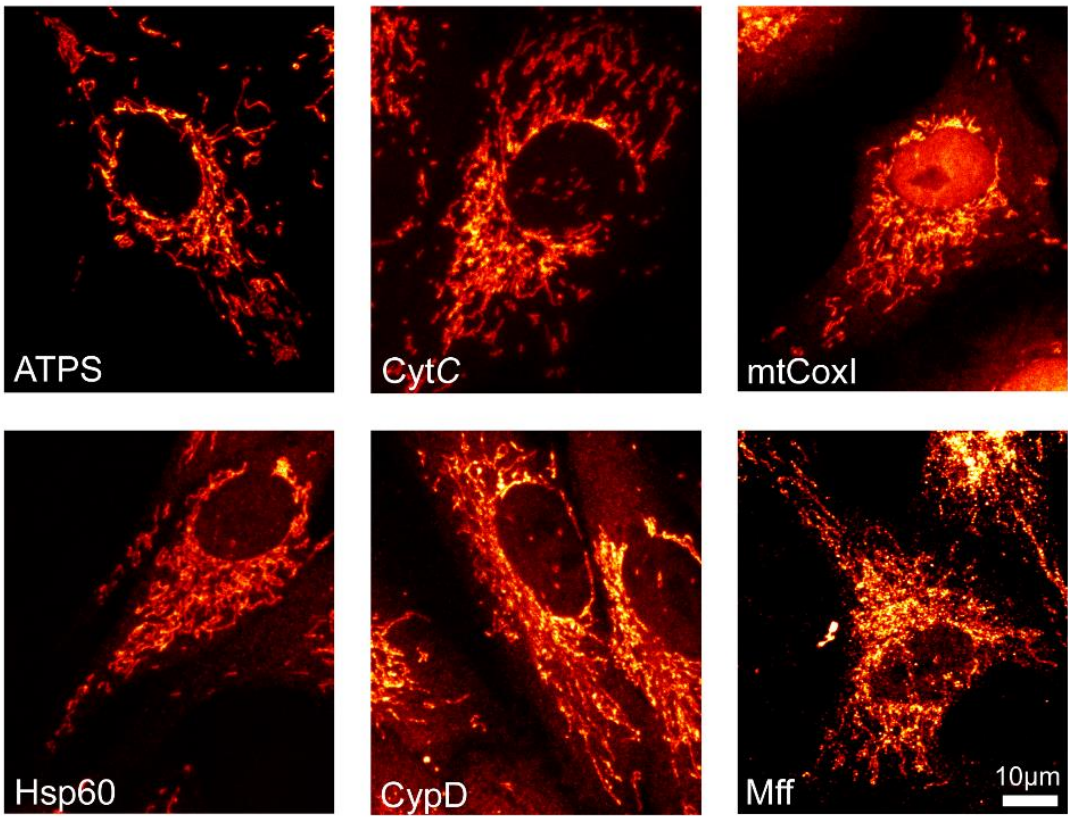


\subsection{Auflistung getesteter Substanzen auf ihren Einfluss auf} mitochondriale Proteinverteilungen

\begin{tabular}{|c|c|}
\hline Substanz & Wirkung \\
\hline EtBr (rho0-Zellen) & \multirow{2}{*}{$\begin{array}{l}\text { Deletion mitochondrialer DNA und dadurch } \\
\text { Atmungskettendefizienz }\end{array}$} \\
\hline & \\
\hline Nigericin & Kalium-Ionophor \\
\hline $\mathrm{CCCP}$ & Entkoppler des mitochondrialen Membranpotentials \\
\hline Bafilomycin & Inhibition der V-ATPase \\
\hline Na-Azid & Inhibition von Komplex IV der Atmungskette \\
\hline ATP & künstliche Erhöhung des Energievorrats \\
\hline Glukosekonzentration & Veränderung der Menge der C-Quelle \\
\hline Deoxyglukose & Inhibition der Glykolyse \\
\hline Thapsigargin & Zerstörung des Endoplasmatische Retikulums \\
\hline Calcimycin & Calcium-lonophor \\
\hline Staurosporin & Inhibierung von Protein-Kinasen \\
\hline TBB & Caseinkinaseinhibitor \\
\hline Dorsomorphin AMPK & Inhibition der AMPK \\
\hline $\mathrm{H}-89$ & PKA-Inhibitor \\
\hline Cycloheximid & Inhibierung zytoplasmatischer Translation \\
\hline Emetine & Inhibierung zytoplasmatischer Translation \\
\hline Puromycin & Inhibierung zytoplasmatischer Translation \\
\hline Chloramphenicol & Inhibierung mitochondrialer Translation \\
\hline Thiamphenicol & Inhibierung mitochondrialer Translation \\
\hline Aphidicolin & Inhibierung DNA-Synthese, Zellproliferation \\
\hline Actinomycin D & Induktion von Apoptose \\
\hline MG-132 & Inhibierung des Proteasoms \\
\hline Taxol & Stabilisierung von Tubulin \\
\hline Cytochalasin D & Depolymerisierung von Aktin \\
\hline
\end{tabular}

Tabelle 7.1: Übersicht über getestete Substanzen. Der Einfluss verschiedenster Substanzen auf die Heterogenität der Verteilung mitochondrialer Proteine wurde untersucht. Keine der hier aufgeführten Bedingungen führte zu einer signifikanten Veränderung der Heterogenität der Tom20-Verteilung. 
7.5 Auflistung untersuchter Proteine auf ihren Einfluss auf mitochondriale Proteinverteilungen

\begin{tabular}{|c|c|}
\hline $\begin{array}{l}\text { genetische Manipulation/ } \\
\text { Überexpression }\end{array}$ & $\begin{array}{l}\text { genetische Manipulation/ } \\
\text { Herunterregulierung }\end{array}$ \\
\hline synT/Synphilin1 & Parkin \\
\hline Traf6 & Pink1 \\
\hline VCP & DJ-1 \\
\hline FoxA1 & Opa1 \\
\hline HMGB1 & Mul1 \\
\hline FBX07 & March5 \\
\hline Parkin & SMCR7L \\
\hline 8UBL-Parkin & MGARP \\
\hline G430D-Parkin & ARMCX3 \\
\hline \multicolumn{2}{|l|}{ W453X-Parkin } \\
\hline \multicolumn{2}{|l|}{ PINK1 } \\
\hline \multicolumn{2}{|l|}{ Mfn1 } \\
\hline \multicolumn{2}{|l|}{ Mfn2 } \\
\hline \multicolumn{2}{|l|}{ Opa1 } \\
\hline \multicolumn{2}{|l|}{ Drp1 } \\
\hline \multicolumn{2}{|l|}{ Tom20 } \\
\hline \multicolumn{2}{|l|}{ HspA9 } \\
\hline \multicolumn{2}{|l|}{ DNAJC } \\
\hline \multicolumn{2}{|l|}{$\mathrm{CHCHD} 3$} \\
\hline \multicolumn{2}{|l|}{ Mtx2 } \\
\hline \multicolumn{2}{|l|}{ Mtx1 } \\
\hline \multicolumn{2}{|l|}{ Minos1 } \\
\hline \multicolumn{2}{|l|}{ IMMT } \\
\hline \multicolumn{2}{|l|}{ SirT1 } \\
\hline \multicolumn{2}{|l|}{ DNAJA3 } \\
\hline \multicolumn{2}{|l|}{ PRKACB } \\
\hline \multicolumn{2}{|l|}{ SIRT3 } \\
\hline \multicolumn{2}{|l|}{ HDAC6 } \\
\hline \multicolumn{2}{|l|}{ PRKAA1 } \\
\hline \multicolumn{2}{|l|}{ SYBU } \\
\hline \multicolumn{2}{|l|}{ SNPH } \\
\hline \multicolumn{2}{|l|}{ DCTN2 } \\
\hline \multicolumn{2}{|l|}{ MYLK2 } \\
\hline \multicolumn{2}{|l|}{ TAGLN } \\
\hline \multicolumn{2}{|l|}{$\mathrm{KLC1}$} \\
\hline \multicolumn{2}{|l|}{ RHOT2 } \\
\hline TRAK2 & \\
\hline
\end{tabular}




\begin{tabular}{|l|l|} 
TRAK1 & \\
\hline RHOT1 & \\
\hline DYNC1H1 & \\
\hline htau40 & \\
\hline Kif1C & \\
\hline MAPRE2 & \\
\hline MAPRE3 & \\
\hline MAP2 & \\
\hline MAP4 & \\
\hline MAP1 & \\
\hline
\end{tabular}

Tabelle 7.2: Übersicht über getestete Bedingungen. Der Einfluss der Überexpression oder Herunterregulierung verschiedenster Proteine auf die Heterogenität der Verteilung mitochondrialer Proteine wurde untersucht. Keine der hier aufgeführten Bedingungen führte zu einer signifikanten Veränderung der Heterogenität der Tom20-Verteilung.

\subsection{Verwendeter Proteingrößenstandard}

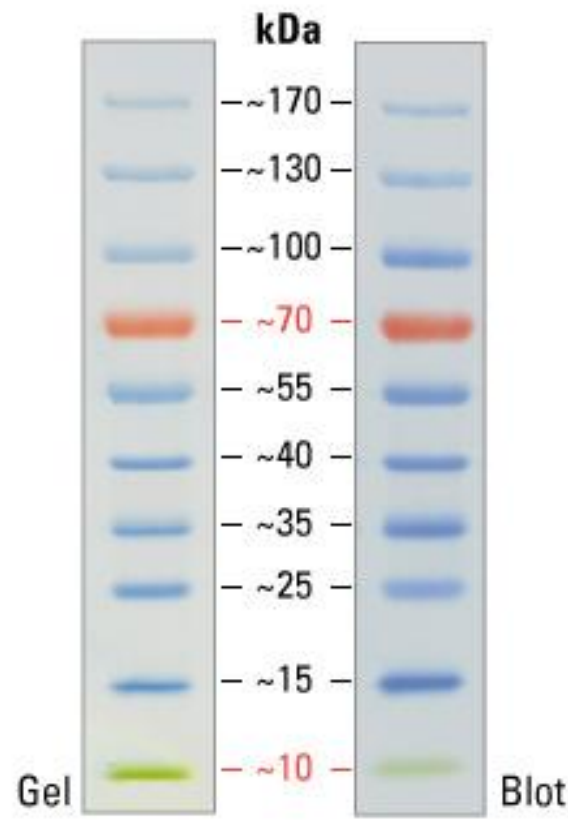




\section{Veröffentlichungen und Konferenzbeiträge}

\subsection{Wissenschaftliche Publikationen}

Jans, D.C., Wurm, C.A., Riedel, D., Wenzel, D., Stagge, F., Deckers, M., Rehling, P., and Jakobs, S. (2013). STED super-resolution microscopy reveals an array of MINOS clusters along human mitochondria. Proc Natl Acad Sci USA, DOI: 10.1073/pnas.1301820110

Stagge, F., Mitronova, G.Y., Belov, V.N., Wurm, C.A., Jakobs, S. (2013) Snap-, CLIP- and Halo-Tag Labelling of Budding Yeast Cells. PLoS ONE 8(10): e78745. doi:10.1371/journal.pone.0078745

Stagge, F., Wurm, C.A., Jakobs, S. (2014). Mitochondrial protein distributions are largely immobile and change under certain conditions. (in Bearbeitung)

\subsection{Konferenzbeiträge}

9th International PhD Student Symposium ,Horizons in Molecular Biology' Göttingen 2012

Stagge F., Wurm C., Jakobs S.

Submitochondrial protein distributions at the nanoscale: The density of mitochondrial proteins correlates to cellular conditions and exhibits innercellular gradients.

Wurm C., Stagge F., Ilgen P., Jakobs S.

Quantification of subcellular protein distributions at the nanoscale - Superresolution microscopy as a tool in cell biology

Meeting of the "Nanoscale Microscopy and Molecular Physiology of the Brain Cluster of Excellence 171 - DFG Research Center 103" Bad Sooden-Allendorf 2012

Stagge F., Kummer S., Wurm C., Hell S., Jakobs S.

Submitochondrial protein distributions at the nanoscale: The density of mitochondrial proteins correlates to cellular conditions and exhibits innercellular gradients.

International Joint Meeting of the German Society for Cell Biology (DGZ) and the German Society for Developmental Biology (GfE) Heidelberg 2013 
Stagge F., Wurm C., Jakobs S.

Submitochondrial protein distributions at the nanoscale

Meeting of the "Nanoscale Microscopy and Molecular Physiology of the Brain Cluster of Excellence 171 - DFG Research Center 103" Bad Sooden-Allendorf 2013

Stagge F., Jans D., Große L., Grotjohann T., Wurm C., Brakemann T., Marquardt T., Hell S., Jakobs S. Focusing on mitochondria with STED and RESOLFT nanoscopy

18th European Bioenergetics Conference Lissabon Portugal 2014

Stagge F., Wurm C., Jakobs S.

Submitochondrial protein distributions at the nanoscale 


\section{Danksagung}

An erster Stelle bedanke ich mich bei Prof Dr. Stefan Jakobs für die Betreuung und die Übernahme des Koreferats dieser Arbeit. Die fruchtbaren wissenschaftlichen Diskussionen haben sehr zum Gelingen dieser Arbeit beigetragen.

Ich danke Prof. Dr. Andreas Wodarz für die Übernahme des Referats dieser Arbeit und die hilfreichen Diskussionen und Vorschläge.

Bei Prof. Dr. Dr. Stefan Hell bedanke ich mich für seine Bereitschaft in der Prüfungskommission diese Arbeit zu begutachten.

PD Dr. Thomas Teichmann, Prof. Dr. Peter Rehling und Prof. Dr. Michael Müller danke ich für ihre Bereitschaft in der Prüfungskommission diese Arbeit zu begutachten.

Besonders bedanken möchte ich mich bei meinem Kollegen Dr. Christian Wurm. Seine stete Hilfsbereitschaft, die vielen Ratschläge und guten Ideen haben sehr zum Gelingen dieser Arbeit beigetragen.

Außerdem möchte ich mich bei Dr. Daniel Jans und Dr. Daniel Neumann für die überaus hilfreichen fachlichen Diskussionen und Anregungen bedanken.

Sylvia Löbermann und Rita Schmitz-Salue möchte ich für ihre hilfreiche Unterstützung im Labor danken.

Der gesamten Abteilung NanoBiophotonik und meinen Kollegen der Arbeitsgruppe ,Mitochondriale Struktur und Dynamik' danke ich für die sehr gute Arbeitsatmosphäre. Besonders bedanke ich mich bei Marlen und Susann für die Gespräche und Unternehmungen abseits der Wissenschaft.

Mein größter Dank gilt meinem Freund Markus, der mich fortwährend unterstützt und motiviert hat und meinen Eltern und Großeltern, die mich stets in meinen Zielen bestärkt und mir somit diese Promotion ermöglicht haben. 


\section{Lebenslauf}

\section{Persönliche Daten}

Name

Anschrift

Geburtsdatum und -ort

Staatsangehörigkeit

Familienstand

\section{Schulbildung}

08.1995 - 07.2004

\section{Auslandsaufenthalt}

$08.2004-09.2005$

\section{Hochschulstudium}

$10.2005-10.2010$

\section{Promotion}

$11.2010-10.2014$
Franziska Stagge

Ludwig-Prandtl-Straße 12

37077 Göttingen

03.01.1985 in Wernigerode

Deutsch

ledig

Heinrich-Heine-Gymnasium, Ilsenburg

Abschluss: Abitur (Note: 2,1)

Mc Lean, VA, USA

Tätigkeit als Au Pair, Culturalcare Au Pair

Gottfried-Wilhelm-Leibniz-Universität, Hannover Diplom-/ Hauptstudium Biochemie (Note: sehr gut)

Studienschwerpunkte: Biochemie, Biophysikalische Chemie, Pharmakologie und Toxikologie

Betreuer der Diplomarbeit: Prof. Dr. S. Jakobs (Abteilung für NanoBiophotonik/Prof. Dr. S. Hell, Max-Planck-Institut für biophysikalische Chemie, Göttingen)

Thema der Diplomarbeit: „Etablierung neuartiger Fluoreszenzmarkierungen in der Bäckerhefe Saccharomyces cerevisiae für die hochauflösende Mikroskopie mitochondrialer Proteine"

Georg-August University School of Science, Göttingen Betreuer der Doktorarbeit: Prof. Dr. S. Jakobs (Abteilung für NanoBiophotonik/Prof. Dr. S. Hell, Max-Planck-Institut für biophysikalische Chemie, Göttingen) Thema der Doktorarbeit: „Untersuchung der Heterogenität submitochondrialer Proteinverteilungen mit hochauflösender Mikroskopie" 